André Luiz Vieira da Silva

\title{
Arquitetura Compacta Para Projeto de Robôs Móveis Visando Aplicações Multipropósitos
}

Dissertação apresentada à Escola de Engenharia de São Carlos da Universidade de São Paulo, sendo parte dos requisitos para obtenção do título de Mestre em Engenharia Elétrica.

Orientador: Prof. Dr. Ivan Nunes da Silva

São Carlos 

Dedico este trabalho às pessoas que sempre estiveram do meu lado nos momentos bons e ruins ao longo deste projeto, principalmente minha noiva Natália. 



\section{Agradecimentos}

Por trás deste projeto há uma grande equipe, cujas sugestões, críticas e elogios foram de extrema importância. Equipe esta, formada por amigos que já conhecia, e outros tive o prazer de conhecer no decorrer do curso de Mestrado. Gostaria de fazer um agradecimento especial à estas pessoas, sendo elas:

Meu orientador Prof. Dr. Ivan, que me deu a oportunidade de fazer parte de um excelente grupo de pesquisa (LAIPS), além do grande incentivo durante a realização deste trabalho.

Aos meus amigos Dr. André Torre Neto, Marcos, Godói, Jorge e Leonardo (todos da Embrapa - Instrumentação Agropecuária) pelas dicas e sugestões.

Ao meu amigo Niltom Vieira Junior pelas contribuições e ajudas na escrita desta dissertação.

Ao meu amigo e professor Sérgio Ricardo pelas valiosas dicas e ensinamentos sobre microcontroladores.

Aos meus pais pelo incentivo e confiança, aos meus sogros por permitirem a construção do ambiente de navegação em sua garagem, e aos meus amigos Ralph e Carlos pela ajuda na montagem.

À minha noiva Natália pela contribuição no desenvolvimento deste trabalho, além da paciência e carinho nos momentos mais difíceis.

Ciclos se encerram, amizades se perpetuam.

Muito Obrigado a todos. 



\section{Resumo}

SILVA, A. L. V. (2008). Arquitetura Compacta Para Projeto de Robôs Móveis Visando Aplicações de Multipropósitos - Dissertação (Mestrado) - Escola de Engenharia de São Carlos, Universidade de São Paulo, 2008.

Com a necessidade de substituir o trabalho humano em áreas de risco, ambientes impróprios ou inalcançáveis, diversos centros de pesquisas e universidades têm desenvolvido aplicações e estratégias de controle para robôs móveis. Porém, o alto custo na aquisição de um ou mais protótipos para estudos e desenvolvimento de novas tecnologias pode se tornar um fator limitante para o incremento dessas pesquisas. Como parte de uma solução para contornar esta eventual limitação em robótica móvel, uma arquitetura de baixo custo, modular e expansível é apresentada neste trabalho. São apresentadas também as metodologias de desenvolvimento dos módulos, os algoritmos de controle, as interfaces de comunicação e os principais componentes utilizados para desenvolvimento do robô móvel ZEUS, cujo sistema eletrônico de controle é a implementação da arquitetura proposta. Análise de custo, resultados experimentais de sensoriamento e navegação concluem este trabalho.

Palavras Chave: Robôs Móveis, sistemas embarcados, arquiteturas compactas, comunicação SPI, RS232. 



\begin{abstract}
SILVA, A. L. V. (2008). Compact Architecture to Design Mobile Robots for Multipurpose Applications - Dissertation (Master Degree) - Escola de Engenharia de São Carlos, Universidade de São Paulo, 2008.

With the need to replace human work in risk's areas, improper or unreachable environments, several research centers, and universities have developed applications and strategies for mobile robots control. However, the high acquisition cost of one or more prototypes used for research and in development of new technologies may become a limiting factor. As part of the solution to get a round any such limitation on mobile robotics, a modular and expandable low-cost architecture is presented in this work. There are also presented the methodologies for modules development, the algorithms of control, the communication interfaces and the main components used for the development of ZEUS mobile robot, whose electronic system control is the implementation of the proposed architecture. Analysis of cost, experimental results of the sensing and the navigation system conclude this work.
\end{abstract}

Keywords: Mobile Robots, embedded systems, compact architecture, SPI communication, RS232. 



\section{Lista de Siglas e Abreviaturas}

\begin{tabular}{|c|c|}
\hline ADC & Analogic to Digital converter \\
\hline$A / D$ & Analogic/Digital \\
\hline AGV & Automated Guided Vehicle \\
\hline ASM & Assembly \\
\hline CAN & Controlled Area Network \\
\hline CCP & Capture Compare PWM \\
\hline CE & Chip Enable \\
\hline CLK & Clock \\
\hline CRC & Cyclic Redundancy Check \\
\hline CS & Chip Select \\
\hline DC & Direct Current \\
\hline DCE & Data Circuit-terminating Equipment (modem) \\
\hline DTE & Data Terminal Equipment \\
\hline EEPROM & Electrically-Erasable Programmable Read-Only Memory \\
\hline EPROM & Erasable Programmable Read-Only Memory \\
\hline FIFO & First In First Out \\
\hline GPS & Global Positioning System \\
\hline 1/O & In/Out \\
\hline${ }^{2} \mathrm{C}$ & Inter Integrated Circuit \\
\hline ICSP & In-circuit Serial Programming \\
\hline MCU & Microcontroller Unit \\
\hline MSSP & Master Synchronous Serial Port \\
\hline
\end{tabular}


PC

Personal Computer

PIC Peripheral Interface Controller

RAM Random Access Memory

RF Rádio Frequência

RISC Reduced Instruction Set Computer

ROM Read Only Memory

RTOS Real Time Operational System

RTC Real Time Clock

RX Receiver

SLAM Simultaneous Localization and Mapping

SPI Serial Peripheral Interface

SS Slave Select

SSP Synchronous Serial Port

TTL Transistor-Transistor Logic

TX Transmitter

USART Addressable Universal Synchronous Asynchronous Receiver Transmitter 


\section{Lista de Figuras}

FIGURA 1.1 - Exemplos de aplicações de robótica móvel ...................................... 1

FIGURA 1.2 - Robô Móvel Khepera® ...............................................................

FIGURA 1.3 - Diagrama de Blocos do sistema proposto ......................................4

FIGURA 2.1 - Robô Móvel Robart I ........................................................... 8

FIGURA 2.2 - Exemplo de Robôs com locomoção através de rodas ........................ 10

FIGURA 2.3 - Exemplo de Robôs com locomoção através de pernas .....................11

FIGURA 2.4 - Rex-16C Round Robot Base, configuração com driver diferencial para um robô móvel ....................................................................... 12

FIGURA 2.5 - ARobot, configuração de um triciclo com um motor de tração............13

FIGURA 2.6 - Configuração Omnidirecional com três drivers ................................. 14

FIGURA 2.7 - Diagrama de um Controlador em Malha Aberta............................... 15

FIGURA 2.8 - Diagrama de um Controlador em Malha Fechada ............................ 15

FIGURA 2.9 - Line Follower Robot, exemplo de um Robô Móvel seguidor de Linha

FIGURA 2.10 - Diagrama da arquitetura Subsumption para um robô seguir de luz com desvio de obstáculos ............................................................20

FIGURA 2.11 - Arquitetura Three Layers ......................................................22

FIGURA 2.12 - Arquitetura do Hardware do Lego® Mindstorm® NXT .....................25

FIGURA 2.13 - Aplicações do Lego® Mindstorms ${ }^{\circledR}$ NXT ....................................26

FIGURA 2.14 - Arquitetura de Hardware do Handy Board/Cricket ..........................27

FIGURA 2.15 - Aspectos de Controlador .....................................................28

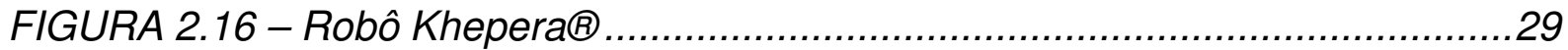

FIGURA 3.1 - Modelo físico de sistemas distribuídos .......................................... 34

FIGURA 3.2 - Arquitetura distribuída do robô móvel ............................................34

FIGURA 3.3 - Diagrama de Blocos da Arquitetura de Microcontroladores PIC ........40

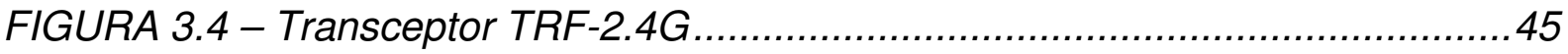

FIGURA 3.5 - Funcionamento do modo ShockBurst ........................................47

FIGURA 3.6 - Fluxograma da transmissão ShockBurst no TRF-2.4G....................51

FIGURA 3.7 - Fluxograma da recepção ShockBurst no TRF-2.4G ........................53

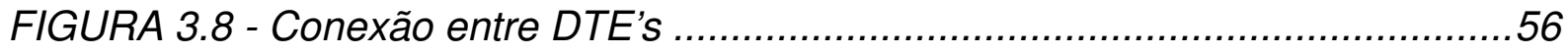

FIGURA 3.9 - Aspectos do Conversor MAX232 .............................................57

FIGURA 3.10 - Circuito típico de operação .......................................................58 
FIGURA 3.11 - Conexão dos Módulos no Barramento SPI ................................... 59

FIGURA 3.12 - Representação do Pacote de dados .......................................... 61

FIGURA 3.13 - Exemplo de um pacote de dados do sistema............................... 62

FIGURA 3.14 - Fluxograma geral de funcionamento do sistema.......................... 64

FIGURA 3.15 - Diagrama de blocos do módulo principal.................................... 65

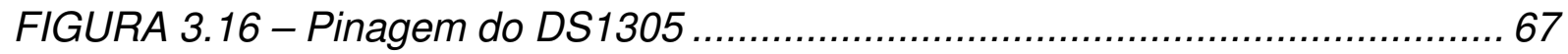

FIGURA 3.17 - Ligação do RTC ao MCU do Módulo Principal ................................68

FIGURA 3.18 - Diagrama de blocos do Controle de Alimentação ........................... 71

FIGURA 3.19 - Circuito eletrônico da fonte de alimentação e tensão de referência do Módulo Principal..................................................................... 71

FIGURA 3.20 - Esquema de ligação do MAX232 utilizando níveis de tensão diferentes ............................................................................... 72

FIGURA 3.21 - Circuito Eletrônico do recarregador de baterias ............................. 73

FIGURA 3.22 - Fluxograma do Software de Monitoramento e Recarregador de Bateria.............................................................................. 74

FIGURA 3.23 - Bateria de Chumbo-Ácido utilizada .......................................... 75

FIGURA 3.24 - Fluxograma de Software do Módulo Principal ............................... 77

FIGURA 3.25 - Hardware do Módulo Principal .................................................. 77

FIGURA 3.26 - Diagrama de Blocos do Módulo PC .......................................... 78

FIGURA 3.27 - Esquema de ligação do Transceptor de RF ................................. 79

FIGURA 3.28 - Firmware de controle do Módulo PC .......................................... 81

FIGURA 3.29 - Hardware do Módulo de PC ...................................................... 81

FIGURA 3.30 - Diagrama de blocos do Módulo de Sensores................................ 82

FIGURA 3.31 - Fluxograma de Leitura do Sonar ............................................ 83

FIGURA 3.32 - Circuito utilizado para conexão dos sonares ao Módulo de Sensores................................................................ 84

FIGURA 3.33 - Sonares utilizados no Módulo de Sensores ................................. 85

FIGURA 3.34 - Circuito de acionamento e leitura do sensor Infravermelho respectivamente................................................................ 86

FIGURA 3.35 - Sensores Infravermelhos utilizados...................................... 86

FIGURA 3.36 - Circuito de medição da temperatura ambiente..............................87

FIGURA 3.37 - Sensor de Temperatura utilizado .......................................... 88

FIGURA 3.38 - Fluxograma do Módulo de Sensores......................................... 89

FIGURA 3.39 - Hardware do Módulo de Sensores ............................................. 89

FIGURA 3.40 - Diagrama de Blocos do Módulo Atuador ...................................... 90

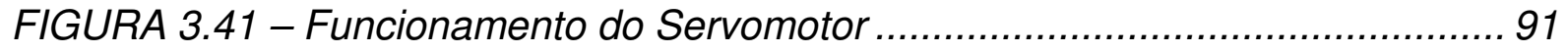

FIGURA 3.42 - Aspectos do servomotor utilizado na pesquisa ............................ 93 
FIGURA 3.43 - Saída de um Encoder Incremental com 2 sensores ópticos ............94

FIGURA 3.44 - Circuito para leitura dos Encoders incrementais............................94

FIGURA 3.45 - Aspectos estruturais do Encoder .................................................95

FIGURA 3.46 - Fluxograma de Sofware do Módulo Atuador...................................96

FIGURA 3.47 - Hardware do Módulo Atuador ....................................................97

FIGURA 3.48 - Diagrama de Blocos do Módulo de RF .....................................97

FIGURA 3.49 - Fluxograma do Módulo de RF....................................................98

FIGURA 3.50 - Hardware do Módulo de RF ...................................................99

FIGURA 3.51 - Hardware completo da arquitetura desenvolvida ...........................99

FIGURA 3.52 - Disposição das rodas na base móvel .......................................100

FIGURA 3.53 - Projeto da base móvel .......................................................... 101

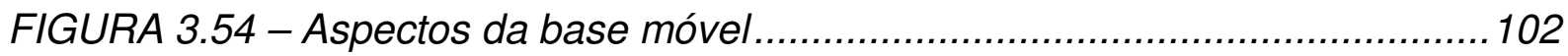

FIGURA 3.55 - Principais medidas da base móvel........................................... 102

FIGURA 3.56 - Suporte de fixação dos sensores.............................................. 103

FIGURA 3.57 - Robô Móvel ZEUS ............................................................. 104

FIGURA 4.1 - Tela principal da interface gráfica do software de visualização e controle .............................................................................. 106

FIGURA 4.2 - Configuração da comunicação serial ......................................... 107

FIGURA 4.3 - Conexão estabelecida com a porta serial .....................................107

FIGURA 4.4 - Tela de monitoramento dos pacotes de dados durante uma transmissão .................................................................... 108

FIGURA 4.5 - Dimensões do ambiente de simulação ....................................... 109

FIGURA 4.6 - Ambiente de simulação em perspectiva (1) .................................110

FIGURA 4.7 - Ambiente de simulação em perspectiva (2) .................................110

FIGURA 4.8 - Seqüência de Navegação (1) ................................................... 115

FIGURA 4.9 - Seqüência de Navegação (2) .................................................116

FIGURA 4.10 - Seqüência de Navegação (3)................................................117

FIGURA 4.11 - Seqüência de Navegação (4)................................................118

FIGURA 4.12 - Seqüência de Navegação (5)................................................119 



\section{Lista de Tabelas}

TABELA 3.1 - Conjunto de Instruções dos MCU's PIC ........................................36

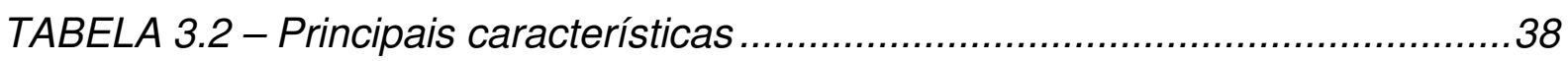

TABELA 3.3 - Descrição dos pinos do Tranceptor ............................................. 45

TABELA 3.4 - Configuração dos modos do tranceptor ...........................................46

TABELA 3.5 - Resumo da palavra de configuração ........................................... 47

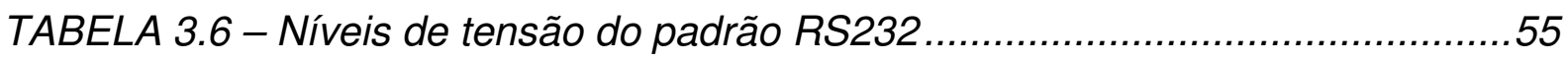

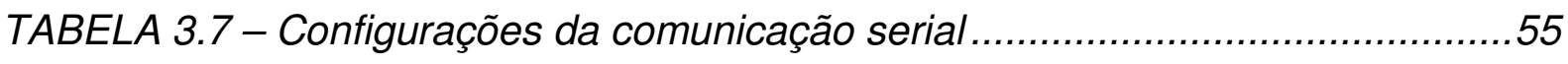

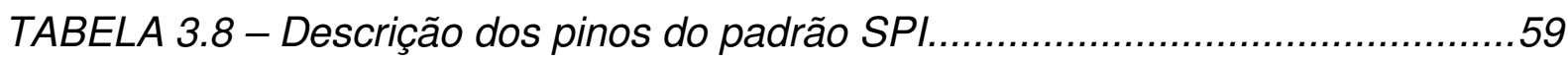

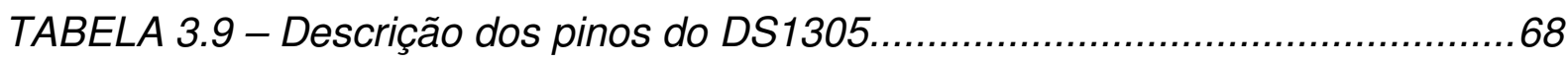

TABELA 3.10 - Pinagem do Barramento de comunicação ..................................... 70

TABELA 4.1 - Análise de custo dos componentes utilizados ..............................121

TABELA 5.1 - Características do Robô Móvel ZEUS .........................................124 



\section{SUMÁRIO}

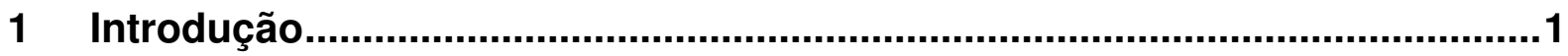

1.1 Motivação e Relevância da Dissertação ..................................................

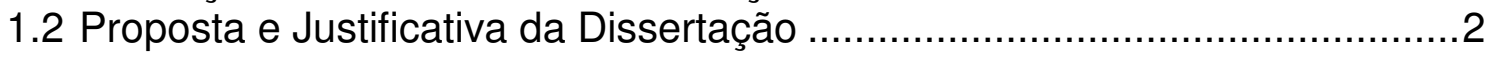

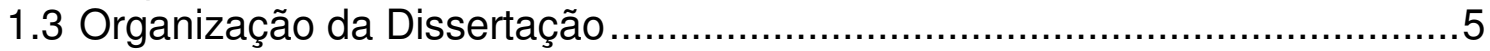

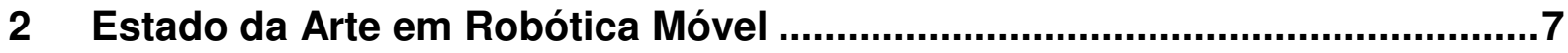

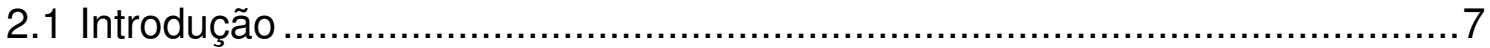

2.2 Características Gerais de Robôs Móveis ..............................................10

2.3 Principais Componentes de Robôs Móveis............................................12

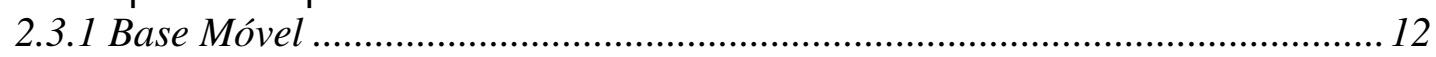

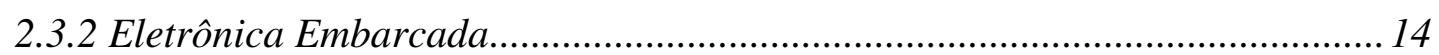

2.3.3 Software Embarcado …………………………………………………1 18

2.3.4 Sistemas de Comunicação …………………………………………………...... 23

2.4 Arquiteturas de Robôs Móveis ...........................................................24

2.5 Considerações Sobre o Capítulo ..........................................................

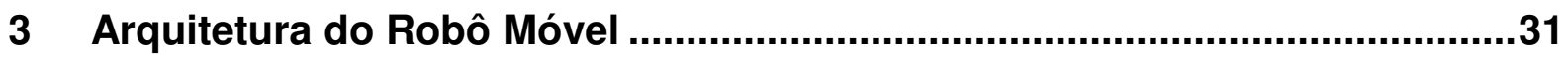

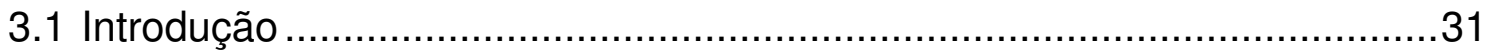

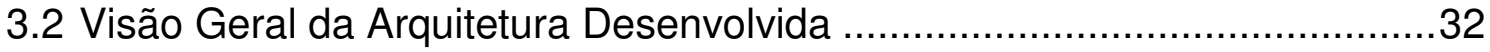

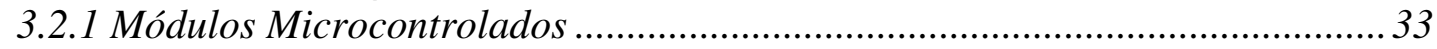

3.2.2 Microcontroladores PIC ………………………………………………...... 35

3.2.3 Controle em Tempo Real ..........................................................................42

3.3 Sistema de Transmissão de Informações ..............................................4

3.3.1 Transmissão em Radiofreqüência ………………………………………....4 44

3.3.2 Comunicação serial: Padrão RS232 ………………………………………....53

3.3.3 Comunicação serial: Padrão SPI...............................................................58

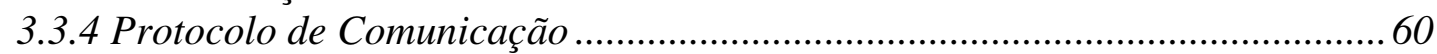

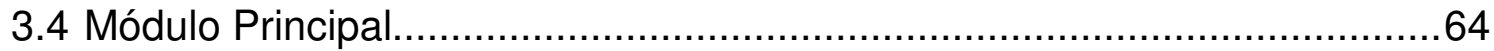

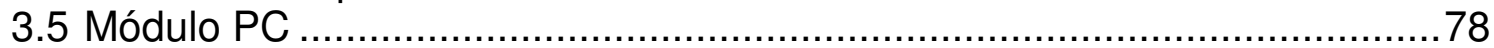

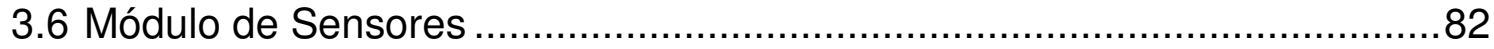

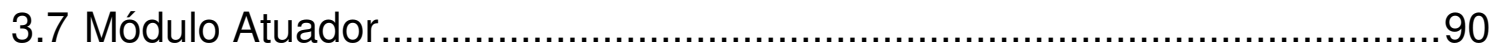

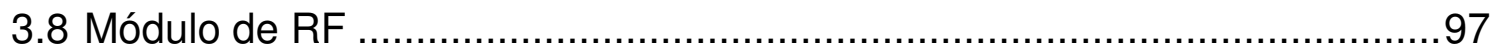

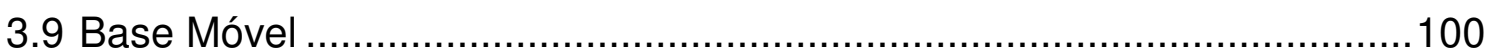

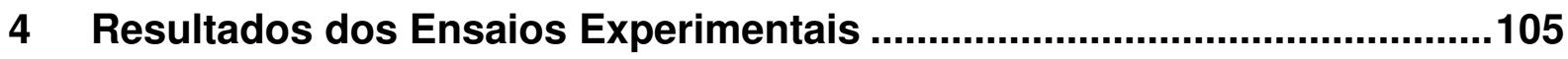

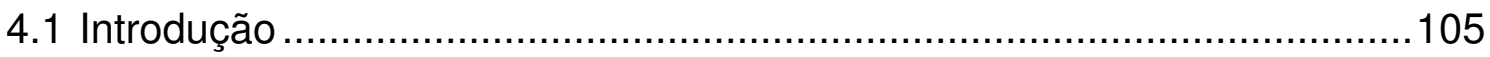

4.2 Software de Visualização e Controle .................................................105

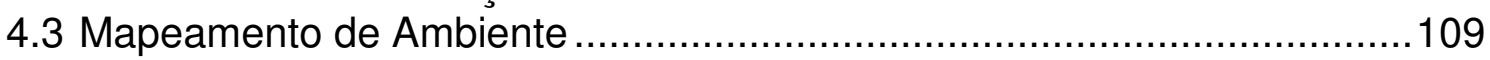

4.4 Avaliação de Custo ......................................................................120

4.4.1 Custo da Estrutura Mecânica...................................................................... 120

4.4.2 Custo dos Principais Componentes Utilizados …………………………...... 121

5 Conclusões Gerais e Trabalhos Futuros …............................................123

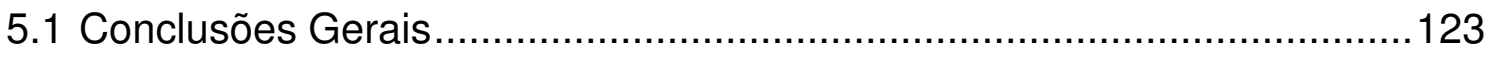

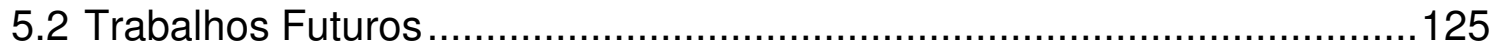




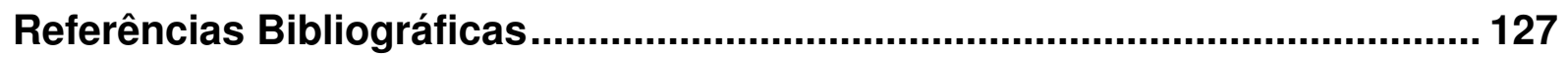

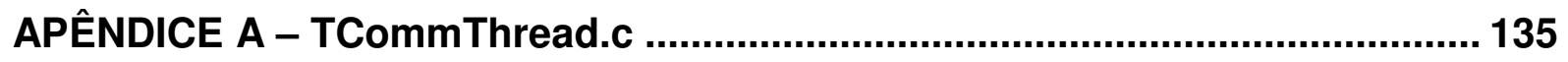

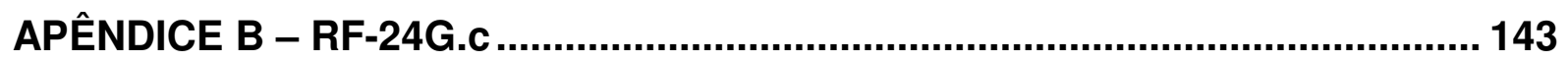

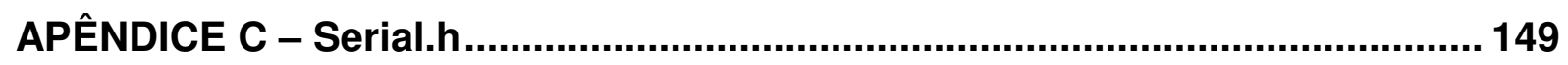

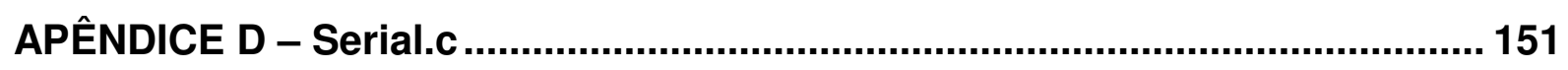

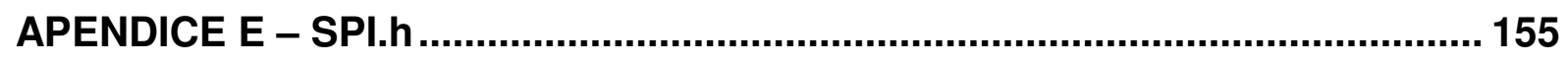

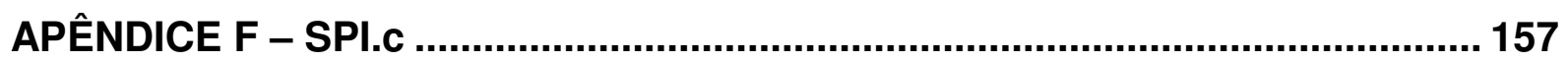




\section{Introdução}

\subsection{Motivação e Relevância da Dissertação}

Com o avanço da tecnologia, Robôs Móveis para as mais diversas aplicações vêm sendo desenvolvidos em centros de pesquisas do mundo inteiro. Dentre essas aplicações destacam-se as que visam à substituição do homem em tarefas repetitivas, susceptíveis a erro ou aplicações em ambientes inacessíveis.

Como exemplo dessas aplicações, podemos citar o robô Groundhog desenvolvido na Universidade Carnegie Mellon, ilustrado pela FIGURA 1.1 (a), com o objetivo de explorar minas abandonadas [1], oferecendo alto risco para presença de seres humanos, e o primeiro robô desenvolvido pela Nasa para exploração do planeta Marte denominado de Sojourner [2], conforme a FIGURA 1.1 (b).

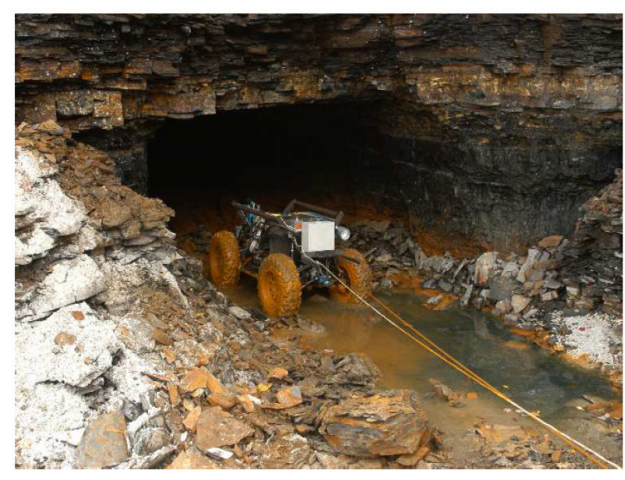

(a)

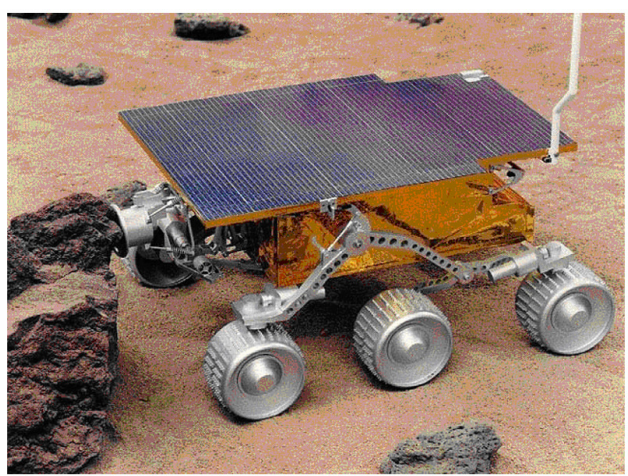

(b)

FIGURA 1.1 - Exemplos de aplicações de robótica móvel:

(a) Explorador de minas Groundhog (fonte: Thrun, 2003)

(b) Explorador de Marte Sojourner (fonte: NASA) 
Muitos robôs utilizados em pesquisas hoje possuem um alto custo em sua concepção, tornando-se uma limitação, pois são poucas as instituições de ensino e pesquisa que possuem suporte financeiro para aquisição dessas tecnologias.

Além disso, a maioria das arquiteturas de Hardware é privativa, sendo que o fabricante apenas disponibiliza protocolos de comunicação com o robô e softwares para configuração do mesmo.

Para tentar contornar este inconveniente, este trabalho propõe uma arquitetura de Hardware de baixo custo para desenvolvimento de robôs móveis para aplicações gerais, que permite desde estudos em navegação autônoma, detecção de obstáculos, até monitoramento de ambientes, possuindo grande capacidade de sensoriamento e processamento.

\subsection{Proposta e Justificativa da Dissertação}

A proposta desse trabalho é o desenvolvimento de uma arquitetura de baixo custo para robótica móvel, com aplicações de propósitos gerais e alta capacidade de processamento. Possuindo as seguintes características:

- Sistema Modular e Expansível;

- Monitoramento e Controle Remoto;

- Aquisição de dados;

- Atuação;

- Identificação e Mapeamento de Ambientes. 
A partir dessas características diversos métodos e conceitos de navegação poderão ser estudados fisicamente, deixando de ser apenas modelos computacionais.

No mercado já existem robôs modulares dedicados a estudos de algoritmos SLAM (Simultaneous Localization and Mapping) [3] e navegação autônoma [4]. Como exemplo, podemos citar o robô Khepera ${ }^{\circledR}$ (FIGURA 1.2) desenvolvido e comercializado pela empresa Suíça $K$-Team $S / A$, muito utilizado por pesquisadores. Porém, possui duas características negativas, sendo elas:

- Alto custo na aquisição de unidades [5];

- Muito complexo para estudantes que desejam implementar aplicações básicas [5].

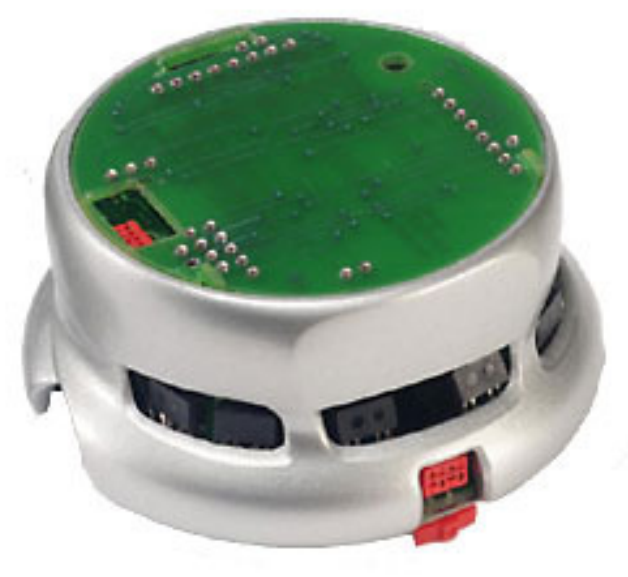

FIGURA 1.2 - Robô Móvel Khepera® (fonte: K-Team SA)

O sistema proposto de forma geral neste trabalho é apresentado pelo diagrama de blocos ilustrado na FIGURA 1.3, onde cada módulo especificado é um sistema microcontrolado. 

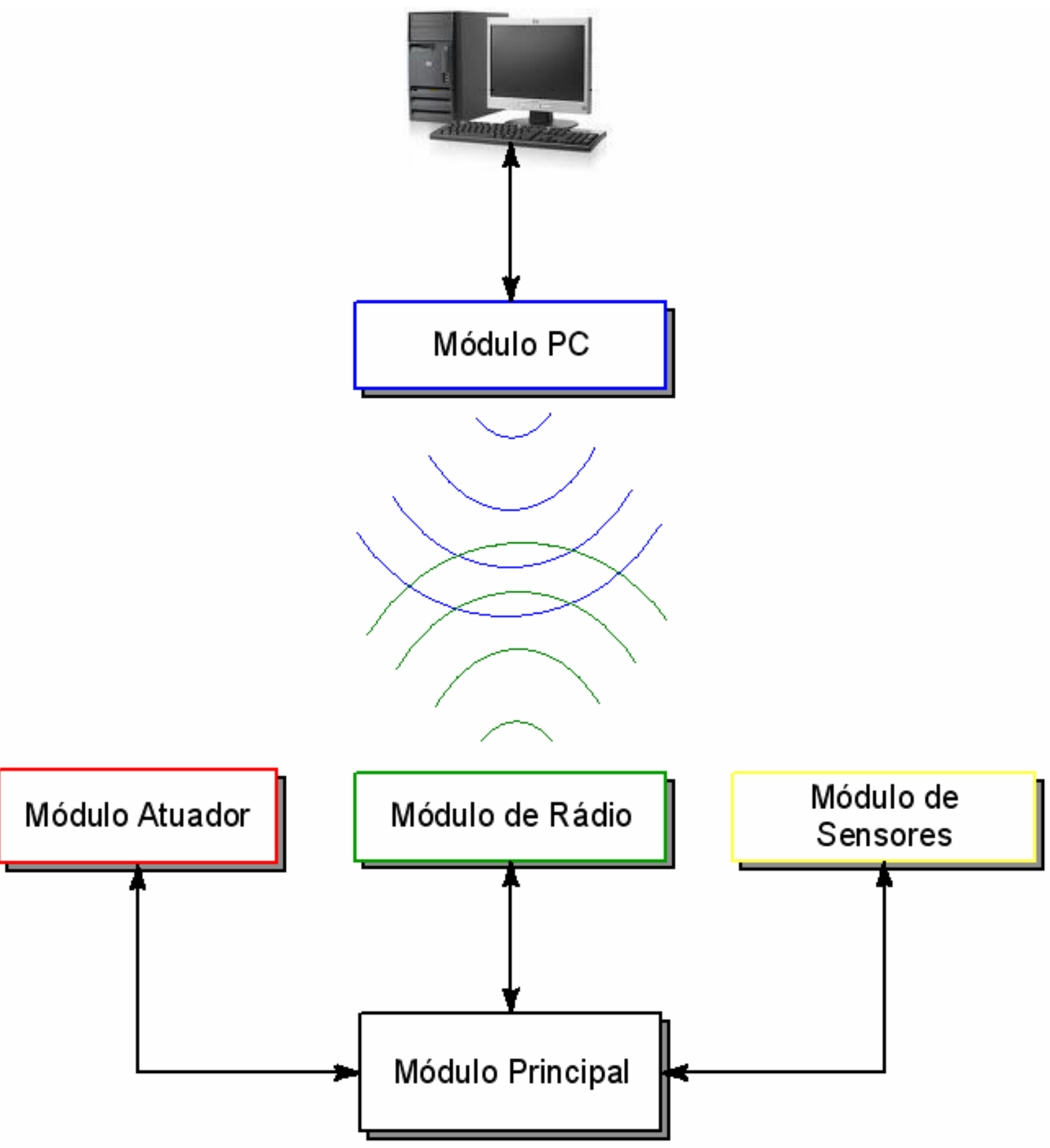

FIGURA 1.3 - Diagrama de Blocos do sistema proposto

A comunicação entre os módulos é feita através de um canal de comunicação e um protocolo dedicado, os quais serão apresentados no decorrer da dissertação. 


\subsection{Organização da Dissertação}

Nesta seção é apresentada uma breve introdução sobre o conteúdo abordado em cada capítulo.

No Capítulo 2 são abordados os aspectos gerais sobre os Robôs Móveis, incluindo componentes principais, sistemas de comunicação e arquiteturas.

O Capítulo 3 detalha o funcionamento e característica de cada módulo da arquitetura proposta. Protocolos e padrões de comunicação também são apresentados em conjunto com algoritmos de controle e navegação.

No Capítulo 4 são abordados os resultados experimentais de uma aplicação utilizando a arquitetura desenvolvida e a análise de custo.

No Capítulo 5 são feitas considerações finais a respeito deste trabalho, mostrando quais foram os pontos chave desta pesquisa visando viabilização de protótipos de robôs móveis de baixo custo. 



\section{Estado da Arte em Robótica Móvel}

\subsection{Introdução}

O termo robô (do tcheco robota - escravo) foi utilizado pela primeira vez em 1923, na peça de Teatro R.U.R. ("Rossum`s Universal - Robots") do tcheco Karel Capek. Rapidamente, popularizou-se entre os escritores de ficção científica, sendo empregado para indicar seres mecânicos antropomórficos.

O interesse pela mobilidade de robôs iniciou-se com hobistas e técnicos da área de Elétrica/Eletrônica, cujos primeiros protótipos foram impulsionados pela curiosidade. Na maioria das vezes, esses protótipos eram construídos a partir de peças sucateadas de rádios, televisores e motores.

Na década de 30 apareceram na ficção os chamados "robôs amigáveis" idealizados pelo escritor Isaac Asimov. Esses robôs eram máquinas bem projetadas, cuja construção e programação eram baseadas em um princípio composto por três regras [6], sendo elas:

1. Um robô não pode ferir um ser humano ou, por inação, permitir que um humano seja ferido.

2. Um robô deve obedecer às ordens dadas por humanos, exceto quando essas ordens se conflitarem com a Primeira Lei. 
3. Um robô deve proteger sua própria existência a menos que isso infrinja a Primeira e Segunda Lei.

A partir da década de 70, projetos com objetivos mais ambiciosos, tais como exploração, transporte e patrulhamento de ambiente, eram muitas vezes patrocinados por órgãos militares, governamentais e grandes empresas [6].

O primeiro robô móvel a ter sucesso foi o Robart I (FIGURA 2.1) desenvolvido pela marinha americana entre 1980 e 1982. O Robart I tinha como função patrulhar ambientes fechados (Indoor) à procura de situações anormais, como por exemplo, indícios de incêndios e vestígios de intrusos [6].

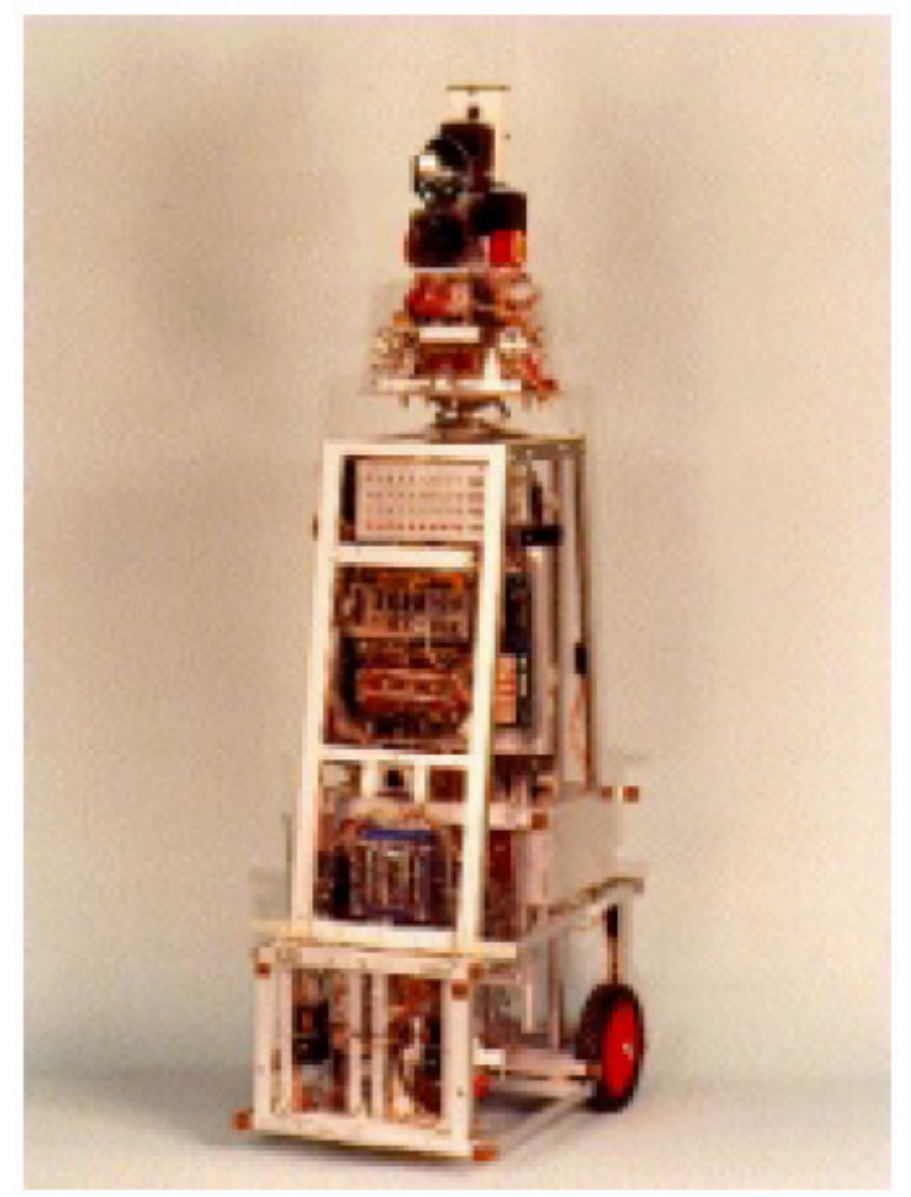

FIGURA 2.1 - Robô Móvel Robart I (fonte: Loughnane, 2001) 
Com o aumento da capacidade de processamento dos computadores foi possível o desenvolvimento de novas tecnologias de navegação e sensoriamento para veículos autônomos. Como conseqüência, surgiram os primeiros robôs móveis industriais.

A literatura define um robô móvel como sendo um dispositivo que compreende, em um só conjunto, a mobilidade de um veículo autônomo, a capacidade de manuseio e a manipulação de robôs [7].

O desenvolvimento de robôs móveis é uma tarefa fortemente interdisciplinar, envolvendo diversas áreas acadêmicas, como Engenharia Mecânica, Elétrica e Computação. Seu principal objetivo no contexto da computação é o desenvolvimento de sistemas autônomos inteligentes, capazes de atuarem em ambientes com situações desconhecidas [3].

Da mesma forma que aconteceu com os computadores atuais, os robôs móveis foram sendo classificados em gerações de acordo com seu surgimento [8], ou seja:

\section{- Primeira Geração: Robôs Seqüenciais}

Manipuladores Automáticos controlados por sistemas em malha aberta, possuindo de 2 a 4 graus de liberdade. Projetados para execução de tarefas simples.

\section{- Segunda Geração: Robôs com Ciclos Programáveis}

São robôs mais elaborados, possuindo de 4 a 8 graus de liberdade. Em função do modo de programação, podem ser divididos em robôs 
programáveis por aprendizagem (Play-Back) e robôs programáveis por linguagem.

\section{- Terceira Geração: Robôs Inteligentes}

São robôs adaptativos, capazes de operar mediante um sistema de controle, percepção, comunicação e decisão, mesmo que ocorram modificações em seu ambiente.

Muitos autores referem-se à Terceira Geração de robôs móveis como aqueles capazes de operar autonomamente em um ambiente desconhecido, tendose como referência comum: robôs autônomos, robôs autônomos inteligentes e robôs móveis autônomos, todos eles pertencentes à terceira geração.

\subsection{Características Gerais de Robôs Móveis}

Os robôs móveis são divididos quanto à sua morfologia em duas classes. Uma classe consiste em robôs que possuem como forma de locomoção rodas, e uma outra classe onde os movimentos são realizados através de pernas, como é visto nas FIGURAS 2.2 e 2.3, respectivamente.
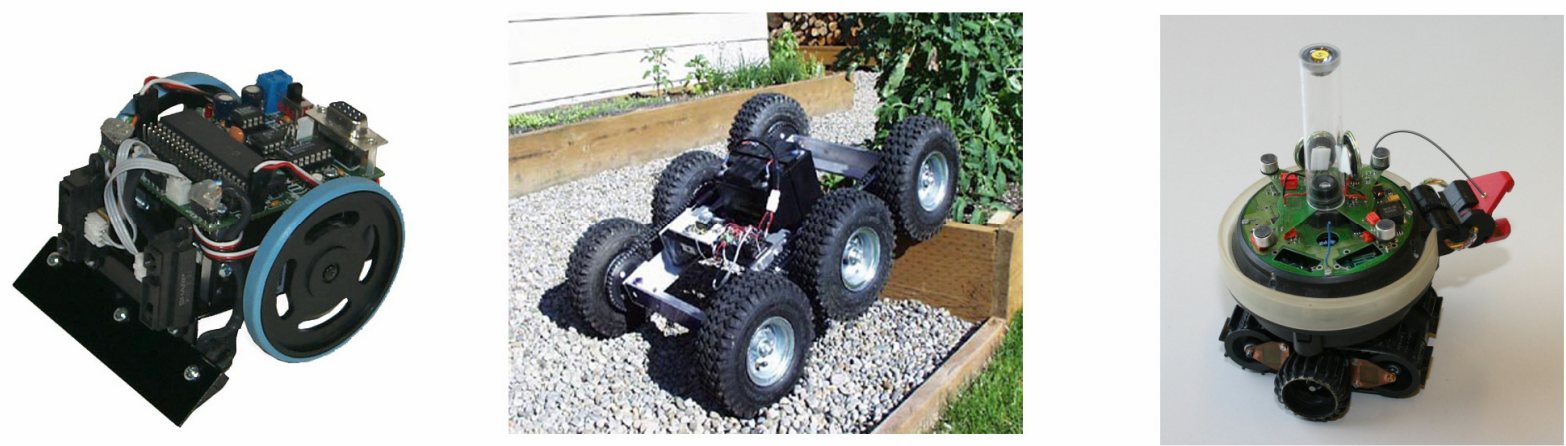

FIGURA 2.2 - Exemplo de Robôs com locomoção através de rodas (fonte: Internet) 


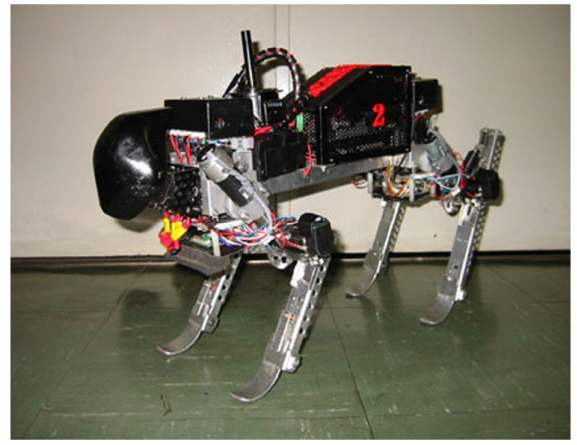

(a)

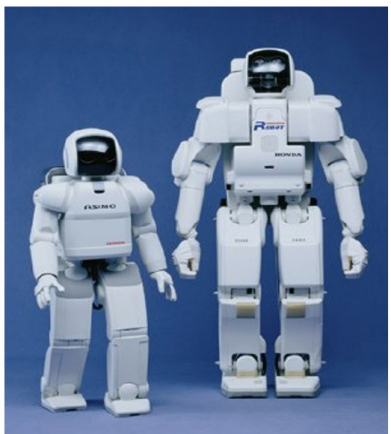

(b)

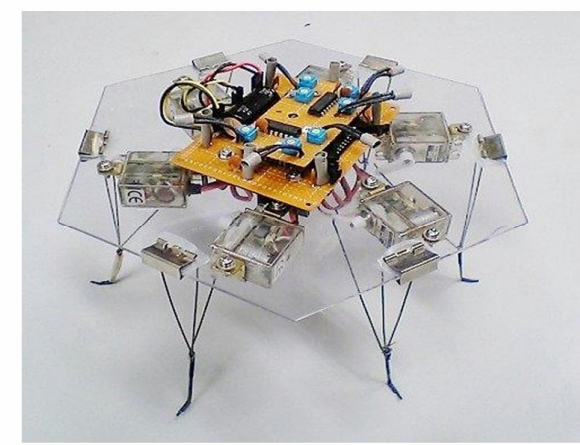

(c)

FIGURA 2.3 - Exemplo de Robôs com locomoção através de pernas:

(a) Robô TEKKEN II (fonte: Kimura, 2003)

(b) Robô ASIMO® (fonte: HONDA®)

(c) Robô Hexapod (fonte: Tsuda, 2006)

A morfologia utilizada no desenvolvimento de cada robô móvel depende principalmente de sua futura aplicação.

Hoje em dia, no Japão principalmente, há um grande investimento na pesquisa e desenvolvimento de modelos de robôs humanóides, como exemplo, o robô Asimo (FIGURA 2.3b) desenvolvido pela HONDA®. Suas aplicações vão desde a substituição do homem em algumas tarefas, nesse caso, recepcionistas e seguranças, até a interação com outras pessoas em lazer e entretenimento [10].

Isso se torna possível com o avanço nos estudos de algoritmos inteligentes de aprendizagem, onde robôs humanóides podem repetir movimentos iguais aos dos humanos com um alto grau de precisão [9].

Por outro lado, tem-se também um grande avanço em pesquisas com robôs móveis com rodas, impulsionadas pelos institutos aeroespaciais e grandes empresas, visando à exploração extraterrestre. 


\subsection{Principais Componentes de Robôs Móveis}

A seguir serão apresentados os principais componentes que constituem um robô móvel.

\subsubsection{Base Móvel}

A base móvel de um robô é um fator muito importante a ser estudado, pois há uma relação muito próxima entre o design escolhido e a precisão em seu posicionamento e movimentação.

Em [4] são citadas as mais populares configurações para construção de um robô móvel, entre elas:

\section{- Driver Diferencial}

Nessa configuração de base móvel (FIGURA 2.4), os encoders incrementais são montados em dois motores para que seja feita a contagem dos pulsos referentes a cada revolução da roda. O robô pode facilmente realizar dead-reckoning, utilizando apenas simples equações geométricas para computar a posição momentânea relativa a uma posição inicial conhecida [4].

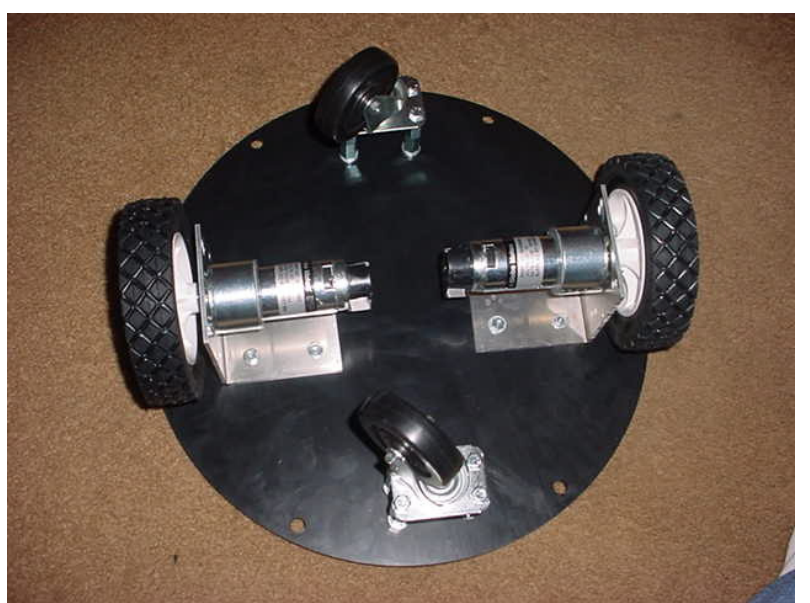

FIGURA 2.4 - Rex-16C Round Robot Base, configuração com driver diferencial para um robô móvel (fonte: Zagrosrobotics) 


\section{- Driver Triciclo}

Essa configuração implica em uma base com três rodas, sendo uma tracionada e outras duas guiadas por motores elétricos. Muito utilizada em aplicações com AGV (Automated Guided Vehicle) devido à sua simplicidade (FIGURA 2.5).

Um problema associado a essa configuração está em seu centro de gravidade, que tende a movimentar-se para frente da roda dianteira quando 0 robô está sobre uma superfície inclinada, causando então a perda de tração [4].

FIGURA 2.5 - ARobot, configuração de um triciclo com um motor de tração (fonte: ARRIC Robotics)

\section{- Driver Omnidirecional}

A configuração Omnidirecional é um pouco mais complexa que as demais. Porém, a solução odométrica para robôs com múltiplos graus de liberdade é similar à configuração de base móvel com tração diferencial [4], estando sua estrutura mostrada na FIGURA 2.6. 


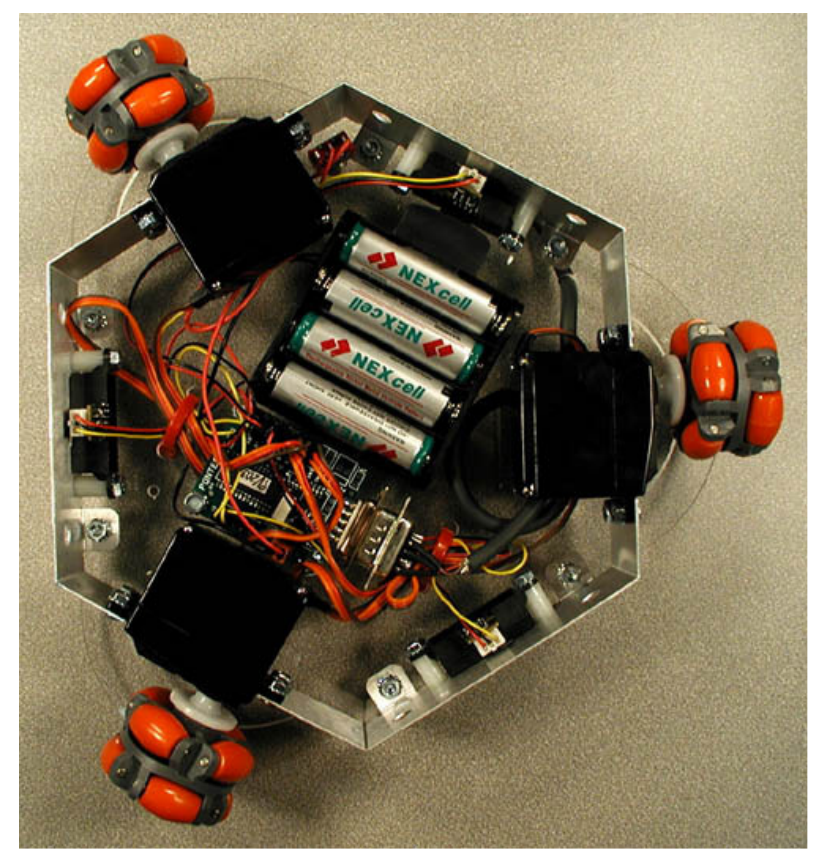

FIGURA 2.6 - Configuração Omnidirecional com três drivers (fonte: PPRK Robot - Carnegie Mellon Robotics Institute)

\subsubsection{Eletrônica Embarcada}

Diferentes tipos de sistemas eletrônicos são responsáveis pela instrumentação e controle do robô, sistemas esses que devem ser cuidadosamente projetados e definidos para aplicações específicas.

A complexidade da eletrônica embarcada nos robôs móveis varia de acordo com suas aplicações, pois seu principal objetivo é executar tarefas mantendo uma precisão especificada [11].

Esses controladores podem seguir duas topologias, sendo elas:

\section{- Controle em Malha Aberta}

Controladores em malha aberta aplicam na planta sinais de controle pré-definidos, independentes do resultado obtido na variável controlada [12]. A FIGURA 2.7 mostra o diagrama de blocos desse sistema, onde é possível notar a inexistência de um bloco para realimentação dos dados. 


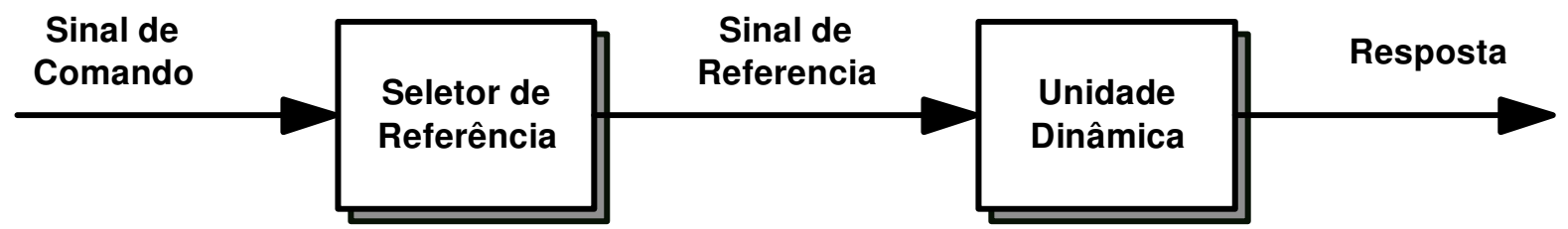

FIGURA 2.7 - Diagrama de um Controlador em Malha Aberta

- Controle em Malha Fechada

Controladores nos quais os sinais de controle aplicados na planta são dependentes da variável controlada, ou seja, a resposta de controle é resultado da relação entre a variável controlada e o valor desejado [12]. Seu diagrama de blocos é mostrado na FIGURA 2.8.

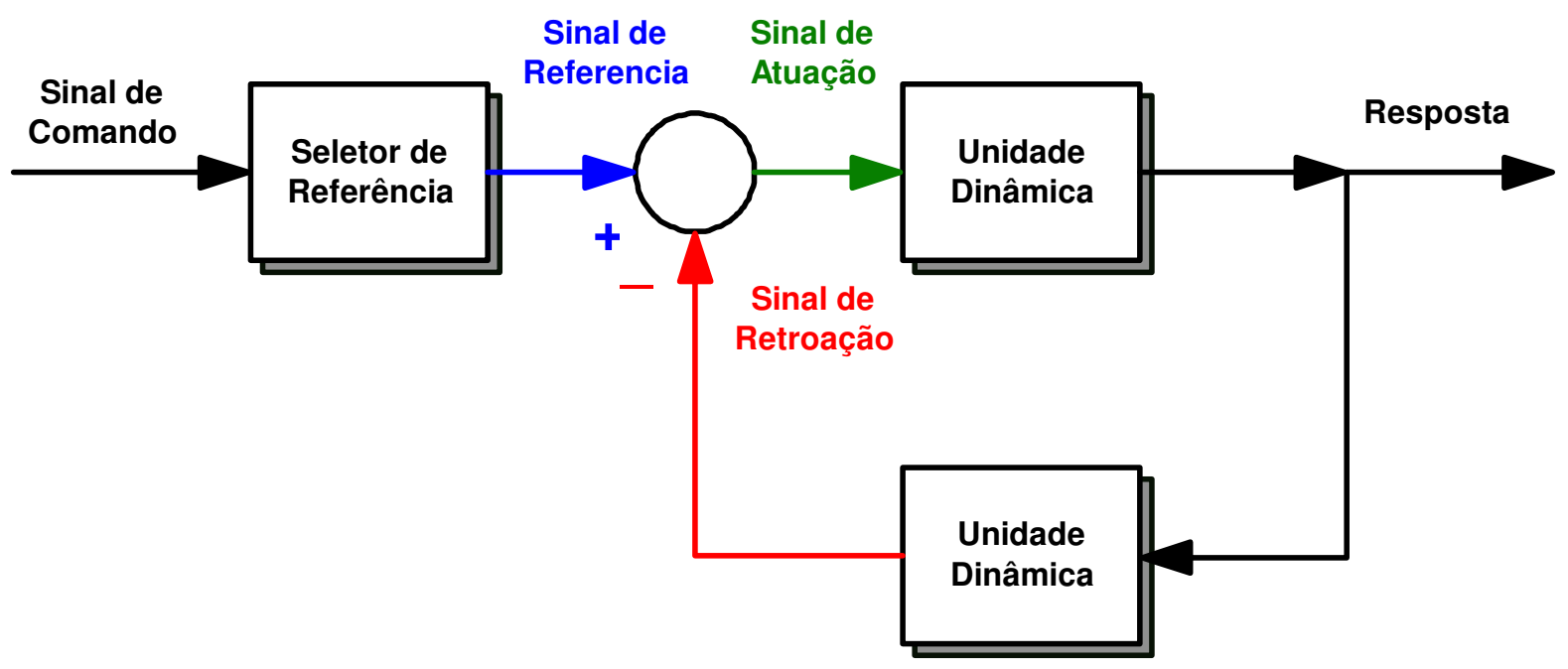

FIGURA 2.8 - Diagrama de um Controlador em Malha Fechada

Para uma melhor compreensão dos blocos segue as seguintes definições:

- Sinal de Comando: sinal de excitação do sistema, responsável por exercer uma ação de controle na malha. 
- Seletor de Referência: gerador do sinal de referência, ou seja, o seu valor é calibrado sempre no valor desejado da variável controlada.

- Sinal de Referência: sinal de excitação real para o sistema de controle, gerado a partir do Seletor de Referência.

- Resposta (Variável Controlada): grandeza submetida ao controle que deve ter seu valor sempre mantido igual ao pré-estabelecido.

- Sinal de Retroação: sinal equivalente ao valor da variável controlada.

- Sinal de Atuação: diferença entre o sinal de Retroação e o Sinal de Comando, com a função de manter a variável controlada estável.

Esses controladores na robótica móvel são utilizados para controle de velocidade e posicionamento de motores, captura e detecção de obstáculos, e muitas outras aplicações. Os sinais de retroação para esses controladores são gerados através de sensores, que serão detalhados no Capítulo 3 desse trabalho. Na FIGURA 2.9 é mostrado um robô móvel seguidor de linha.

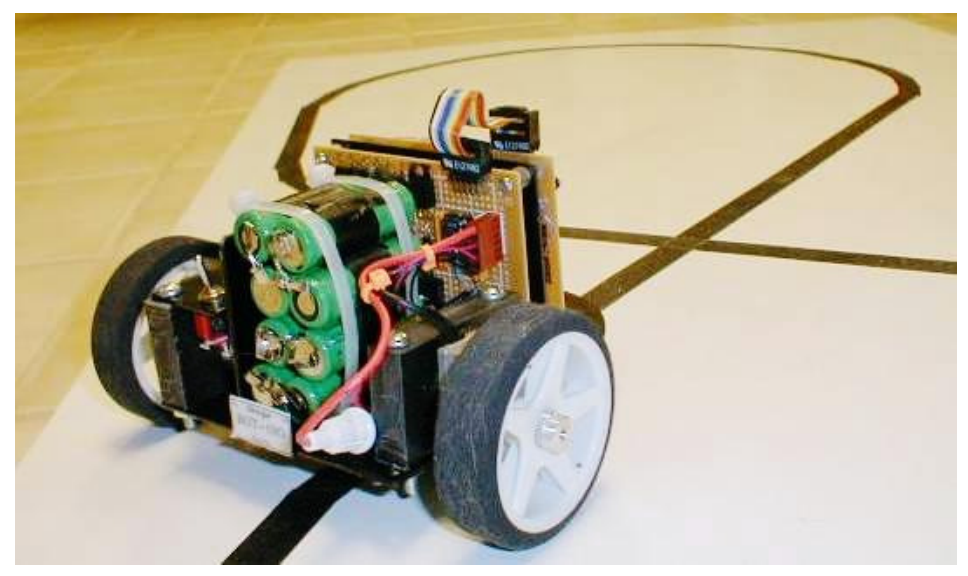

FIGURA 2.9 - Line Follower Robot, exemplo de um Robô Móvel seguidor de Linha (fonte: Atlanta Hobby Robot Club) 
A classe de controladores em malha fechada permite o controle baseado no cálculo do erro temporal do sistema controlado e a resposta desejada. Desta forma, é necessário para fins de controle determinar com precisão o estado do robô [11].

O estado do robô móvel, indicado por $X$, possui as seguintes variáveis de estado:

$$
X=\left[\begin{array}{l}
x \\
y \\
\theta \\
v \\
\omega
\end{array}\right]
$$

onde: $x$ e $y$ são posições no espaço cartesiano, $\theta$ é a orientação do robô, $v$ é a velocidade linear de deslocamento e $\omega$ é sua velocidade angular.

Para medição do estado do robô, os métodos utilizados baseiam-se em dois grupos de sensores [11], sendo eles:

\section{- Sensores Proprioceptivos}

Essa classe de sensores fornece informações a respeito do robô por meio de medições internas, ou seja, o sistema não utiliza dados de sensores externos. Em robôs móveis com dois graus de liberdade (planares), onde sua locomoção é realizada através de rodas, os encoders incrementais são os sensores proprioceptivos mais utilizados [11]. No caso de robôs que tenham mais graus de liberdade, outros sensores proprioceptivos como acelerômetros e giroscópios são também utilizados. 
Esses sensores oferecem um risco ao serem utilizados isoladamente.

Erros sistemáticos e acumulativos podem ser gerados durante a movimentação do robô, como por exemplo: em se realizar manobras, em deslizamento e até mesmo na diferença do diâmetro das rodas.

\section{- Sensores Externoceptivos}

São sensores que informam o estado do robô através de dados coletados do ambiente.

Os dados gerados por esses sensores são mais precisos que os proprioceptivos, pois se baseiam em pontos fixos no ambiente, fornecendo informação para cálculo do deslocamento relativo do robô. Os sensores externoceptivos mais utilizados são: GPS (Global Positioning System), Sonares, Câmeras e Lasers [11].

As limitações para esse tipo de sensoriamento ficam por conta do alcance dos sensores utilizados, como por exemplo: raio de visão de uma câmera, potência dos sonares e lasers, e no caso de exploração extraterrestre (exceto Marte [26]), inutilidade do GPS.

Diversos projetistas de robôs móveis utilizam sensores das duas classes citadas acima, proporcionando um melhor método de navegação [4].

\subsubsection{Software Embarcado}

Com o avanço da tecnologia e a diminuição no custo dos microcontroladores, muitos pesquisadores têm procurado desenvolver cada vez mais sistemas microcontrolados para os robôs móveis. Esses sistemas aumentam a gama de aplicações do robô. 
Os Firmwares (Softwares Embarcados) podem ser escritos em diversas linguagens, dependendo da disponibilidade do compilador, necessidade de memória e conhecimento do projetista. Essas linguagens podem ser: C, Assembly e até mesmo BASIC.

Porém, esses microcontroladores possuem limitações. Dependendo do problema no qual será aplicado, o Firmware pode ficar muito extenso o que impossibilita sua alocação na memória de programa, ou ainda, a quantidade de pinos de 1/O (Input/Output) do microcontrolador pode ser insuficiente. Para isso, uma pesquisa cuidadosa sobre qual componente utilizar deve ser realizada com antecedência.

Robôs móveis autônomos com alto grau de complexidade, além de possuírem processadores de excelente desempenho, precisam ter seus recursos otimizados. Para isso há uma grande utilização dos RTOS (Real Time Operational System).

Um RTOS pode ser definido como uma coleção de funções que contém uma serie de serviços básicos de interação com um hardware específico [13].

Por outro lado, quando uma aplicação necessita de mais recursos, sistemas mais completos são utilizados, como por exemplo, as plataformas embarcadas PC104, que possuem todas as características de um computador portátil, inclusive podendo executar sistemas operacionais completos como o Windows® e Linux.

Com todas essas possibilidades de desenvolvimento, pesquisas em navegação autônoma vêm aumentando consideravelmente. Hoje em dia existem algoritmos inteligentes capazes de fazer com que o robô móvel navegue autonomamente por meio de visão e olfato artificiais [14]. 
As arquiteturas de softwares mais conhecidas para desenvolvimento de software embarcado para robôs móveis são:

\section{- Arquitetura Subsumption}

$\mathrm{Na}$ década de 80 um grupo de pesquisadores, composto pelo pesquisador do Artificial Intelligence Lab. do Massachusetts Institute of Technology (MIT), Rodney Brooks, acreditava que o nível da inteligência humana era pouco entendido e muito complexo para ser decomposto [16] .

Com isso uma arquitetura totalmente diferente foi proposta pelo grupo de pesquisadores [17], dando uma outra solução ao problema do controle de robôs autônomos móveis [8].

A arquitetura Subsumption, conforme mostrado na FIGURA 2.10, organiza o agente móvel como um conjunto de camadas ou blocos, cada um apresentando de forma distinta uma tarefa ou comportamento completo [8].

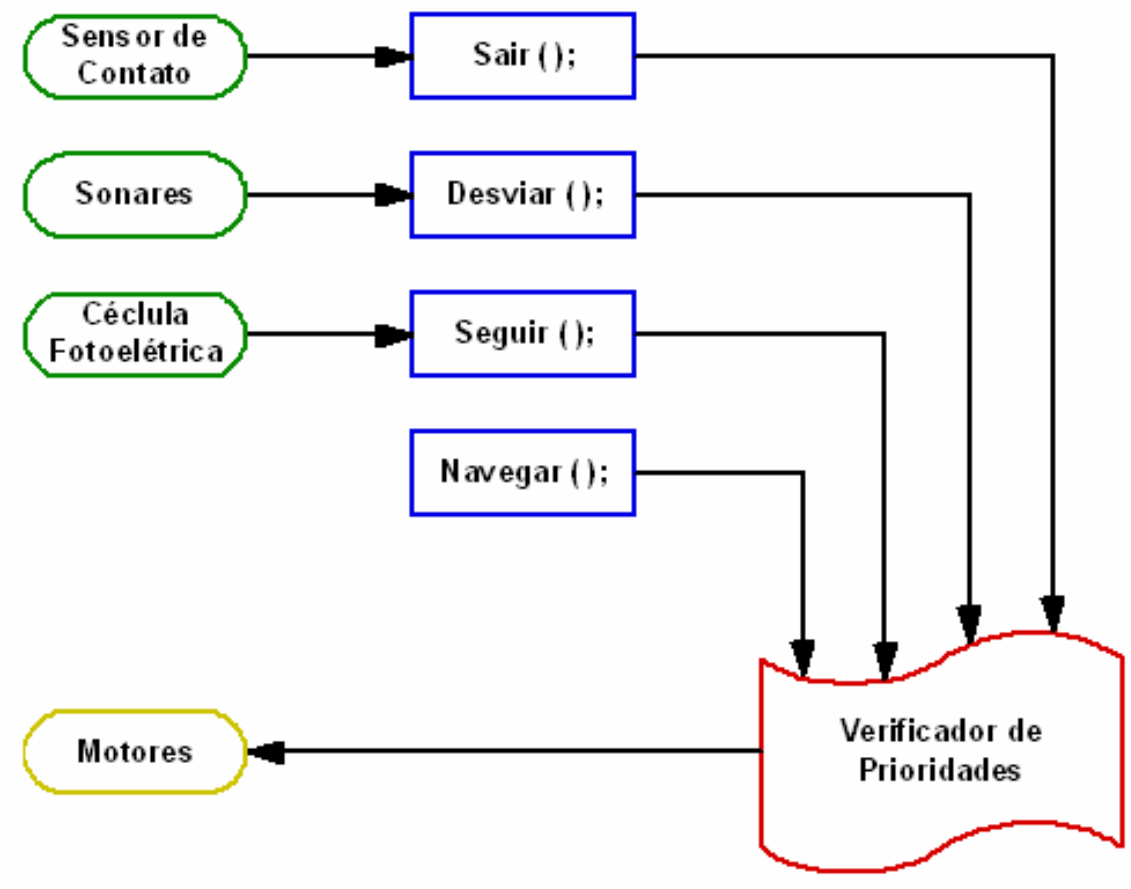

FIGURA 2.10 - Diagrama da arquitetura Subsumption para um robô seguidor de luz com desvio de obstáculos 
De acordo com [18] essa arquitetura não possui seus módulos decompostos de maneira tradicional, e sim são divididos em pequenas máquinas de estados finitos [20]. Essas máquinas funcionam como se estivessem conectadas por um "fio" internamente, ligando as portas de saídas nas portas de entradas de seus módulos [18].

Algumas limitações foram encontradas nessa arquitetura desde que problemas mais complexos foram surgindo. Essas limitações deviam-se ao fato da arquitetura Subsumption não ser suficientemente modular [18]. Os módulos de alto nível eram intimamente relacionados com os módulos de baixo nível, ou seja, quando uma alteração era necessária em um desses módulos, todos os demais também deviam ser alterados.

\section{- Arquitetura Three Layers (Três Camadas)}

A arquitetura Three Layers foi criada a partir de um grupo de pesquisadores independentes que vinham desenvolvendo soluções similares para os problemas apresentados pela arquitetura Subsumption [19].

As três camadas típicas referentes a essa arquitetura são apresentadas na FIGURA 2.11. 


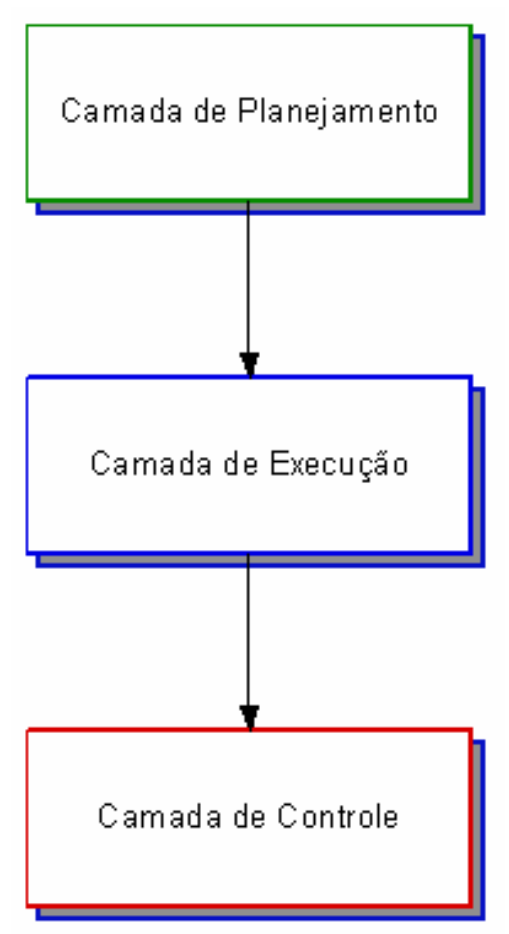

FIGURA 2.11 - Arquitetura Three Layers

Camada de Planejamento (Planning Layer): Nessa camada encontram-se os processos que consomem tempo de processamento, como por exemplo, planejamento de trajetória e algoritmos baseados em busca, além de responder a pedidos requisitados pela camada de execução. Comportamentos transitórios podem ocorrer durante o período em que essa camada é acionada até o momento da geração do resultado [21].

Camada de Execução (Execution ou Sequencing Layer): Camada responsável por selecionar funções e parâmetros para a camada de controle, possuindo estados definidos que podem cooperar em situações inesperadas [21].

Camada de Controle (Functional ou Skill Layer): Essa camada tem a função de controlar os laços de Feedback, ler dados de sensores, inferir nos 
atuadores e executar funções de transferências. Todas as funções relacionadas com o hardware estão presentes nessa camada [21].

\subsubsection{Sistemas de Comunicação}

Robôs móveis podem ser utilizados para diversas aplicações, inclusive onde se exige cooperação entre os elementos dinâmicos que as compõem. Além disso, dependendo da arquitetura utilizada e níveis de exigência de hardware, sistemas de comunicação entre os periféricos são utilizados.

A forma de comunicação é escolhida de acordo com a aplicação, e a velocidade com que as informações entre os robôs (ou entre robôs e operadores) e entre seus periféricos devem ser trocadas.

Considerando sistemas de comunicação como um todo, existe uma grande quantidade de interfaces utilizadas na robótica móvel, como por exemplo:

\section{- Sistemas Wired (com fio)}

Esse método de comunicação atualmente é mais utilizado entre os periféricos que constituem o robô móvel, podendo esses também se utilizarem de sistemas Wireless. Como exemplo de padrões de comunicação com fio, podemos citar os mais conhecidos: SPI, I²C, RS232, RS485, CAN e o padrão de 4 a 20mA no caso de sinais analógicos transmitidos em corrente elétrica.

\section{- Sistema Wireless (sem fio)}

Esse sistema normalmente é utilizado em robôs que se comunicam com uma central ou trabalham de forma cooperativa, onde a limitação de 
movimentação causada pela utilização de cabos para comunicação torna-se um inconveniente.

Os sistemas Wireless [15] existentes são: Óptica em espaço livre [22], Ondas milimétricas [23], Sistemas de radiação Teraherts [24], WiFi (Padrão IEEE 802.11a, b, g), Micropower Impulse Radio (MIR) [25], sistemas transceptores em $900 / 415 \mathrm{MHz}$ e $2.4 \mathrm{GHz}$.

\subsection{Arquiteturas de Robôs Móveis}

Na literatura é possível encontrar diversas arquiteturas para robôs móveis já utilizadas comercialmente para desenvolvimento. Algumas mais relevantes [8] e disponíveis foram selecionadas e serão citadas como exemplo a seguir:

\section{- Lego $\AA_{\text {Mindstorms } \AA N X T}$}

Muito utilizados por pesquisadores iniciantes em robótica [30]. Esse sistema oferece uma interface simples de programação que facilita a iteração de sensores, atuadores e controladores.

Na FIGURA 2.12 podemos observar a modularidade da arquitetura de Hardware. 


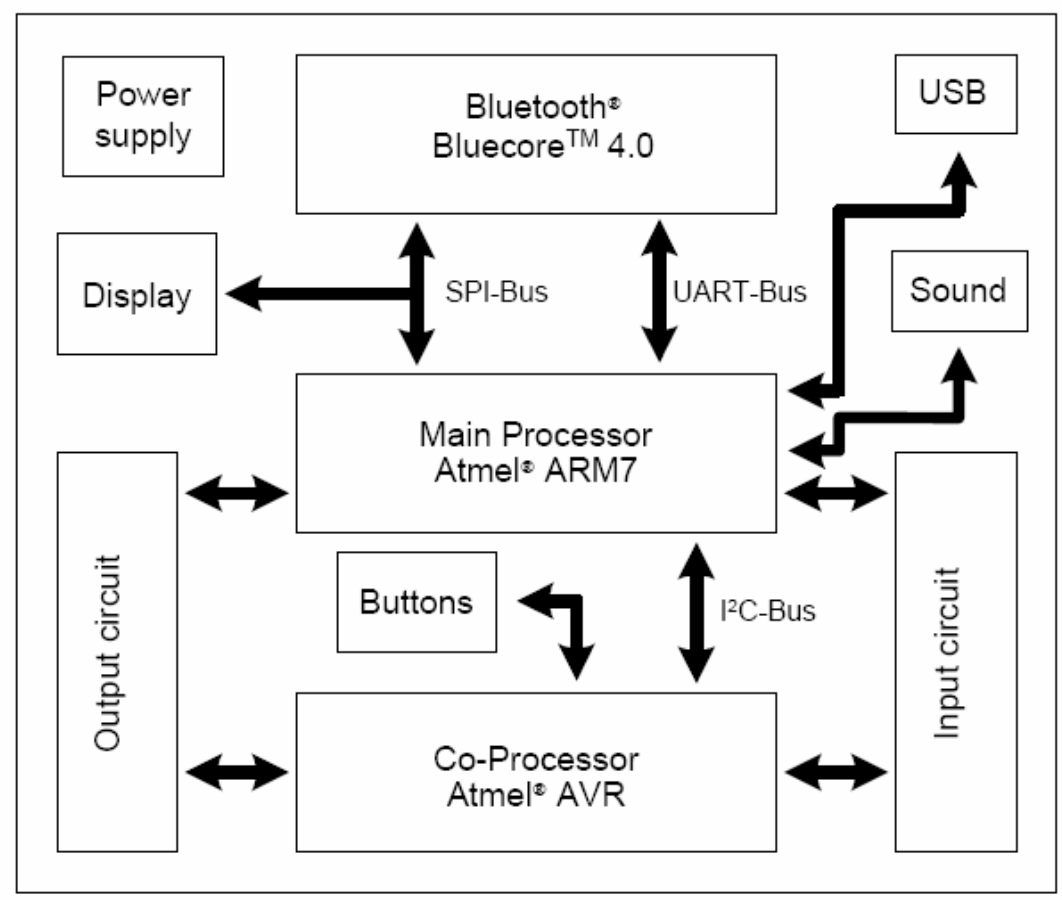

FIGURA 2.12 - Arquitetura do Hardware do Lego® Mindstorm $\AA$ NXT (fonte: Lego®, 2007)

Essa arquitetura possui as seguintes características:

- Processador principal: ATMEL® 32-bit ARM®, AT91SAM7S256

- 256KB de memória Flash;

- 64KB de memória RAM;

- Clock de $48 \mathrm{MHZ}$.

- Co-Processador: Atme/ß 8-bit AVR processor, ATmega48

- 4KB de memória Flash;

- 512 Bytes de RAM;

- $8 \mathrm{MHZ}$.

- Comunicação sem fio Bluetooth: CSR BlueCoreTM 4 v2.0 +EDR System

- 47KB de memória RAM interna;

- 8 MBit de memória Flash externa.

○ Porta de comunicação USB 2.0; 
- Portas de I/O: 4 de entradas e 3 de saídas;

- Quatro botões de interfaceamento com o usuário;

- Alimentação: 4 Baterias AAA (Lithium-Ion de preferência);

- Seis conectores RJ12.

A FIGURA 2.13 mostra algumas aplicações utilizando esse sistema, sendo a primeira um robô móvel em forma de escorpião, e a segunda um robô humanóide.
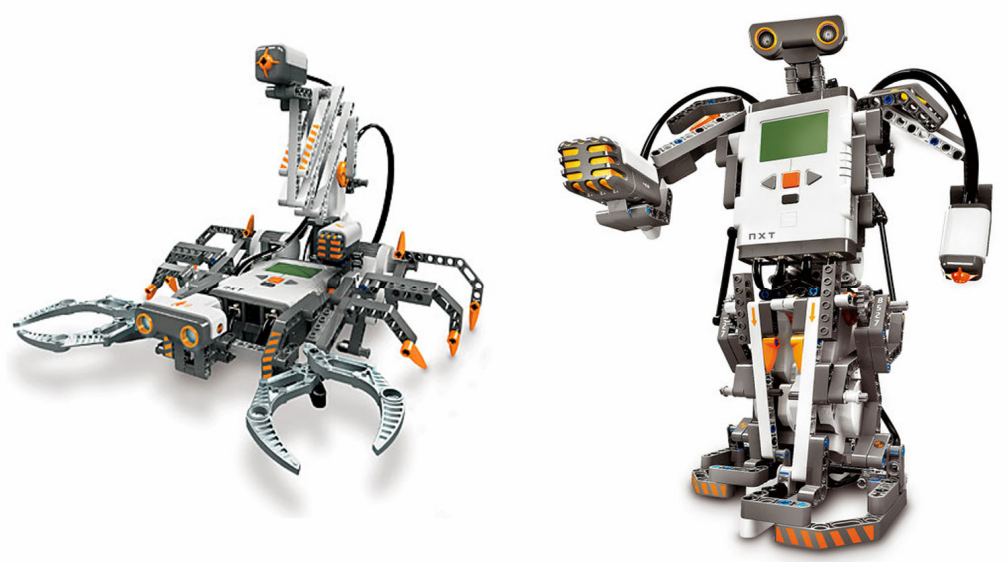

FIGURA 2.13 - Aplicações do Lego® Mindstorms ${ }^{\circledR}$ NXT (fonte: Lego $\circledast$, 2007)

- Handy Board/Cricket

São sistemas de controle para robôs projetados pelo MIT Media Lab. (Massachusetts Institute of Technology) [32].

O Controlador Handy Board permite uma alta flexibilidade de aplicações em robótica móvel, com suporte a uma grande quantidade de periféricos. A arquitetura desse controlador é mostrada na FIGURA 2.14. 


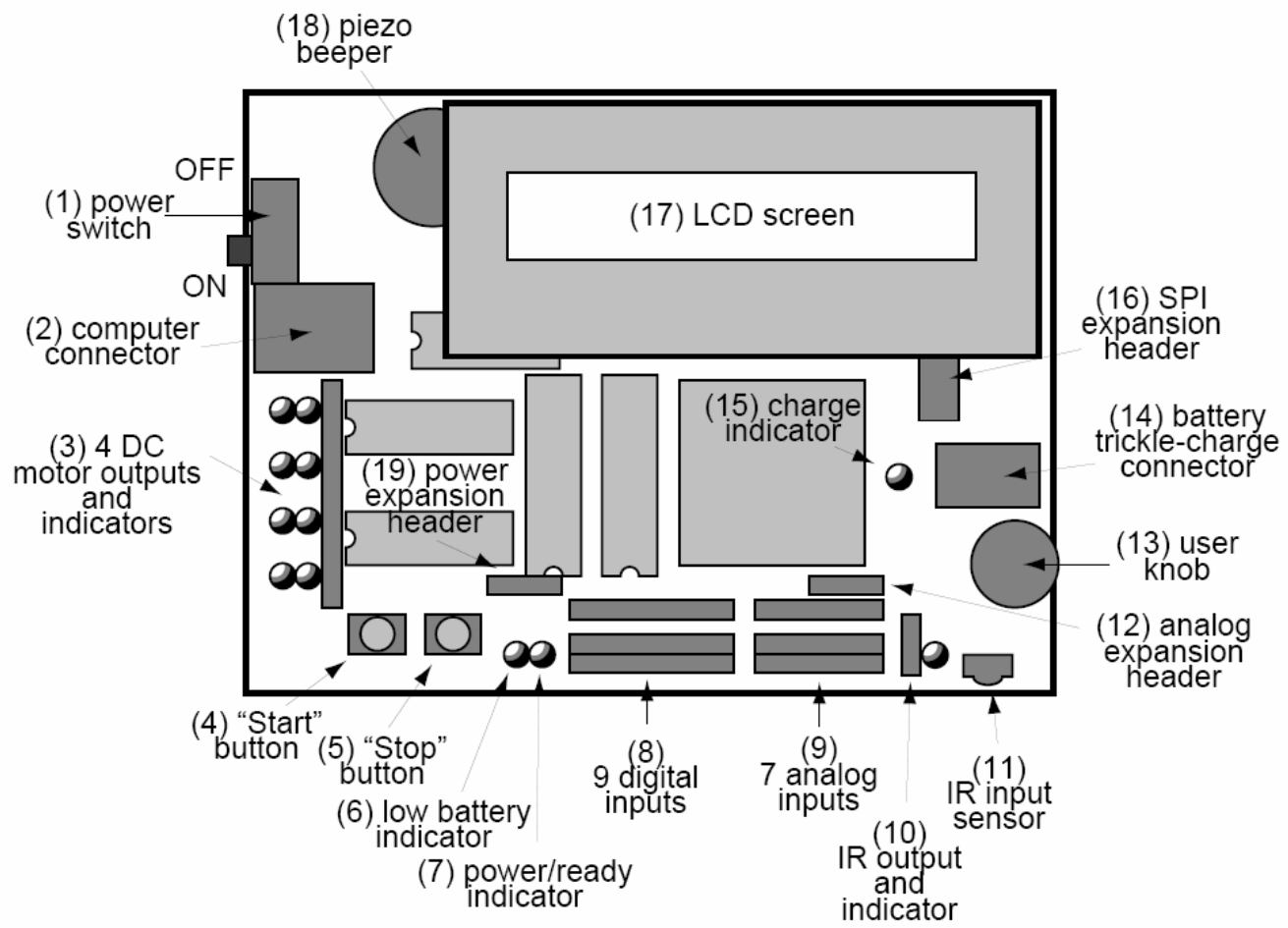

FIGURA 2.14 - Arquitetura de Hardware do Handy Board/Cricket (fonte: MIT Media Lab)

As características [33] desse sistema são:

- placa única de controle;

- microprocessador Motorola® $68 \mathrm{HC} 11$;

- 32k de memória RAM (Random Access Memory);

- Clock de 2MHZ;

- dois chips L293D para controle de 4 Motores DC;

- sete entradas analógicas e 9 digitais para sensores;

- display $L C D$ de 16 caracteres por 2 linhas;

- barramento disponível: SPI e Expansion Bus com Chip Select.

Abaixo, nas FIGURAS 2.15(a) e 2.15(b), segue uma implementação e utilização do Hardware Handy Board/Cricket: 


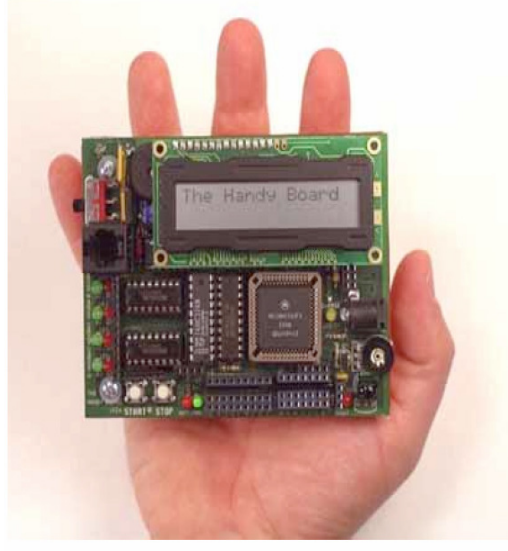

(a)

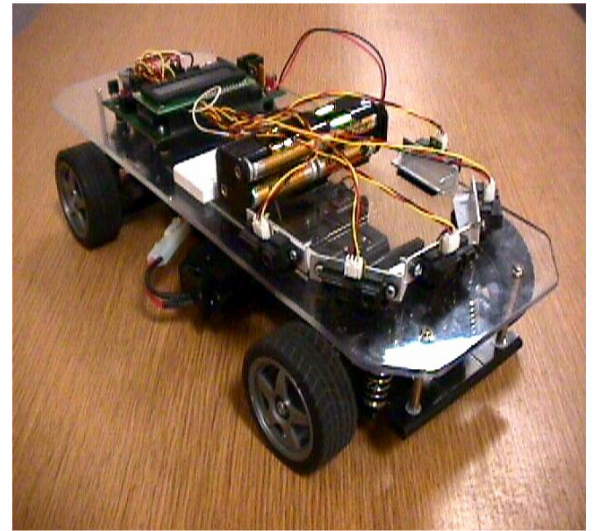

(b)

FIGURA 2.15 - Aspectos de Controlador:

(a) Handy Board/Cricket (fonte: Martin, 2001)

(b) Handy Car, utilização do Handy Board em um robô móvel (fonte: Computer Science Department of Plattsburgh Stat University)

\section{- Khepera®}

O robô Khepera®, como já citado no Capítulo 1 deste trabalho, desenvolvido e comercializado pela empresa Suíça $K$-Team $S / A$, é muito utilizado para estudo em navegação autônoma por pesquisadores no mundo inteiro [5].

Sua arquitetura modular permite uma grande expansão de funcionalidades, além de oferecer um alto poder computacional. Os módulos são conectados em um barramento chamado de K-extension bus [34].

Devido às suas dimensões, o robô Khepera® é considerado um minirobô, limitando assim sua utilização apenas a ambientes indoor [5].

A FIGURA 2.16(a), 2.16(b) e 2.16(c) mostram o robô Khepera® somente em seu módulo principal, um módulo de RF e, por fim, a conexão de um módulo atuador, respectivamente. 


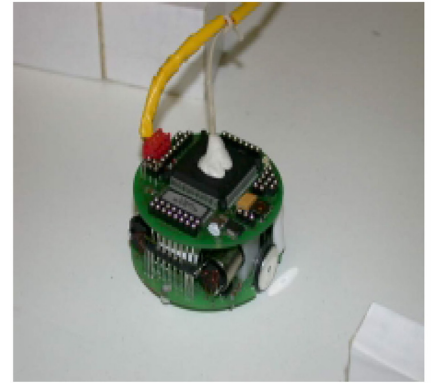

(a)

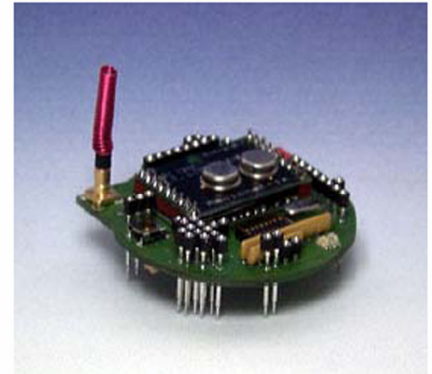

(b)

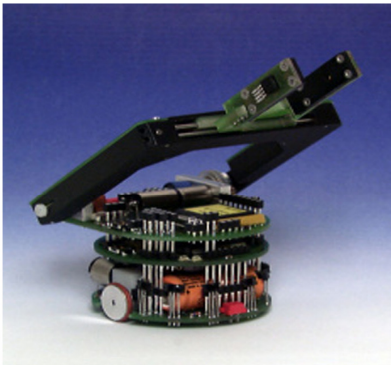

(c)

FIGURA 2.16 - Robô Khepera®:

(a) Módulo principal (fonte: Krohling, 2002)

(b) Módulo de RF (fonte: Yamada. 2003)

(c) Módulo atuador conectado ao módulo principal (fonte: K-Team $S / A)$

As principais características desse robô são:

- Microprocessador Motorola® 68331;

- 256Kbytes de Memória RAM;

- 256 a 512Kbytes de Memória ROM;

- Clock de 16MHZ, 25MHZ e $60 \mathrm{MHZ}$ (Modelo I, II e III, respectivamente);

- Sistema de movimentação composto por 2 motores $D C$ com encoders incrementais (10 pulsos por milímetro);

- 8 sensores infravermelhos de proximidade, sendo 6 posicionados na dianteira e 2 na parte traseira do robô;

- Baterias recarregáveis de NiCd, com possibilidade de alimentação externa, e autonomia de 30 minutos utilizando a configuração básica (sem módulos adicionais);

- Sistema modular expansível pelo barramento K-extension bus;

- Dimensões do robô (configuração básica) $55 \mathrm{~mm}$ de diâmetro por $30 \mathrm{~mm}$ de altura, com peso de $40 \mathrm{~g}$. 


\subsection{Considerações Sobre o Capítulo}

Como visto anteriormente há uma série de robôs móveis desenvolvidos e comercializados com o intuito de viabilizar estudos e aplicações práticas que, eventualmente, são realizados computacionalmente.

Entretanto, esses robôs apresentam arquiteturas dispendiosas, sendo na sua maioria importados, uma vez que poucas empresas desenvolvem robôs móveis didáticos no Brasil. Em conseqüência disso, a aquisição em larga escala por instituições de pesquisas pode ser um fator limitante.

Para isso, no capitulo a seguir é apresentada uma arquitetura didática de baixo custo do robô proposto neste trabalho: O Projeto Zeus. 


\section{Arquitetura do Robô Móvel}

\subsection{Introdução}

Nesse capítulo será detalhado cada bloco do sistema, representado pela FIGURA 1.3 na primeira parte desse trabalho. Além de cada módulo, serão apresentados também os principais componentes, padrões e protocolos utilizados.

A arquitetura desenvolvida é composta por:

- Interface de comunicação sem fio;

- Interface de comunicação serial entre módulos;

- Sniffer ou Debugger para o módulo principal do robô móvel;

- Módulos independentes microcontrolados;

- Sensoriamento para medições de tensão de alimentação, temperatura ambiente, distâncias e obstáculos.

- Recarregador interno de Baterias;

- Relógio de tempo real (RTC - Real Time Clock).

A apresentação desses itens e os métodos de desenvolvimento são divididos nas seguintes seções: 
Na Seção 3.2 é apresentada a visão geral da arquitetura desenvolvida para o robô móvel, detalhando seus principais componentes.

Na Seção 3.3 são apresentadas as interfaces de comunicação presentes e disponíveis para controle, monitoramento e expansibilidade dos módulos.

Na Seção 3.4 é apresentado o Módulo principal (Motherboard), detalhando seu Hardware e métodos de gerenciamento dos demais módulos.

Na Seção 3.5 são apresentados o Hardware e funcionalidades do Módulo PC.

Os sensores e métodos de aquisição de dados são apresentados na Seção 3.6, em que é detalhado o Módulo de Sensores.

A Seção 3.7 mostra em detalhes o Módulo Atuador.

A Seção 3.8 detalha o Módulo de Radiofreqüência (RF).

Por fim, a Seção 3.9 apresenta a base móvel utilizada para testes.

\subsection{Visão Geral da Arquitetura Desenvolvida}

A arquitetura de Hardware desenvolvida tem como base de processamento os microcontroladores (MCU's) PIC da Microchip®.

A escolha desses MCU's deve-se ao fato da enorme quantidade de material de pesquisa e aplicação disponível pela empresa fabricante, baixo custo e acesso no mercado interno, além da grande diversidade de ferramentas para desenvolvimento existentes.

Na seção a seguir são caracterizados os módulos microcontrolados. 


\subsubsection{Módulos Microcontrolados}

Resumidamente, o microcontrolador é definido como um dispositivo eletrônico que oferece um nível de inteligência que depende diretamente de sua programação [36].

Sua maior aplicação está relacionada ao controle de processos, onde problemas que envolvem lógicas combinacionais complexas não podem ser resolvidos utilizando circuitos combinacionais comuns.

Cada módulo da arquitetura apresentada neste trabalho é um sistema independente, que tem como responsabilidade o controle e monitoramento de partes específicas do robô móvel, mas que em regime de trabalho atuam como se fossem uma única unidade.

Essa metodologia foi utilizada a partir do conceito de sistemas distribuídos, definido como uma coleção de computadores que parecem aos seus utilizadores como um sistema único e coerente [37], sendo que cada computador descrito na definição representa um módulo da arquitetura.

A FIGURA 3.1 mostra uma visão geral do modelo físico de sistemas distribuídos e a FIGURA 3.2 a sua utilização no trabalho desenvolvido. 
Estações de Usuários

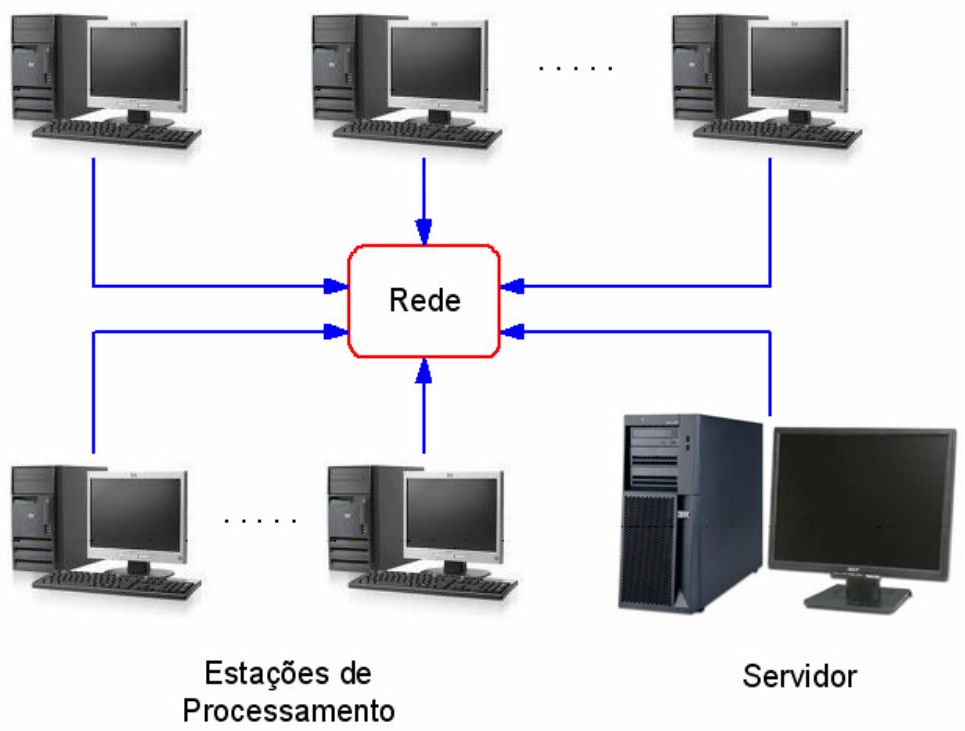

FIGURA 3.1 - Modelo físico de sistemas distribuídos

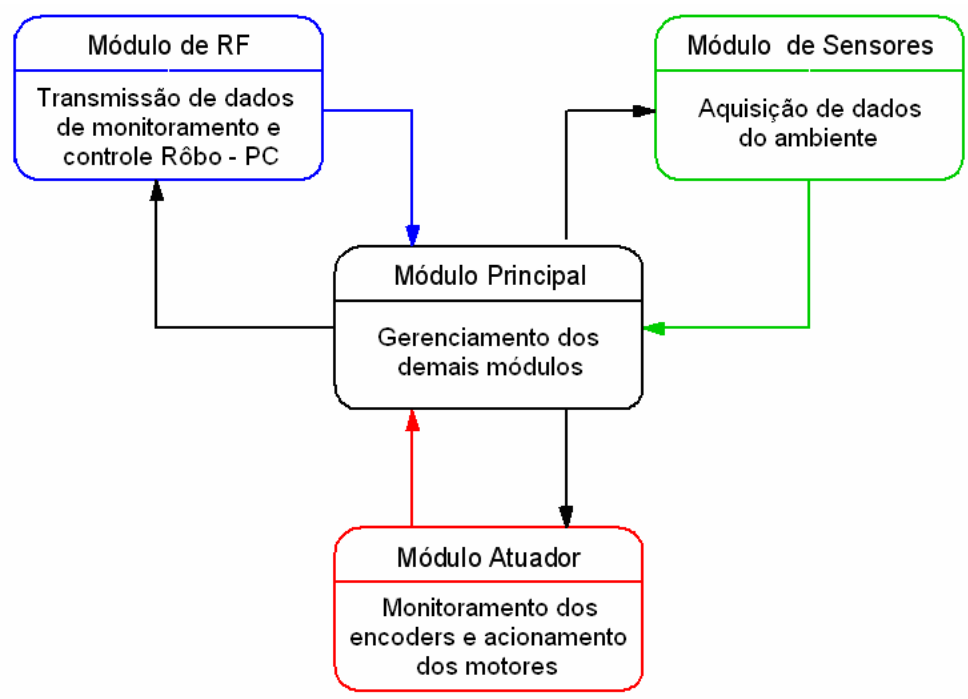

FIGURA 3.2 - Arquitetura distribuída do robô móvel

O Módulo PC por ser uma unidade externa, não está apresentado no diagrama da FIGURA 3.2. A representação é apenas do sistema eletrônico presente no robô. 


\subsubsection{Microcontroladores PIC}

Em 1965 surgiram as primeiras raízes do que viriam a ser hoje os MCU's PIC da Microchip, quando a companhia GI (General Instruments) criou uma divisão de microeletrônica, que foi responsável pelo desenvolvimento das primeiras arquiteturas de memórias EPROM (Erasable Programmable Read-Only Memory) e EEPROM (Eletrically-Erasable Programmable Read-Only Memory) viáveis.

No início dos anos 70 a Gl criou o CP1600, um dos primeiros processadores de 16 bits do mercado; porém, esse processador não fez muito sucesso devido à baixa quantidade de portas de $/ / O$ disponíveis.

Para tentar solucionar esse problema a Gl desenvolveu, por volta de 1975, uma interface controladora de periféricos (Peripheral Interface Controller - PIC) que tinha como principais características sua alta velocidade, dado que era para ser portas de $/ / O$ de uma máquina de 16 bits.

Entretanto, sua funcionalidade era muito pequena devido à baixa quantidade de instruções. Com isso, a arquitetura PIC projetada em 1975 evoluiu para o PIC16C5x.

A arquitetura do PIC difere dos demais MCU's por ser do tipo Harvard, enquanto a dos outros são do tipo Von-Neumann. A diferença entre essas arquiteturas está na forma em que os programas são processados.

MCU's tradicionais (Von-Neumann) possuem apenas um barramento interno, geralmente de 8bits, para dados e instruções em sua arquitetura, enquanto o microcontrolador PIC baseado na arquitetura Harvard possui dois barramentos internos, sendo um para instruções e outro para dados.

A vantagem do PIC está em seu barramento de instruções que pode ser de 12, 14 ou 16bits dependendo da família escolhida. Além disso, possui alta 
velocidade no processamento (10 MIPS), devido sua arquitetura de execução de instruções em Pipeline.

Complementarmente, os MCU's PIC possuem a tecnologia Reduced Instruction Set Computer - RISC (Computador com conjunto de instruções reduzido), contendo apenas 35 instruções (TABELA 3.1), tornando assim fácil sua programação e utilização.

TABELA 3.1 - Conjunto de Instruções dos MCU's PIC (fonte: www.mikroe.com)

\begin{tabular}{|c|c|c|c|c|c|c|}
\hline \multicolumn{2}{|c|}{ Menemónica } & Descrição & & Flag & CLK & Notas \\
\hline \multicolumn{7}{|c|}{ Transferéncia de dados } \\
\hline MOVLW'W & $\mathrm{k}$ & Mova literal para $\mathrm{W}$ & $k \rightarrow W$ & & 1 & \\
\hline MOVWF & $f$ & Mova W paraf & $W \rightarrow f$ & & 1 & \\
\hline MOVF & $f, d$ & Mova $f$ & $f \rightarrow d$ & Z & 1 & 1,2 \\
\hline CLRW' & - & Clear $W$ (limpar $W$ ) & $0 \rightarrow W$ & Z & 1 & \\
\hline CLRF & $f$ & Clearf (limpar $f)$ & $0 \rightarrow f$ & $\bar{Z}$ & 1 & 2 \\
\hline SWAPF & $f, d$ & Swap nibbles in $f$ (trocar) & $f(7: 4),(3: 0) \rightarrow f(3: 0),(7: 4)$ & & 1 & 1,2 \\
\hline \multicolumn{7}{|c|}{ Lógicas e Aritméticas } \\
\hline$\overline{\mathrm{ADDL}} \mathbf{W}^{\prime}$ & $\mathrm{k}$ & Adicionar literal \& $\mathrm{W}$ & $\mathrm{W}+\mathrm{k} \rightarrow \mathrm{W}$ & $C, D C, Z$ & 1 & \\
\hline ADDWF & $f, d$ & Adicionar $W$ af & $W+f \rightarrow d$ & C, DC, Z & 1 & 1,2 \\
\hline SUBLW & $\mathrm{k}$ & Subtrair $W$ de literal & $\mathrm{k}-\mathrm{W} \rightarrow \mathrm{W}$ & $C, D C, Z$ & 1 & \\
\hline SUBWF & $f, d$ & Subtrair $w$ de $f$ & $f-W \rightarrow d$ & $\mathrm{C}, \mathrm{DC}, \mathrm{Z}$ & 1 & 1,2 \\
\hline ANDL'W & $\mathrm{k}$ & AND literal com $W$ & $W, A N D, k \rightarrow W$ & $z$ & 1 & \\
\hline ANDWF & $f, d$ & AND $W \operatorname{com} f$ & $W, A N D, f \rightarrow d$ & $\mathrm{Z}$ & 1 & 1,2 \\
\hline IORLW' & k & Inclusivo $0 R$ de literal com $W$ & $\mathrm{~W}, \mathrm{OR}, \mathrm{k} \rightarrow \mathrm{W}$ & Z & 1 & \\
\hline IORWW & $f, d$ & Inclusivo $0 \mathrm{R}$ de $W \operatorname{com} f$ & $W, O R, f \rightarrow d$ & Z & 1 & 1,2 \\
\hline XORWF & $f, d$ & Exclusivo $0 R$ de $W \operatorname{com} f$ & W. XOR, $f \rightarrow d$ & $\bar{Z}$ & 1 & 1,2 \\
\hline XORLW & $\mathrm{k}$ & Exclusivo $0 R$ de literal com $W$ & $W . X O R, k \rightarrow W$ & Z & 1 & \\
\hline INCF & $f, d$ & Incrementar $\mathrm{f}$ & $f+1 \rightarrow f$ & Z & 1 & 1,2 \\
\hline DECF & $f, d$ & Decrementar $f$ & $f-1 \rightarrow f$ & $\bar{Z}$ & 1 & 1,2 \\
\hline RLF & $f, d$ & Rode f p / esquerda com o carry & $40 \times-776] 514: 3: 2104$ & $\mathrm{C}$ & 1 & 1,2 \\
\hline RRF & $f, d$ & Rode f p/a direita com o carry & 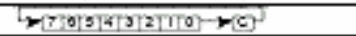 & $\mathrm{C}$ & 1 & 1,2 \\
\hline COMF & $f, d$ & Complementar $f$ & $\bar{f} \rightarrow d$ & $Z$ & 1 & 1,2 \\
\hline \multicolumn{7}{|c|}{ Operações sobre bits } \\
\hline $\mathrm{BCF}$ & $f, b$ & Bit Clearf(bit de $\mathrm{f}_{\mathrm{a}}^{\prime}\left(\mathrm{O}^{\prime}\right)$ & $0 \rightarrow f(b)$ & & 1 & 1,2 \\
\hline $\mathrm{BSF}$ & $f, b$ & Bit Set f (bit de f a ' 1 ') & $1 \rightarrow f(b)$ & & 1 & 1,2 \\
\hline \multicolumn{7}{|c|}{ Direccionamento do programa } \\
\hline BTFSC & $f, b$ & Bit Test f, Salte se Clear ('0') & salte sef(b)=0 & & 1(2) & 3 \\
\hline BTFSS & $f, b$ & Bit Test f, Salte se Set(' $\left.1^{\prime}\right)$ & salte sef(b)=1 & & 1(2) & 3 \\
\hline DECFSZ & $f, d$ & Decremente $f$, salte se der 0 & $\mathrm{f}-1 \rightarrow \mathrm{d}$, salte se der 0 & & 1(2) & $1,2,3$ \\
\hline INCFSZ & $f, d$ & Incremente f, salte se der 0 & $\mathrm{f}+\mathrm{l} \rightarrow \mathrm{d}$, salte se der 0 & & $1(2)$ & $1,2,3$ \\
\hline GOTO & $\mathrm{k}$ & Go to address(Ir p/ endereço) & $k \rightarrow P C$ & & 2 & \\
\hline САШ & $\mathrm{k}$ & Chamar subrotina & $\mathrm{PC} \rightarrow \mathrm{TOS}, \mathrm{k} \rightarrow \mathrm{PC}$ & & 2 & \\
\hline RETURN & - & Retorno de subrotina & $\mathrm{TOS} \rightarrow \mathrm{PC}$ & & 2 & \\
\hline RETLW & $\mathrm{k}$ & Retorno com literal em w & $\mathrm{k} \rightarrow \mathrm{W}, \mathrm{TOS} \rightarrow \mathrm{PC}$ & & 2 & \\
\hline RETFIE & - & Retomo de interrup são & $\mathrm{TOS} \rightarrow \mathrm{PC}, 1 \rightarrow \mathrm{GIE}$ & & 2 & \\
\hline \multicolumn{7}{|c|}{ Outras instruçôes } \\
\hline NOP & - & Nenhuma operaça & & & 1 & \\
\hline CLRWDT & - & Temporizador do Watchdog $=0$ & $0 \rightarrow$ WDT, $1 \rightarrow$ TO, $1 \rightarrow$ PD & $\overline{\mathrm{TO}}, \overline{\mathrm{PD}}$ & 1 & \\
\hline SLEEP & - & Entrar no modo 'sleep' & $0 \rightarrow$ WDT, $1 \rightarrow$ TO, $0 \rightarrow \mathrm{PD}$ & $\overline{\mathrm{TO}}, \overline{\mathrm{PD}}$ & 1 & \\
\hline
\end{tabular}

(1) Se a porta de entrada/saída for o operando origem, é lido o estado dos pinos do microcontrolador.

(2) Se esta instrução for executada no registo TMR0 e se $d=1$, o Prescaler atribuído a esse temporizador é automaticamente limpo.

(3) Se o PC for modificado ou se resultado do teste for verdadeiro, a instrução é executada em dois ciclos. 
A transferência de dados nos PIC's ocorre sempre entre o registrador de trabalho (W) e um registrador 'f' que representa uma variável qualquer localizada em uma posição na memória RAM interna.

Como nos demais MCU's com tecnologia RISC (Reduced Instruction Set Computer) apenas operações aritméticas de adição e multiplicação são suportadas, sendo que para a realização do complemento de uma variável, Flags (bits dedicados) são afetadas.

A grande velocidade de processamento de dados nos PIC's se deve ao fato de que todas suas operações são executadas em apenas 1 ciclo de instrução, exceto quando existem ramificações condicionais no código ou o valor do contador de programa (PC) for alterado pela instrução.

Os MCU's utilizados nesta arquitetura proposta foram o PIC16F88 e PIC16F876A. A escolha foi feita sob os seguintes critérios:

- Tamanho da memória de programa;

- Periféricos disponíveis;

- Quantidade de I/Os;

- Relação Custo/Benefício.

A TABELA 3.2 apresenta suas principais características de acordo com os critérios citados. 
TABELA 3.2 - Principais características (Microchip - 2007)

\begin{tabular}{|c|c|c|}
\hline Característica & PIC16F88 & PIC16F876A \\
\hline Preço (US\$) & 1.93 & 3.40 \\
\hline Arquitetura & 8 bits & 8-bit \\
\hline Memória de Programa (Flash) & 7 Kbytes & 14 Kbytes \\
\hline Memória EEPROM & 256 Bytes & 256 Bytes \\
\hline Memória RAM & 368 Bytes & 368 Bytes \\
\hline Quantidade de $/ / O$ & 16 & 22 \\
\hline Canais de Conversão $A / D$ & 7 & 5 \\
\hline $\begin{array}{l}\text { Resolução } \\
\text { Amostragem dos canais } A / D\end{array}$ & $\begin{array}{l}10 \text { bits } \\
30 \text { ksps }\end{array}$ & $\begin{array}{l}10 \text { bits } \\
30 \text { ksps }\end{array}$ \\
\hline Quantidade de Comparadores & 2 & 2 \\
\hline Quantidade de Timers & $\begin{array}{l}2 \text { de } 8 \text { bits } \\
1 \text { de } 16 \text { bits }\end{array}$ & $\begin{array}{l}2 \text { de } 8 \text { bits } \\
1 \text { de } 16 \text { bits }\end{array}$ \\
\hline Cão de Guarda (Watchdog Timer) & SIM & SIM \\
\hline Interface de Comunicação & $\begin{array}{c}\text { AUSART } \\
I^{2} \mathrm{C} \\
\text { SPI }\end{array}$ & $\begin{array}{c}\text { AUSART } \\
\mathrm{Ml}^{2} \mathrm{C} \\
\mathrm{SPI}\end{array}$ \\
\hline Oscilador Interno & $8 \mathrm{MHz}$ & NÃO \\
\hline Velocidade de Clock Máxima & $20 \mathrm{MHz}$ & $20 \mathrm{MHz}$ \\
\hline Gravação In-circuit (ICSP) & SIM & SIM \\
\hline Módulos CCP/ECCP & $1 / 0$ & \\
\hline Canais PWM & 1 de 10 bits & 2 de 10 bits \\
\hline Tecnologia Nanowatt & SIM & NÃO \\
\hline Alimentação & $2 \sim 5.5 \mathrm{~V}$ & $2 \sim 5.5 \mathrm{~V}$ \\
\hline Quantidade de Pinos & 16 & 28 \\
\hline
\end{tabular}

Os diagramas de blocos apresentados pela FIGURA 3.3(a) e 3.3(b) mostram a estrutura interna dos MCU's utilizados. 


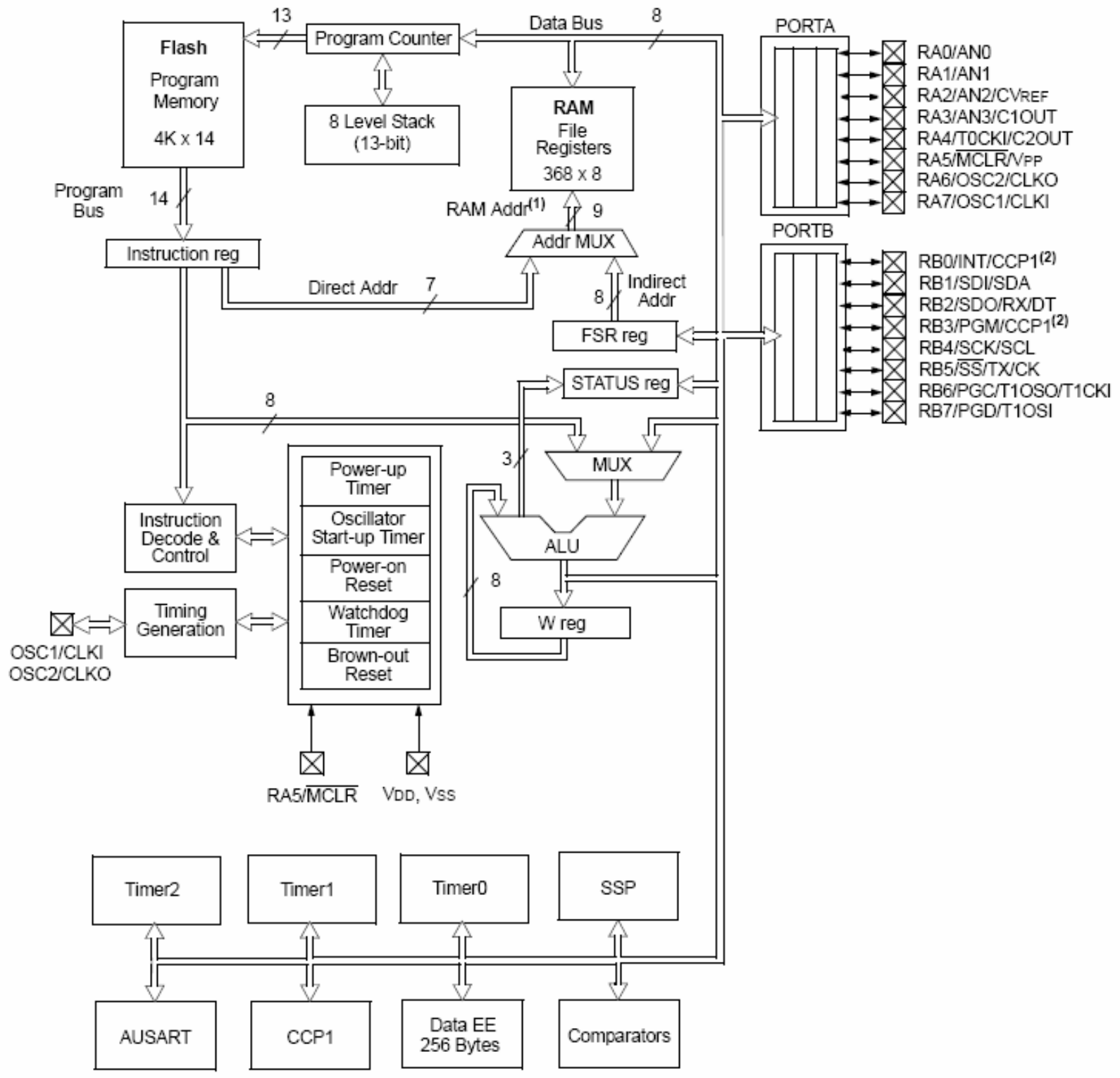

(a) PIC16F88 (Fonte: Microchip) 


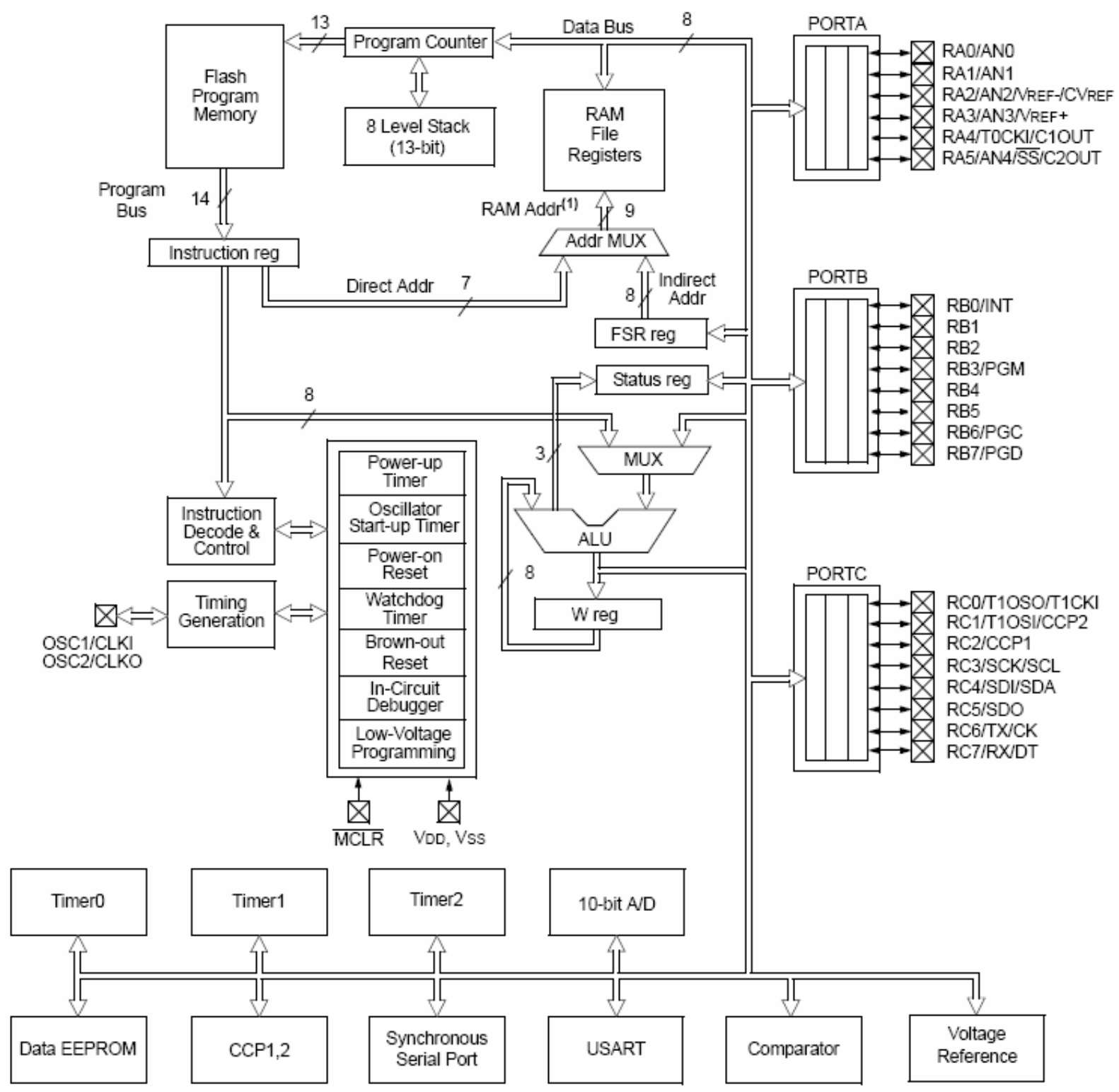

(b) PIC16F876A (fonte: Microchip)

FIGURA 3.3 - Diagrama de Blocos da Arquitetura de Microcontroladores PIC.

Alguns blocos desses diagramas merecem uma atenção maior, e serão detalhados a seguir.

\section{- Power-up Timer}

Ao alimentar o PIC os procedimentos para execução do Firmware são

iniciados. Porém, a fonte de alimentação pode levar certo tempo para 
estabilizar a tensão de saída que, em conseqüência, pode inferir no funcionamento do MCU.

Ativando a função de Power-up Timer esse problema é resolvido, pois - PIC após ser energizado tem a inicialização atrasada, entrando em operação apenas quando a alimentação estiver estável.

Para ativar a função Power-up Timer a Flag PWRTEN (bit 3) do registrador CONFIG1 (endereço físico 2007h) deve ser ajustada em '0' na hora da programação, caso contrário, a função é desativada.

\section{- Watchdog Timer}

O Wachtdog Timer é um periférico interno ao PIC, mas que tem seu funcionamento independente. Sua função é de reiniciar o MCU caso ocorra algum erro na execução do Firmware ou qualquer outro problema que cause um travamento no dispositivo.

Com essa função habilitada, a cada intervalo de tempo definido pelo Timer (1ms a 268s) um sinal de Reset é enviado ao MCU, fazendo com que ele reinicie seu funcionamento. Porém, em operação normal, o MCU envia um comando de Reset para o Watchdog Timer em um tempo menor. Com isso, o MCU não será reinicializado, a menos que ocorra um problema.

Para Ativar o Watchdog timer a Flag WDTEN (bit 2) do registrador CONFIG1 deve ser ajustada em '1' na hora da programação; caso contrário, a função é desativada. 


\section{- Brown-out Reset}

O Brown-out Reset é um periférico muito importante do PIC. Sua função é de reiniciar o MCU caso o nível da tensão de alimentação caia abaixo de um valor seguro para seu funcionamento.

No caso do PIC16F88 a tensão de Brown-out é fixa em 4 Volts, ou seja, se a tensão de alimentação for menor que esse valor o MCU é reiniciado. Em alguns PIC's esse valor pode ser alterado durante a programação do dispositivo.

Para ativar o Brown-out Reset a Flag BOREN (bit 6) do registrador CONFIG1 deve ser ajustada em '1'; caso contrário, essa função não é ativada

$\mathrm{Na}$ arquitetura desenvolvida o Brown-out Reset não é habilitado em virtude da tensão de alimentação ser de apenas 3.3V.

\subsubsection{Controle em Tempo Real}

Em computação, o termo tempo real significa sistemas computacionais que devem ser executados em um tempo preciso, absoluto ou relativo, e dentro de uma duração previsível, quase sempre restrita [40].

Desse modo um sistema de controle é caracterizado como sendo em tempo real quando as respostas são produzidas em um tempo definido ou esperado.

A arquitetura desenvolvida, como já dita anteriormente, possui um sistema modular independente. Com isso, o processamento das informações em cada módulo pode ser executado em seu tempo determinado, sendo a única interrupção causada por um pedido de leitura ou escrita do Módulo Principal. 
Cada tarefa (Task) executada no Módulo Principal da arquitetura ocupa um tempo definido de 50ms; portanto, a arquitetura desenvolvida pode ser considerada como um sistema em tempo real.

\subsection{Sistema de Transmissão de Informações}

As transmissões de dados na robótica móvel podem ser realizadas tanto por comunicação com fio quanto sem fio (Wireless) e, dependendo da necessidade, a utilização dos dois métodos no mesmo sistema se faz necessário.

$\mathrm{Na}$ arquitetura para robôs móveis desenvolvida, os dois métodos de comunicação foram implementados, sendo suas aplicações em:

- Comunicação entre o PC e o Módulo PC;

- Comunicação entre o Módulo PC e o Módulo de Radiofreqüência no robô móvel;

- Comunicação entre os módulos do robô móvel.

Na comunicação sem fio foi utilizado um transceptor de Radiofreqüência de 2.4GHz com modulação GFSK e, para as comunicações com fio os padrões de comunicação serial RS232 e SPI foram também usados.

A seguir são detalhados os métodos e padrões citados acima. 


\subsubsection{Transmissão em Radiofreqüência}

A comunicação entre o Módulo PC e o Módulo de RF situado no robô móvel é realizada por meio do transceptor de Radiofreqüência TRF-2.4G, fabricado pela Laipac Tech, que possui as seguintes características principais:

- Faixa de Freqüência de 2.4 2.524GHZ ISM Band (Banda pública utilizada para as áreas Industriais, Médicas e Científicas) com modulação GFSK;

- Velocidade de Transmissão de dados: 250kbps e 1Mbps;

- Operação em multi-canais, 125 canais disponíveis com tempo de multiplexação menor que 200uS;

- Emula transmissão Full Duplex com velocidade de 1Mbps;

- Possui codificador, decodificador, Buffer de dados e verificador CRC internos;

- Sensibilidade de -90dBm;

- Antena Integrada à placa;

- Tensão de alimentação de 1.9 a 3.6V;

- Consumo (TX) de 10.5 mA (pico)@ -5dBm de potência de saída;

- Consumo $(\mathrm{RX})$ de $18 \mathrm{~mA}$ (pico) no recebimento;

- Consumo em modo Power Down de 1uA;

- Baixo Custo.

O Transceptor de RF é apresentado na FIGURA 3.4. 


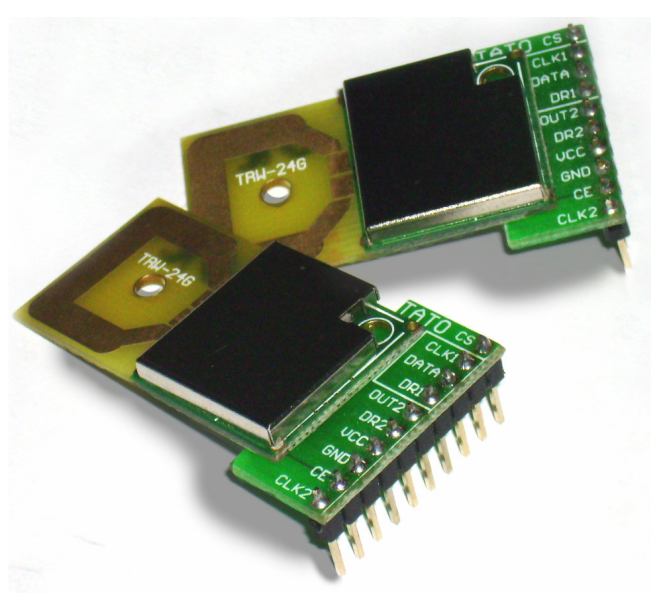

FIGURA 3.4 - Transceptor TRF-2.4G

Esse transceptor consiste em uma antena integrada à placa, sintetizador de freqüência totalmente integrado, amplificador de potência, cristal oscilador e modulador.

A potência de saída e os canais de freqüência são facilmente programáveis por meio de comunicação serial por 3 fios.

A TABELA 3.3 apresenta a descrição dos pinos deste transceptor.

TABELA 3.3 - Descrição dos pinos do Tranceptor

\begin{tabular}{|c|c|c|l|}
\hline Pino & Nome & Função & \multicolumn{1}{c|}{ Descrição } \\
\hline 1 & GND & Alimentação & Terra (0V) \\
\hline 2 & CE & Entrada & Chip Enable - Ativa o modo TX ou RX \\
\hline 3 & CLK2 & $I / O$ & Entrada/Saída de clock para o Canal de dados RX 2 \\
\hline 4 & CS & Entrada & Chip Select - Ativa o modo de configuração \\
\hline 5 & CLK1 & $I / O$ & $\begin{array}{l}\text { Entrada de Clock (TX) \& I/O (RX) para o canal de } \\
\text { dados 1 }\end{array}$ \\
\hline 6 & DATA & I/O & Canal de dados RX 1/ Entrada de dados TX \\
\hline 7 & DR1 & Saída & $\begin{array}{l}\text { Dados RX prontos no canal de dados 1 (Modo } \\
\text { ShockBurst) }\end{array}$ \\
\hline 8 & DOUT2 & Saída & Canal de dados RX 2 \\
\hline 9 & DR2 & Saída & $\begin{array}{l}\text { Dados RX prontos no canal de dados 2 (Modo } \\
\text { ShockBurst) }\end{array}$ \\
\hline 10 & VCC & Alimentação & Alimentação (1.9 3.6VDC) \\
\hline
\end{tabular}


O tranceptor TRF-2.4G possui 3 modos de operação, sendo eles:

- Modo transmissor (TX) e modo receptor (RX) ativo;

- Modo de configuração;

- Modo em Stand by (economia de energia);

A configuração desses modos é mostrada na TABELA 3.4.

TABELA 3.4 - Configuração dos modos do tranceptor

\begin{tabular}{|c|c|c|}
\hline Modo & CE & CS \\
\hline (TX/RX) Ativo & 1 & 0 \\
\hline Configuração & 0 & 1 \\
\hline Stand by & 0 & 0 \\
\hline
\end{tabular}

Além disso, o transceptor pode operar em dois modos de transmissão, sendo eles ShockBurst e Direct Mode.

O modo escolhido para este projeto foi o ShockBurst devido a sua velocidade de transmissão e eficiência na transmissão dos dados; portanto, a configuração desse modo é apresentada a seguir.

\section{- Modo ShockBurst}

A tecnologia ShockBurst utiliza uma fila (FIFO) On-Chip para receber dados provenientes de outros periféricos em baixa velocidade, e transmitir em alta velocidade, com isso habilitando uma extrema redução no consumo de energia [38] .

Quando o TRF-2.4G opera nesse modo os dados transmitidos por RF chegam à velocidade de $1 \mathrm{Mbps}$, mesmo no caso de o sistema que estiver enviando os dados para o tranceptor estiver operando em baixa velocidade [38]. 
A FIGURA 3.5 mostra o diagrama de funcionamento do modo ShockBurst para dados sendo enviados ao tranceptor em uma velocidade de $10 \mathrm{KHz}$.

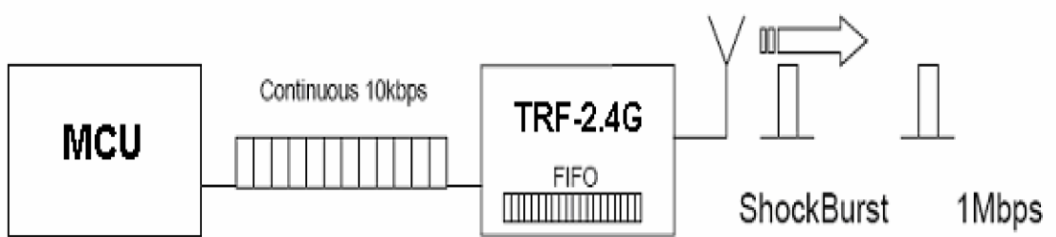

FIGURA 3.5 - Funcionamento do modo ShockBurst [38]

\section{- Configuração do modo ShockBurst}

A palavra de configuração no modo ShockBurst habilita o TRF-2.4G para manipular o protocolo RF.

A TABELA 3.5 mostra um resumo da palavra de configuração.

TABELA 3.5 - Resumo da palavra de configuração

\begin{tabular}{|c|c|c|c|c|}
\hline & $\begin{array}{l}\text { Bit } \\
\text { position }\end{array}$ & $\begin{array}{l}\text { Number } \\
\text { of bits }\end{array}$ & Name & Function \\
\hline \multirow{8}{*}{ 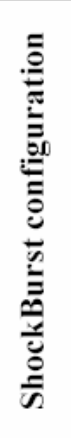 } & 143:120 & 24 & TEST & Reserved for testing \\
\hline & 119:112 & 8 & DATA2_W & Length of data payload section RX channel 1 \\
\hline & 111:104 & 8 & DATA1_W & Length of data payload section RX channel 1 \\
\hline & $103: 64$ & 40 & ADDR2 & Up to 5 bytes address for channel 2 \\
\hline & 63:24 & 40 & ADDR1 & Up to 5 bytes address for channel 1 \\
\hline & $23: 18$ & 6 & ADDR_W & Number of address bits(both RX channels) \\
\hline & 17 & 1 & CRC_L & 8 or 16 bits $\mathrm{CRC}$ \\
\hline & 16 & 1 & CRC_EN & Enable on-chip CRC generation/checking \\
\hline & & & & \\
\hline \multirow{7}{*}{ 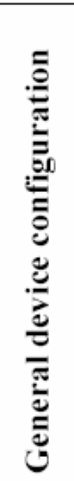 } & 15 & 1 & RX2_EN & Enable two channel receive mode \\
\hline & 14 & 1 & $\mathrm{CM}$ & Communication mode ( Direct or ShockBurst) \\
\hline & 13 & 1 & RFDR_SB & RF data rate (1Mbps requires $16 \mathrm{MHz}$ crystal) \\
\hline & $12: 10$ & 3 & XO_F & Crystal frequency (Factory default 16MHz crystal mounted) \\
\hline & 9:8 & 2 & RF_PWR & RF output power \\
\hline & $7: 1$ & 7 & RF_CH\# & Frequency channel \\
\hline & 0 & 1 & RXEN & $\mathrm{RX}$ or TX operation \\
\hline
\end{tabular}


Como pode ser observada, a tabela de palavras de configuração é mostrada no sentido em que as palavras devem ser enviadas, ou seja, do bit mais significativo (MSB) para o bit menos significativo (LSB).

O procedimento para configuração do modo ShockBurst é apresentado a seguir:

1. Definir o número de bits de dados da mensagem para o canal 1 e canal 2 (DATAx_W);

2. Ajustar o endereço ( 5 bytes) para os canais 1 e 2 (ADDRx);

3. Informar o número de bytes reservados para o endereçamento (ADDR_W);

4. Ajustar o número de bits para cálculo do $\mathrm{CRC}\left(\mathrm{CRC} \_\mathrm{L}\right)$, sendo os valores '0' para ajustar em 8bits e '1' para ajustar em 16bits;

5. Se desejar habilitar o CRC (CRC_EN), então ajustar o nível lógico '1', caso contrário '0';

6. Se desejar habilitar o recebimento em apenas um canal (RX2_EN), então ajustar o nível lógico '0'; caso contrário, ajustar em ' 1 ' ;

7. Definir o modo ShockBurst (CM): ajustar em nível lógico '1';

8. Definir a velocidade de transmissão dos dados por RF: para 1Mbit o valor do clock do TRF-2.4G deve ser definido em $16 \mathrm{MHz}$ (RFDR_SB); $1 \mathrm{Mbit} \rightarrow \mathrm{CM}=$ '1', 256kbit $\rightarrow \mathrm{CM}=$ '0';

9. Ajustar a freqüência do cristal de oscilação (XO_F): valor default montado na placa do TRF-2.4G é de $16 \mathrm{MHz}$, implicando nos bits D12 = '0', D11 = '1' e D10 = '1' ; 
10. Ajustar a potência de saída do sinal em RF (RF_PWR): potência máxima $\rightarrow$ bits D9 = '1' e D8 = '1',

11. Ajustar a freqüência do canal $\left(\mathrm{RF} \_\mathrm{CH}\right)$ consultar [38];

12. Escolher entre o modo transmissor ou receptor (RX_EN): nível lógico '0' para transmissor e '1' para receptor.

A única limitação em se utilizar esse modo de transmissão fica a cargo do comprimento da mensagem que deve ser transmitida, sendo esse valor um total de 256 bits. Tal valor constitui o comprimento total, ou seja, além de dados válidos para envio de comando, torna-se ainda necessário reservar espaço para bits de endereçamento, preâmbulo e CRC.

O número de bits de dados (DATAx_W) é definida pela Equação (3.1), ou seja:

$$
D A T A x_{-} W(\text { bits })=256-A D D R_{-} W-C R C
$$

onde DATAx_W é o número de bits da mensagem, $A D D R \_W$ é o número de bits reservados para endereçamento e CRC o número de bits para verificação de erro.

Para envio e recebimento de dados utilizando o modo ShockBurst as instruções seguintes devem ser seguidas: 
Modo Transmissor:

Pinos CE, CLK1 e DATA

1. Quando o $M C U$ tiver dados para enviar, CE deve ser ajustado para o nível Alto. Dessa forma, o processamento de dados on-board do TRF-2.4G será ativado.

2. O endereço para o nó de recebimento (endereço do RX) e os dados que serão transmitidos são enviados para o TRF2.4G.

3. Ajustar CE para nível baixo, com isso a transmissão em ShockBurst é ativada.

4. Durante a transmissão em ShockBurst o TRF-2.4G segue automaticamente o seguinte protocolo:

- O receptor de RF é habilitado;

- Os dados que serão transmitidos são empacotados (preâmbulo adicionado e CRC calculado);

- Os dados são transmitidos em alta velocidade (1 Mbps ou 256 Kbps, dependendo da configuração);

- Quando terminado o envio, o TRF-2.4G volta para o modo Standby.

A FIGURA 3.6 mostra o fluxograma de software utilizado para o procedimento anterior: 


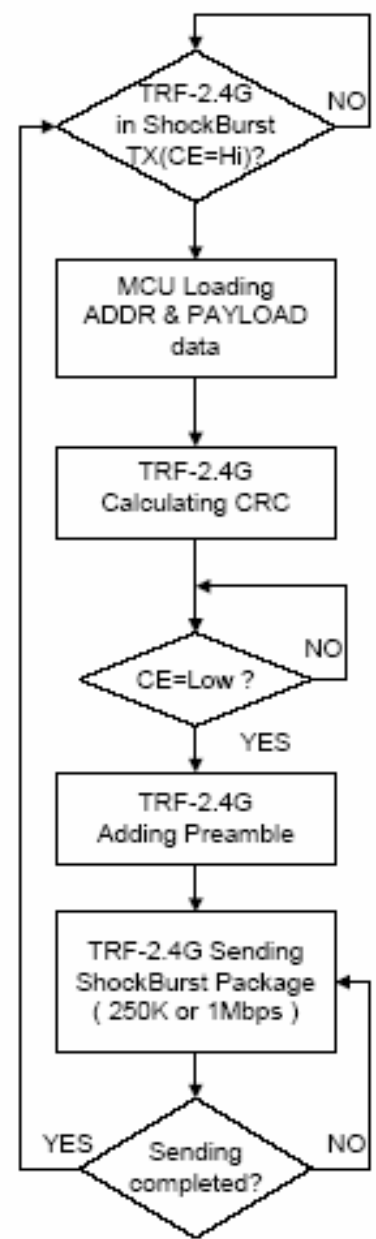

Data content of registers:
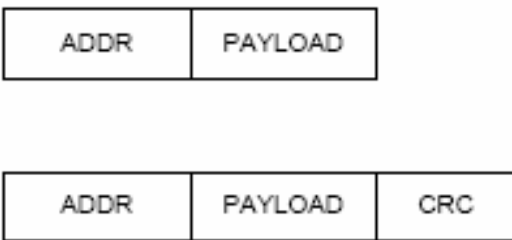

- - - - - vax1rus 286 bits

\begin{tabular}{|l|l|l|l|}
\hline $\begin{array}{c}\text { Pre- } \\
\text { arb1e }\end{array}$ & ADDR & PAYLOAD & CRC \\
\hline
\end{tabular}

Input FIFO not Empty

FIGURA 3.6 - Fluxograma da transmissão ShockBurst no TRF-2.4G [38]

\section{Modo Receptor:}

Pinos CE, DR1, CLK1 e DATA (um canal RX para recebimento)

1. Quando o TRF-2.4G é ajustado como RX em uma transmissão em modo Shockburst, o endereço e tamanho do pacote que será recebido por RF são configurados.

2. O modo RX é ativado ajustando CE em nível alto.

3. Depois de $200 \mu S$ em que o modo $R X$ foi ajustado, o TRF-2.4G fica monitorando o espaço verificando se algum dado será transmitido. 
4. Quando um pacote válido é recebido (endereço correto e CRC encontrado), o TRF-2.4 remove os bits de preâmbulo, o endereço e CRC.

5. TRF-2.4G avisa ao MCU (interrupção) ajustando DR1 em nível alto.

6. O MCU pode ou não ajustar CE em nível baixo para desabilitar o receptor (modo de economia).

7. O MCU envia os pulsos de clock para o TRF-2.4G para obter a informação recebida por RF.

8. Quando toda a informação é transmitida para o $M C U$ o TRF-2.4G ajusta novamente DR1 em nível baixo; logo em seguida, o tranceptor está pronto para receber um novo dado caso CE for mantido em nível alto enquanto o $M C U$ recebe os dados. Caso contrário, uma nova seqüência de inicialização pode ser realizada.

A FIGURA 3.7 mostra o fluxograma de software utilizado para o procedimento anterior: 


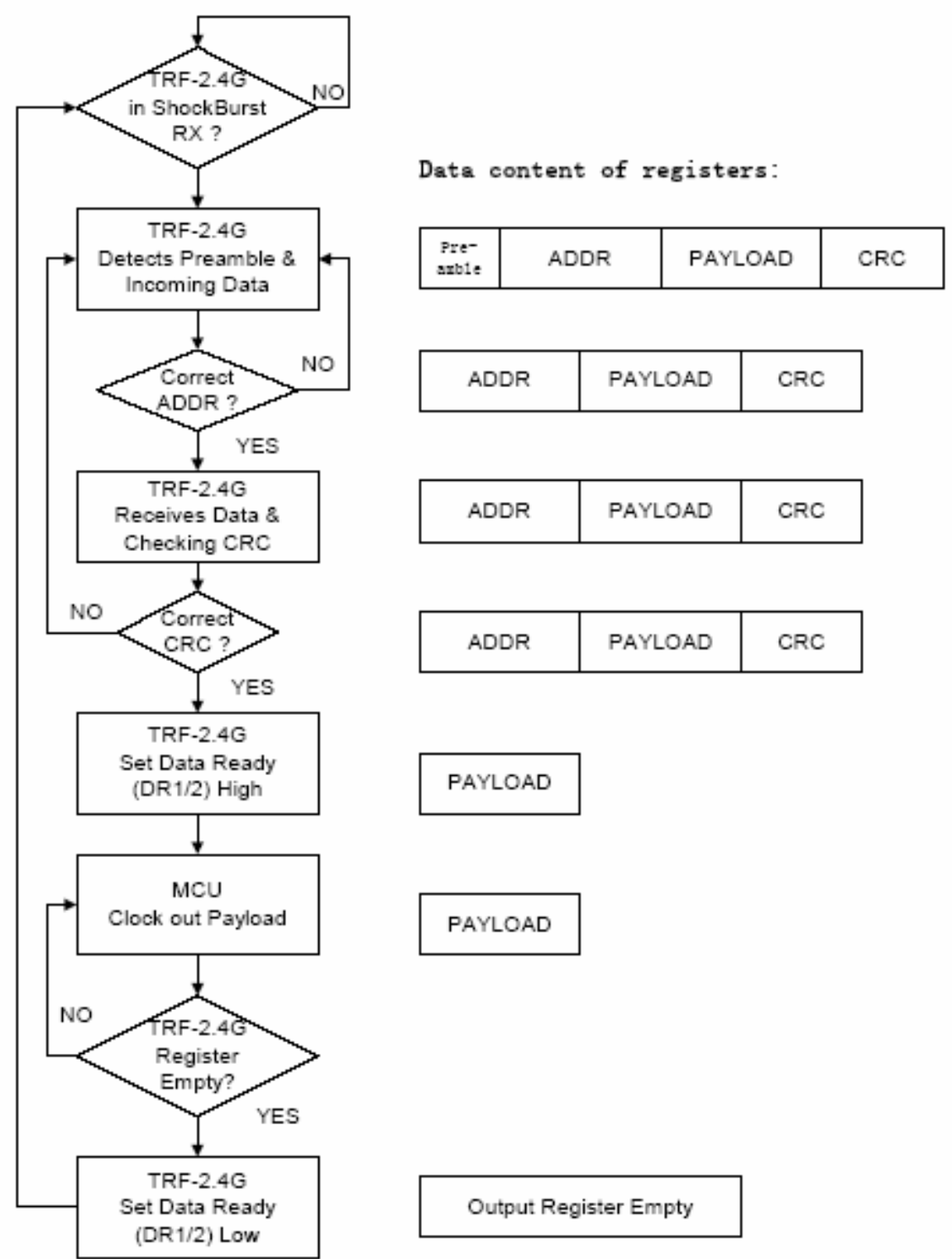

FIGURA 3.7 - Fluxograma da recepção ShockBurst no TRF-2.4G [38]

\subsubsection{Comunicação serial: Padrão RS232}

Em meados de 1960, um comitê de padronização conhecido como Eletronic Industries Association (EIA) desenvolveu um padrão de interface comum para comunicação de dados em equipamentos distintos.

Naquele tempo, comunicações de dados foram planejadas para intercambiar dados digitais entre um computador central (Mainframe) e um computador remoto 
(Terminal) ou, possivelmente, entre dois terminais sem um computador central envolvido. Esses dispositivos eram conectados através de linhas telefônicas e, consequentemente, o uso de um modem para cada canal de transmissão fazia-se necessário [39].

Projetos relativamente complexos são necessários quando existem oportunidades para ocorrência de erros durante a transmissão de dados por um canal analógico. Com isso um padrão era necessário primeiro para assegurar confiança na comunicação, e segundo para habilitar interconexões de equipamentos produzidos por fabricantes diferentes. Desse modo, promovendo benefícios como produções em massa e competitividade no mercado [39].

A partir dessas idéias, surgiu o padrão RS232. Nesse padrão são especificados os níveis de tensão do sinal, sincronismo, função, um protoclo para trocas de informações e conectores mecânicos.

Quarenta anos depois desde que esse padrão foi desenvolvido, a $E I A$ publicou três modificações, sendo a mais recente o padrão EIA232F que foi introduzido em 1997. Além da troca do nome de RS232 para EIA232, alguns sinais foram renomeados e outros novos foram definidos, incluindo condutores blindados para transmissão com maior velocidade em ambientes ruidosos [39].

A nomenclatura RS232 é a mais utilizada pelos desenvolvedores, sendo assim continuar-se-á com o nome RS232.

O padrão RS232 difere do padrão TTL por gerar sinais de tensão com valores diferentes de 0 e 5 Volts, podendo ser melhor visualizado na TABELA 3.6. 
TABELA 3.6 - Níveis de tensão do padrão RS232

\begin{tabular}{|c|c|c|}
\hline TTL (V) & EIA232 (V) & Nível Lógico \\
\hline $0 \sim 0.8$ & $+3 \sim+12$ & 0 \\
\hline $2 \sim 5$ & $-3 \sim-12$ & 1 \\
\hline
\end{tabular}

A comunicação serial utilizando o padrão $\mathrm{RS} 232$ é realizada de forma assíncrona, ou seja, ambos os dispositivos devem ser ajustados na mesma velocidade de comunicação.

Uma comunicação assíncrona realiza transmissão de dados individualmente. A cada dado enviado são acrescentados bits de controle para que o outro terminal, ao receber a informação, identifique se a transmissão foi completada corretamente.

A TABELA 3.7 lista as configurações que podem ser feitas no padrão RS232.

TABELA 3.7 - Configurações da comunicação serial

\begin{tabular}{|l|c|}
\hline \multicolumn{1}{|c|}{ Configuração } & Ajustes \\
\hline Tamanho do Dado & $5,6,7,8$ e 9 bits \\
\hline Número de Stop-Bits & $1,1.5,2$ bits \\
\hline Paridade & Par, Impar, Marca, Espaço e Nenhum \\
\hline Velocidade da Transmissão & $1200,2400,4800,9600 \ldots, 115200$ \\
\hline Porta de Comunicação & COM1, COM2 .... COMx \\
\hline
\end{tabular}

A configuração do cabo serial segundo o padrão EIA232 é definida por:

TD - Envia os dados seriais (Transmit Data)

$\mathrm{RD}$ - Recebe os dados seriais (Receive Data)

RTS - Informa ao PC que o periférico pretende iniciar uma transmissão (Request To Send)

CTS - Informa ao PC que o periférico está pronto para transmitir (Clear To Send) 
DTR - Informa ao periférico que o PC está pronto para transmitir (Data Terminal Ready)

DSR - Informa ao PC que o periférico esta pronto para comunicar (Data Set Ready)

CD - Periférico (Modem) indica que detectou a portadora (Carrier Detect)

RI - O Periférico (Modem) indica que recebeu o tom da linha (Ring Indicator)

GND - Referência (Terra), não é conectado à carcaça (Signal Ground)

A FIGURA 3.8 mostra a forma de conexão entre DTE's.

\section{Interface Serial no PC}

Cabo Serial "Null-Modem" - Conexão entre DTE's (Laplink / Interlink / Fastlink)

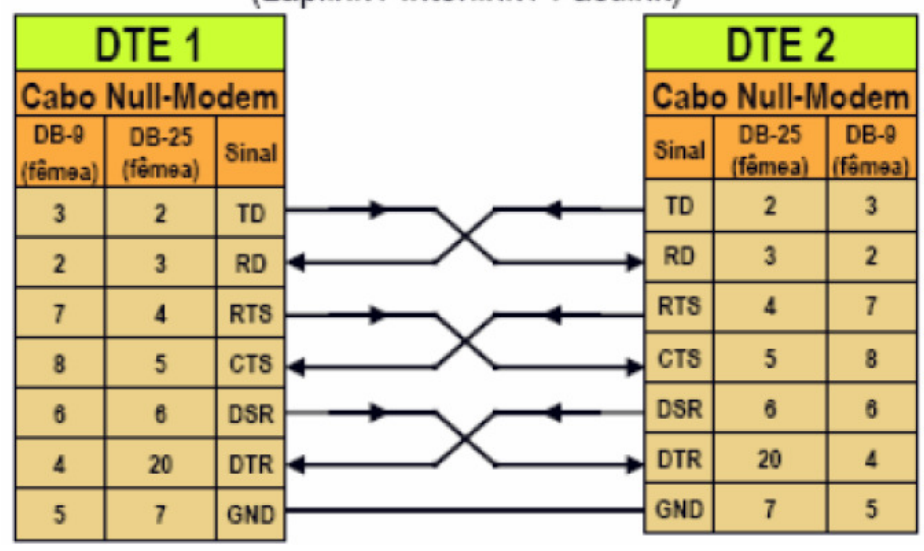

FIGURA 3.8 - Conexão entre DTE's [40]

Computadores são facilmente interligados utilizando o padrão RS232, necessitando apenas fazer o crossover entre os sinais de entrada e saída.

No interfaceamento entre o microcomputador do tipo PC, que possui o padrão serial RS232, e um periférico utilizando o padrão TTL, um conversor de padrões deve ser empregado; caso contrário, o enlace de comunicação não será fechado, podendo até danificar os componentes envolvidos no circuito. 
O componente eletrônico utilizado neste projeto para converter os padrões seriais é o conversor MAX232, que será explicado a seguir.

\section{- O conversor TTL-RS232: MAX232}

O MAX232 é um conversor que produz níveis de tensão no padrão RS232 a partir de uma fonte de alimentação de 5 Volts, utilizando dobradores de tensão capacitivo.

As FIGURAS 3.9(a) e 3.9(b) mostra a simbologia lógica e encapsulamento do MAX232, respectivamente.

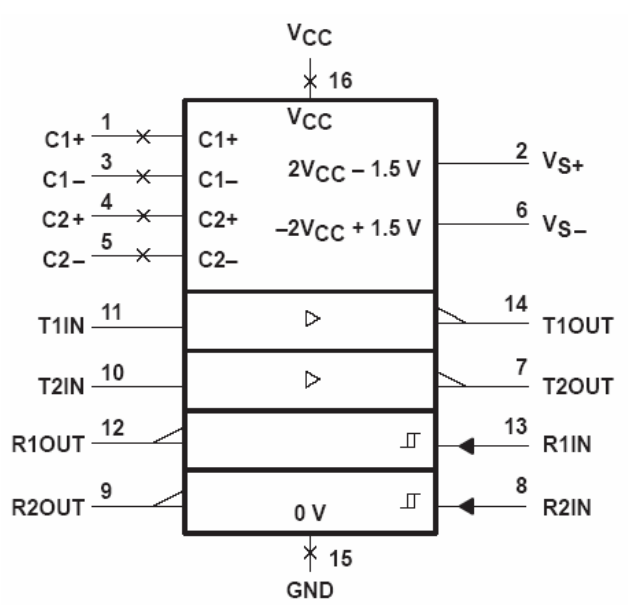

(a)

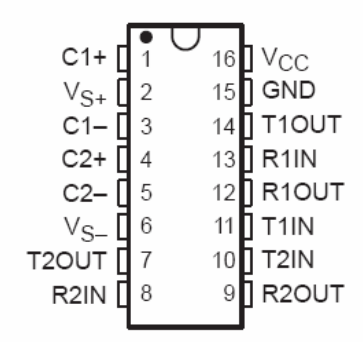

(b)

FIGURA 3.9 - Aspectos do Conversor MAX232:

(a) Simbologia Lógica ANSI/IEEE (fonte: MAXIM)

(b) Encapsulamento DIP

O esquemático a seguir, FIGURA 3.10, define a forma de utilização do MAX232. 


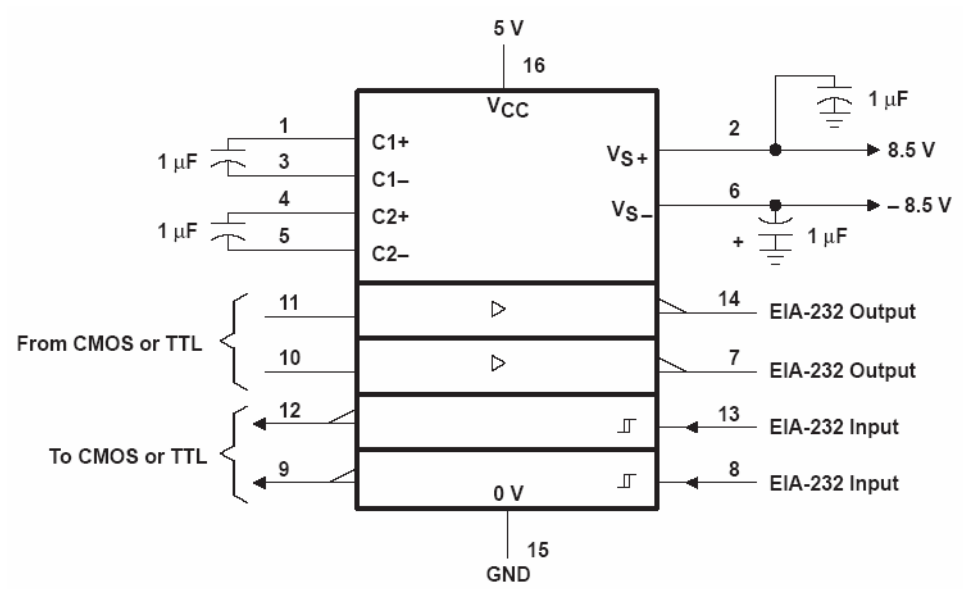

FIGURA 3.10 - Circuito típico de operação (fonte: MAXIM)

\subsubsection{Comunicação serial: Padrão SPI}

Diferentemente do padrão RS232, o padrão SPI utiliza a modo síncrono para transmissão dos dados. Neste modo, tanto o transmissor quanto o receptor devem ser sincronizados para a troca de informação.

Essa sincronização é realizada por meio de um sinal dedicado denominado de Clock (Relógio). A cada transmissão, um pulso de Clock é enviado antes, visando realizar o sincronismo do receptor de acordo com o transmissor.

O padrão SPI foi desenvolvido pela Motorola $\Theta$ com o objetivo de interligar MCU's e outros periféricos [41].

Suas principais características são:

- Comunicação utilizando 4 fios;

- Alta velocidade de transmissão (> 10Mbps);

- Comunicação utilizando protocolo baseado em Master-Slave;

- Quantidade de Slaves limitada apenas à quantidade de SlaveSelect disponíveis no Master;

- Transmissão de dados Full-Duplex. 
A FIGURA 3.11 apresenta o esquema de ligação entre os módulos da arquitetura desenvolvida utilizando o barramento SPI.

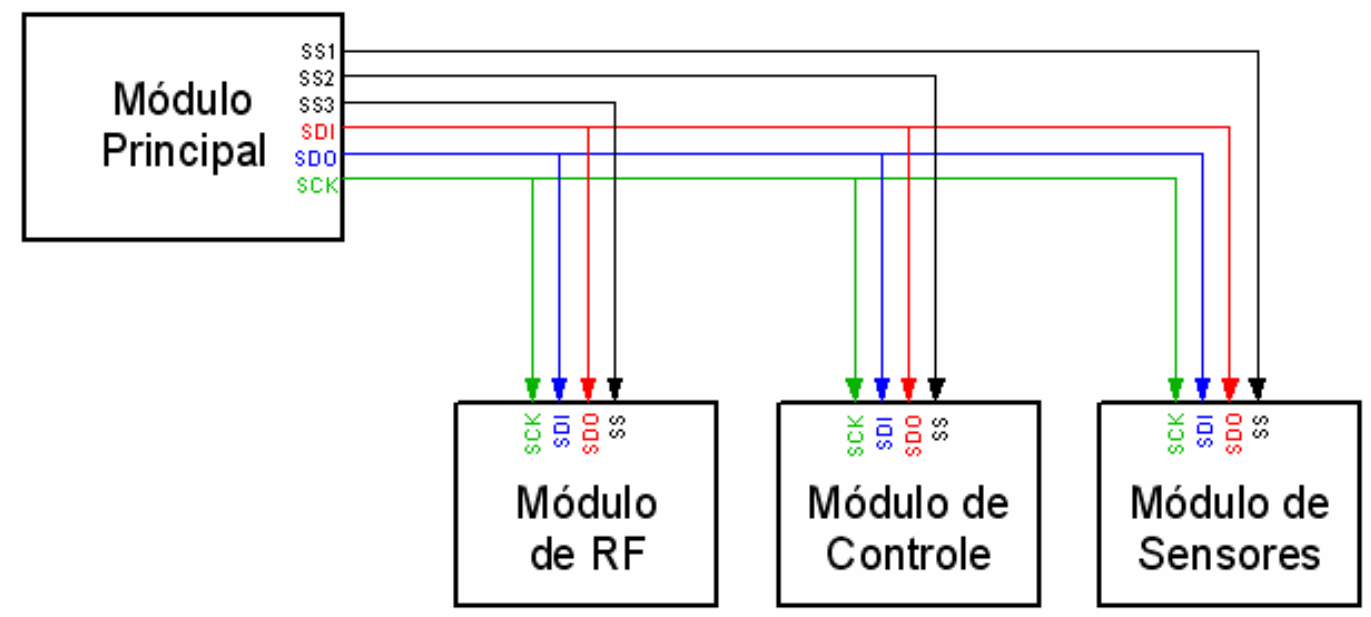

FIGURA 3.11 - Conexão dos Módulos no Barramento SPI

Pode ser observado que a conexão dos Slaves no barramento deve ter seus sinais de comunicação (SDI e SDO) inversos ao do Master.

Na TABELA 3.8 segue a descrição dos pinos utilizados no diagrama anterior.

TABELA 3.8 - Descrição dos pinos do padrão SPI

\begin{tabular}{|c|l|}
\hline Sinal (Pino) & \multicolumn{1}{c|}{ Descrição } \\
\hline SS & $\begin{array}{l}\text { Seleção do Slave, ativado com nível lógico ‘0’ } \\
\text { (saída no Master entrada no Slave) }\end{array}$ \\
\hline SDI & $\begin{array}{l}\text { Caminho por onde os dados serão recebidos } \\
\text { (entrada) }\end{array}$ \\
\hline SDO & $\begin{array}{l}\text { Caminho por onde os dados serão enviados } \\
\text { (saída) }\end{array}$ \\
\hline SCK & $\begin{array}{l}\text { Clock de Sincronização } \\
\text { (saída no Master e entrada no Slave) }\end{array}$ \\
\hline
\end{tabular}

A comunicação utilizando o padrão SPI, por ser Full-Duplex, é considerada um tipo de comunicação por intercâmbio de dados [42], ou seja, enquanto um dado 
é enviado, outro é recebido ao mesmo tempo. Nenhum dispositivo conectado ao barramento é somente transmissor ou receptor.

Utilizando o MCU no modo Master, os pulsos de Clock para a comunicação são gerados automaticamente quando um dado é colocado em seu registrador de saída. Desta forma, não somente na escrita mas também para leitura os pulsos devem ser gerados, e isso somente acontece quando um dado é enviado.

Quando é desejado ler valores de variáveis contidas em um módulo Slave, e o mesmo não receber nenhum dado importante para seu funcionamento, o seguinte procedimento pode ser executado.

1. Selecionar o Slave colocando o nível lógico '0' no pino de controle SS;

2. Colocar um dado qualquer no registrador de saída do módulo SPI para que os pulsos de Clock sejam gerados;

3. Ao finalizar a transmissão, copiar o valor do registrador de entrada do módulo SPI em uma variável;

4. Liberar o Slave colocando nível lógico '1' no pino de controle SS.

O padrão SPI é implementado no PIC por intermédio de um módulo chamado de Synchronous Serial Port no caso dos Slaves, e Master Synchronous Serial Port para os Masters.

\subsubsection{Protocolo de Comunicação}

Nos sistemas onde há comunicação de dados ou interligações de MCU's, a metodologia e o formato em que esses dados são organizados devem seguir um 
padrão, o qual é chamado de protocolo. O protocolo especifica como o programa deve preparar os dados para serem enviados ao estágio seguinte da comunicação.

Neste trabalho, o pacote de dados que é processado por todos os módulos da arquitetura está representado pela FIGURA 3.12.

\begin{tabular}{|c|c|c|}
1 Byte & 23 Bytes & 1 Byte \\
\hline INÍCIO & MENSAGEM DE CONTROLE (LEITURAIESCRITA) & FIM \\
\hline
\end{tabular}

FIGURA 3.12 - Representação do Pacote de dados

O protocolo de comunicação desenvolvido aqui para esse sistema define o pacote de dados da seguinte forma:

- O tamanho de cada pacote é invariável, tendo o comprimento fixo de 24 Bytes;

- O pacote de dados tem seu início sinalizado pelo caractere '\$', e seu final por '\#';

- Todos os dados válidos presentes na mensagem deve ser separados por ';' exceto na situação seguinte;

- Caso a quantidade de dados válidos não preencher todos os espaços do pacote, o caractere '@' deve ser adicionado para completar a seqüência;

- Dentro dos 24 bytes totais do pacote de dados, estão incluídos os caracteres de início, fim e separação; 
Portanto, de acordo com o protocolo definido, o pacote de dados é exemplificado pela FIGURA 3.13, onde D1 é o caractere por meio do qual se informa a qual módulo pertence o pacote, sendo 'P' para o principal, 'S' para os sensores e 'A' para os atuadores.

$\begin{array}{lllllllllllllllllll}1 & 2 & 3 & 4 & 5 & 6 & 7 & 8 & 9 & 1011 & 1213 & 14 & 15 & 161718 & 19 & 20 & 2122 & 23 & 24\end{array}$

\$D1; D2 ; D3 ; D4 @ @ @ @ @ @ @ @ @ @ @ @ \#

FIGURA 3.13 - Exemplo de um pacote de dados do sistema

Como o Módulo de RF é apenas para link de comunicação com o PC, não possui pacote de dados dedicado.

Além desse byte de identificação, cada módulo adiciona os seguintes valores:

\section{- Módulo Principal}

No pacote de dados deste módulo é adicionado o caractere 'S' para sucesso ou ' $N$ ' de navegando durante a busca pelo alvo, além do nível de tensão da bateria. O seguinte exemplo é um pacote de dados válido referente a este módulo:

\section{\$P;S;6.3@@@@@@@@@@@@@@@}

Esta mensagem indica que a navegação até o alvo foi concluída com sucesso e o nível atual da tensão da bateria é de 6.3V. 
- Módulo Atuador

Neste pacote de dados são adicionados os valores referentes ao estado da navegação, a coordenada da posição atual do robô em um plano cartesiano e o ângulo de desvio referente ao alvo (objetivo). $\mathrm{O}$ exemplo a seguir demonstra um exemplo do pacote de dados:

\section{\$A;N;101.5;102.3;3.8@@@@\#}

A mensagem acima indica que o robô ainda está em navegação com a seguinte localização: $101.5 \mathrm{~cm}$ em $x$ e $102.3 \mathrm{~cm}$ em $y$ partindo da origem, e um desvio de 3.8 graus em relação ao destino.

\section{- Módulo de Sensores}

Os valores referentes à leitura dos sonares e infravermelhos são adicionados nesse pacote de dados. Um pacote de dados deste módulo segue o seguinte exemplo:

\section{$\$ S ; 80 ; 70 ; 85 ; 29 ; 1.4 ; 2.4 @ \#$}

A mensagem indica que o sonar direito detectou um obstáculo a $80 \mathrm{~cm}$, o central a $70 \mathrm{~cm}$ e o esquerdo a $85 \mathrm{~cm}$. A temperatura ambiente onde 0 robô se encontra é de $29^{\circ} \mathrm{C}$, um obstáculo está a $1.4 \mathrm{~cm}$ à direita do robô e sua esquerda está livre de obstáculos $(2.4 \mathrm{~cm}$ é o valor máximo indicado pelos sensores infravermelhos). 
Decorrida toda a teoria empregada e os métodos utilizados para o desenvolvimento dessa arquitetura, o fluxograma do funcionamento geral é apresentado na FIGURA 3.14.

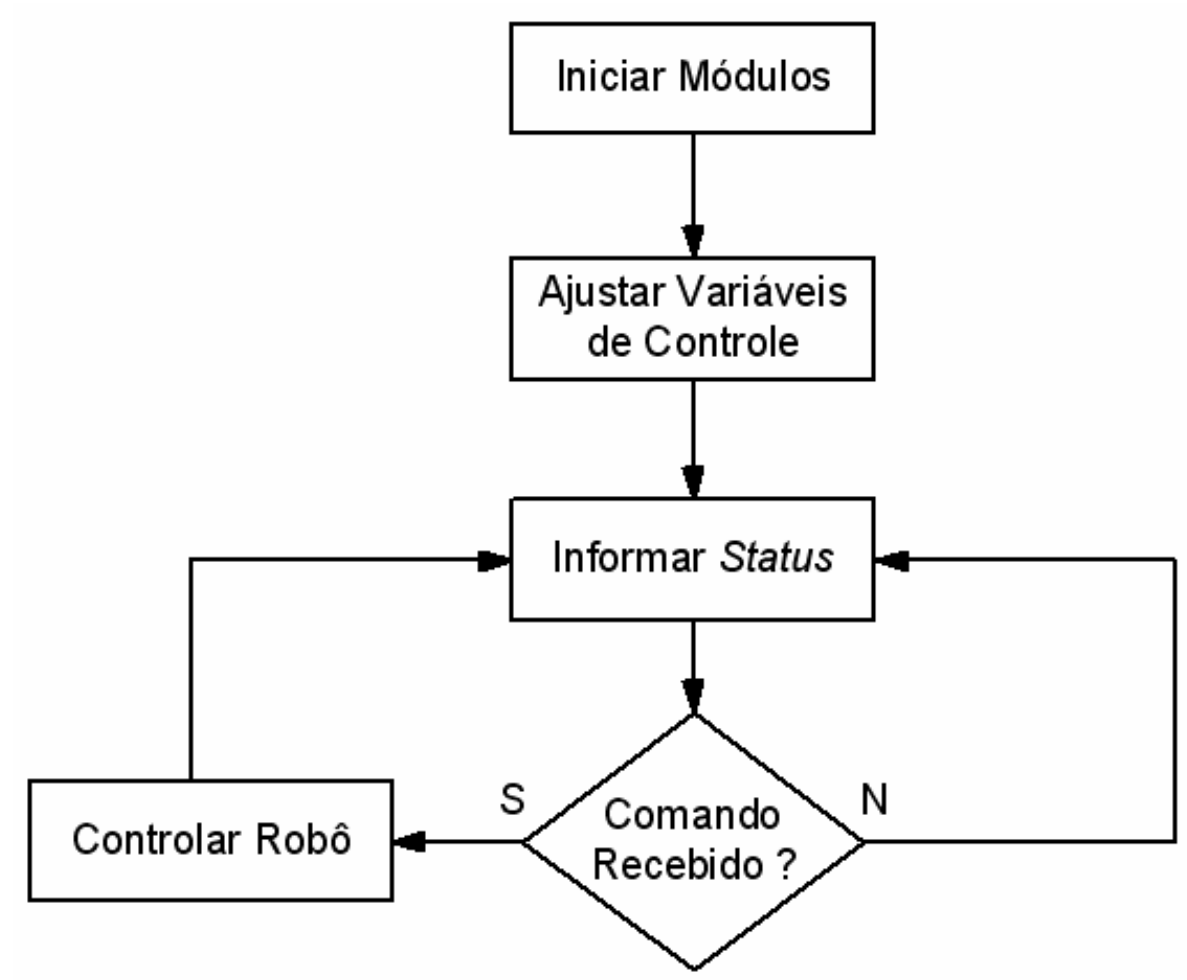

FIGURA 3.14 - Fluxograma geral de funcionamento do sistema

Cada bloco será detalhado no decorrer dessa dissertação.

\subsection{Módulo Principal}

O Módulo principal é o gerenciador de todos os processos da arquitetura desenvolvida.

Sua função é enviar e receber comandos dos demais módulos, formatar os dados recebidos seguindo o protocolo descrito na Subseção 3.3.4, além de monitorar a carga da bateria e seu relógio interno. 
A FIGURA 3.15 apresenta o diagrama de blocos das funções presentes no Módulo Principal.

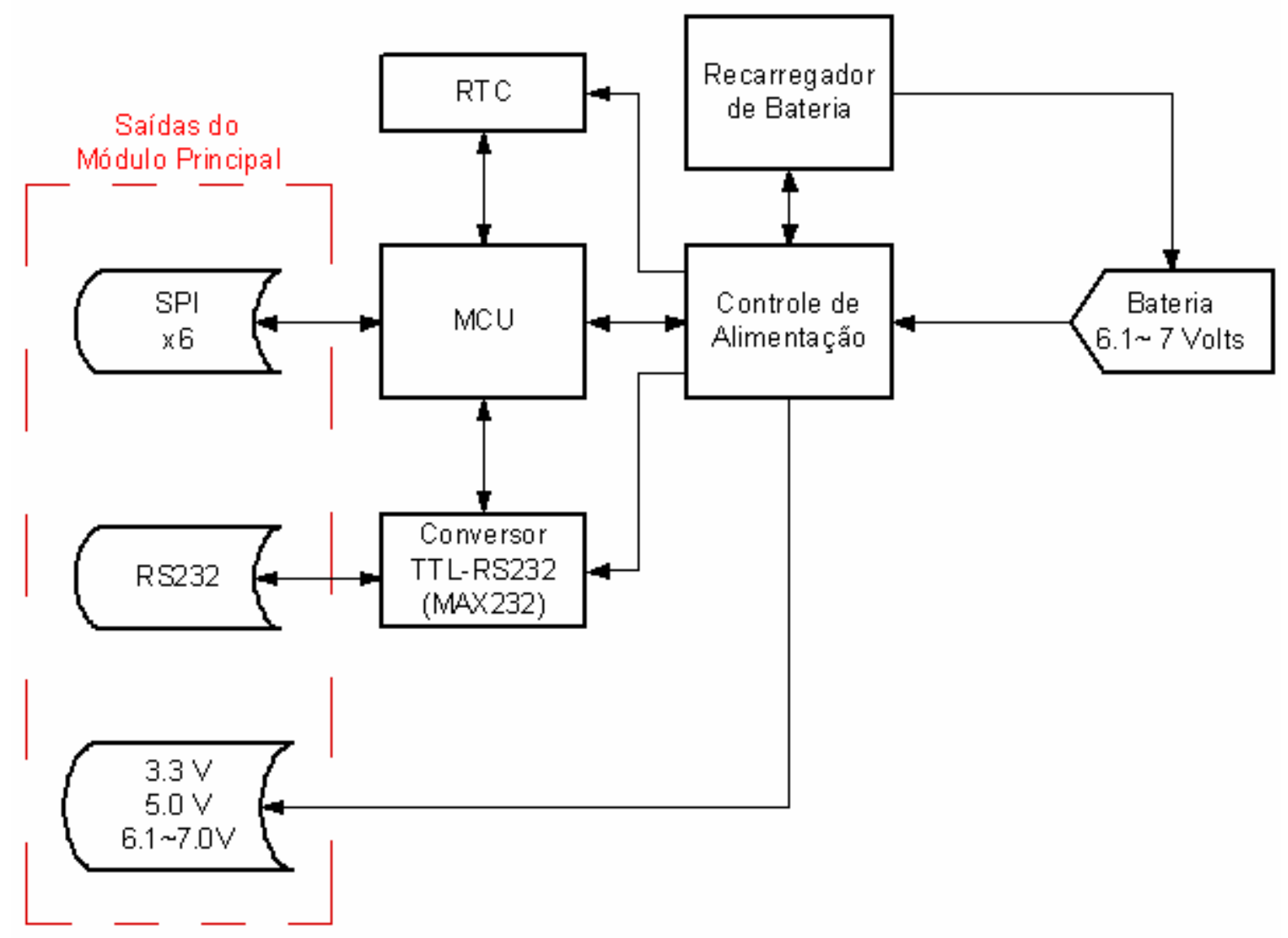

FIGURA 3.15 - Diagrama de blocos do módulo principal

As funções de cada bloco do diagrama, exceto o conversor TTL-RS232 que já foi abordado na Subseção 3.3.2, são detalhadas a seguir:

\section{- RTC (Real Time Clock)}

O RTC é um dispositivo com a capacidade de contar o tempo com precisão (Relógio), e está em todos os sistemas que necessitam de uma base de tempo estável para execução de processos, agendas e calendários. 
Um RTC pode ser implementado tanto por software como por hardware, sendo que a segunda opção oferece algumas vantagens em relação à primeira, sendo elas:

1. Diminuição do Software e, em conseqüência a memória utilizada no Firmware do MCU é também menor;

2. A precisão dos "tic's" do relógio é maior, pois nenhuma interrupção ocorre durante a contagem; já em software, isso pode acontecer;

3. Leitura dos dados feita por meio da comunicação serial.

As desvantagens são:

1. O custo do projeto aumenta, pois necessita a adição de novos componentes;

2. Necessidade de um barramento serial $\left(\mathrm{SPI}\right.$ ou $\mathrm{I}^{2} \mathrm{C}$ ) para leitura e escrita no RTC.

$\mathrm{Na}$ arquitetura desenvolvida a economia da memória é necessária para versatilidade do sistema, e quanto mais memória disponível no MCU, maior será a quantidade de comandos e rotinas que podem ser implementadas.

A partir disso, o RTC adotado para esse trabalho foi o componente DS1305. Suas principais características são: 
- Contagem de segundos, minutos, horas, dia do mês, mês, dia da semana e ano com compensação em anos bissextos;

- 96 bytes de memória não volátil para armazenamento de dados;

- 2 alarmes diário programáveis;

- Interface de comunicação utilizando o padrão SPI ou comunicação serial a 3 fios;

- Burst Mode para leituras e escritas em sucessivos endereços da RAM;

- 2 pinos de alimentação, sendo um para alimentação normal e outro para utilização de bateria (Backup);

○ Tensão de alimentação de 2.0 a 5.5 Volts.

A TABELA 3.9 apresenta a descrição e a FIGURA 3.16 a pinagem do DS1305.

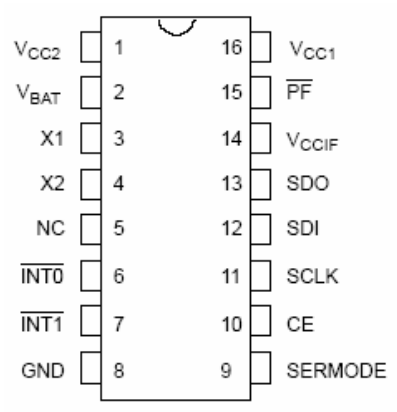

FIGURA 3.16 - Pinagem do DS1305 (fonte: DALLAS Semiconductor) 
TABELA 3.9 - Descrição dos pinos do DS1305

\begin{tabular}{|c|l|}
\hline Vcc1 & Alimentação Primária \\
\hline Vcc2 & Alimentação Secundária \\
\hline VBat & Entrada para Bateria de 3 Volts \\
\hline Vccif & Entrada da Interface lógica de alimentação \\
\hline GND & Terra \\
\hline X1 e X2 & Conexão do cristal de 32,168 KHz \\
\hline INT0 & Interrupção 0 (Saída) \\
\hline INT1 & Interrupção 1 (Saída) \\
\hline SDI & Entrada de dados (Serial Data In - SPI) \\
\hline SDO & Saída de dados (Serial Data Out - SPI) \\
\hline CE & Seletor (Chip Enable - SPI) \\
\hline SCLK & Entrada de Clock (Serial Clock - SPI) \\
\hline SERMODE & Seleção do padrão de comunicação Serial \\
\hline PF & Saída do status da alimentação (Power Fail) \\
\hline
\end{tabular}

Em [43] segue um exemplo detalhado da programação e utilização do DS1305. A ligação do RTC no módulo principal é feita utilizando, além da alimentação do módulo, uma bateria de 3Volts para Backup da base de tempo, caso a alimentação principal seja cortada.

Na FIGURA 3.17 é mostrado o esquema de ligação do DS1305 ao MCU do Módulo Principal.
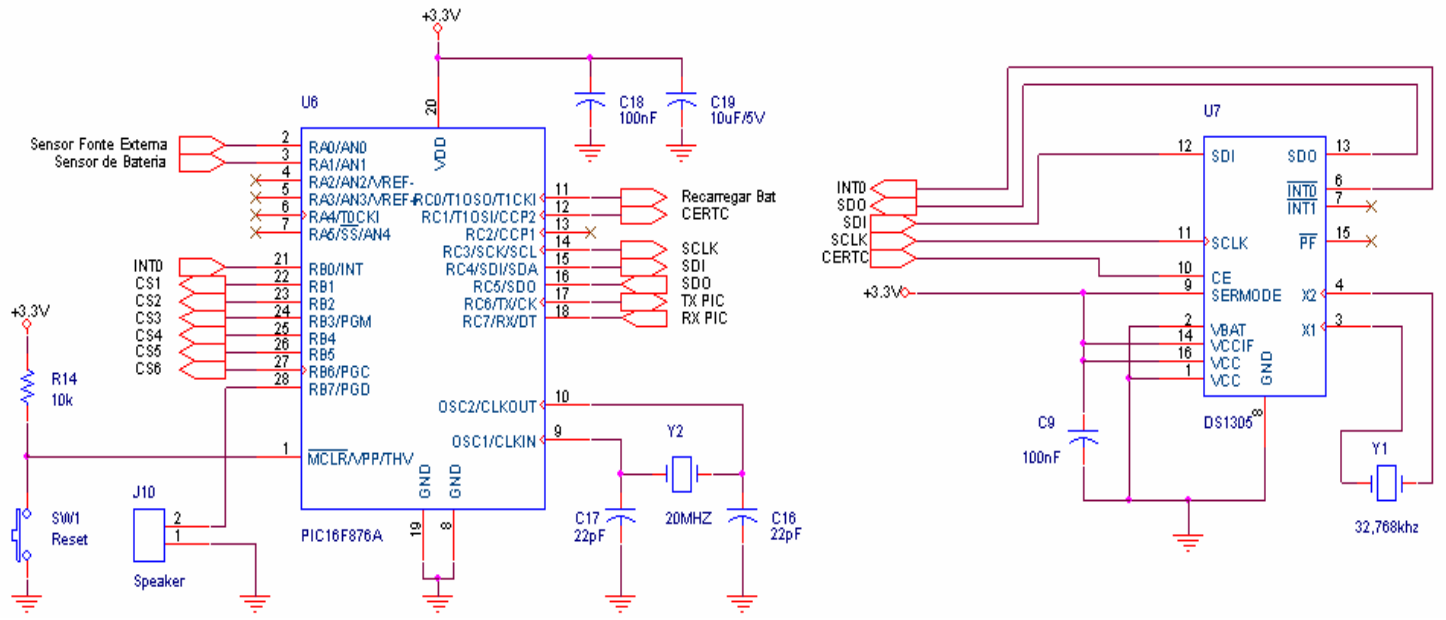

FIGURA 3.17 - Ligação do RTC ao MCU do Módulo Principal 
- SPI

Esse bloco apresenta o padrão de comunicação principal da arquitetura. Para conexões dos demais módulos ao Módulo Principal foi definido um barramento de dados com a seguinte característica:

- Possuir pinos de tensões variadas para alimentação de todos os demais módulos;

- Possuir um padrão de comunicação serial, nesse caso o padrão SPI.

A arquitetura foi projetada para que as conexões dos demais módulos ao Módulo Principal seguissem o padrão utilizado nos PC's. O módulo principal deve ser posicionado no robô em uma superfície plana e horizontal, enquanto os outros módulos conectam-se ao Módulo Principal por meio de Slots fixados na posição vertical.

Para que os módulos conectados não fossem danificados quanto à conexão vertical, um conector com 16 pinos foi utilizado para assegurar uma melhor fixação.

A TABELA 3.10 apresenta os pinos e suas funções no barramento de comunicação dos módulos, onde:Vbat é o valor da bateria que alimenta o sistema; SDO, SDI, SCLK e CSx são pinos para SPI; x são pinos não utilizados. 
TABELA 3.10 - Pinagem do Barramento de comunicação

\begin{tabular}{|l|c|c|c|c|c|c|c|c|}
\hline Pino & 1 & 2 & 3 & 4 & 5 & 6 & 7 & 8 \\
\hline Função & Vbat & $5.0 \mathrm{~V}$ & $3.3 \mathrm{~V}$ & $\mathrm{x}$ & $\mathrm{x}$ & $\mathrm{x}$ & $\mathrm{x}$ & $\mathrm{SDO}$ \\
\hline Pino & 9 & 10 & 11 & 12 & 13 & 14 & 15 & 16 \\
\hline Função & SDI & SCLK & $\mathrm{CSx}$ & $\mathrm{x}$ & $\mathrm{x}$ & $\mathrm{x}$ & $\mathrm{x}$ & $\mathrm{GND}$ \\
\hline
\end{tabular}

Nesse trabalho a expansibilidade de módulos conectados ao barramento está limitada a seis dispositivos, mas a arquitetura não define essa quantidade, ou seja, o número de conexões no barramento depende apenas do nível de I/O’s disponíveis para seleção dos módulos.

- RS232

A finalidade dessa interface de comunicação presente no Módulo Principal é de ajudar no desenvolvimento de seu Software embarcado (Firmware), podendo ser utilizada como um Sniffer ou Debugger.

Sniffer é um dispositivo com o intuito de monitorar e observar o que está acontecendo em um canal de comunicação; por outro lado, o Debugger tem a capacidade de ler valores de variáveis em execução. Portanto, com essas duas ferramentas disponíveis o desenvolvimento de Software torna-se mais amigável.

\section{- Controle de alimentação}

O controle de alimentação é um circuito eletrônico com o objetivo de filtrar, estabilizar e fornecer os diversos níveis de tensão necessários para todos os módulos e dispositivos presentes na arquitetura.

O diagrama de blocos desse circuito é apresentado na FIGURA 3.18. 


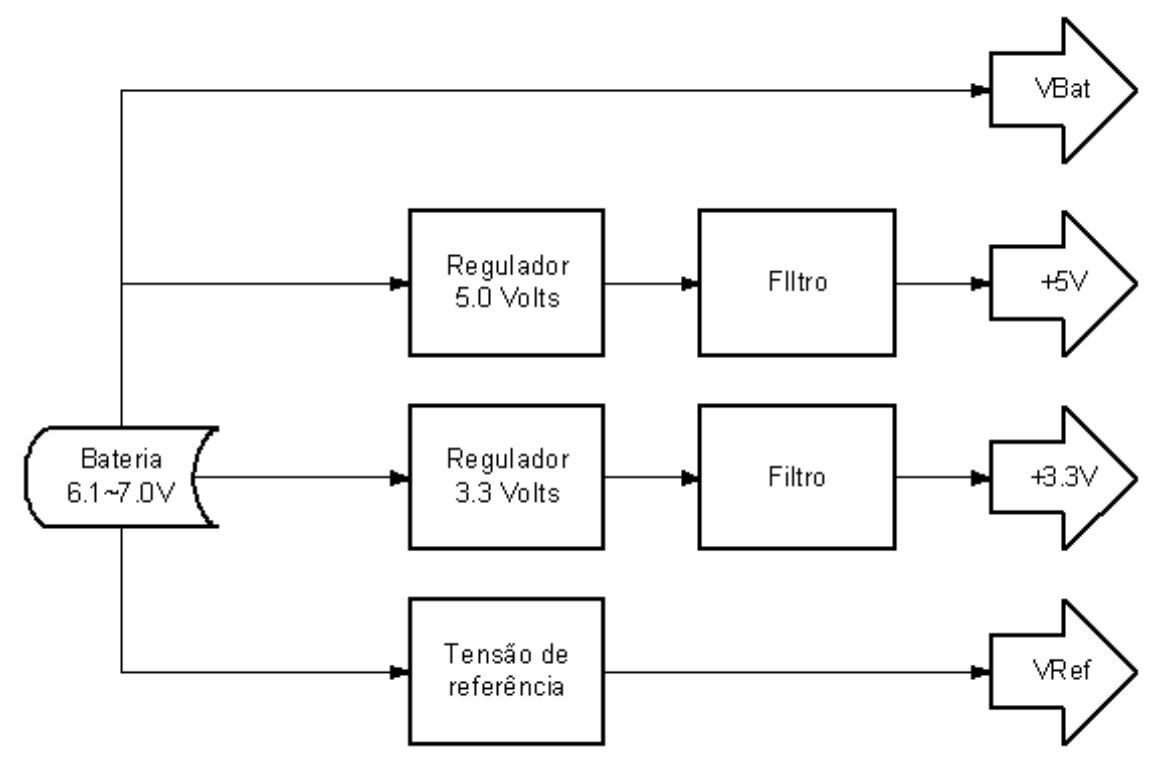

FIGURA 3.18 - Diagrama de blocos do Controle de Alimentação

O circuito eletrônico referente ao diagrama de blocos do controle de alimentação é apresentado na FIGURA 3.19.
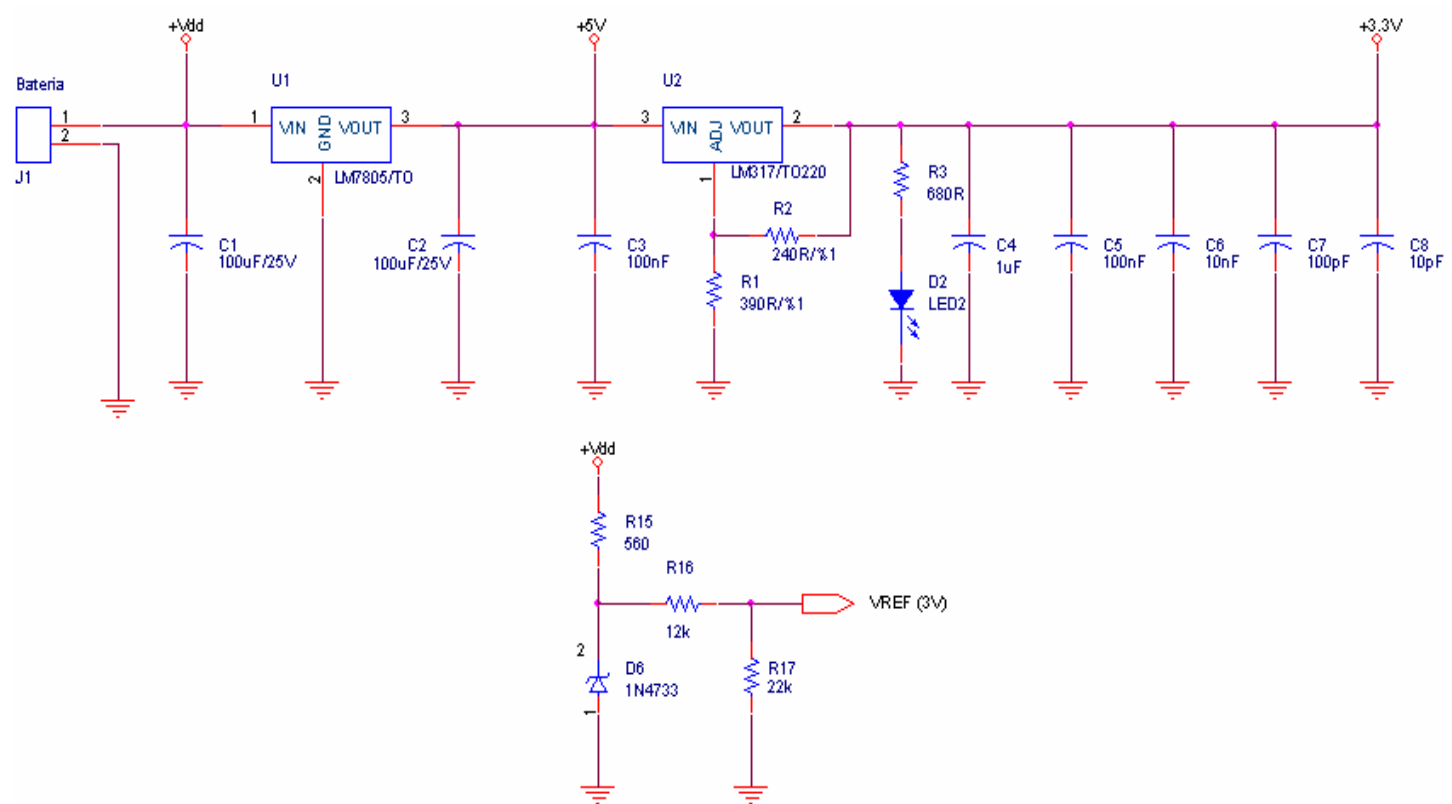

FIGURA 3.19 - Circuito eletrônico da fonte de alimentação e tensão de referência do Módulo Principal 
Os diferentes níveis de tensão são necessários para:

1. +3.3V: Alimentação dos MCU's e os circuitos de rádio freqüência;

2. +5.0V: Alimentação do conversor TTL-RS232 para poder operar em velocidade máxima (115200 bps), alimentação e Drivers de corrente para acionamento dos Servomotores;

3. VRef: Tensão de referência para o conversor A/D do MCU do Módulo Principal, utilizado para monitorar o nível de bateria.

A FIGURA 3.20 mostra a ligação do conversor TTL-RS232 alimentado com 5.0V ao MCU com 3.3V, utilizando um circuito conversor.

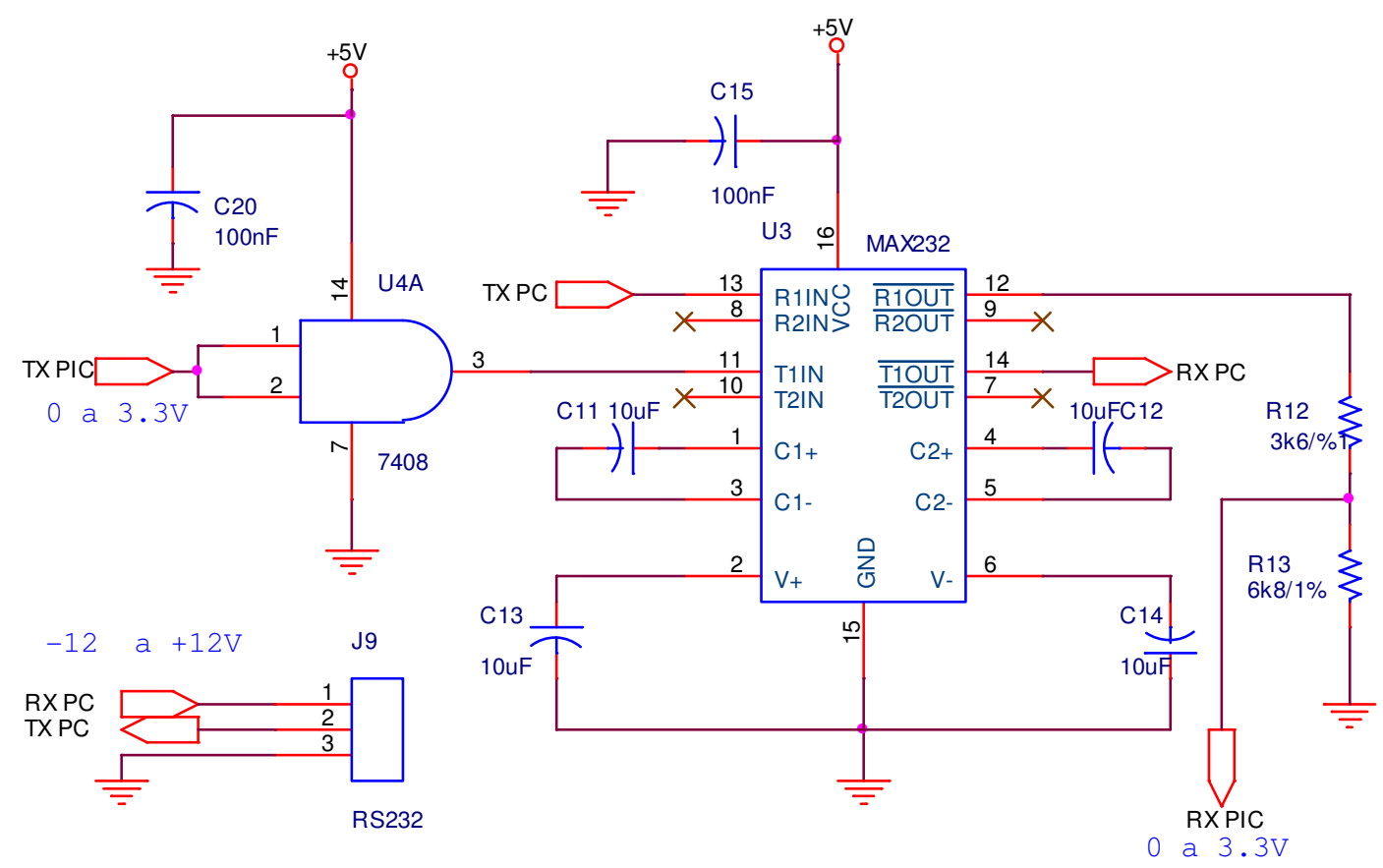

FIGURA 3.20 - Esquema de ligação do MAX232 utilizando níveis de tensão diferentes 


\section{- Recarregador de Bateria}

O circuito recarregador projetado para essa arquitetura tem a finalidade de informar o estado atual da bateria, além de fazer o recarregamento da mesma.

O circuito apresentado na FIGURA 3.21 tem sinais de controle que, ao detectar a presença de uma fonte externa conectada ao robô, ligam e desligam o recarregador quando necessário.

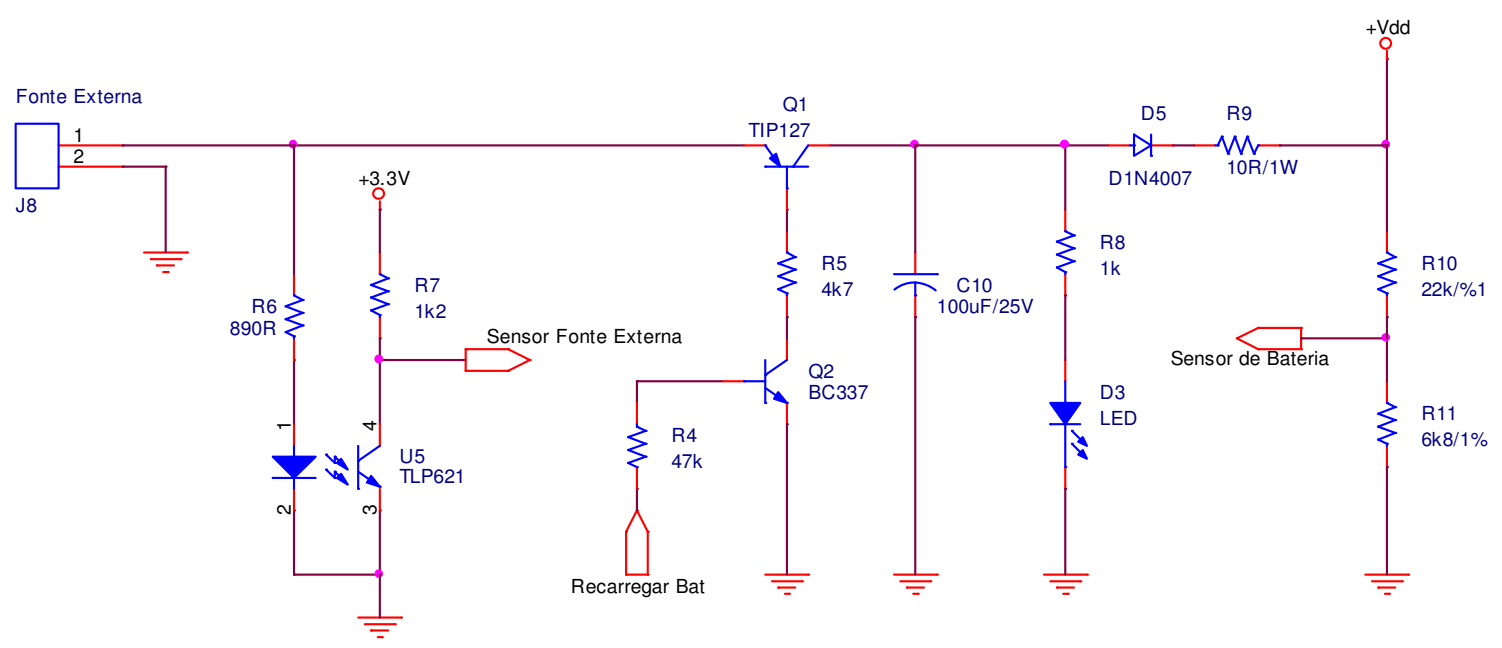

FIGURA 3.21 - Circuito Eletrônico do recarregador de baterias

Quando uma fonte de energia externa é conectada ao Módulo Principal, um sinal ("Sensor de Fonte Externa") é enviado ao MCU, que por sua vez realiza a leitura do valor atual da bateria através do nível de tensão referenciado pelo "Sensor de Bateria".

Esse nível de tensão é convertido através do módulo $A / D$ de 10 bits interno ao MCU e seu valor digital é calculado pela Equação (3.2):

$$
\text { TensãoBat }=0.00134 \times \text { ValorDaBateria }-0.8916
$$


onde TensãoBat é a resposta em Volts do valor da bateria, e ValorDaBateria é o valor do sensor convertido pelo módulo $A / D$ do $M C U$.

A equação anterior foi deduzida por meio de comparações de níveis de tensão amostrados em um multímetro digital em relação ao sinal do sensor de carga após a conversão A/D.

Portanto, dependendo das condições de carga, um sinal é enviado ao pino "Recarregar Bat" fazendo com que inicie ou finalize o recarregamento da bateria.

O Software de controle e monitoramento da carga da bateria descrita nos parágrafos anteriores é representado pelo fluxograma da FIGURA 3.22.

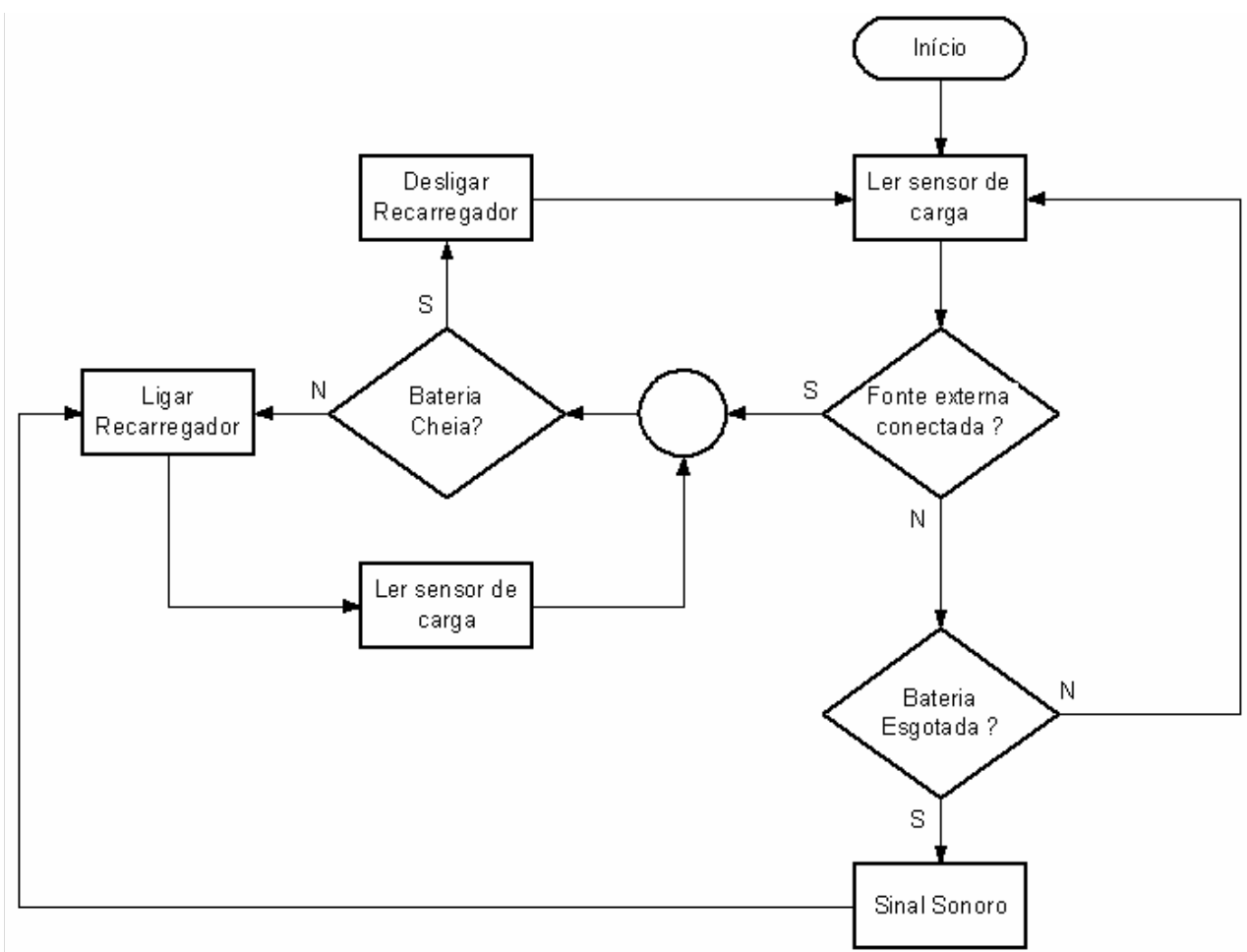

FIGURA 3.22 - Fluxograma do Software de Monitoramento e Recarregador de Bateria

A bateria utilizada é do tipo chumbo-ácido selada, sendo que suas principais características são: 
1. Tensão nominal: 6V@1.3AH. Flutuação de carga em tensão constante: 6.8 6.9V;

2. Corrente inicial: $0.52 \mathrm{~A}$ Máxima;

3. Tensão de recarregamento 7.2 7.3V;

4. Dimensões: 97x56x25mm. Peso: 0.3kg;

5. 400 ciclos de recarregamento (em média), sendo cada ciclo a recarga da bateria após uma descarga completa.

A FIGURA 3.23 mostra a bateria utilizada.

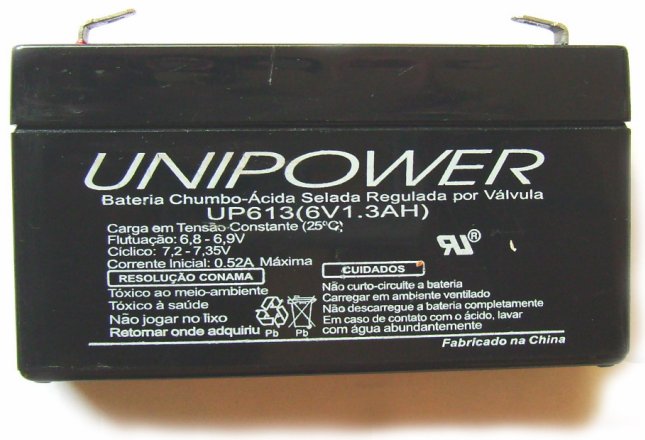

FIGURA 3.23 - Bateria de Chumbo-Ácido utilizada

A bateria de chumbo-ácido além de seu baixo custo possui também grande durabilidade quando operada de forma correta. A vida útil desse tipo de bateria diminui significativamente quando a tensão de saída é $20 \%$ abaixo da nominal.

Como dito no início desse item, a função do Módulo Principal é gerenciar os demais módulos e formatar os pacotes de comunicação de acordo com o protocolo especificado. A arquitetura de software do Módulo Principal é baseada no modelo Subsumption, cujo funcionamento decorre da seguinte forma: 
1. Pelo fato da comunicação SPI ser Full-Duplex os dados devem ser enviados pelo Master para obter as respostas dos Slaves. Portanto, os pacotes de dados são inicializados com valores Default de controle.

2. A cada pacote de dados recebido por um módulo Slave, seus dados são tratados e novamente empacotados para uma futura transmissão.

3. Ao finalizar a recepção de dados de todos os módulos Slaves, exceto o Módulo de RF, os dados tratados são enviados a esse módulo e posteriormente enviados ao PC. No mesmo instante em que os dados são enviados pelo Módulo de RF, se houver alguma informação de controle vinda do Módulo PC, tal informação é tratada pelo Módulo Principal e então é gerada uma ação de controle.

Para um melhor entendimento, o fluxograma da FIGURA 3.24 demonstra o respectivo funcionamento, indicando as principais sub-rotinas. 


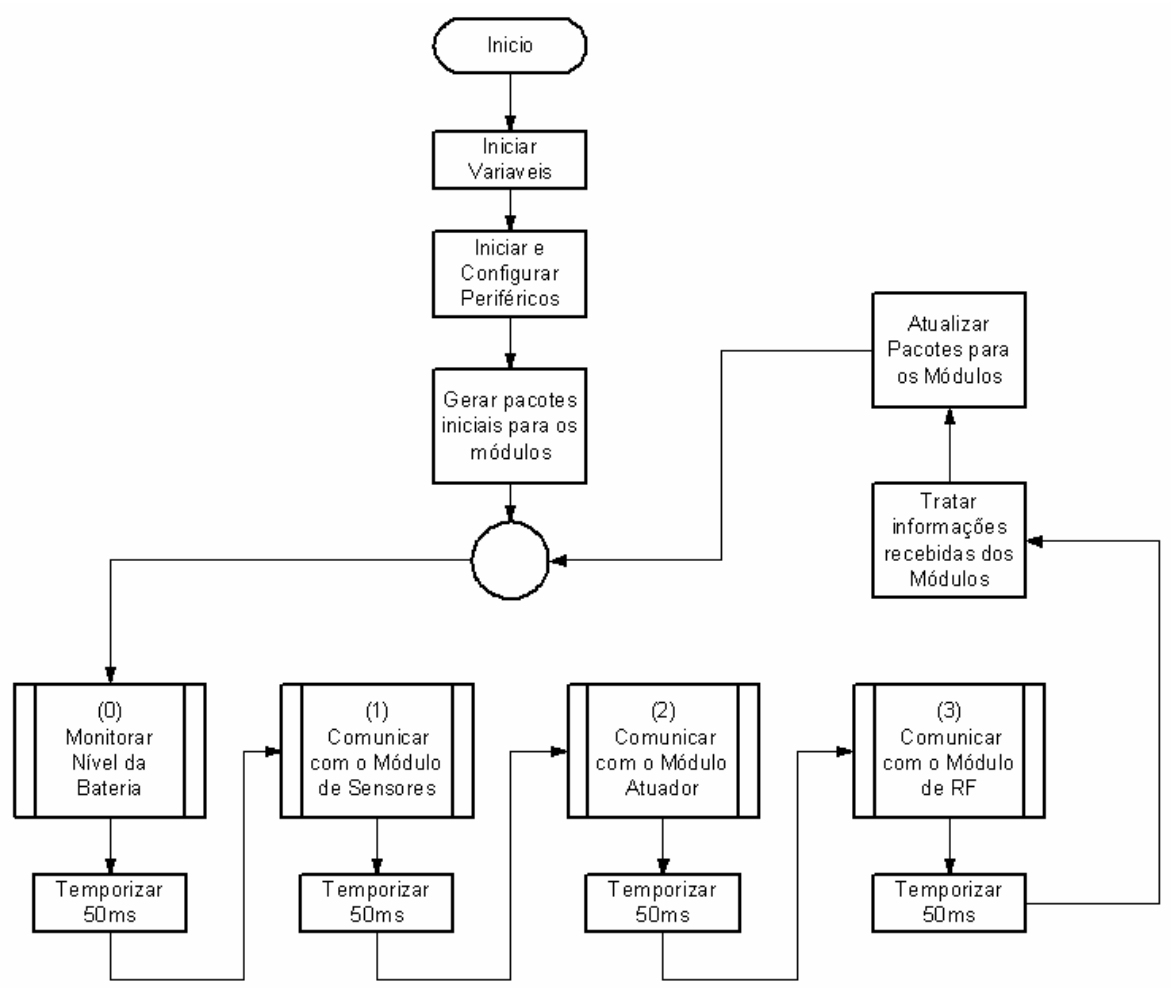

FIGURA 3.24 - Fluxograma de Software do Módulo Principal

Após o detalhamento do Módulo Principal e seus principais componentes, sua implementação física (Hardware) é mostrada na FIGURA 3.25 .

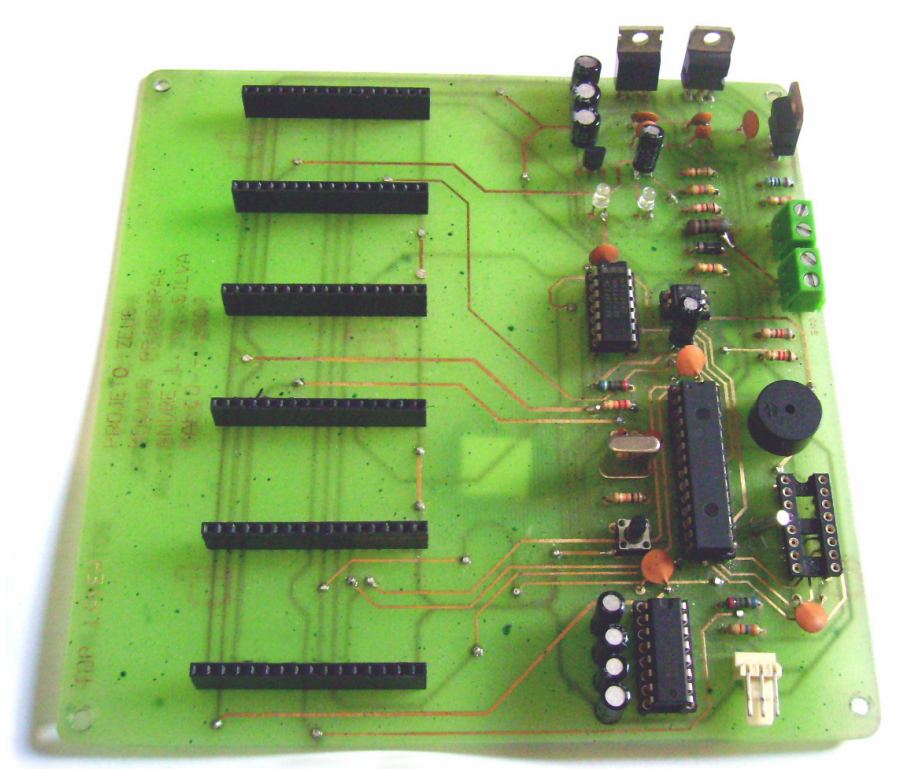

FIGURA 3.25 - Hardware do Módulo Principal 


\subsection{Módulo PC}

O Módulo PC é o controle remoto do sistema de controle definido nessa arquitetura. Sua função é fazer um Link Wireless entre o robô móvel e um computador externo, tendo a finalidade de monitorar a navegação por meio de dados obtidos a partir dos demais módulos.

O diagrama de blocos da FIGURA 3.26 ilustra sua metodologia de funcionamento.

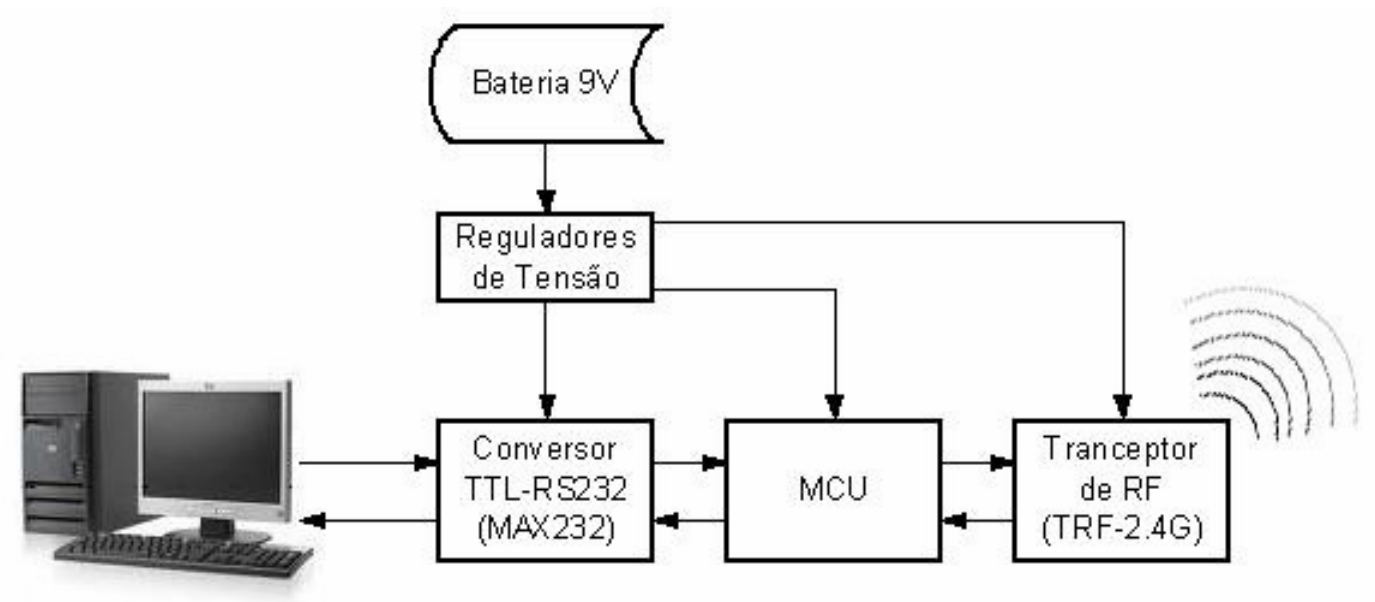

FIGURA 3.26 - Diagrama de Blocos do Módulo PC

A principal característica desse módulo é a velocidade com que ele recebe e envia informações, tanto para o PC quanto para o robô móvel. As configurações para os diferentes padrões de comunicação são listadas como se segue:

- Comunicação serial com o computador utilizando o padrão RS232, com velocidade máxima de $115200 \mathrm{bps}$, sem paridade, 1 StopBit e 8 bits de dados. O circuito utilizado é o mesmo já apresentado na seção 3.4 (FIGURA 3.20); 
- Comunicação Wireless utilizando o tranceptor TRF-2.4G (Subseção 3.3.1), configurado para transmitir dados no modo ShockBurst a 1Mbit de velocidade.

O transceptor de RF (TRF-2.4G) comentado na Subseção 3.3.1 opera na mesma faixa de tensão utilizada para alimentação de todo o circuito lógico do módulo (MCU). O esquema de ligação é apresentado na FIGURA 3.27.

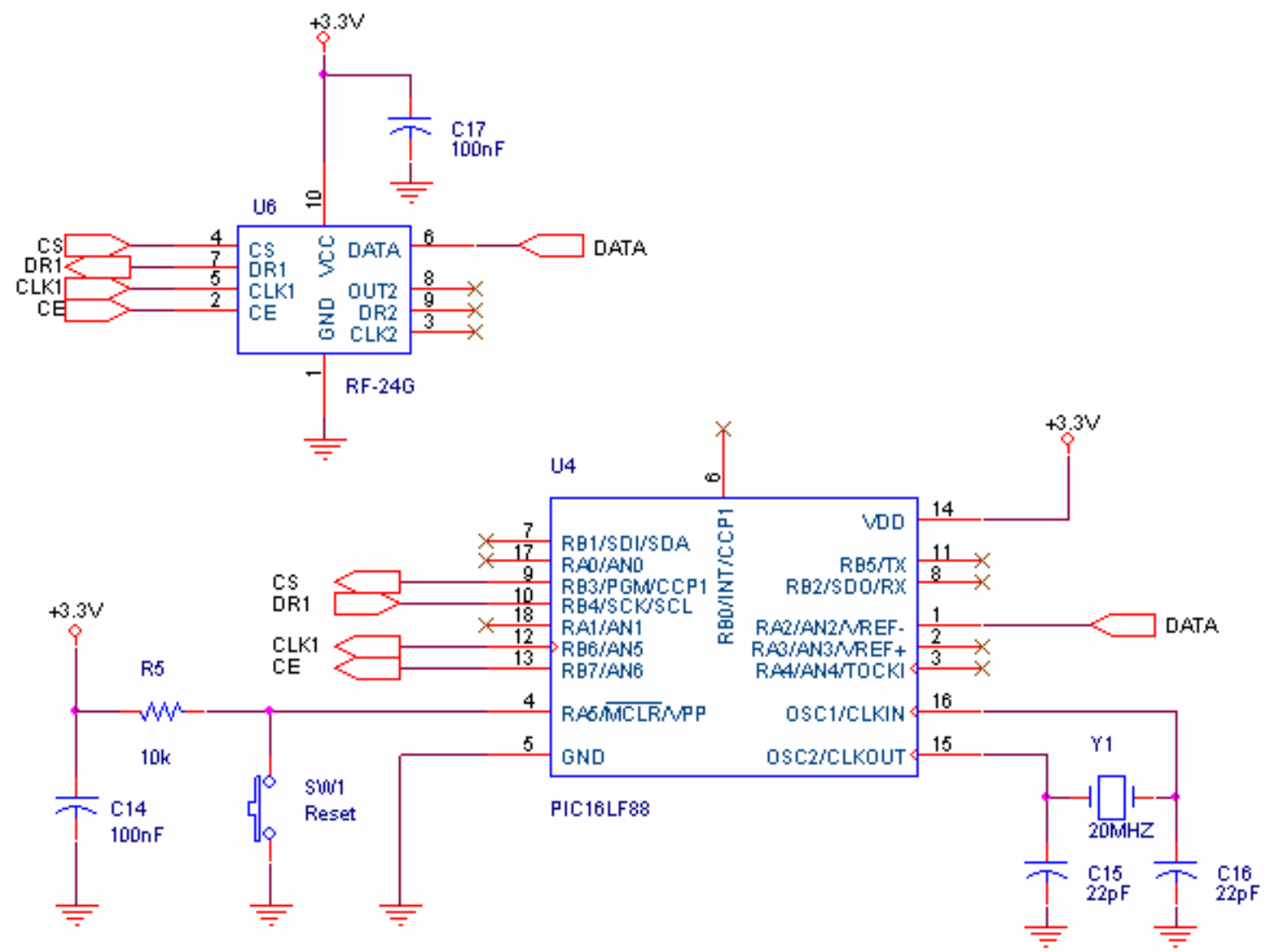

FIGURA 3.27 - Esquema de ligação do Transceptor de RF

A transferência de dados do PC para o robô e vice-versa acontece da seguinte forma: 
1. O comando é enviado pelo PC através da porta serial;

2. O dado recebido é armazenado em um Buffer;

3. Quando o transceptor estiver livre para enviar o dado, então o pacote é transmitido;

4. O Módulo Principal após realizar a varredura nos módulos de atuação e controle envia os dados para o Módulo de RF, enquanto o dado de controle recebido pelo transceptor é lido;

5. O Módulo Principal interpreta os dados recebidos do Módulo RF e executa o comando ordenado;

6. Caso nenhum comando seja passado e o Módulo de RF tente fazer a leitura dos dados do Módulo PC, e um pacote contendo os valores Default é enviado. Esse pacote Default contém a última informação enviada para o robô; portanto, se seu objetivo tiver sido alçando nenhuma ação será tomada.

O fluxograma mostrado na FIGURA 3.28 mostra a seqüência de tarefas executadas pelo Firmware desenvolvido para o Módulo PC. 


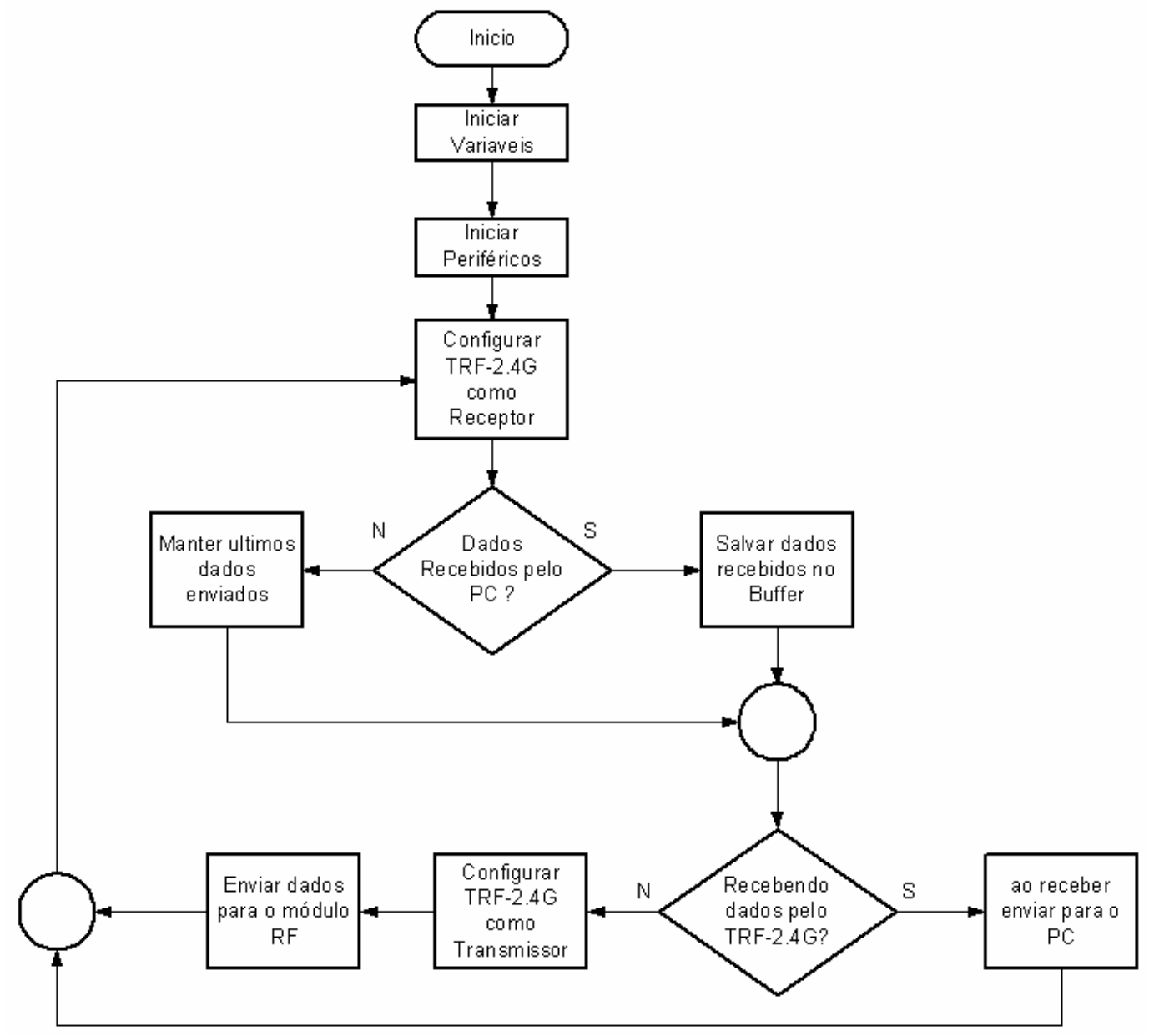

FIGURA 3.28 - Firmware de controle do Módulo PC

A implementação em Hardware do Módulo PC é mostrada na FIGURA 3.29.

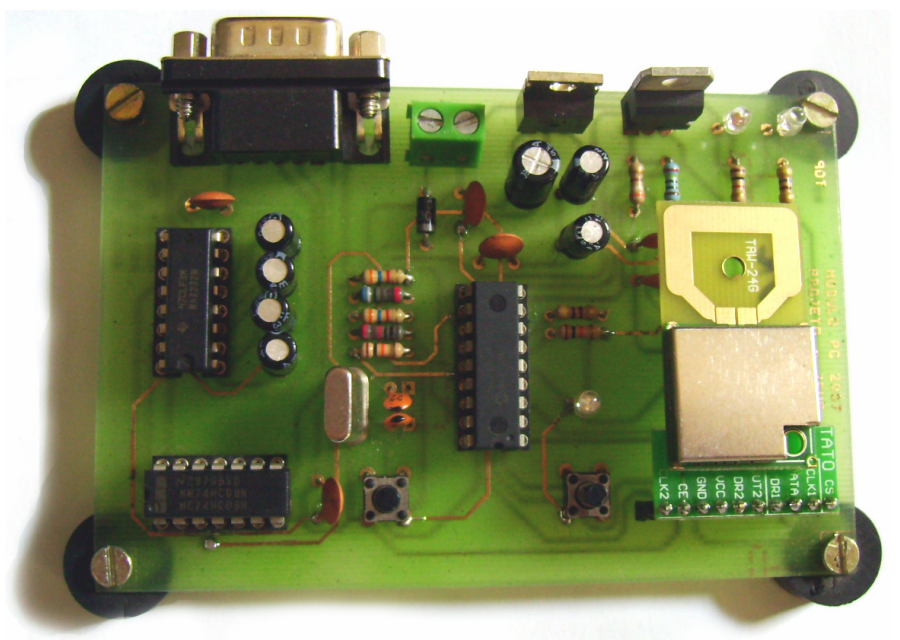

FIGURA 3.29 - Hardware do Módulo de PC 


\subsection{Módulo de Sensores}

O Módulo de Sensores possui características básicas necessárias para estudo de algoritmos em navegação autônoma e mapeamento de ambiente.

Dotado de 6 sensores sua principal função é detectar obstáculos, além de poder monitorar outras grandezas, como por exemplo, temperatura e luminosidade.

O Módulo de Sensores é composto pelos seguintes elementos:

- 3 módulos sonares;

- 2 infravermelhos;

- 1 sensor de temperatura.

A FIGURA 3.30 apresenta o diagrama de blocos desse módulo.

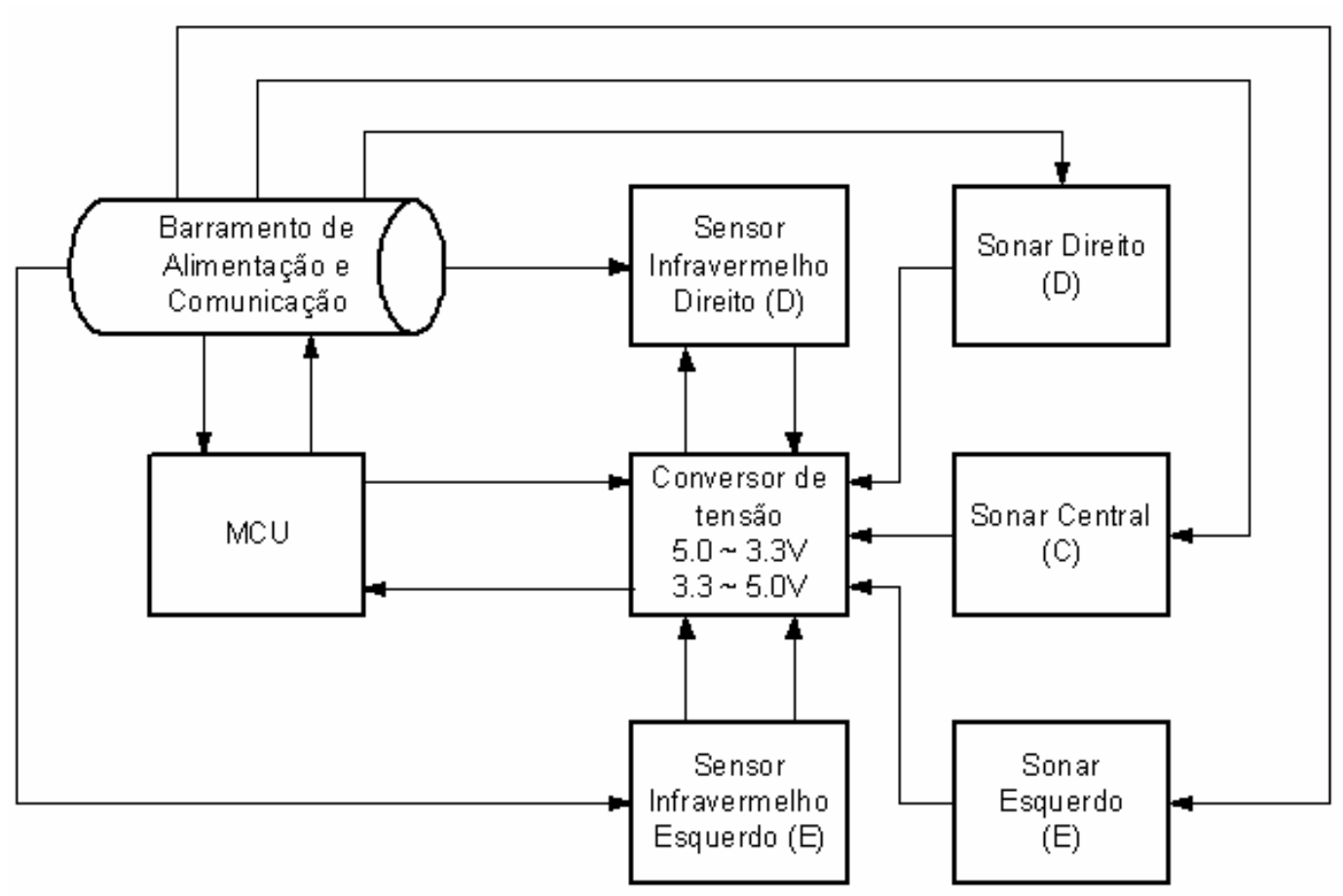

FIGURA 3.30 - Diagrama de blocos do Módulo de Sensores 
A seguir são detalhados os sensores utilizados no respectivo módulo.

\section{- Módulo Sonar}

Esse módulo, adquirido da empresa TATO, compõe um sistema completo para medição de distâncias compreendidas entre 2 a 200cm.

A cada $20 \mathrm{~ms}$ um pulso de ultrasom é enviado pelos transdutores e um sinal em nível alto é disponibilizado na saída do módulo. Quando algum objeto for detectado ou o período de $20 \mathrm{~ms}$ for concluído, então o sinal de saída assume um estado lógico em nível baixo e, logo em seguida, o processo se repente.

O fluxograma referente à parte do Firmware, responsável pela leitura dos dados dos sonares, é apresentado na FIGURA 3.31.

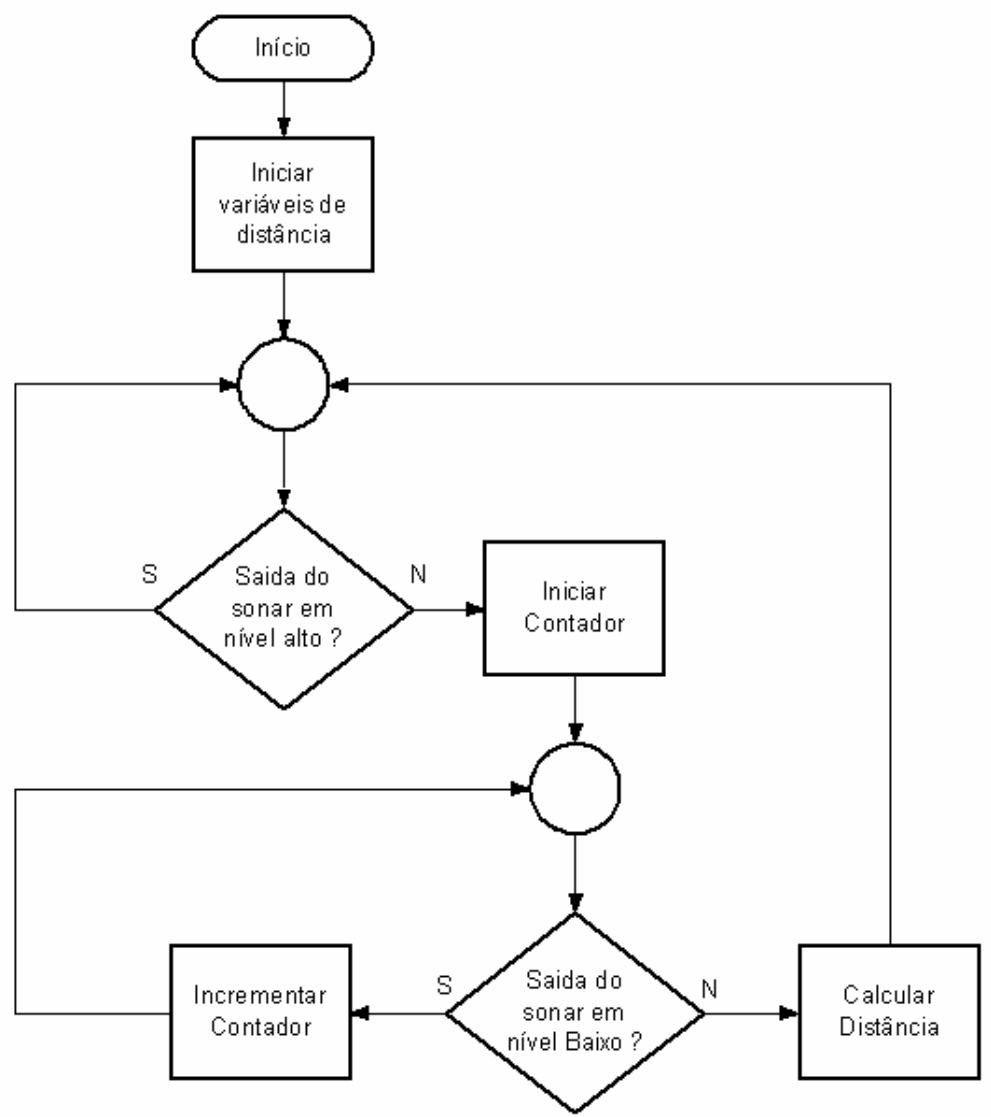

FIGURA 3.31 - Fluxograma de Leitura do Sonar 
De acordo com o fluxograma acima, ao final da leitura do sonar a variável "Contador" terá um valor referente a distância percorrida pelo pulso de ultrasom.

A Expressão (3.3) realiza o cálculo da distância, tendo como entrada o valor do contador, gerando então uma saída referente à detecção de algum objeto em centímetros.

$$
\text { Dist }=(0.882 \times \text { ValorSonarC })-4.696
$$

onde Dist é a distância até o objeto mais próximo em centímetro e ValorSonarC é o valor do contador.

Essa expressão foi deduzida a partir de leituras feitas do valor "contador" em distâncias fixas definidas, com isso, os parâmetros referentes a uma equação linear puderam ser calculados. A precisão obtida nas medições de acordo com a Equação (3.2) é de aproximadamente 0.882 centímetros.

Os módulos sonares utilizados necessitam de uma tensão de alimentação de 5.0V, portanto, o sinal de saída é convertido para uma tensão de 3.3V, possibilitando a leitura pelo MCU. O circuito eletrônico utilizado por esse módulo é mostrado na FIGURA 3.32.

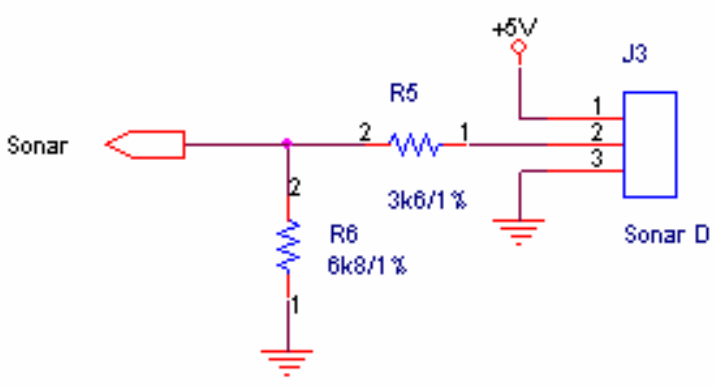

FIGURA 3.32 - circuito utilizado para conexão dos sonares ao Módulo de Sensores 
A FIGURA 3.33 mostra o modelo dos sonares utilizados:

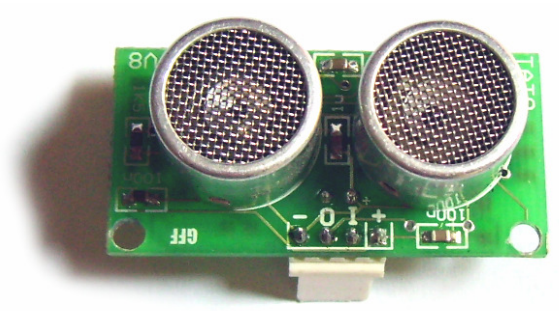

FIGURA 3.33 - Sonares utilizados no Módulo de Sensores

\section{- Sensor Infravermelho}

Esse sensor é constituído por um emissor e um receptor de luz infravermelha, disponibilizados de forma a ser possível fazer a leitura da reflexão dessa luz em objetos próximos ao robô.

A distância máxima alcançada com precisão é de $2.5 \mathrm{~cm}$, e a partir desse valor os dados tornam-se não confiáveis. Esse valor é calculado pela Expressão (3.4).

$$
\text { Distlnfra }=(0.00146 \times \text { ValorInfra })+0.949
$$

onde DistInfra é o resultado em $\mathrm{cm}$ indicando a distância lateral do robô até o objeto mais próximo, e ValorInfra é o valor do sensor convertido pelo módulo A/D de 10bits do MCU.

O circuito eletrônico referente ao acionamento do emissor e leitura dos dados do receptor é mostrado na FIGURA 3.34. 

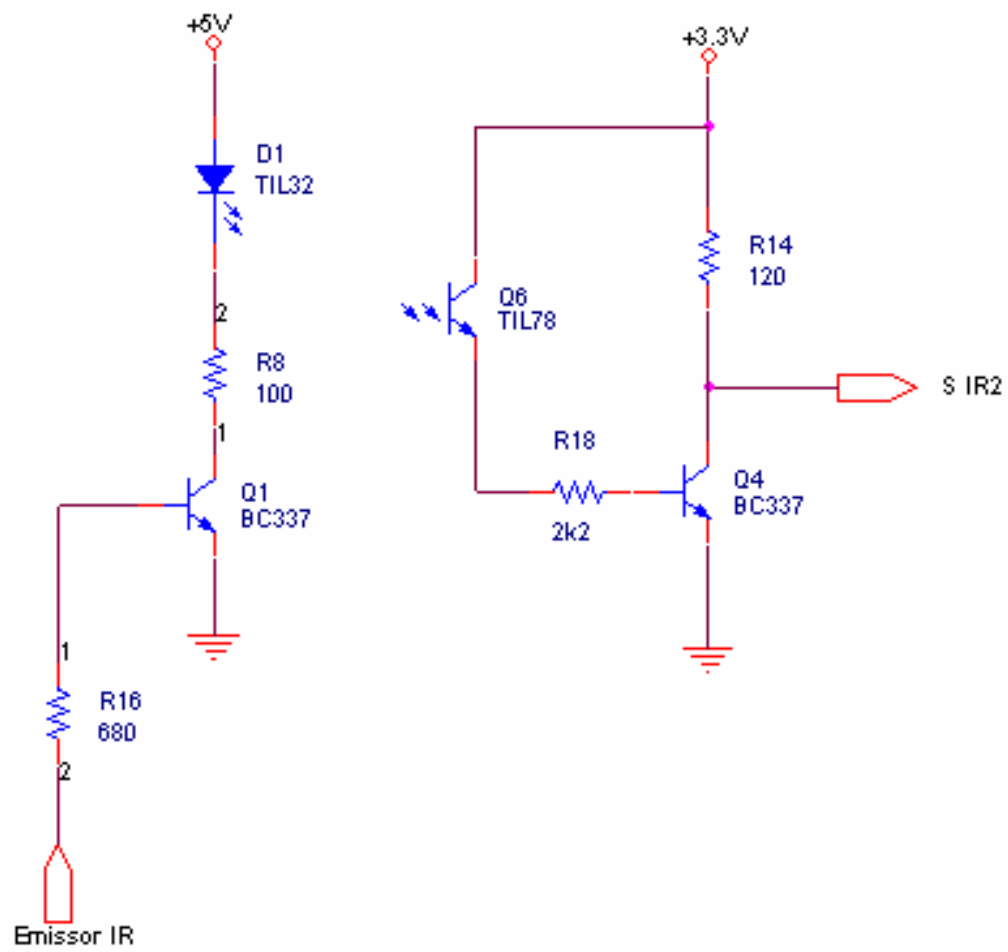

FIGURA 3.34 - Circuito de acionamento e leitura do sensor Infravermelho respectivamente

O sinal de saída do circuito receptor é convertido por um ADC de 10bits presente no MCU.

A FIGURA 3.35 mostra os sensores infravermelhos utilizados:

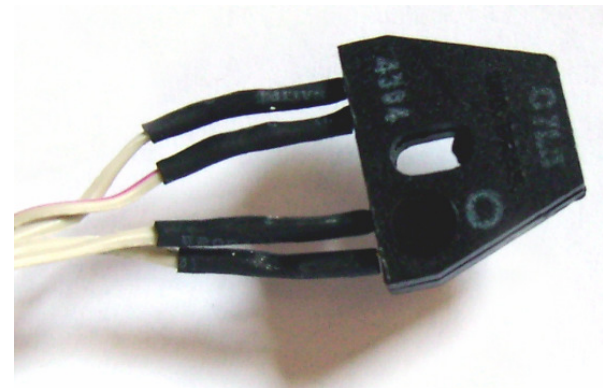

FIGURA 3.35 - Sensores Infravermelhos utilizados 


\section{- Sensor de Temperatura}

O sensor de temperatura utilizado foi um termistor NTC de uso geral, sendo sua principal característica a relação direta entre o aumento da temperatura e a diminuição de sua resistência.

O circuito utilizado para medição da temperatura por meio desse sensor é mostrado na FIGURA 3.36.

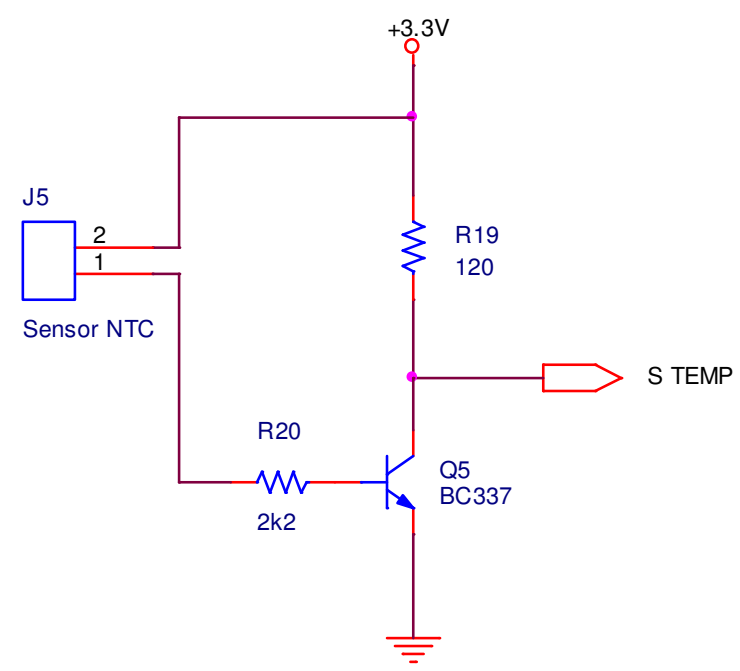

FIGURA 3.36 - Circuito de medição da temperatura ambiente

O circuito para leitura da temperatura é praticamente o mesmo usado para leitura do sensor infravermelho, mudando apenas as equações utilizadas para conversão. A Expressão (3.5) é utilizada no cálculo da temperatura ambiente:

$$
\text { Temp }=(0.115 \times \text { ValorTemp })-36.24
$$

onde Temp é o valor da temperatura ambiente em ${ }^{\circ} \mathrm{C}$ e ValorTemp é o valor do sensor convertido pelo módulo A/D de 10bits do MCU. 
O sensor de temperatura pode ser substituído por uma fotocélula dependendo da aplicação do robô móvel.

A FIGURA 3.37 apresenta o sensor de temperatura NTC utilizado.

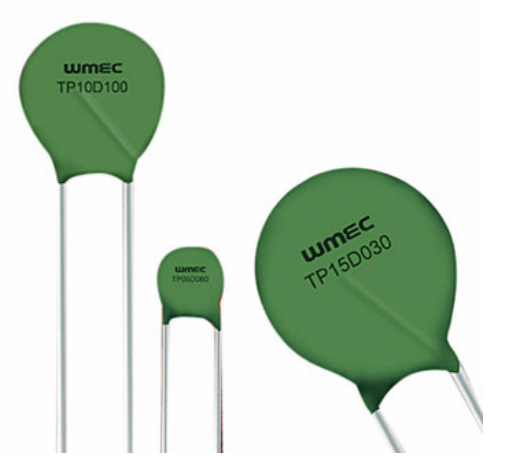

FIGURA 3.37 - Sensor de Temperatura utilizado

O Módulo de Sensores como todos os outros é independente em seu funcionamento, com isso, o ambiente em que o robô móvel se encontra é constantemente monitorado.

Quando o Módulo Principal entra em comunicação com o Módulo de Sensores os dados atualizados de suas leituras são transmitidos, mesmo que nem todas as leituras tenham sido concluídas. Isso é possível pelo fato de que durante a transmissão apenas os últimos dados válidos são enviados.

O fluxograma da FIGURA 3.38 mostra o funcionamento do Módulo de Sensores. 


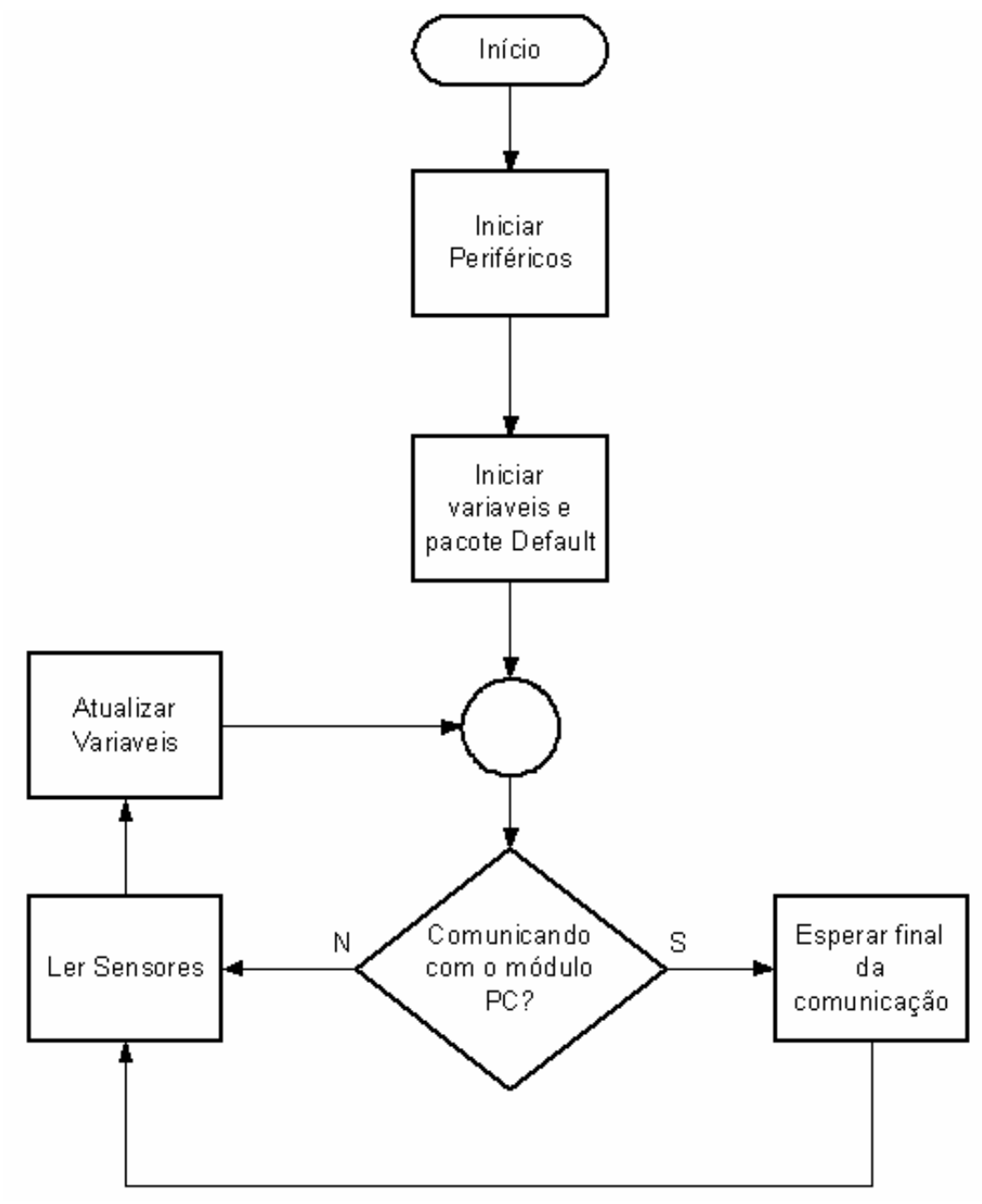

FIGURA 3.38 - Fluxograma do Módulo de Sensores

A implementação em Hardware do Módulo de Sensores é apresentada na FIGURA 3.39.

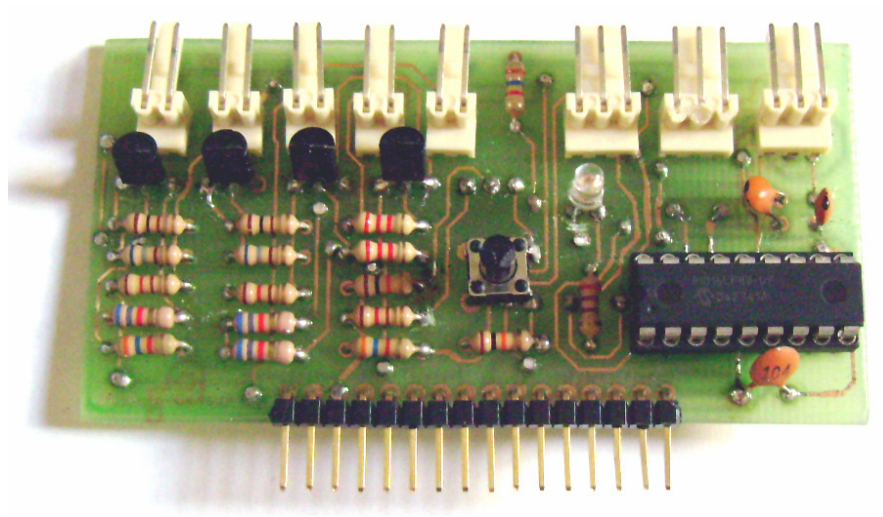

FIGURA 3.39 - Hardware do Módulo de Sensores 


\subsection{Módulo Atuador}

O Módulo Atuador é responsável pelo controle dinâmico da arquitetura desenvolvida, tendo como objetivo informar posição e localização por meio de um sistema odométrico alimentado com informações de Encoders incrementais.

Esse módulo possui interface de controle para servomotores de baixa potência, com a opção de alimentação externa, se necessário.

As características desse módulo são listadas como segue:

- Possibilidade de alimentação externa dos motores;

- Acionamento de 2 servomotores e leitura de 2 encoders incrementais;

- Informar dados da navegação.

O diagrama de blocos da FIGURA 3.40 mostra os principais componentes desse módulo.

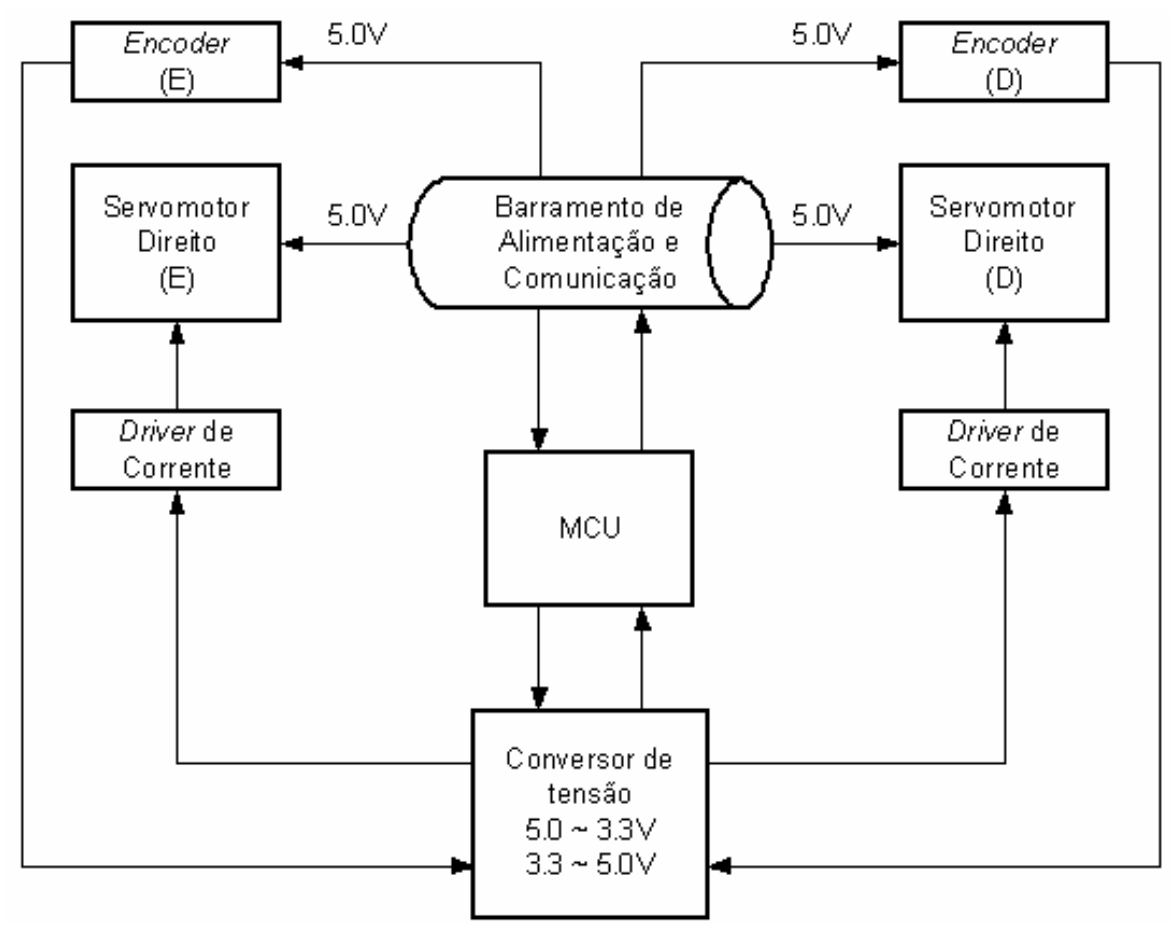

FIGURA 3.40 - Diagrama de Blocos do Módulo Atuador 
As descrições dos motores e encoders utilizados são apresentados a seguir.

\section{- Servomotor}

O servomotor utilizado é o mesmo aplicado em aeromodelismo como posicionador dos Flaps dos aeromodelos, sendo suas principais características:

1. Tensão de alimentação: $4.8 \sim 6.0 \mathrm{~V}$;

2. Torque: $3.06 \sim 3.57 \mathrm{~kg}-\mathrm{cm}$;

3. Peso: 44.9g;

4. Pulso positivo de controle: $1520 \mu s$ para posição central.

O funcionamento de um servomotor de posição é mostrado na FIGURA 3.41.

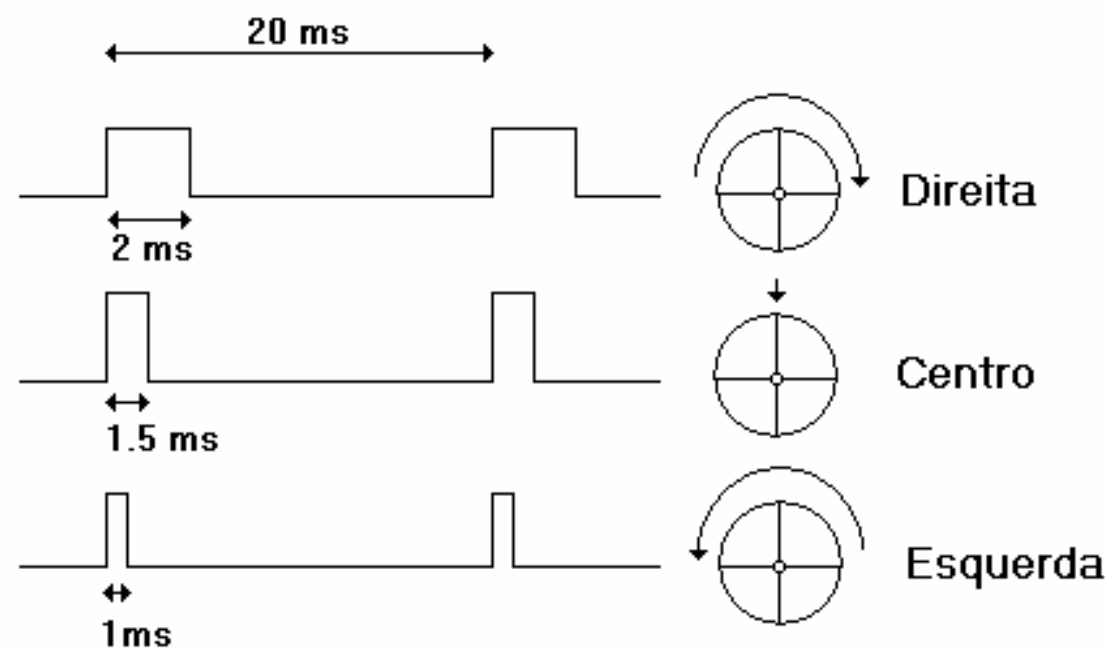

FIGURA 3.41 - Funcionamento do Servomotor

O ângulo de posicionamento desses servomotores é ajustado conforme a razão cíclica do PWM injetado em seu sistema de controle.

Pelo fato desse motor ser dedicado a posicionamento, algumas alterações foram feitas para manter sua rotação contínua. 
O circuito controlador de posição, interno de um servomotor, faz com que a velocidade de posicionamento fique cada vez menor quando o giro se aproxima do valor desejado. A partir desse princípio de funcionamento, as seguintes alterações foram feitas:

1. Foi retirado o pino do sistema de redução que limita o ângulo de giro do servomecanismo;

2. O potenciômetro de posicionamento foi substituído por um divisor de tensão com resistores de 10k.

Com essas alterações o servomotor passa a ter rotação contínua para posicionamento em um ângulo diferente de $0^{\circ}$. Quanto maior a diferença entre o ângulo desejado e o de referência (definido pelo divisor resistivo) maior será a velocidade de giro. Da mesma forma, quanto menor a diferença menor será também a velocidade.

Por meio dessas modificações o funcionamento do servomotor fica idêntico ao de um motor DC comum controlado por PWM, com a diferença do mecanismo já possuir caixa de redução e Driver para acionamento interno. Com isso é possível obter um motor com alto torque, caixa de redução e sistema de controle interno de baixo custo.

As FIGURAS 3.42(a) e 3.42(b) mostram o servomotor utilizado e o seu circuito de controle modificado, respectivamente. 


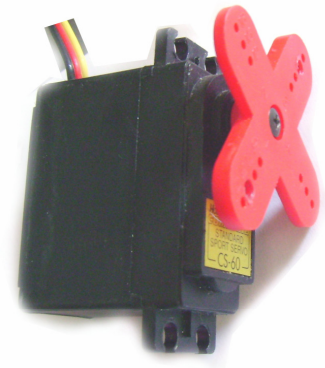

(a)

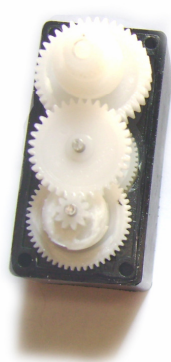

(b)

FIGURA 3.42 - Aspectos do servomotor utilizado na pesquisa:

a) Servomotor Utilizado

b) Circuito de controle interno modificado

Os Encoders utilizados em conjunto com os servomotores são detalhados a seguir.

\section{- Encoder Óptico Incremental}

Os Encoders incrementais são componentes utilizados para medição de movimento e posicionamento. Na indústria são largamente empregados em máquinas operatrizes (CNC), automação de processos (Esteiras), entre outras aplicações.

O funcionamento de um Encoder óptico incremental dá-se por meio de um feixe de luz que é interrompido ou não por um disco janelado. A cada interrupção do feixe de luz um pulso é gerado.

Porém, um único feixe de luz utilizado é suficiente apenas para informar a velocidade ou distância percorrida, mas não em qual direção está se movimentando. Para isso 2 feixes de luz devem ser utilizados. 
A FIGURA 3.43 mostra pulsos defasados gerados por um Encoder óptico incremental com 2 sensores.

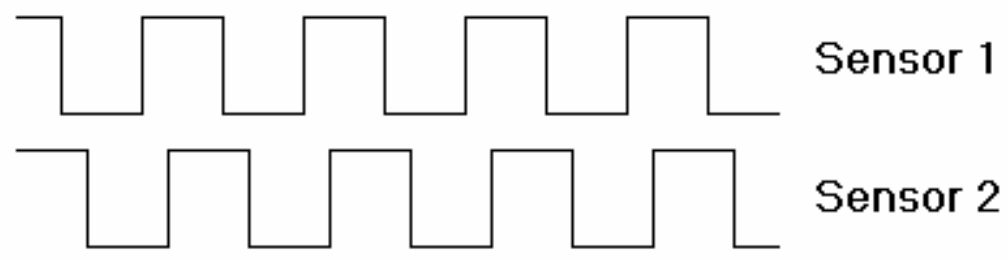

FIGURA 3.43 - Saída de um Encoder Incremental com 2 sensores ópticos

A resolução de um Encoder é definida pela quantidade de pulsos que podem ser gerados em uma revolução de seu eixo, podendo ultrapassar o valor de 1000 pulsos.

Devido à sua complexidade de construção e alta resolução, o custo é elevado ( $\mathrm{R} \$ 400,00$ em média), e como esse trabalho visa minimizar o custo de uma arquitetura para robôs móveis, um Encoder com uma resolução razoável para aplicações Indoor foi projetado.

O circuito eletrônico presente na FIGURA 3.44 faz a leitura do Encoder construído para este projeto.

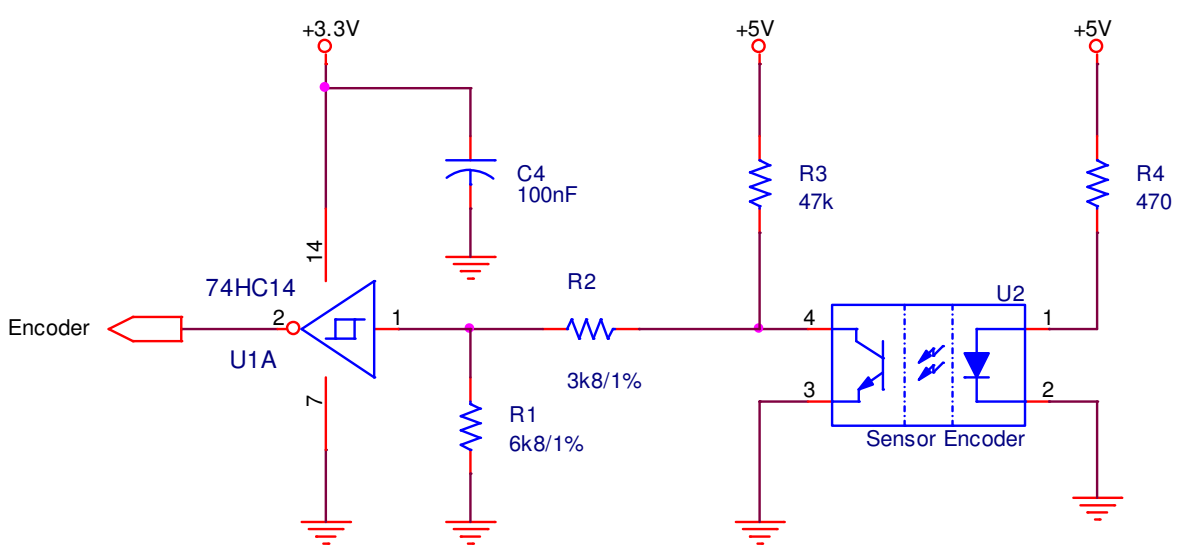

FIGURA 3.44 - Circuito para leitura dos Encoders incrementais 
Os Encoders construídos apresentam apenas 1 sensor interno, pois sempre é conhecido o sentido de giro dos servomotores. A única necessidade é a de medir a distância percorrida por cada roda.

As FIGURAS 3.45(a) e 3.45(b) mostram a construção mecânica e os sensores utilizados para esse Encoder.

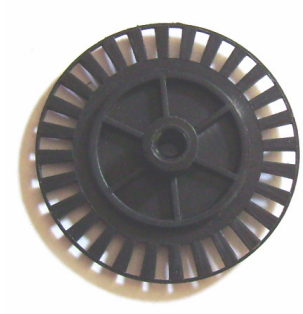

(a)

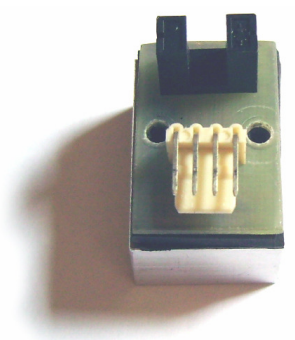

(b)

FIGURA 3.45 - Aspectos estruturais do Encoder:

a) Disco janelado do Encoder Óptico Incremental

b) Sensor de "Ferradura" utilizado no Encoder

O disco janelado utilizado possibilita a leitura de 28 pulsos por revolução. De acordo com os dados apresentados na Seção 3.9, a resolução do encoder construído é de $1.96 \mathrm{~mm}$ por pulso.

A partir desses componentes utilizados para sensoriamento e controle da movimentação do robô móvel, o funcionamento do Módulo Atuador é mostrado pelo fluxograma presente na FIGURA 3.46. 


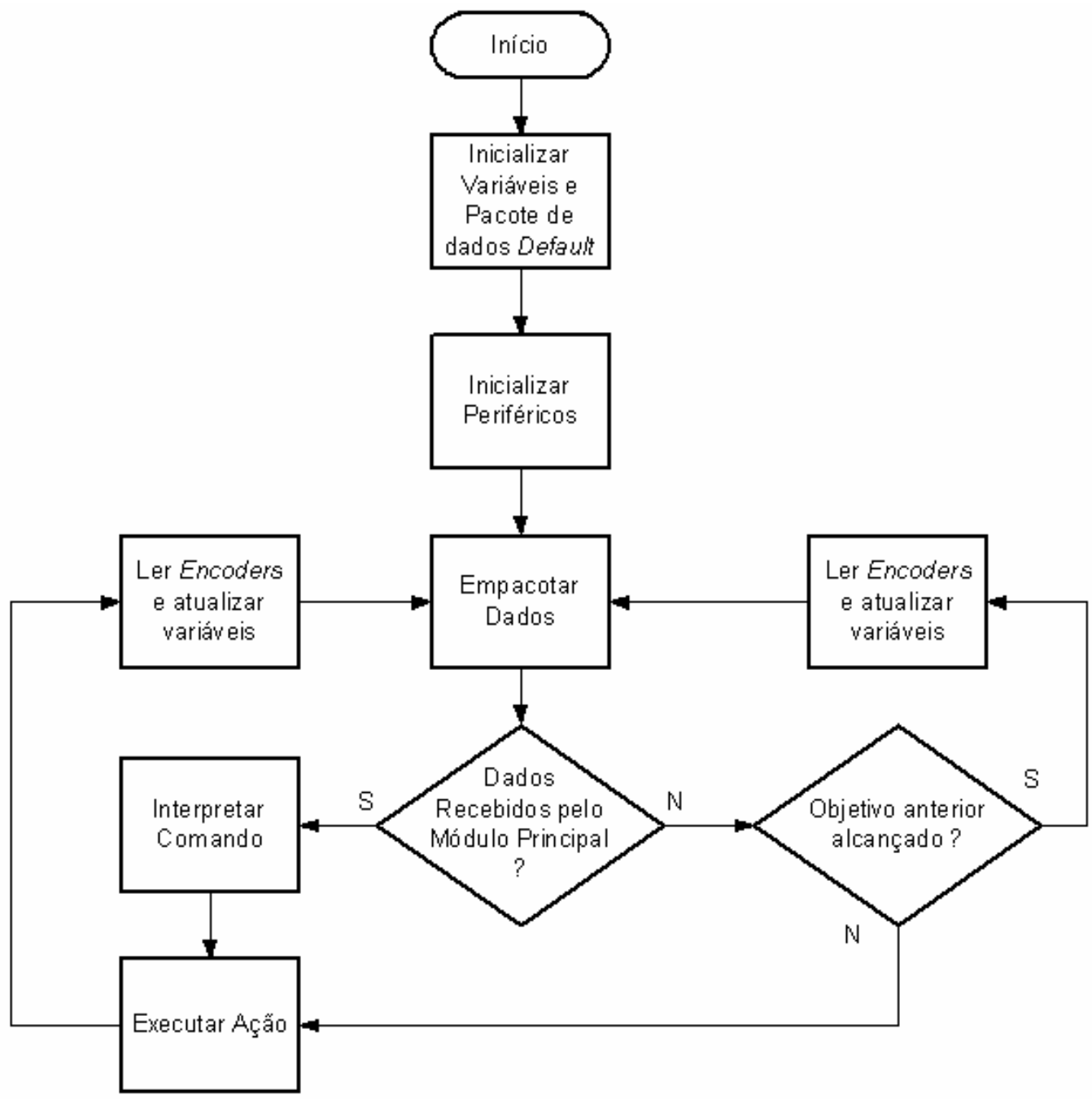

FIGURA 3.46 - Fluxograma de Sofware do Módulo Atuador

Os encoders são lidos através do módulo CCP do MCU. Com isso, a cada pulso recebido é gerada uma interrupção no software, e um contador é incrementado.

Como no Módulo de Sensores, durante a comunicação com o Módulo Atuador, os últimos dados válidos são enviados.

A implementação em Hardware desse módulo é apresentada na FIGURA 3.47 . 


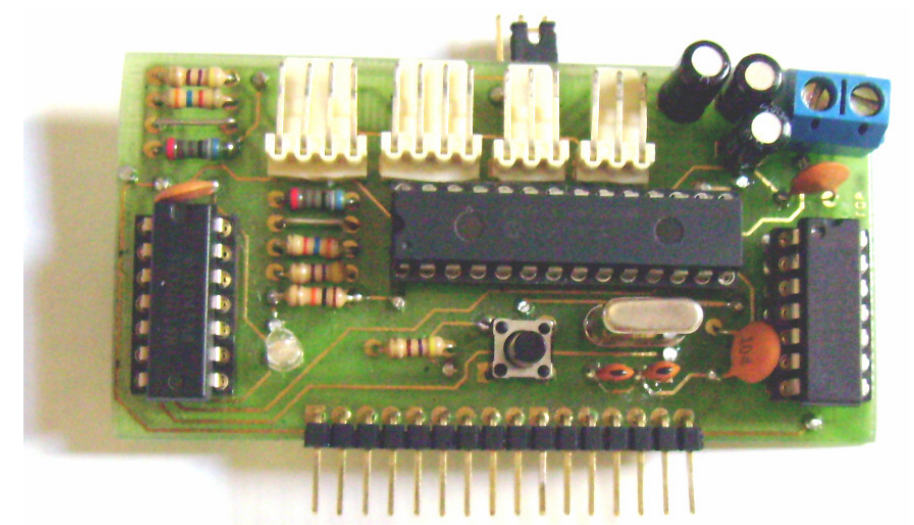

FIGURA 3.47 - Hardware do Módulo Atuador

O último módulo de Hardware da arquitetura é detalhado na próxima seção.

\subsection{Módulo de RF}

O Módulo de RF tem as mesmas funcionalidades do Módulo PC; porém, ao invés de receber dados do PC ele recebe do Módulo Principal através do barramento de dados. Além disso, é o módulo com menor complexidade de toda a arquitetura.

A FIGURA 3.48 apresenta o diagrama de blocos desse módulo.

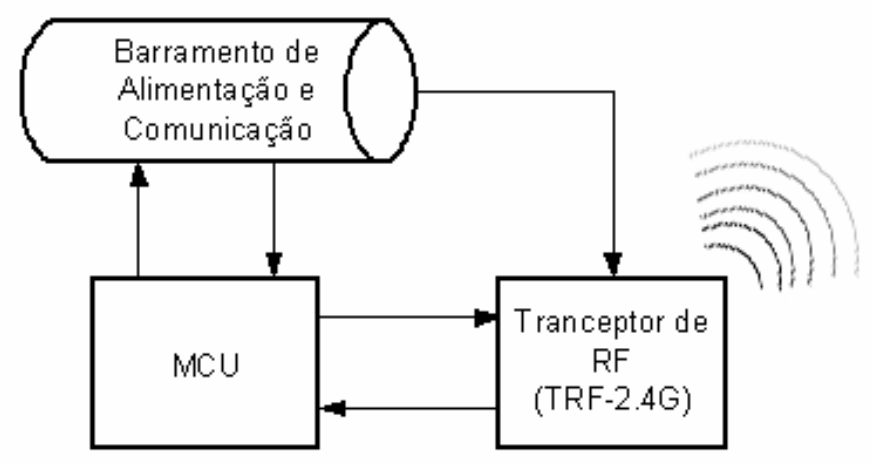

FIGURA 3.48 - Diagrama de Blocos do Módulo de RF

A funcionalidade desse módulo resume-se em enviar dados e receber comandos do Módulo PC. Os dados recebidos do Módulo Principal são enviados 
diretamente pelo transceptor que, logo em seguida, é configurado como receptor e aguarda algum comando vindo do Módulo PC.

Como nos demais módulos, se nenhuma mensagem for recebida do Módulo PC, então na transmissão para o Módulo Principal são enviados os valores Default ou o último pacote válido recebido.

O Módulo de RF é preparado para receber os dados de todos os módulos (3 pacotes distintos). Ao finalizar a transmissão esses dados são enviados consecutivamente para o Módulo PC, sendo que só o transceptor é configurado para trabalhar como receptor. Dessa forma, os dados podem ser recebidos por radiofreqüência.

O fluxograma da FIGURA 3.49 mostra o funcionamento do Módulo de RF.

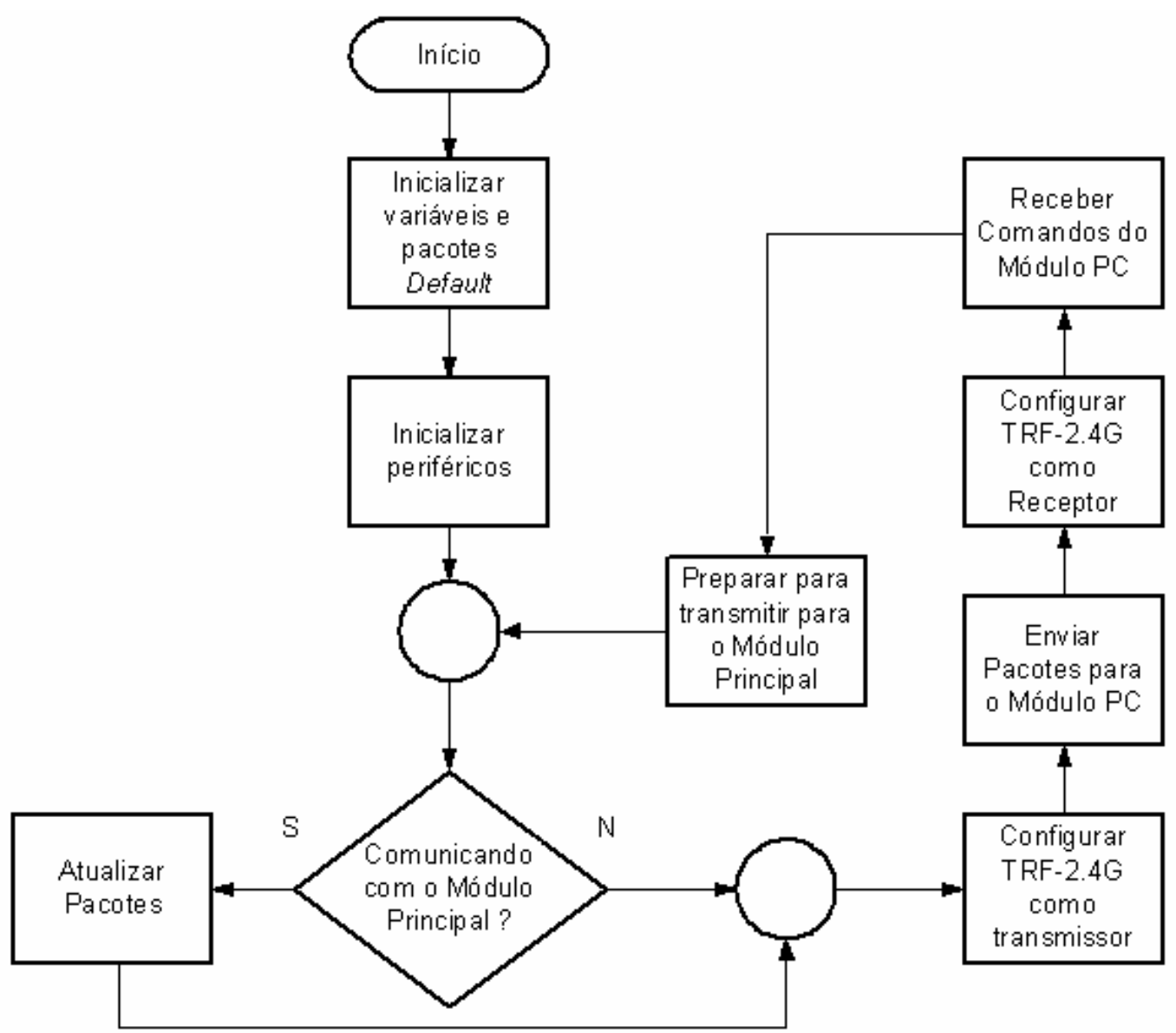

FIGURA 3.49 - Fluxograma do Módulo de RF 
A implementação em Hardware do Módulo de RF é apresentada na FIGURA 3.50 .

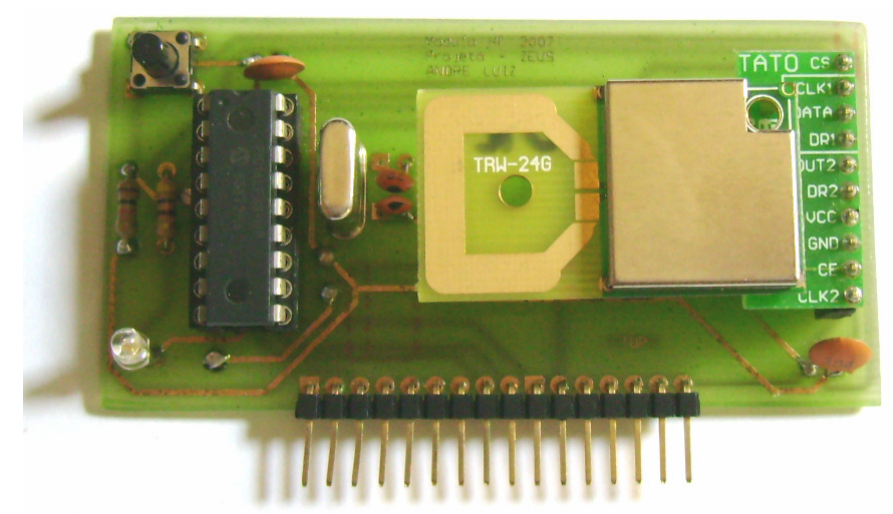

FIGURA 3.50 - Hardware do Módulo de RF

Após o detalhamento de todos os módulos envolvidos na arquitetura, a FIGURA 3.51 apresenta o Hardware resultante desse projeto.

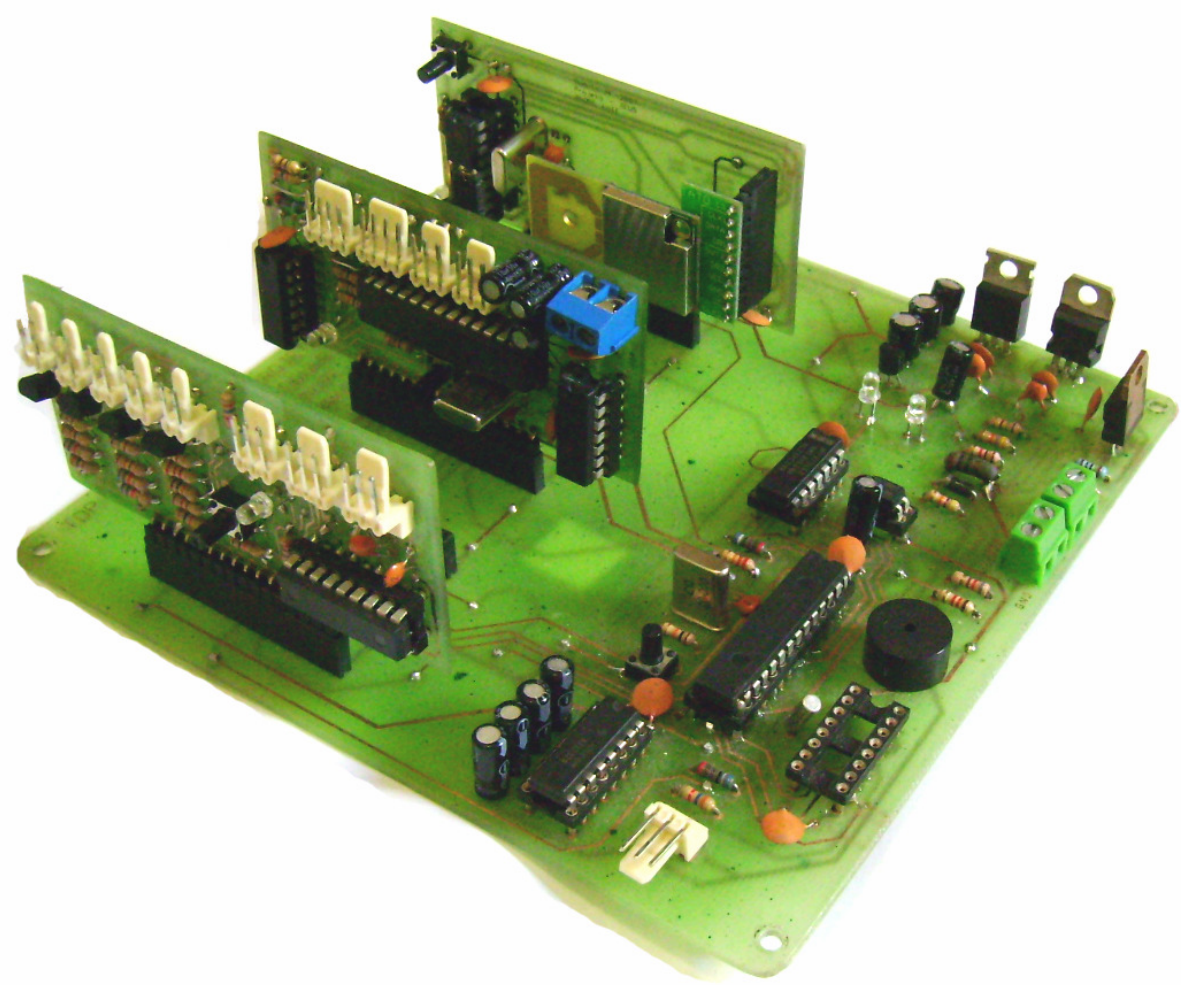

FIGURA 3.51 - Hardware completo da arquitetura desenvolvida 


\subsection{Base Móvel}

A base móvel desenvolvida para testes dessa arquitetura possui um sistema de transmissão diferencial com tração gerada por dois servomotores, e uma roda de giro livre para equilíbrio.

O posicionamento das rodas de tração e de giro livre é mostrado na FIGURA 3.52, onde $\mathrm{R} 1$ e $\mathrm{R} 2$ são as rodas tracionadas pelos motores, $\mathrm{R} 3$ é a roda de giro livre e C é o centro.

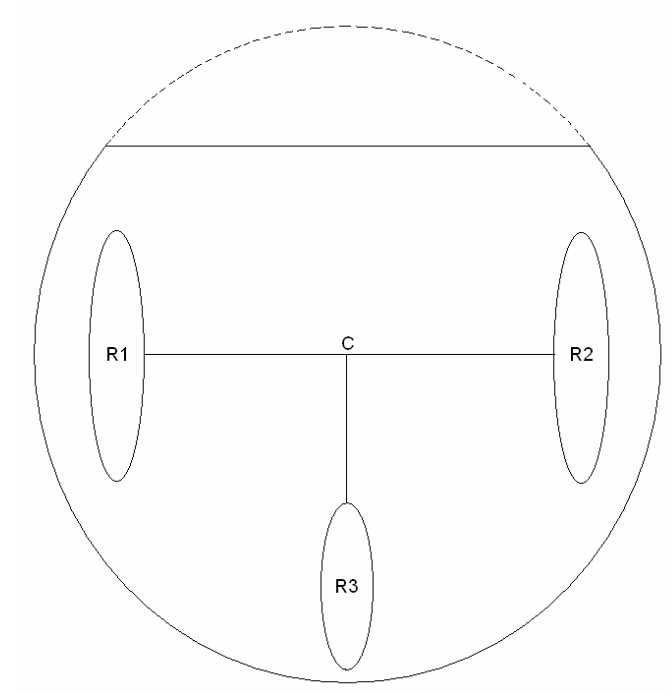

FIGURA 3.52 - Disposição das rodas na base móvel

A base de sustentação possui $25 \mathrm{~cm}$ de diâmetro, sendo $18 \mathrm{~cm}$ a distância entre o eixo das rodas motoras, ou ainda, $9 \mathrm{~cm}$ a distância do centro do robô a cada roda.

A base ainda possui um chanfro em sua parte frontal, visando o posicionamento dos sonares, sendo que este detalhe será apresentado mais adiante. 
A FIGURA 3.53 apresenta a base com as rodas e motores ainda em fase de projeto.

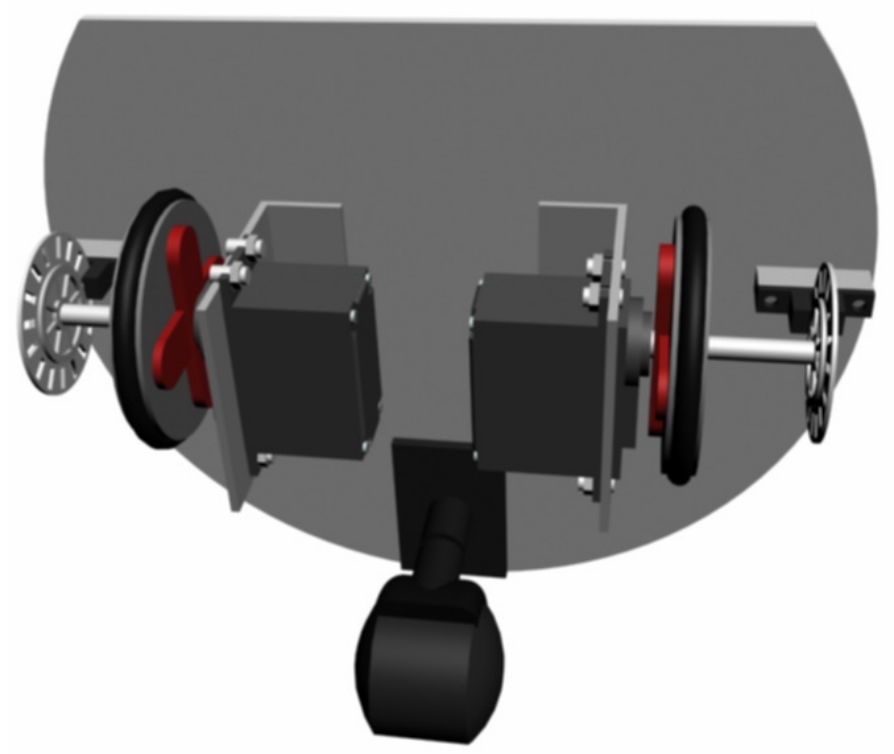

FIGURA 3.53 - Projeto da base móvel

Com essa disposição de rodas o robô pode executar diversos movimentos, sendo eles:

- Movimentação linear para frente e para trás;

- Rotação horária e anti-horária em torno do centro da base móvel;

- Rotação horária e anti-horária em torno do eixo de cada roda.

As rodas de tração em conjunto com a base foram feitas em alumínio visando diminuir o peso do robô.

A roda de tração com o disco encoder acoplado é apresentada na FIGURA 3.54(a) e a roda de giro livre na FIGURA 3.54(b). 


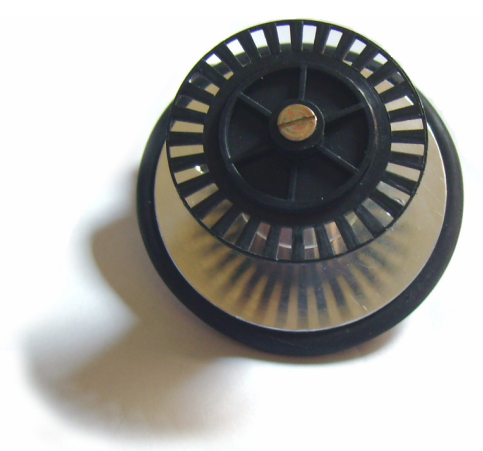

(a)

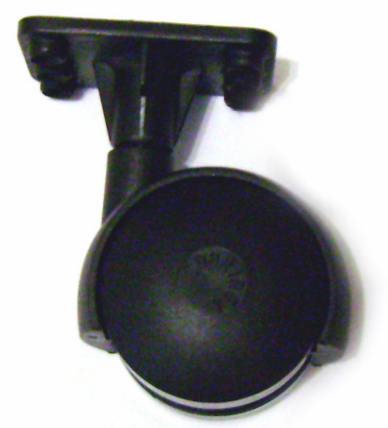

(b)

FIGURA 3.54 - Aspectos da base móvel:

a) Roda de tração do robô móvel com o disco do Encoder Acoplado

b) Roda de giro livre utilizada

As medidas dessas rodas são as seguintes:

- Roda de tração com o pneu: $5.5 \mathrm{~cm}$ de diâmetro;

- Roda de giro livre: $3.7 \mathrm{~cm}$ de diâmetro.

O disco janelado é fixado à roda por meio de uma extensão perpendicular de menor diâmetro.

A altura do robô móvel é definida pelo comprimento da roda de giro livre. A FIGURA 3.55 apresenta essas medidas.

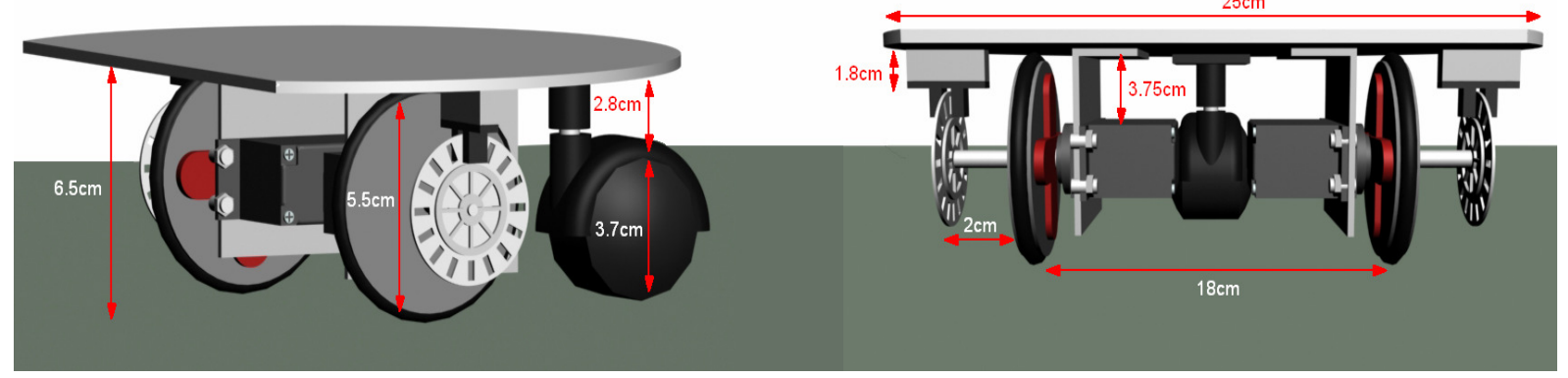

FIGURA 3.55 - Principais medidas da base móvel 
Os sensores são fixados na parte chanfrada da base móvel através de um suporte cujas dimensões são apresentadas na FIGURA 3.56.

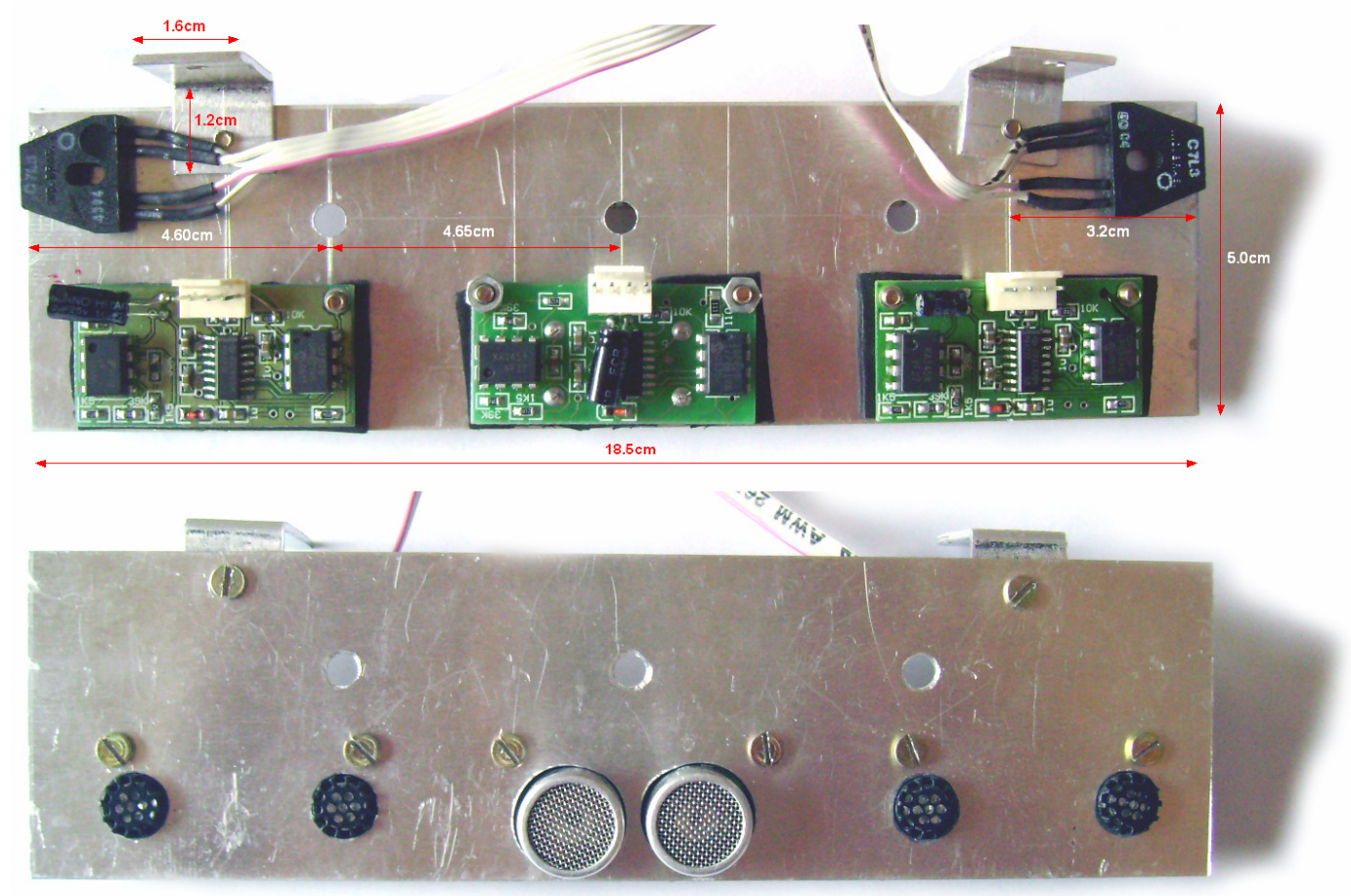

FIGURA 3.56 - Suporte de fixação dos sensores

O peso total do robô móvel com todos os componentes conectados é de $1,325 \mathrm{~kg}$, o que é aceitável considerando o torque fornecido pelos motores e com a bateria selada de chumbo-ácido utilizada, possuindo uma autonomia de 40 minutos em média.

Concluindo esse capítulo, a FIGURA 3.57 apresenta o robô móvel, denominado ZEUS, sendo totalmente desenvolvido a partir da arquitetura proposta nesse trabalho. 


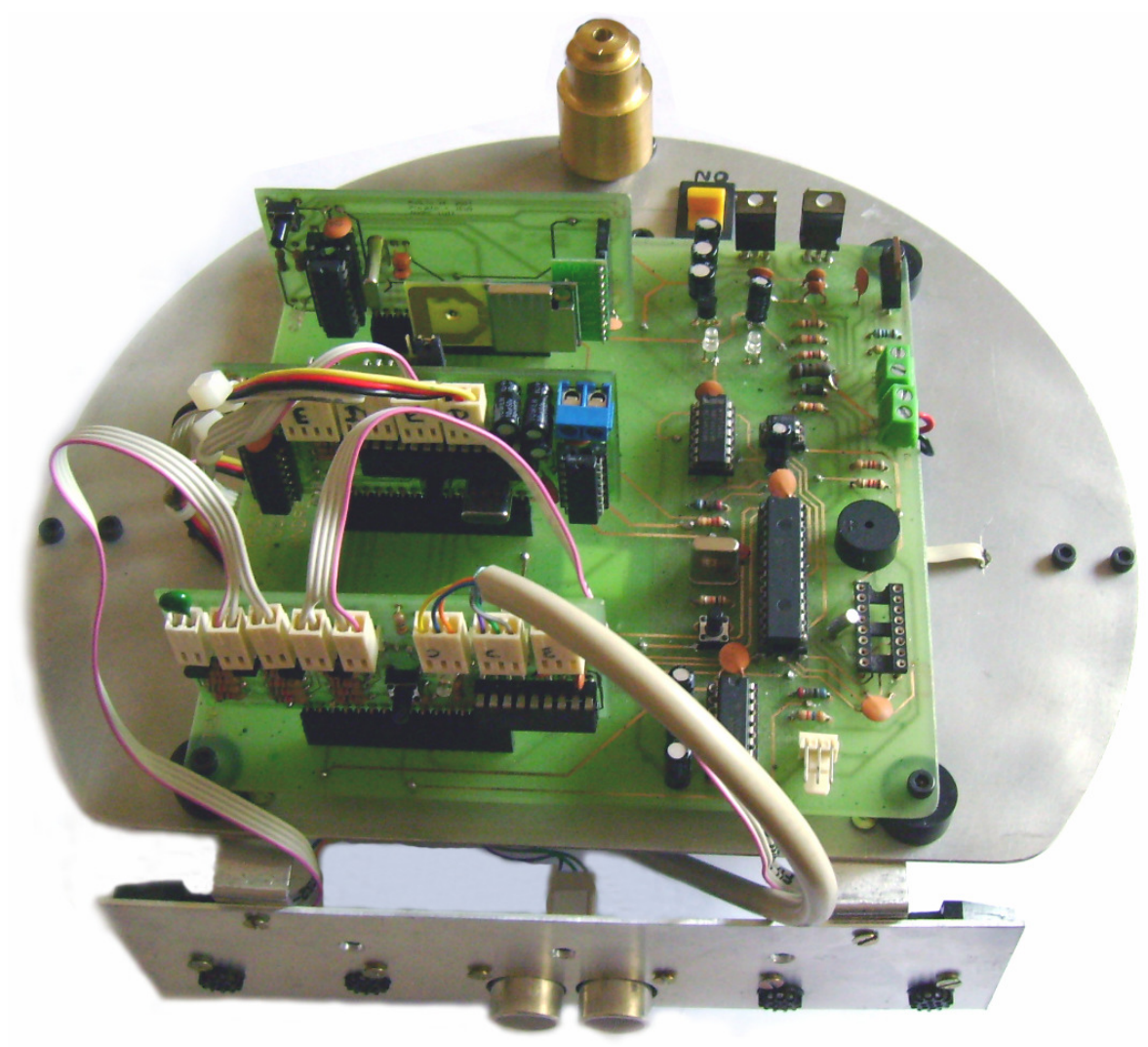

FIGURA 3.57 - Robô Móvel ZEUS

A seguir, no Capítulo 4, serão apresentadas algumas aplicações para testes do robô móvel ZEUS. 


\section{Resultados dos Ensaios Experimentais}

\subsection{Introdução}

Nesse capítulo são analisadas algumas funcionalidades do robô móvel ZEUS, desenvolvido a partir da arquitetura proposta neste trabalho.

Na Seção 4.2 é apresentado o software desenvolvido para análise, controle e aquisição de dados do robô, referentes à navegação e ao ambiente em que se encontra.

Na Seção 4.3 são mostrados ensaios realizados em um ambiente indoor, onde algoritmos de odometria e detecção de obstáculos foram implementados para - Módulo Atuador e Controle Remoto por meio do software de visualização e controle, respectivamente.

Na Seção 4.4 é discutida a avaliação de custo para desenvolvimento de robôs móveis utilizando a arquitetura apresentada.

\subsection{Software de Visualização e Controle}

Para integração homem-máquina, desenvolveu-se um software para visualização e controle remoto do robô móvel. O software escrito em linguagem C++ possui uma interface gráfica construída utilizando a plataforma de desenvolvimento Borland® $\mathrm{C}_{+}+$Builder ${ }^{\mathrm{TM}}$, apresentada pela FIGURA 4.1. 


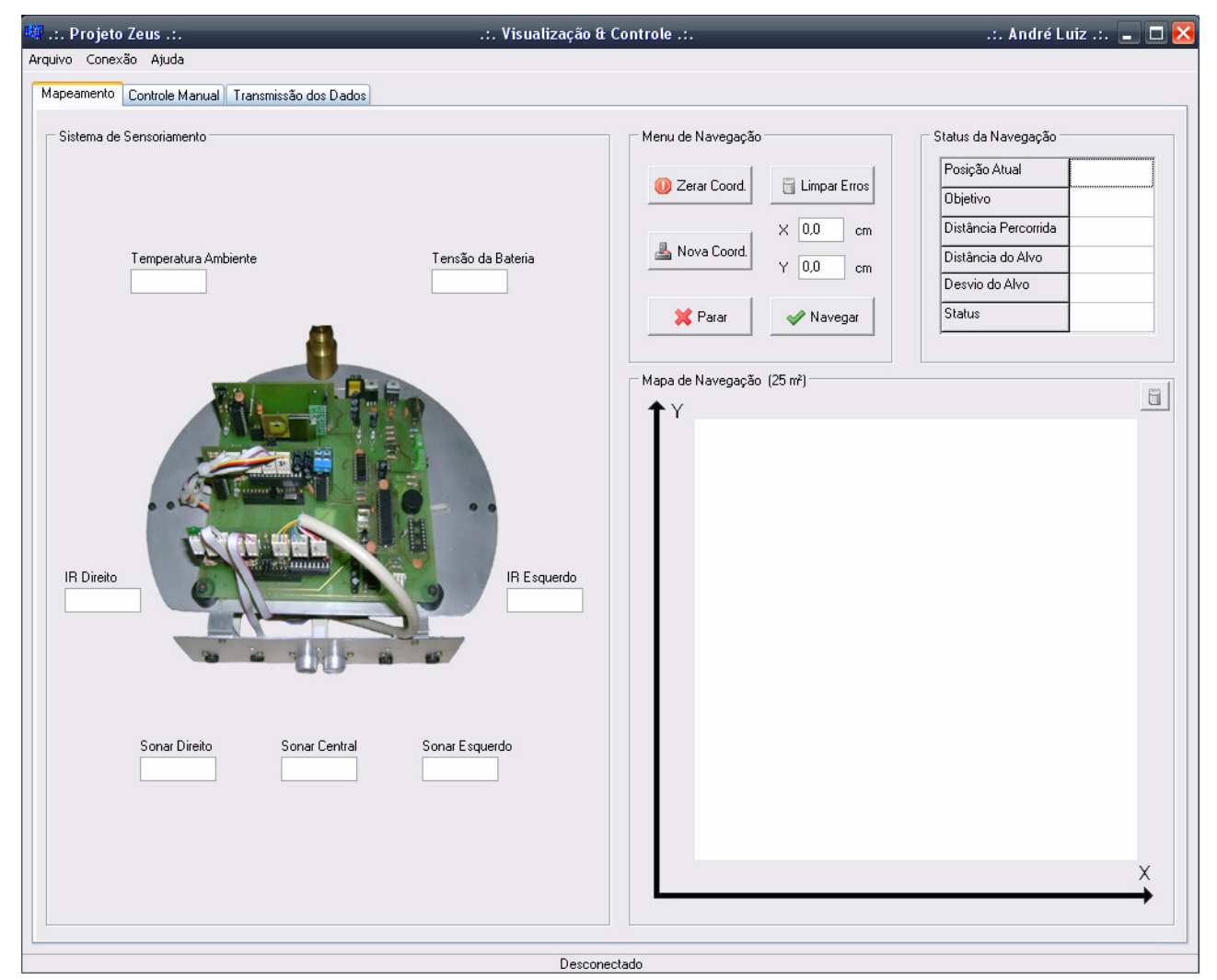

FIGURA 4.1 - Tela principal da interface gráfica do software de visualização e controle

A interface gráfica foi desenvolvida com a finalidade de se obter todos os dados referentes à navegação e estado do robô móvel. Cada caixa de texto presente na FIGURA 4.1 indica o valor de seus sensores, como por exemplo, nível de bateria e temperatura ambiente. Os dados de navegação são observados através da tabela no canto superior direito e de um mapa no qual é traçada a rota percorrida pelo robô até o momento da aquisição dos dados.

O software realiza a comunicação com a porta serial do computador por meio de um objeto em $\mathrm{C}++$ compatível com a plataforma utilizada, denominado de TCommThread, cujo código é disponibilizado no APÊNDICE A.

Os parâmetros de configuração da porta serial podem ser ajustados por intermédio da interface mostrada na FIGURA 4.2 e FIGURA 4.3. 


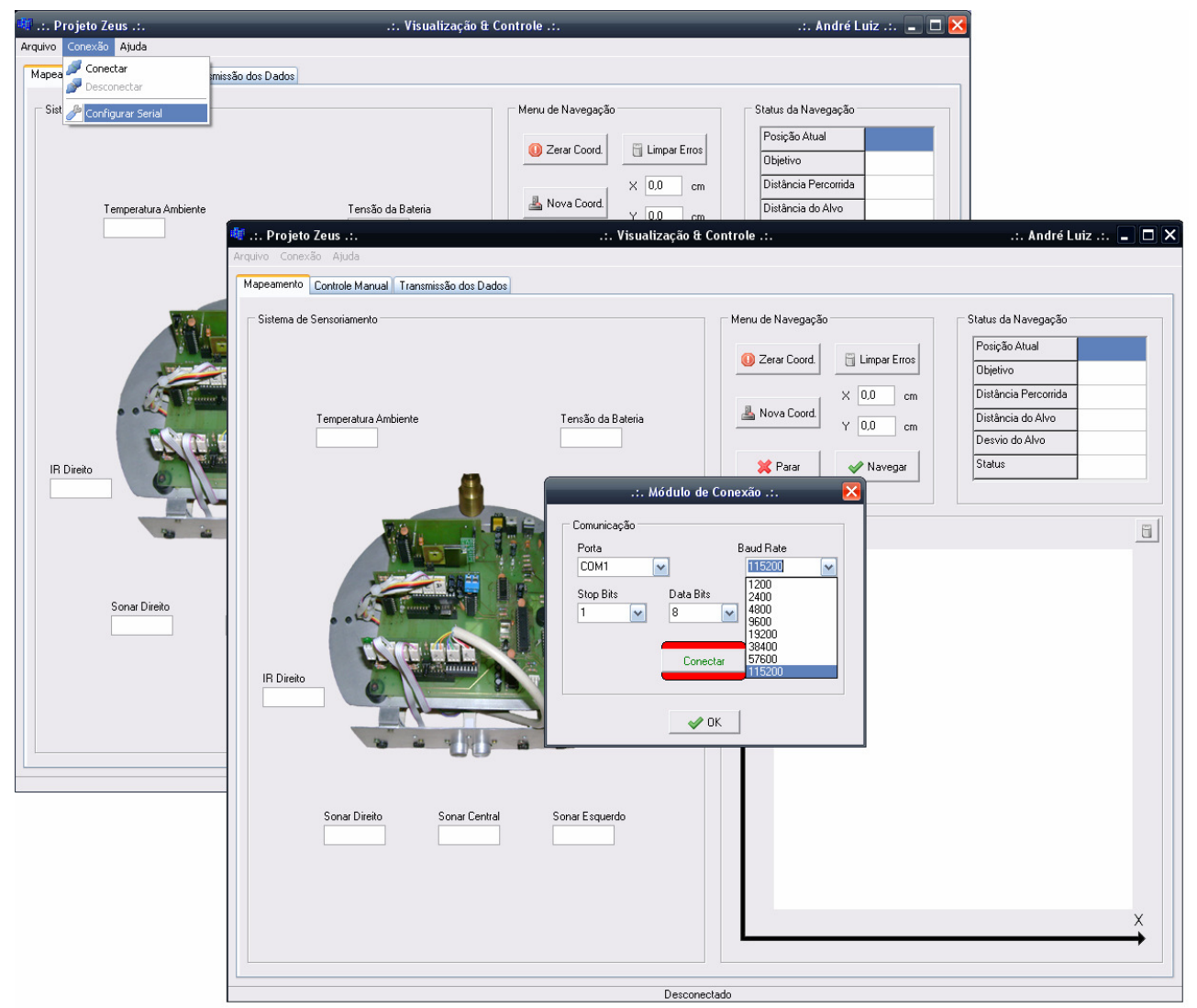

FIGURA 4.2 - Configuração da comunicação serial

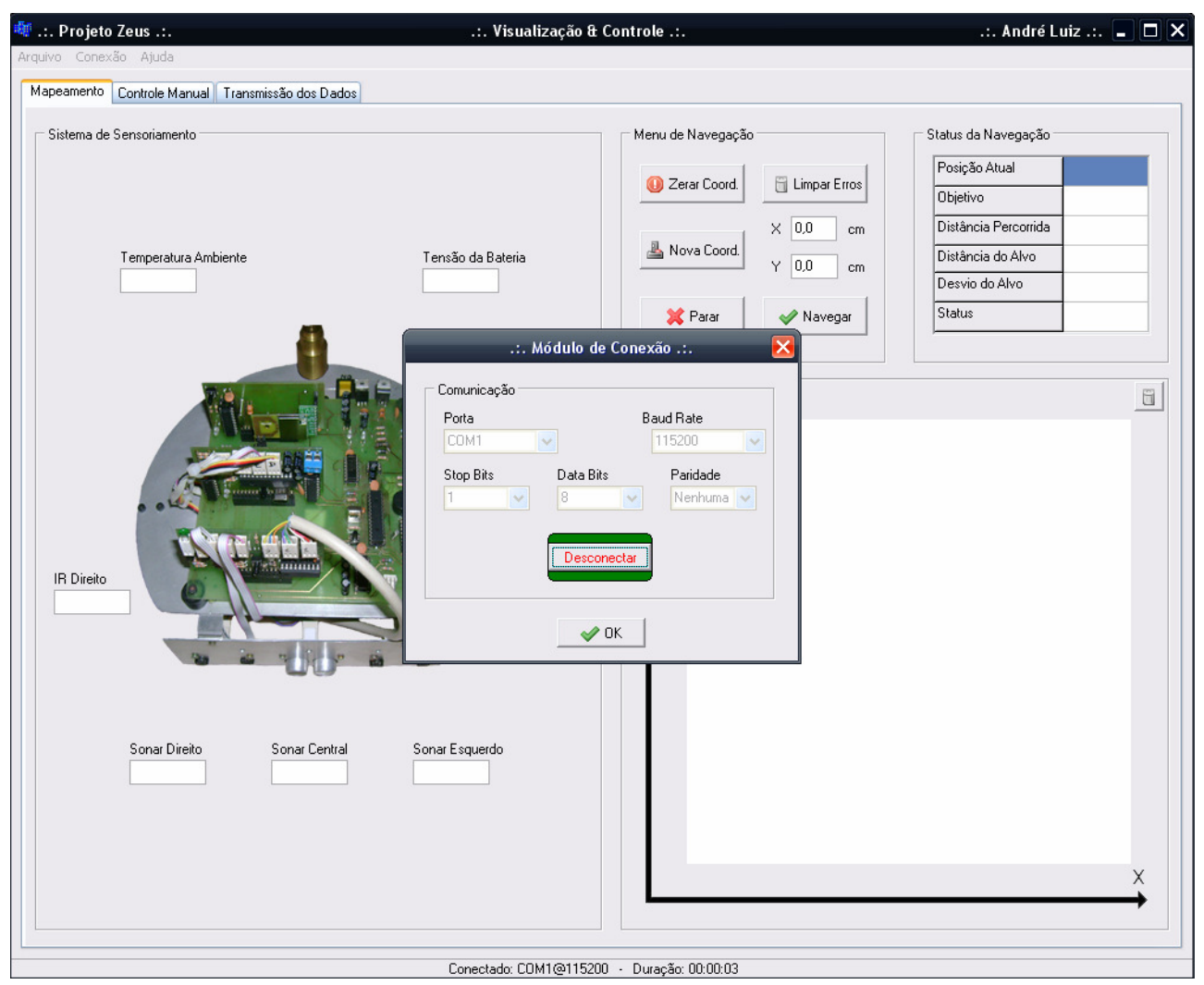

FIGURA 4.3 - Conexão estabelecida com a porta serial 
O software de visualização permite também o monitoramento de todos os dados de comunicação entre o PC e o Módulo PC, mostrando os pacotes formatados conforme o protocolo apresentado no Capítulo 3 deste trabalho (Subseção 3.3.4).

A interface gráfica disponível para esse monitoramento é mostrada na FIGURA 4.4.

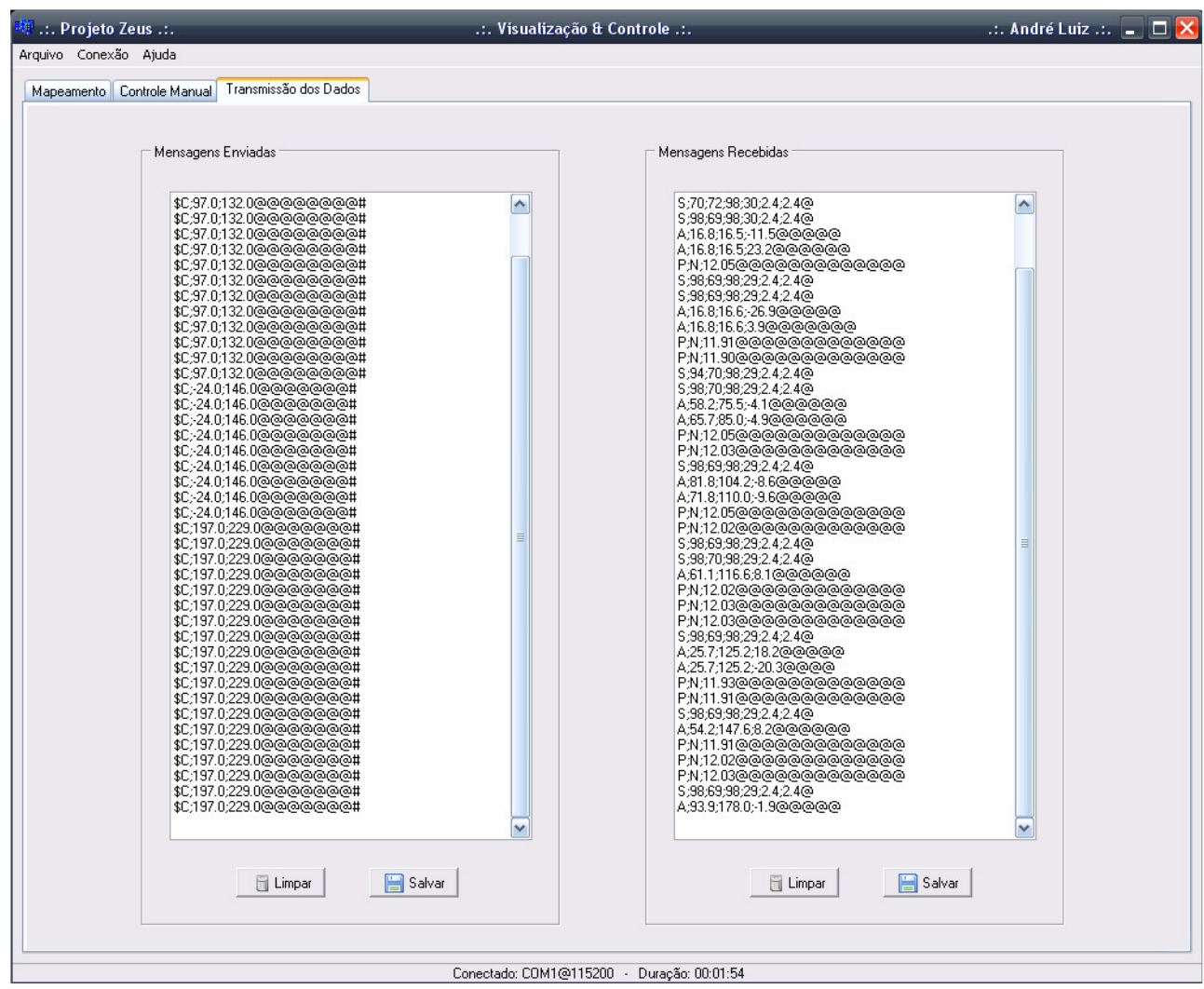

FIGURA 4.4 - Tela de monitoramento dos pacotes de dados durante uma transmissão

A seguir, na Seção 4.3, são analisados dados resultantes de uma aplicação visando o mapeamento de ambientes, cuja rota de navegação é corrigida automaticamente por meio de um algoritmo de odometria implementado no Módulo Atuador. 


\subsection{Mapeamento de Ambiente}

Para essa aplicação um ambiente indoor para simulação foi construído de acordo com as dimensões apresentadas pela FIGURA 4.5, onde a área total do ambiente é de $25 \mathrm{~m}^{2}$.

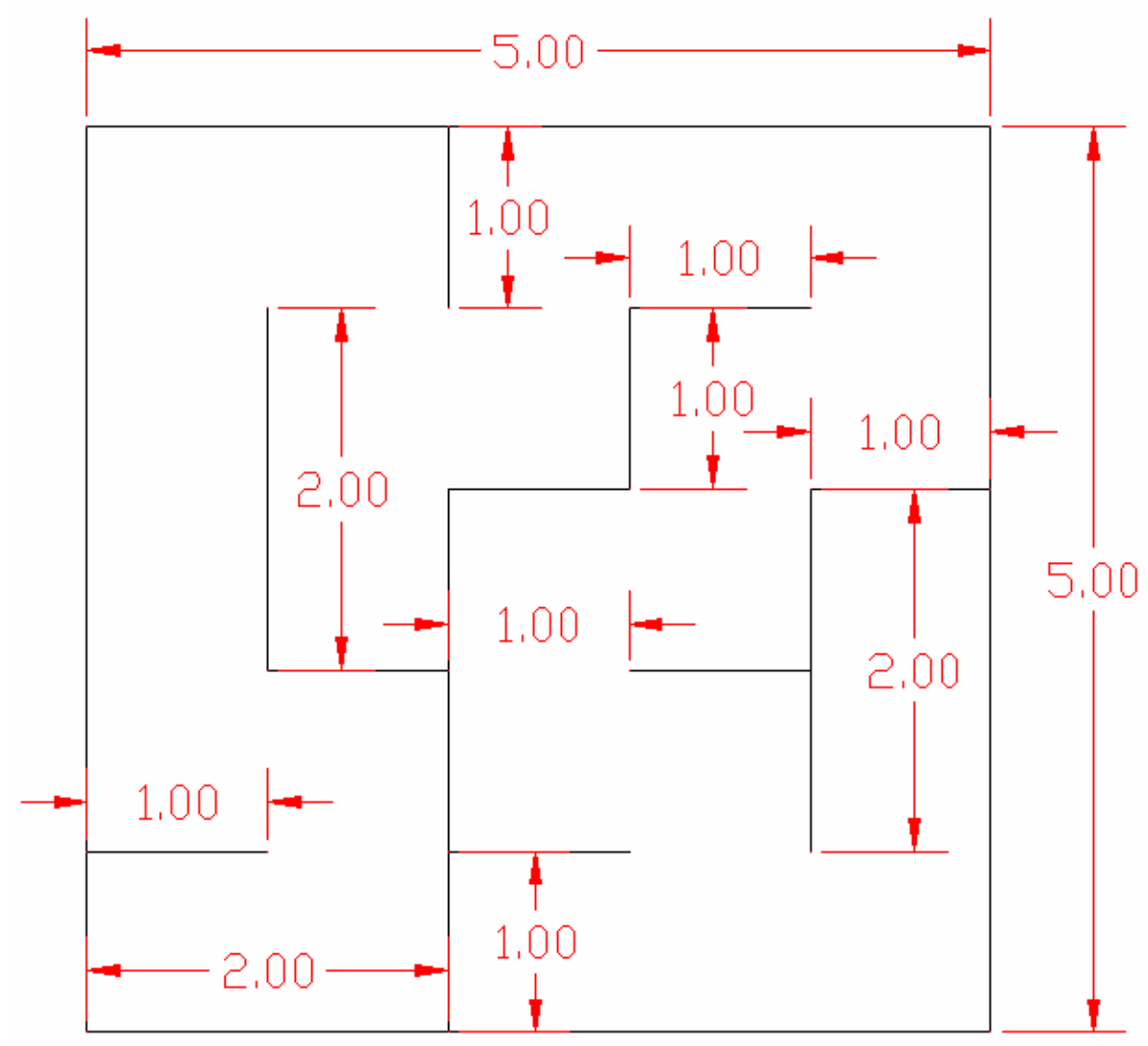

FIGURA 4.5 - Dimensões do ambiente de simulação

O objetivo desta aplicação consiste em determinar pontos de destino no mapa e monitorar a aproximação de obstáculos, utilizando o software de Visualização e Controle.

As FIGURAS 4.6 e 4.7 mostram o ambiente de simulação construído. 


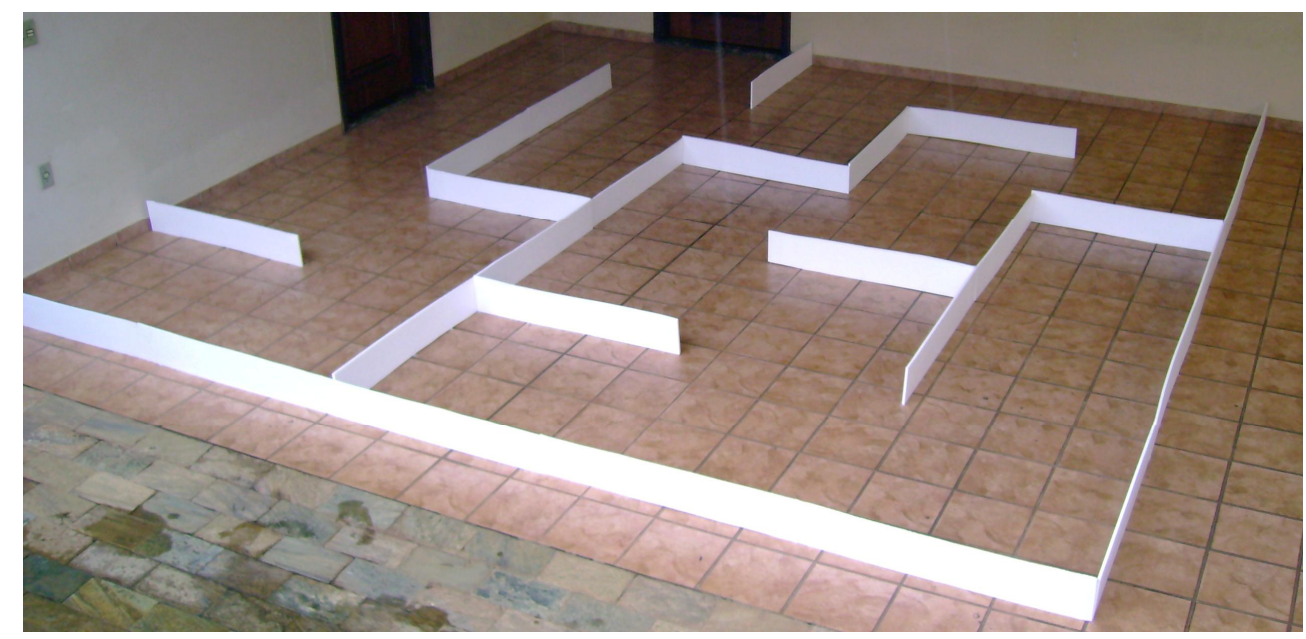

FIGURA 4.6 - Ambiente de simulação em perspectiva (1)

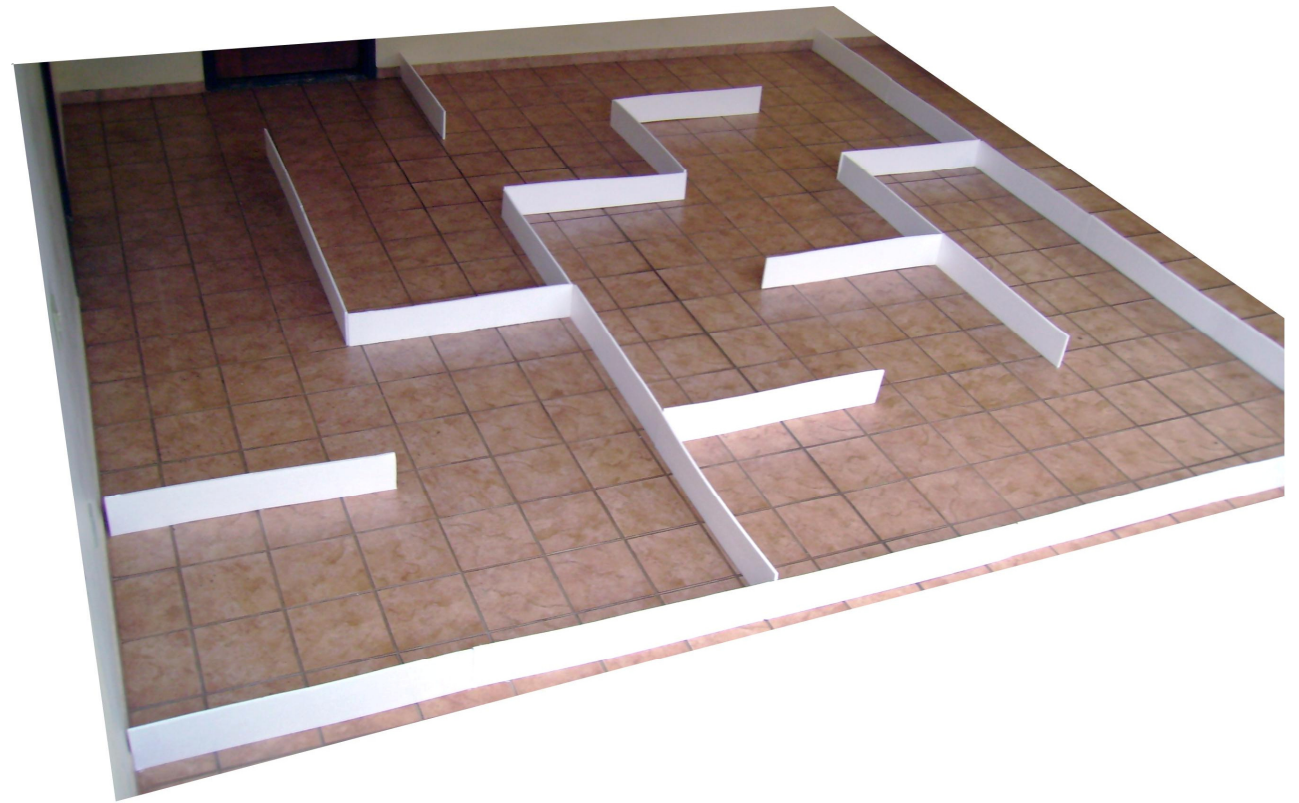

FIGURA 4.7 - Ambiente de simulação em perspectiva (2)

O método de navegação foi desenvolvido com base no sistema de odometria abordado por [44]. O algoritmo implementado no Módulo Atuador é preparado para receber os seguintes comandos:

- 'Z' $\rightarrow$ Zerar Coordenadas

- 'E' $\rightarrow$ Limpar Erros acumulados

- 'C' $\rightarrow$ Nova Coordenada 
Quando uma nova coordenada é passada para o módulo o código executa um algoritmo de cálculo da distância entre o robô e o alvo, o desvio em relação ao alvo, rotações realizadas em seu próprio eixo, além das posições $\mathrm{X}$ e $\mathrm{Y}$ no plano cartesiano do mapa. Com isso, pode-se dizer que o robô é um vetor, cuja direção sempre está voltada para o alvo.

O código responsável pela odometria é apresentado abaixo:

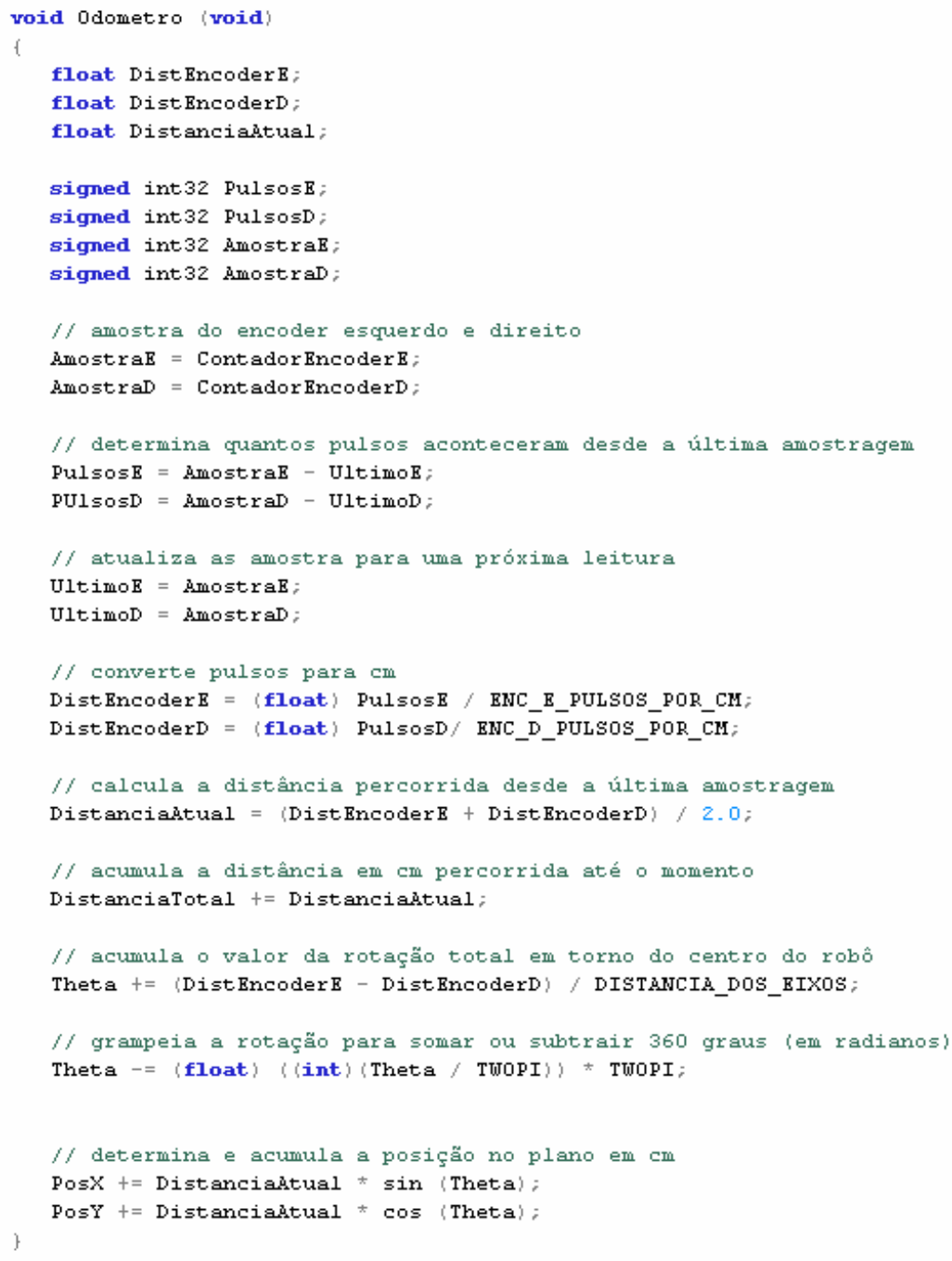


Os dados advindos dos cálculos realizados por esse algoritmo são utilizados para determinar a posição e desvio do alvo em relação ao robô.

O código responsável por essa função é apresentado a seguir:

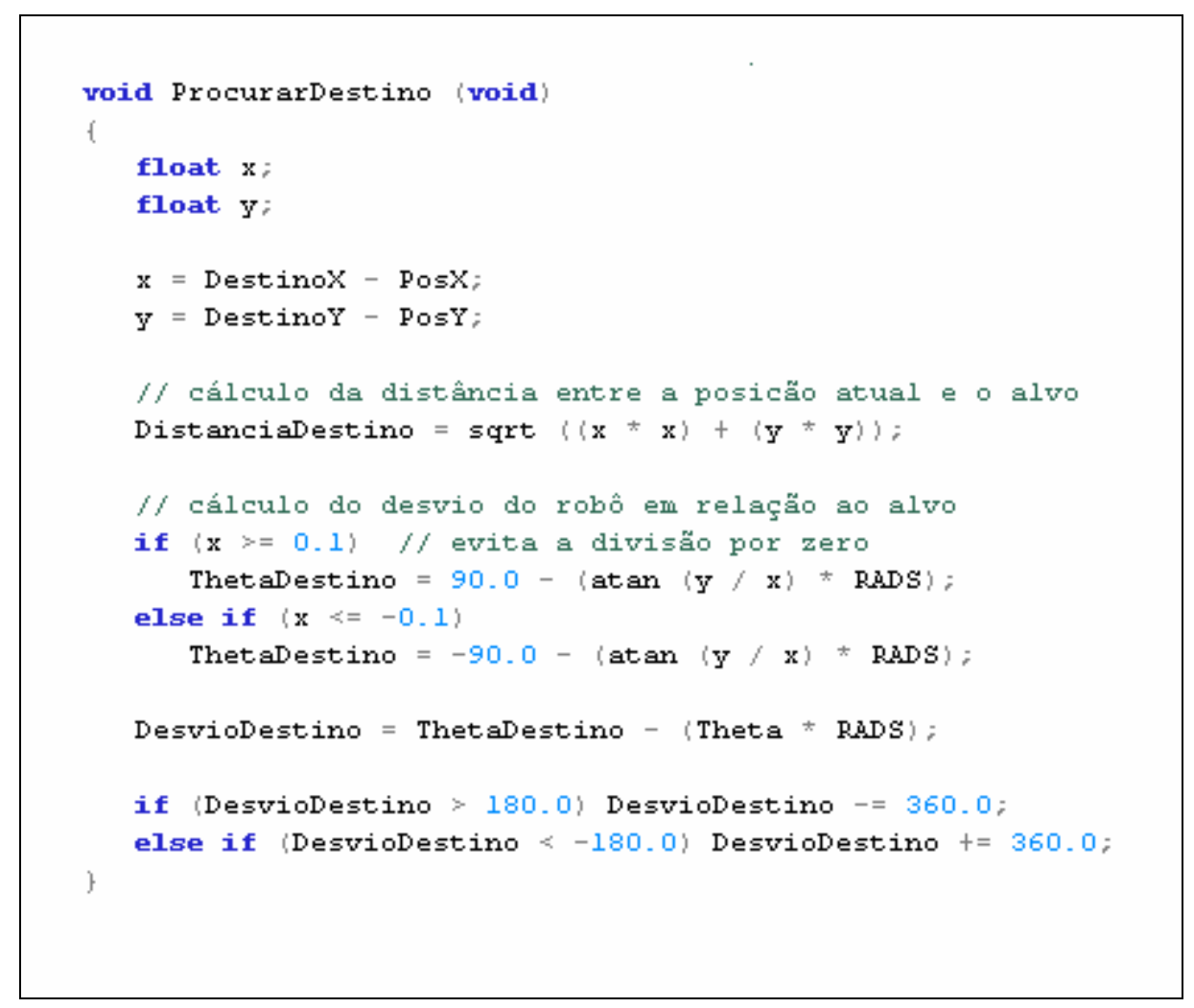

A partir destes dados é possível realizar a correção da trajetória atual em tempo real, fazendo com que o robô vire para um lado ou para outro dependendo do desvio em relação ao destino. Todas as unidades de medidas são em centímetros e o desvio em graus.

Além disso, a velocidade de movimentação do robô é controlada de acordo com a distância do alvo, sendo esse controle realizado a partir das seguintes possibilidades:

a) Distâncias maiores que $20 \mathrm{~cm}$ do alvo $\rightarrow$ Velocidade máxima de movimentação;

b) Distâncias entre 11 e $20 \mathrm{~cm} \rightarrow$ Velocidade média de movimentação;

c) Distâncias entre 3 e $10 \rightarrow$ Velocidade mínima de movimentação; 
d) Distâncias menores que $3 \mathrm{~cm} \rightarrow$ Parar robô (destino alcançado).

O controle de velocidade e correção da trajetória é realizado por intermédio do seguinte código:

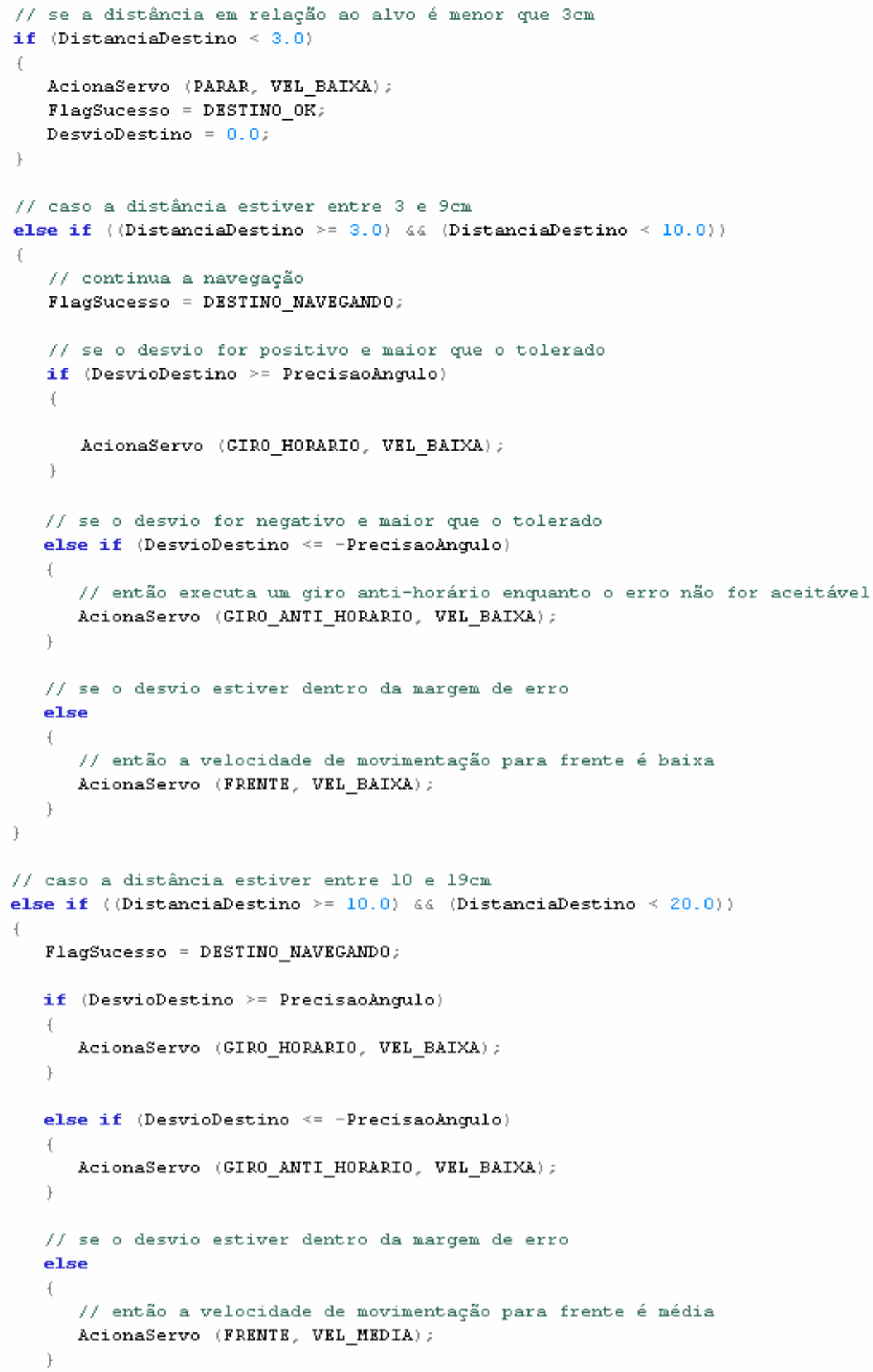




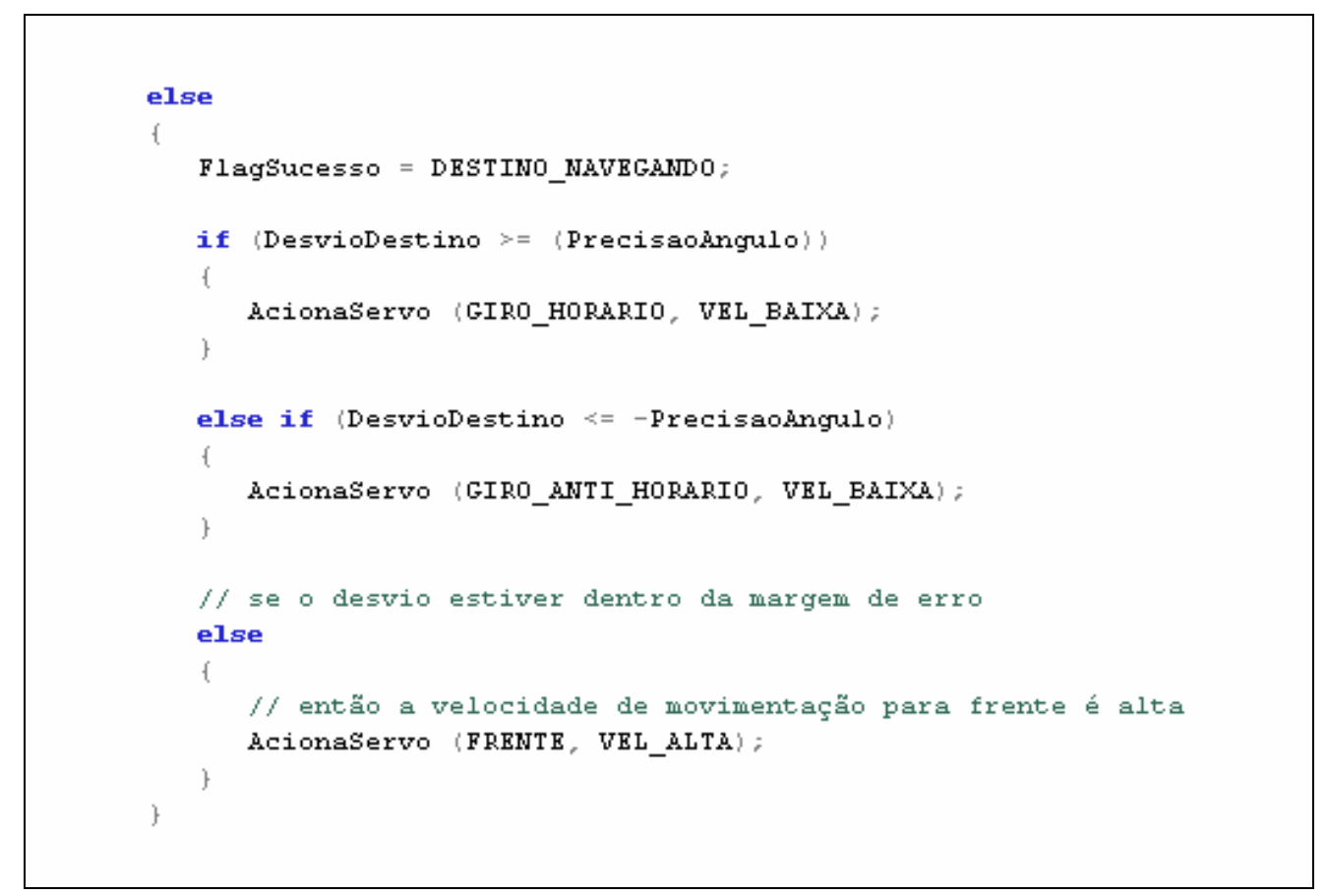

Em conjunto com este algoritmo, o Software de Visualização e Controle monitora e executa todas as funções desejadas.

A origem (ponto de partida) do robô é ajustada no mapa de acordo com a necessidade. Ao selecionar alguma posição deste mapa indicado pelo software, uma circunferência azul marca uma possível coordenada, sendo ela tanto para destino ou para nova origem. A coordenada desta posição não é enviada para o robô.

Quando a opção "Zerar Coord” é utilizada, a marcação azul torna-se verde, indicando que aquele ponto passou a ser a origem e todo comando executado pelo robô é realizado a partir desta coordenada.

Se a origem já foi ajustada, ao selecionar outro ponto do mapa por meio da opção "Nova Coord", a marcação azul é então substituída por vermelha e a coordenada referente a esse ponto de destino é ajustada.

Com este procedimento o robô inicia então uma navegação partindo da marca verde (origem) até a marca vermelha (destino), fazendo correções na trajetória conforme seja necessário. 
A seqüência das cinco figuras seguintes apresenta a navegação no mapa do ambiente de simulação construído.
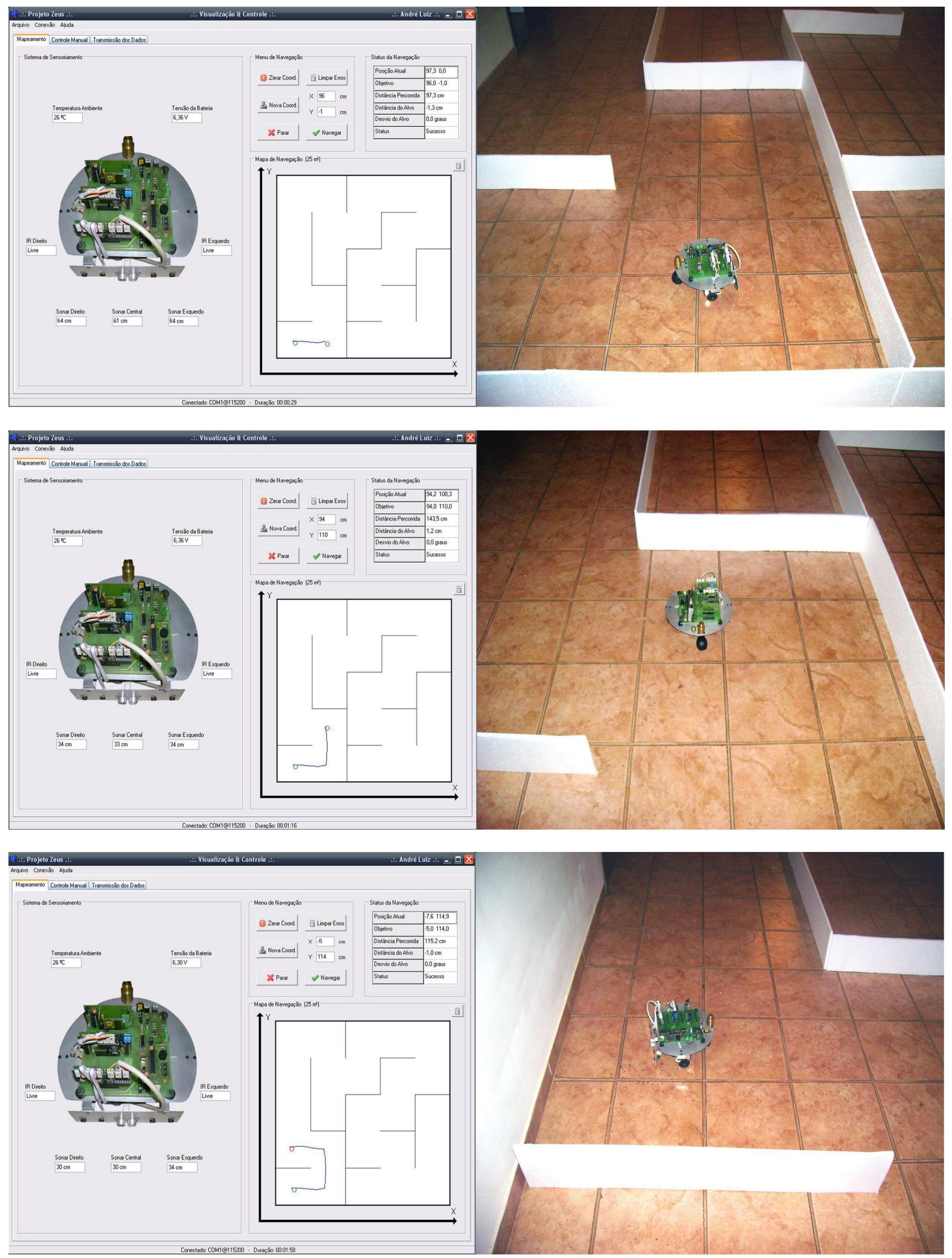

FIGURA 4.8 - Seqüência de Navegação (1) 

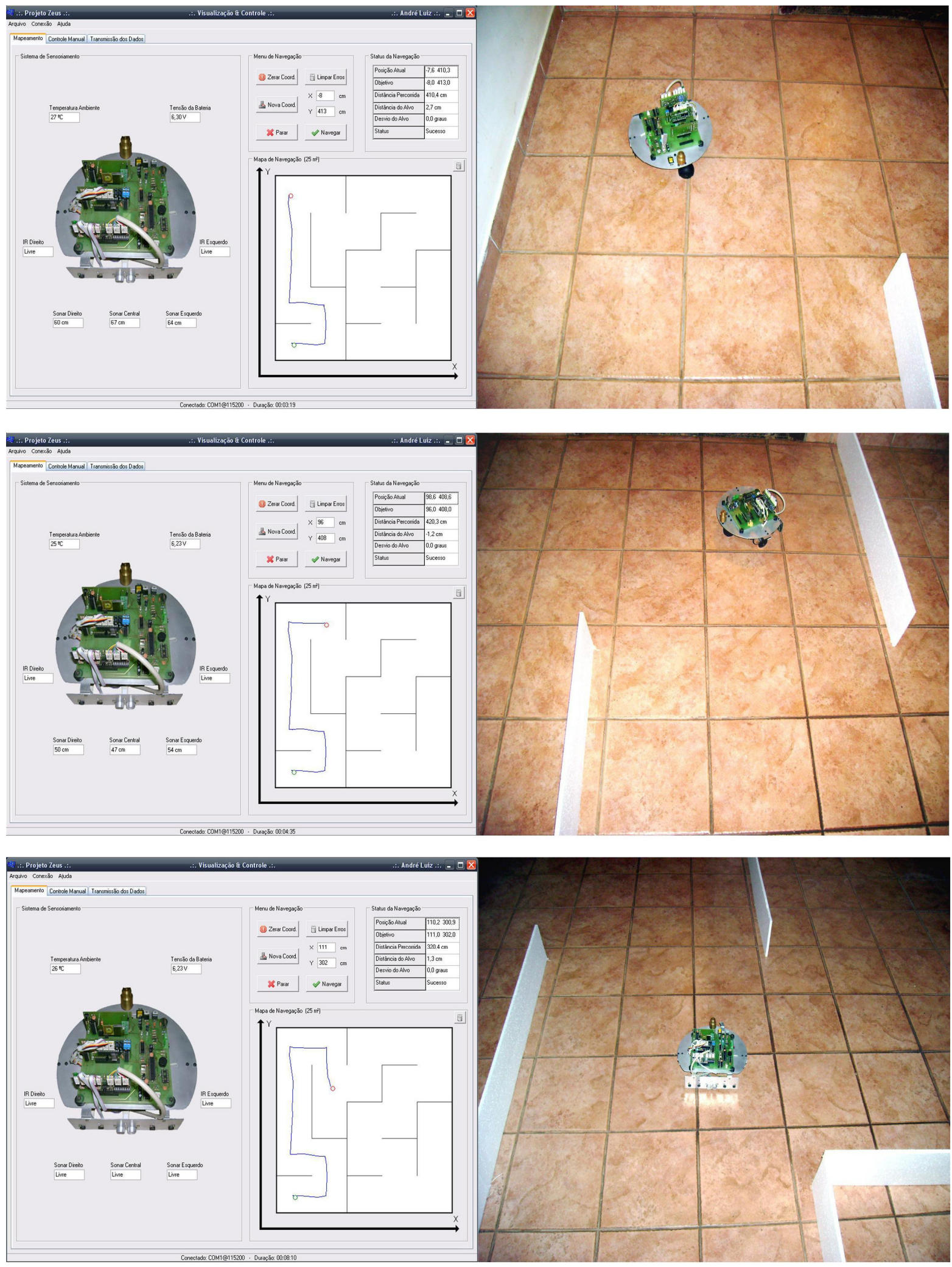

FIGURA 4.9 - Seqüência de Navegação (2) 

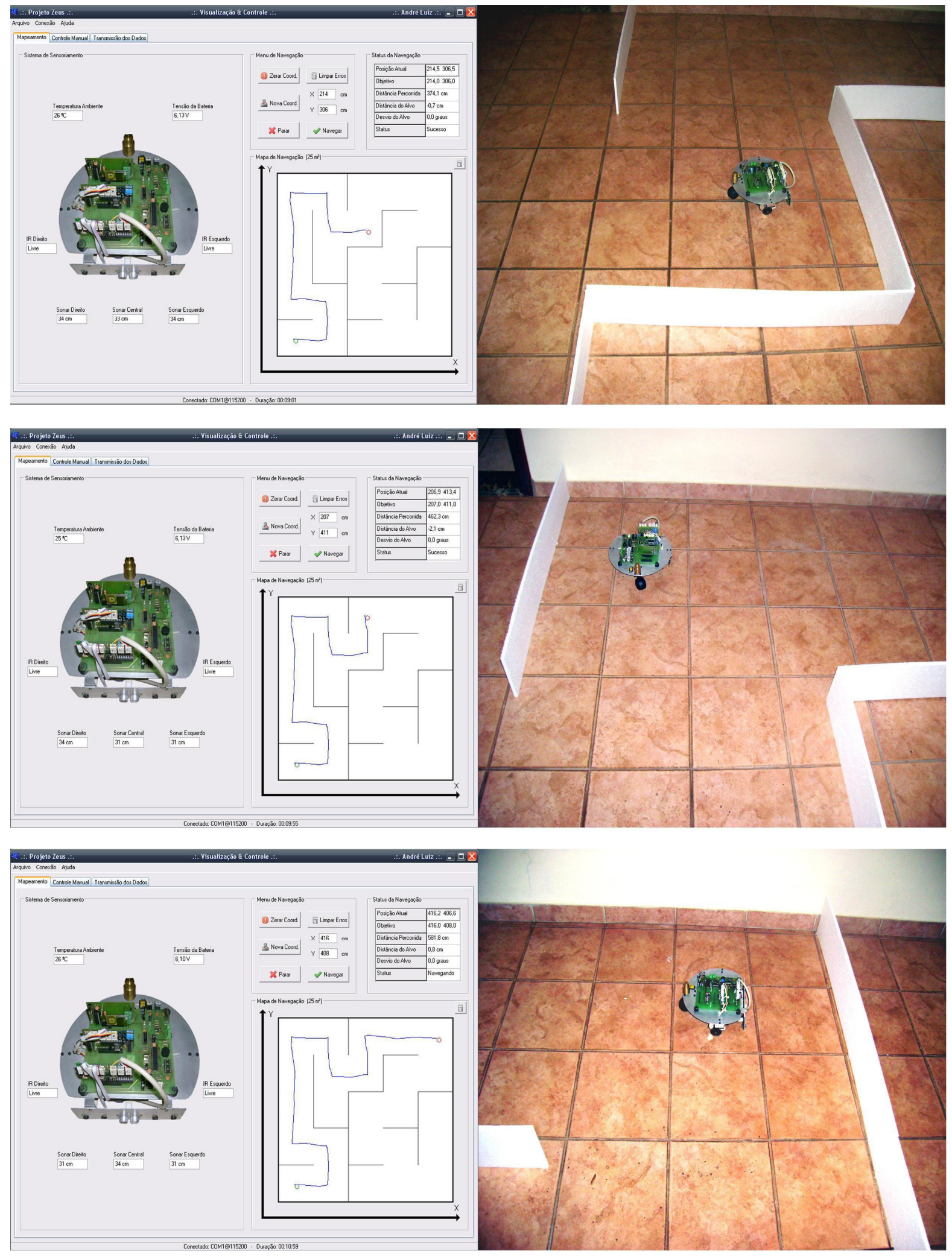

FIGURA 4.10 - Seqüência de Navegação (3) 

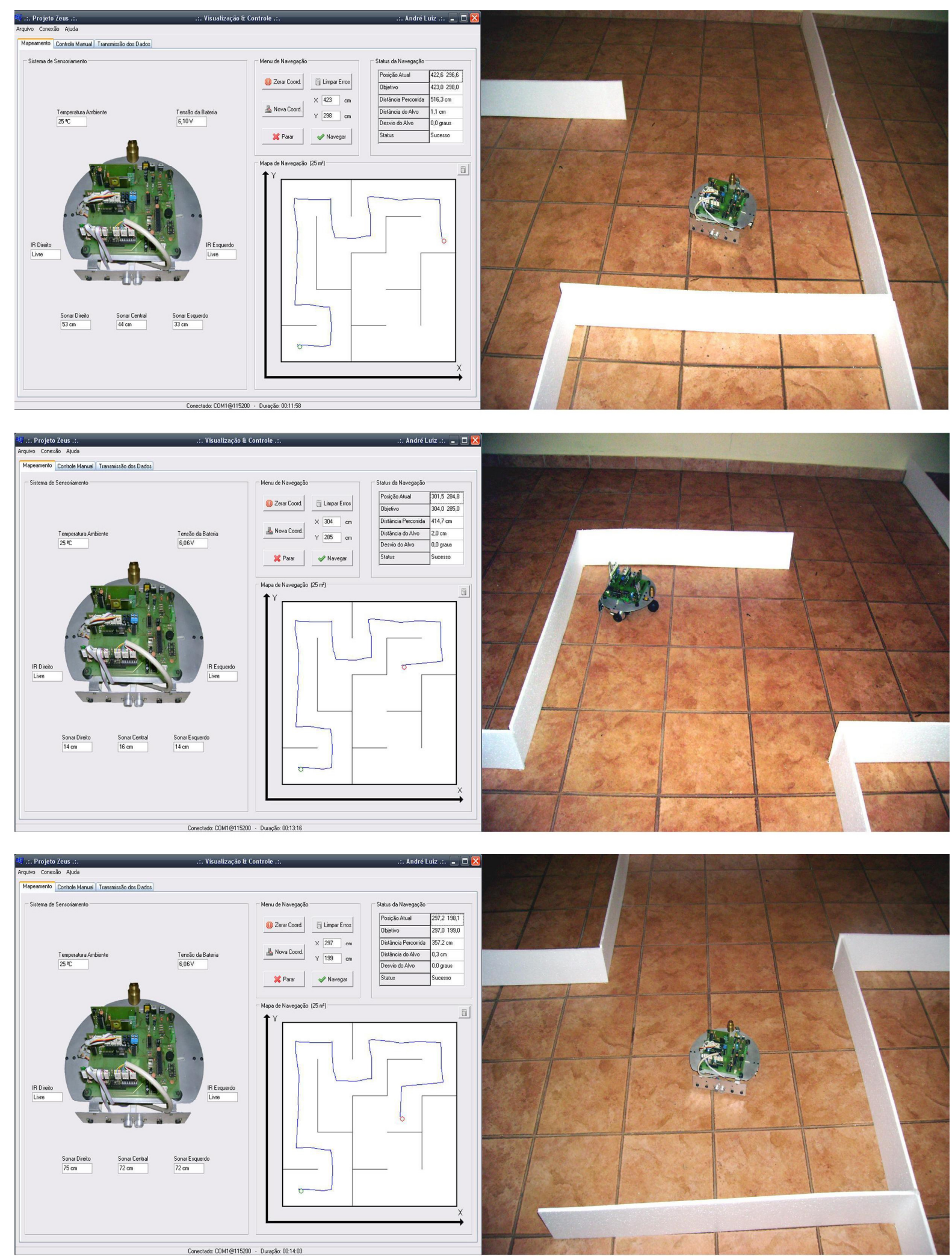

FIGURA 4.11 - Seqüência de Navegação (4) 

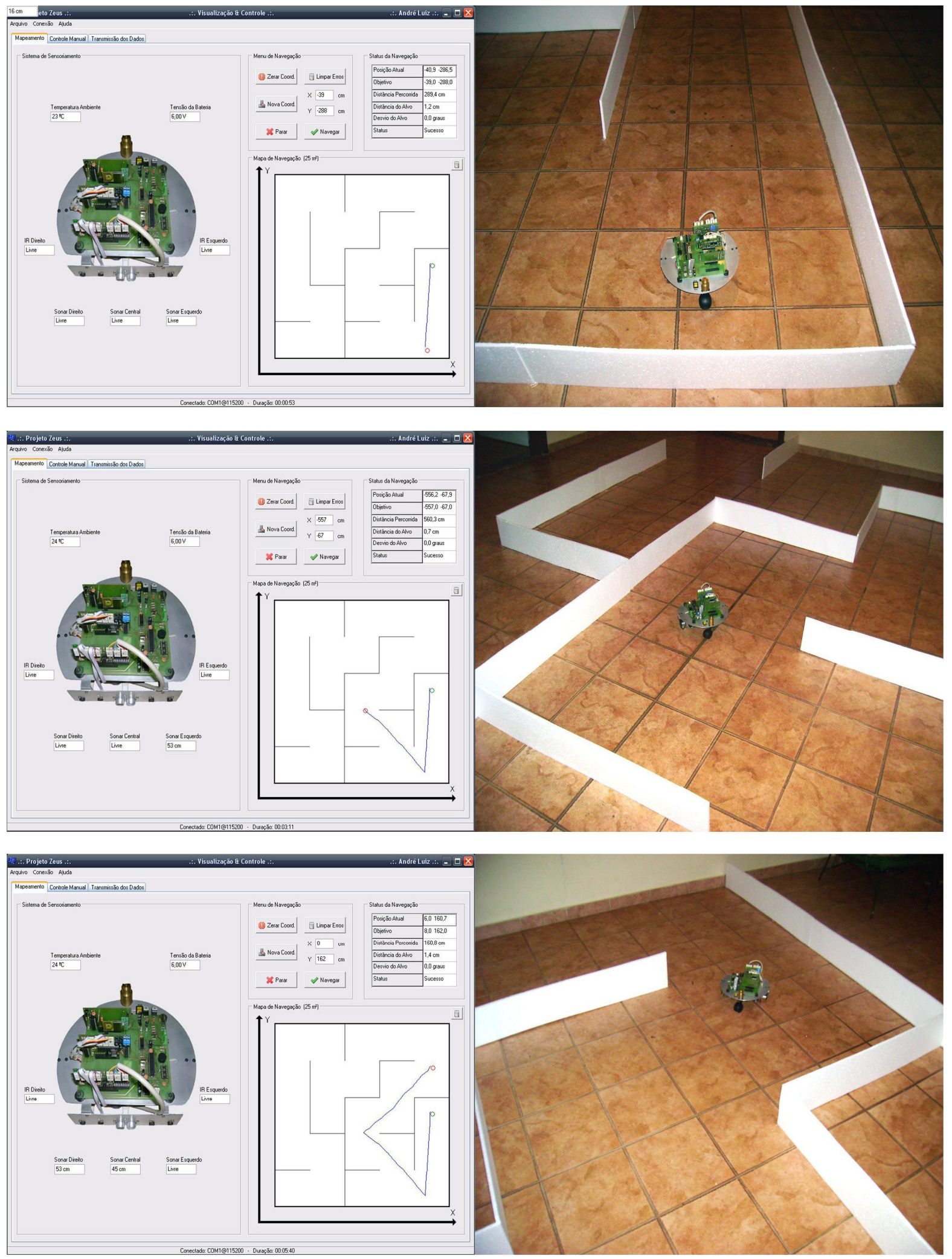

FIGURA 4.12 - Seqüência de Navegação (5) 
Nas imagens das figuras anteriores pode ser observado o ponto de origem, o ponto de destino, a trajetória percorrida pelo robô com as devidas correções e os dados captados pelos sensores.

A posição final do robô ao alcançar o objetivo (destino) é relativa à última correção feita. Como todos os dados de navegação são acumulativos, se uma nova coordenada de destino for passada, a correção da direção é ajustada automaticamente e a navegação é então realizada corretamente.

Os erros acumulados devem ser eliminados de acordo com a necessidade, caso contrário, a navegação poderá sofrer variações e com isso dificultar a localização do destino.

\subsection{Avaliação de Custo}

A avaliação de custo para confecção do robô móvel ZEUS utilizando a arquitetura proposta neste trabalho é dividida em duas partes, sendo elas:

- Custo da estrutura mecânica;

- Custo dos principais componentes utilizados.

\subsubsection{Custo da Estrutura Mecânica}

A estrutura mecânica foi desenvolvida pelo autor com a orientação de profissionais da área, sendo os materiais doados para propósitos da pesquisa.

O custo para produção de todos os componentes mecânicos pertencentes ao protótipo desenvolvido foi avaliado pela empresa GJR Comércio e Indústria Mecânica LTDA, situada na cidade de São Carlos/SP, a qual estimou um valor de 
$\mathrm{R} \$ 80,00$ (US\$ 44,00 aprox.), incluindo o material (Alumínio) e mão de obra utilizada para construção. Essa cotação foi realizada em 31 de Outubro de 2007.

\subsubsection{Custo dos Principais Componentes Utilizados}

Os componentes avaliados foram aqueles que tiveram custo significativo em relação ao custo total do projeto, sendo eles apresentados pela TABELA 4.1:

TABELA 4.1 - Análise de custo dos componentes utilizados (04/11/2007)

\begin{tabular}{|c|c|c|c|}
\hline Componente & Quantidade & $\begin{array}{l}\text { Custo Médio } \\
\text { (Un) R\$ }\end{array}$ & Fornecedor \\
\hline $\begin{array}{l}\text { Bateria de chumbo- } \\
\text { ácido-6.1V@1.3A }\end{array}$ & 1 & 20,60 & $\begin{array}{c}\text { Ca and Ma Componentes } \\
\text { Eletrônicos }\end{array}$ \\
\hline ВС337 & 5 & 0,13 & $\begin{array}{l}\text { Farnell Newark Dist. Comp. } \\
\text { Eletrônicos Ltda. }\end{array}$ \\
\hline Capacitor Eletrolítico & 18 & 0,40 & $\begin{array}{l}\text { Soldafria Componentes } \\
\text { Eletrônicos }\end{array}$ \\
\hline Capacitor Cerâmico & 27 & 0,10 & $\begin{array}{c}\text { Soldafria Componentes } \\
\text { Eletrônicos }\end{array}$ \\
\hline $\begin{array}{l}\text { Conector Fêmea - } 16 \\
\text { pinos }\end{array}$ & 6 & 0,35 & $\begin{array}{l}\text { Soldafria Componentes } \\
\text { Eletrônicos }\end{array}$ \\
\hline $\begin{array}{l}\text { Conector Macho - } 16 \\
\text { pinos }\end{array}$ & 3 & 0,65 & $\begin{array}{l}\text { Soldafria Componentes } \\
\text { Eletrônicos }\end{array}$ \\
\hline Cristal 32.768 kHz & 1 & 0,45 & $\begin{array}{l}\text { Soldafria Componentes } \\
\text { Eletrônicos }\end{array}$ \\
\hline Cristal $20 \mathrm{MHz}$ & 4 & 0,90 & $\begin{array}{l}\text { Soldafria Componentes } \\
\text { Eletrônicos }\end{array}$ \\
\hline DB9 Fêmea & 1 & 0,90 & $\begin{array}{c}\text { Soldafria Componentes } \\
\text { Eletrônicos }\end{array}$ \\
\hline DB9 Macho & 1 & 1,00 & $\begin{array}{c}\text { Soldafria Componentes } \\
\text { Eletrônicos }\end{array}$ \\
\hline Diodo de uso geral & 3 & 0,10 & $\begin{array}{c}\text { Soldafria Componentes } \\
\text { Eletrônicos }\end{array}$ \\
\hline DS1305 & 1 & 13,95 & $\begin{array}{l}\text { Farnell Newark Dist. Comp. } \\
\text { Eletrônicos Ltda. }\end{array}$ \\
\hline LED & 9 & 0,15 & $\begin{array}{l}\text { Soldafria Componentes } \\
\text { Eletrônicos }\end{array}$ \\
\hline LM317 & 3 & 1,60 & $\begin{array}{c}\text { Soldafria Componentes } \\
\text { Eletrônicos }\end{array}$ \\
\hline LM7805 & 4 & 0,90 & $\begin{array}{l}\text { Farnell Newark Dist. Comp. } \\
\text { Eletrônicos Ltda. }\end{array}$ \\
\hline MAX232 & 2 & 2,19 & $\begin{array}{c}\text { Farnell Newark Dist. Comp. } \\
\text { Eletrônicos Ltda. }\end{array}$ \\
\hline
\end{tabular}




\begin{tabular}{|c|c|c|c|}
\hline PIC 16F876A & 2 & 19,99 & $\begin{array}{c}\text { Lab Tools Mosaico Didactic } \\
\text { Division }\end{array}$ \\
\hline PIC 16LF88 & 3 & 14,87 & $\begin{array}{l}\text { Farnell Newark Dist. Comp. } \\
\text { Eletrônicos Ltda. }\end{array}$ \\
\hline Push Botton & 3 & 0,20 & $\begin{array}{c}\text { Soldafria Componentes } \\
\text { Eletrônicos }\end{array}$ \\
\hline Resistor 1\% & 22 & 0,10 & $\begin{array}{c}\text { Soldafria Componentes } \\
\text { Eletrônicos }\end{array}$ \\
\hline Resistor 5\% & 22 & 0,05 & $\begin{array}{c}\text { Soldafria Componentes } \\
\text { Eletrônicos }\end{array}$ \\
\hline $\begin{array}{l}\text { Sensor Optico com aba } \\
\text { ITR8102 }\end{array}$ & 2 & 2,90 & $\begin{array}{c}\text { Ca and Ma Componentes } \\
\text { Eletrônicos }\end{array}$ \\
\hline $\begin{array}{l}\text { Sensor Óptico } \\
\text { Triangular C7L3 }\end{array}$ & 2 & 4,00 & $\begin{array}{l}\text { Ca and Ma Componentes } \\
\text { Eletrônicos }\end{array}$ \\
\hline Sensor Sonar & 3 & 50,00 & $\begin{array}{l}\text { Tato Equipamentos } \\
\text { Eletrônicos }\end{array}$ \\
\hline $\begin{array}{c}\text { Servo Motor Hobbico } \\
\text { CS-60 }\end{array}$ & 2 & 37,74 & Flademir Aeromodelismo \\
\hline Speaker & 2 & 1,43 & $\begin{array}{l}\text { Farnell Newark Dist. Comp. } \\
\text { Eletrônicos Ltda. }\end{array}$ \\
\hline Termistor NTC & 1 & 1,83 & $\begin{array}{c}\text { Farnell Newark Dist. Comp. } \\
\text { Eletrônicos Ltda. }\end{array}$ \\
\hline TIP127 & 1 & 1,12 & $\begin{array}{l}\text { Farnell Newark Dist. Comp. } \\
\text { Eletrônicos Ltda. }\end{array}$ \\
\hline TLP621 & 1 & 1,07 & $\begin{array}{l}\text { Farnell Newark Dist. Comp. } \\
\text { Eletrônicos Ltda. }\end{array}$ \\
\hline TRF-24G & 2 & 60,00 & $\begin{array}{l}\text { Tato Equipamentos } \\
\text { Eletrônicos }\end{array}$ \\
\hline $74 \mathrm{HC} 08$ & 2 & 0,54 & $\begin{array}{l}\text { Farnell Newark Dist. Comp. } \\
\text { Eletrônicos Ltda. }\end{array}$ \\
\hline $74 \mathrm{HC} 14$ & 1 & 0,61 & $\begin{array}{l}\text { Farnell Newark Dist. Comp. } \\
\text { Eletrônicos Ltda. }\end{array}$ \\
\hline \multicolumn{2}{|c|}{ Custo total dos componentes } & 525,87 & \\
\hline
\end{tabular}

Por meio desta análise, o protótipo ZEUS apresentou um custo médio equivalente a $\mathrm{R} \$ 605,87$ (US\$ 336,00 aprox.), que em relação aos robôs (Khepera® e Lego $\circledast$ Mindstorms - $\mathrm{R} \$ 1700,00$ a $\mathrm{R} \$ 3000,00$ aprox.) e controladores (Handy Board - $\mathrm{R} \$ 700,00$ ) utilizados em pesquisas citados neste trabalho possui uma diferença de valor significante. 


\section{Conclusões Gerais e Trabalhos Futuros}

\subsection{Conclusões Gerais}

Por intermédio desse trabalho foi possível a construção de um protótipo chamado ZEUS para aplicações em robótica móvel com um baixo custo construtivo.

Os sensores e métodos utilizados produziram excelentes respostas para aplicações em ambientes indoor de pequeno porte; Contudo, modificações devem ser realizadas para testes em ambientes maiores que $25 \mathrm{~m}^{2}$.

O sistema de comunicação entre os módulos apresentou estabilidade e confiança nos pacotes de dados transmitidos, para taxa de transmissão de $312,5 \mathrm{kHz}$

Dificuldades no sincronismo da comunicação wireless e controle diferencial dos servomotores marcaram o desenvolvimento desse projeto; Porém, esses problemas foram superados por meio de modificação do protocolo de comunicação e rotinas para geração de PWMs para acionamento dos servomotores utilizando o sistema de interrupção do MCU.

A base móvel desenvolvida apresentou inicialmente problemas de equilíbrio quando acoplado o suporte de sensoriamento, fato esse resolvido com a adição de um contrapeso na parte traseira. De forma geral, todos os módulos produziram respostas eficientes para os testes durante o desenvolvimento e validação da arquitetura. 
Algumas informações extras sobre o robô podem ser observadas na TABELA 5.1.

TABELA 5.1 - Características do Robô Móvel ZEUS

\begin{tabular}{|c|c|c|}
\hline Característica & Robô Móvel & Módulo PC \\
\hline Tensão de Alimentação & 6 a $12 \mathrm{Vdc}$ & 6 a $12 \mathrm{Vdc}$ \\
\hline Consumo Máximo & $\sim 200 \mathrm{~mA}$ & $\sim 20 \mathrm{~mA}$ \\
\hline Autonomia & $\begin{array}{l}3 \text { horas }(6 \mathrm{Vdc}) \text { ou } 6 \\
\text { horas }(12 \mathrm{Vdc})\end{array}$ & $\begin{array}{c}30 \text { horas }(6 \mathrm{Vdc}) \text { ou } 60 \\
\text { horas }(12 \mathrm{Vdc})\end{array}$ \\
\hline Taxa de comunicação RF & $1 \mathrm{Mbit} / \mathrm{s}$ & $1 \mathrm{Mbit} / \mathrm{s}$ \\
\hline Taxa de comunicação SPI & $312,5 \mathrm{kHz}$ & - \\
\hline $\begin{array}{c}\text { Taxa de Comunicação } \\
\text { RS232 }\end{array}$ & 115200bps & 115200bps \\
\hline $\begin{array}{l}\text { Alcance máximo dos } \\
\text { sonares }\end{array}$ & 2 metros & - \\
\hline $\begin{array}{l}\text { Alcance máximo dos } \\
\text { infravermelhos }\end{array}$ & 25 milímetros & - \\
\hline $\begin{array}{l}\text { Temperatura medida pelo } \\
\text { Sensor }\end{array}$ & $0^{\circ} \mathrm{C}$ a $50^{\circ} \mathrm{C}$ & - \\
\hline $\begin{array}{c}\text { Alcance máximo do módulo } \\
\text { de RF }\end{array}$ & 100 metros com visada & 100 metros com visada \\
\hline
\end{tabular}




\subsection{Trabalhos Futuros}

Como parte de trabalhos futuros, alguns aperfeiçoamentos poderão ser realizados para aumentar a precisão e eficiência dos algoritmos. Além da otimização de memória dos MCU utilizados, pode-se também investigar os seguintes assuntos:

- Substituição dos servomotores por motores DC com caixa de redução integrada;

- Instalação do disco óptico do encoder diretamente no eixo do motor ao invés do eixo da roda;

- Utilização do Módulo de RF em modo de comunicação full-duplex;

- Utilização de um padrão de comunicação Wireless conhecido, como por exemplo: ZigBee;

- Aumentar o nível de modularidade, disponibilizando um sinal no barramento de comunicação, para detectar a conexão de um módulo e gerar seu respectivo endereço (Hot-plug).

Em relação às técnicas de navegação autônoma, a arquitetura desenvolvida pode também auxiliar em diversos estudos e aplicações, tais como:

- Proposição de novos algoritmos para navegação autônoma;

- Avaliação de algoritmos de mapeamento de ambientes e detecção de obstáculos. 



\section{Referências Bibliográficas}

[1] THRUN, S., et. al. A System for Volumetric Robotic Mapping of Abandoned Mines. Proceedings of ICRA-2003, p.1-6.

[2] MORRISON, J., NGUYEN, T. On-Board Software for the Mars Pathfinder Microrover. Second International Academy of Astronautics Conference on Low Cost Planetary Missions, paper IAA-L-0504P, abr. 1996

[3] WOLF, F. D., SUKHATME, G. V. S. Mobile Robot Simultaneous Localization and Mapping in Dynamic Environments. Autonomous Robots, v. 19, p. 5365, 2005.

[4] BORESNSTEIN, J., EVERETT, H. R., FENG, L., "Where am I?" Sensors and Methods for Mobile Robot Positioning. Universidade de Michigan, abr. 1996.

[5] HOWE, J. A Flexible and Innovative Platform for Autonomous Mobile Robots. Massachusetts Institute of Technology (http://www.ai.mit.edu), p. 114, jan. 2003. 
[6] SILVA, L. R. Análise e Programação de Robôs Móveis Autônomos da Plataforma Eyebot. Universidade Federal de Santa Catarina, Dissertação de Mestrado, Brasil, mar. 2003.

[7] ROCHA, R. P. Estado da Arte da Robótica Móvel em Portugal. Universidade de Coimbra, Instituto de Sistemas e Robótica, Portugal, mar. 2001.

[8] JÁCOBO, J. E. A. Desenvolvimento de um Robô Autônomo Móvel Versátil utilizando Arquitetura Subsumption. Universidade Estadual de Campinas, Dissertação de Mestrado, Brasil, 2001.

[9] ITO, M., TANI, J. On-line Imitative Interaction with a Humanoid Robot Using a Dynamic Neural Network Model of a Mirror System. International Society for Adaptive Behavior, v. 12, p. 93-115, 2004.

[10] SAKAGAMI, Y., WATANABE, R., AOYAMA, C., MATSUNAGA, S., HIGAKI, N., FUJIMURA, K. The Intelligent ASIMO: System Overview and Integration. IEEE/RSJ, p. 1-6, out. 2002.

[11] VIEIRA, F. C. Controle Dinâmico de Robôs Móveis com Acionamento Diferencial. Universidade Federal do Rio Grande do Norte, Dissertação de Mestrado, Brasil, fev. 2005.

[12] KATSUIKO, O. Engenharia de controle Moderno. Prentice-Hall, 1990, 2ª Edição. 
[13] OLIVER, R. S. Real Time Operating Systems - RTOS - Kaiserslautern University of Technology, jun. 2006.

[14] ISHIDA, H., TANAKA, H., TANIGUCHI, H., MORIZUMI, T. Mobile Robot Navigation Using Vision and Olfaction to Search for a Gas/Odor Source. Auton Robot, v. 20, p. 231-238, 2006.

[15] FUtTERMAN, J. A., PAO, H.-Y. Communications Systems for Mobile Robotics. Lawrence Livermore National Laboratory, p. 1-8, abr. 2004.

[16] BROOKS, R. A. Intelligence without Representation. Artificial Intelligence, v. 47, p. 139-159, 1991.

[17] MAES, P., BROOKS, R. A. Learning to Coordinate Behaviors. Massachusetts Institute of Technology, Al-Laboratory, p. 1-7, 1990.

[18] GAT, E. On Three-Layer Architectures. Artificial Intelligence and Mobile Robots, p. 1-11, 1998.

[19] CONNELL, J. SSS: A Hybrid Architecture Applied to Robot Navigation. Proceedings of the IEEE Conference on Robotics and Automation, 1992.

[20] CHEN, Y., LIN, F. Modeling of Discrete Event Systems Using Finite State Machines with Parameters. Proceedings of IEEE, International Conference on Control Applications, p. 1-6, set. 2000. 
[21] THOMAS, P. Three-Layer Architectures. Presentation based on "On ThreeLayer Architectures” by Erann Gat (1998), set. 2006.

[22] GOUVEIA, F. Projeto de um Transceptor Óptico para Comunicação Digital em Espaço Livre. Universidade de São Paulo (Escola Politécnica), Dissertação de Mestrado, Brasil, 2007.

[23] TROLL, T., DETLEFESEN, J. Motion Monitoring with a Milimeter Wave Radar Sensor. $27^{\text {th }}$ European Microwave Conference and Exhibition, v. 1, p. 39-44, set. 1997.

[24] PINTO, A. N., Análise e Optimização de Sistemas de Comunicação Ópticos Baseados em Solitões. Universidade de Avareio, Tese de Doutorado, Portugal, 1999.

[25] ROSENBURY, T. et. al - Micropower Impulse Radio [MIR]. Lawrence Livermore National Laboratory, jan. 2002.

[26] MALIK, T. Red Planet Wayfinder: A GPS System for Mars. Disponível em: http://www.space.com/businesstechnology/technology/mars_gps_040707.ht ml, Data de acesso: 20/09/2007.

[27] NILSSON, J. N. Shakey the Robot. Technical Note 323, Artificial Intelligence Center, abr. 1984. 
[28] OTTONI, G. L., LAGES, W. F. Navegação de Robôs Móveis em Ambientes Desconhecidos Utilizando Sonares de Ultra-Som. Revista Controle \& Automação, v. 14, no. 4, nov.-dez. 2003.

[29] LEGO® MINDSTORMS $\circledast$ NXT Hardware Developer Kit. Disponível em: http://mindstorms.lego.com/Overview/NXTreme.aspx, Data de acesso: 28/09/2007.

[30] FERRARI, M. Building Robots with Lego Mindstorms: The Ultimate Tool for Mindstorm Maniacs. Syngress Media Inc., 2001.

[31] LEGO® MINDSTORMS $\Theta$. Disponível em: http://mindstorms.lego.com/, Data de acesso: 28/09/2007.

[32] MARTIN, F. G., PANTAZOPOULOS, G. J. Designing the Next-Generation Handy Board. Disponível em: www.cs.uml.edu/ fredm/papers/SS104MartinF.pdf, Data de acesso: 28/09/2007.

[33] MARTIN, F. G. The Handy Board Technical Reference. Disponível em: http://handyboard.com/, Data de acesso: 28/09/2007.

[34] K-TEAM. The Khepera Miniature Móbile Robot. Disponível em: http://diwww.epfl.ch/lami/robots/K-family/Khepera.html, Data de Acesso: 30/09/2007. 
[35] NASA. Sojourner Rover, Mars Pathfinder Mission, Disponível em: http://mars.jpl.nasa.gov/MPF/rover/sojourner.html, Data de acesso: 30/09/2007.

[36] SOUZA, D. Desbravando o PIC. Editora Érica Ltda., 12ª Edição, São Paulo, 2000.

[37] SÁ, A. A. R. Sistemas Distribuídos. Centro Universitário FEB (Fundação Educacional de Barretos), jan. 2005.

[38] Laipac Technology Inc. TRF-2.4G Transceiver Datasheet, www.laipac.com.

[39] STRANGIO, C. The RS232 Standard. Disponível em: http://www.camiresearch.com/Data_Com_Basics/RS232_standard.html, Data de acesso: 30/09/2007.

[40] SILVA. A. L. V., FUGITA, M. D. Projeto SkateMorph. Centro Universitário FEB (Fundação Educacional de Barretos), Trabalho de Conclusão de Curso, dez. 2005.

[41] KALINSKY, D., KALINSKY, R. Introduction to Serial Peripheral Interface. Embedded System Design, Disponível em: http://www.embedded.com/shared/printableArticle.jhtml?articlelD=9900483, Data de acesso: 02/10/2007. 
[42] MICROCHIP. SPITM Overview and use of The PICmicro Serial Peripheral Interface. Disponível em:

ww1.microchip.com/downloads/en/devicedoc/spi.pdf, Data de acesso: 02/06/2007.

[43] MAXIM. Interfacing a SPI RTC with a Motorola DSP. Application Note 2833, Disponível em: www.maxim-ic.com/appnotes.cfm/an_pk/2833, Data de acesso: 02/06/2007.

[44] DAVID. P. Anderson, IMU Odometry. Southern Methodist University Department of Geological Sciences. Dallas, Texas. Disponível em http://www.geology.smu.edu/ dpa-www/robo/Encoder/imu_odo/, Data de acesso: 03/05/2007 



\section{APÊNDICE A - TCommThread.c}

Código da rotina de comunicação serial TCommThread. Compilador utilizado:

Borland $\AA^{\mathrm{C}}++$ Builder ${ }^{\mathrm{TM}}$

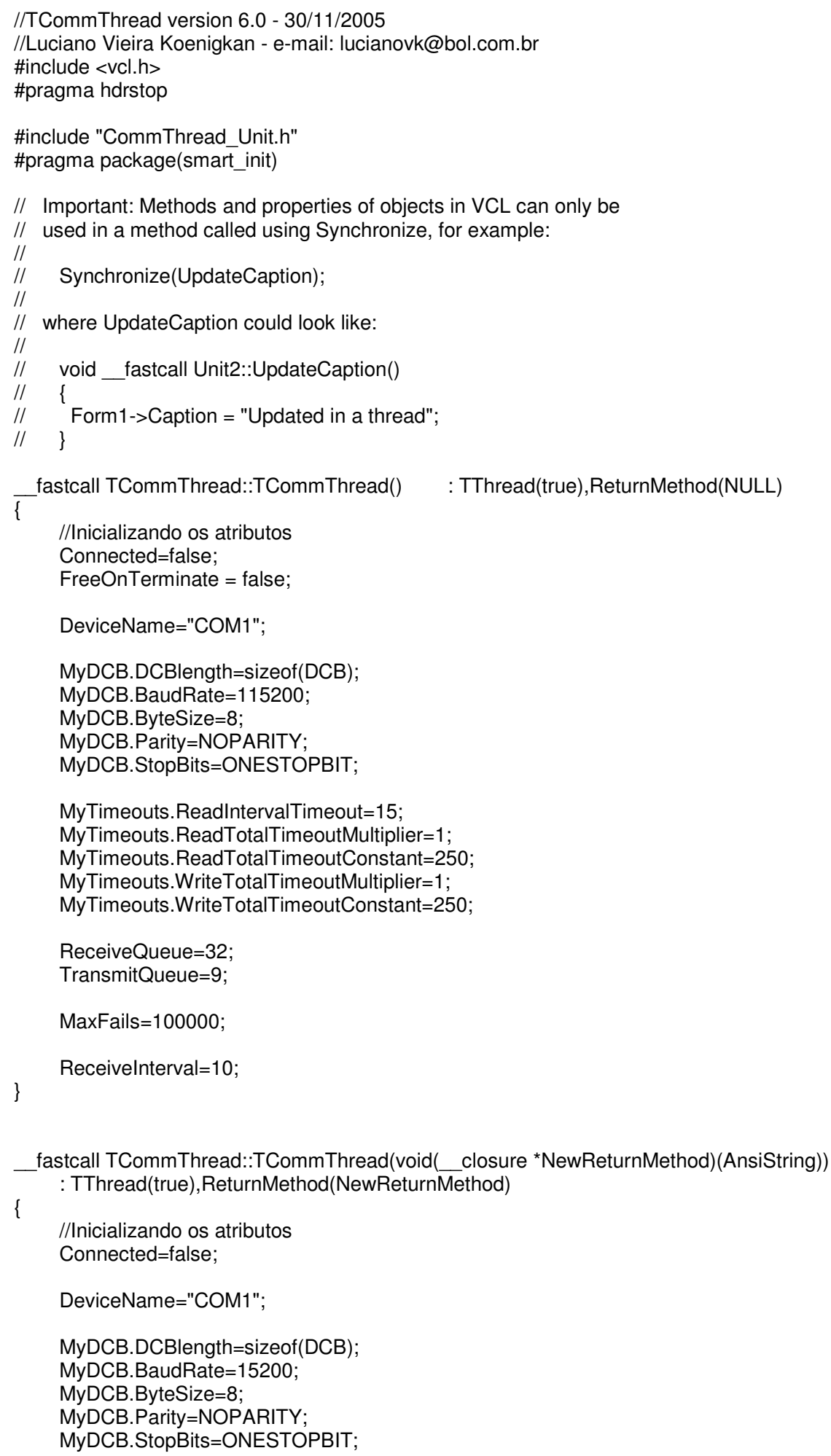


MyTimeouts. ReadlntervalTimeout $=15$;

MyTimeouts. ReadTotalTimeoutMultiplier=1;

MyTimeouts. ReadTotalTimeoutConstant $=250$;

MyTimeouts. WriteTotalTimeoutMultiplier $=1$;

MyTimeouts. WriteTotalTimeoutConstant=250;

ReceiveQueue=32;

TransmitQueue=9;

MaxFails $=100000$;

\}

Receivelnterval=10;

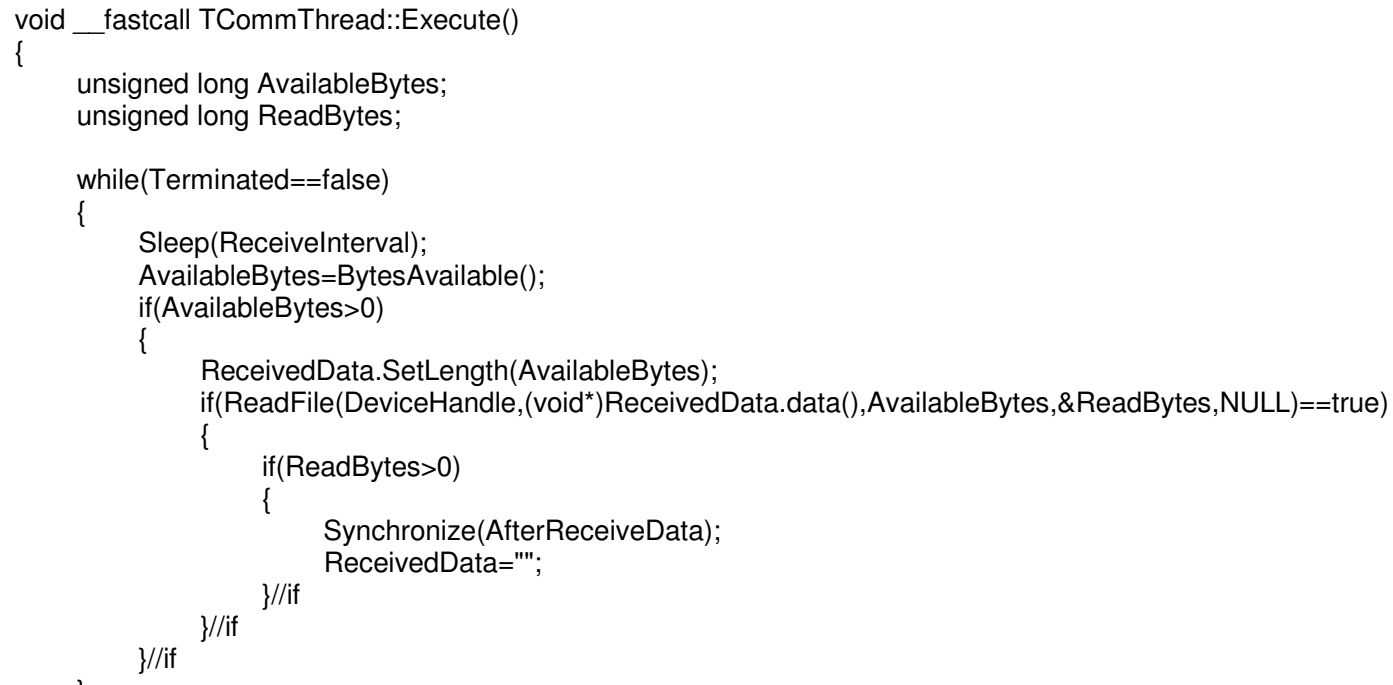




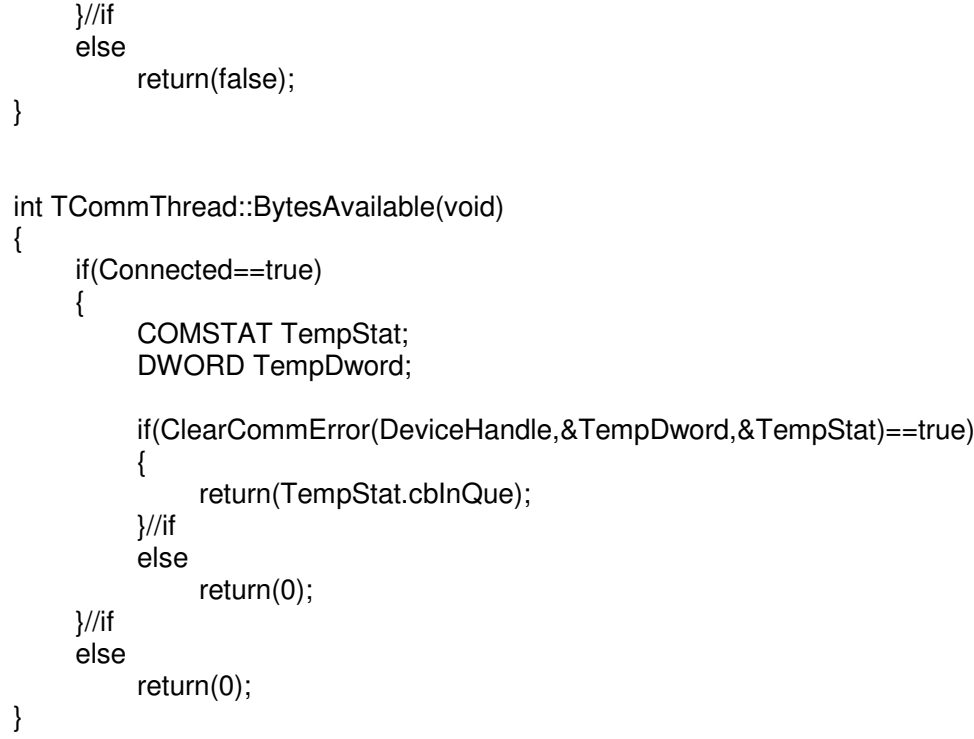




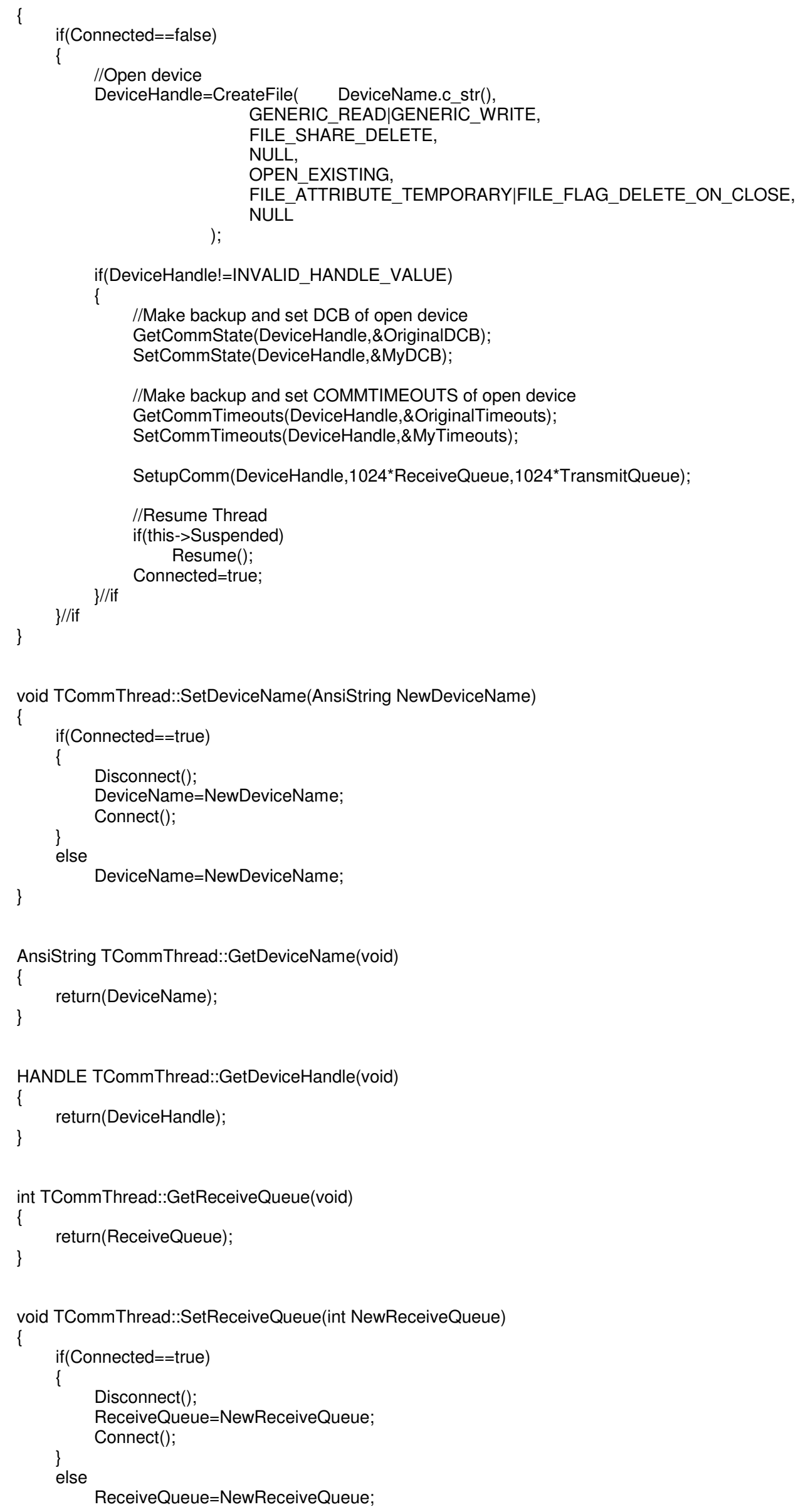


Void TCommThread::SetReturnMethod(void(_closure *NewReturnMethod)(AnsiString))

\{

if(Connected==true)

\{

Disconnect();

ReturnMethod=NewReturnMethod;

\}

Connect();

else

ReturnMethod=NewReturnMethod;

\}

int TCommThread::GetTransmitQueue(void)

\{

\}

return(TransmitQueue);

void TCommThread::SetTransmitQueue(int NewTransmitQueue)

if (Connected $==$ true $)$

\{

Disconnect();

TransmitQueue=NewTransmitQueue;

\}

Connect();

else

TransmitQueue=NewTransmitQueue;

void TCommThread::SetMaxFails(int NewMaxFails)

\{

if (Connected==true)

\{

Disconnect();

MaxFails=NewMaxFails;

\}

Connect();

else

MaxFails=NewMaxFails;

int TCommThread::GetMaxFails(void)

\{

return(MaxFails);

int TCommThread::GetBaudRate(void)

\{

return(MyDCB.BaudRate);

void TCommThread::SetBaudRate(int NewBaudRate)

\{

if(Connected==true)

\{

Disconnect();

MyDCB.BaudRate=NewBaudRate;

\}

Connect();

MyDCB.BaudRate=NewBaudRate;

int TCommThread::GetByteSize(void)

\}

return(MyDCB.ByteSize);

void TCommThread::SetByteSize(int NewByteSize) 


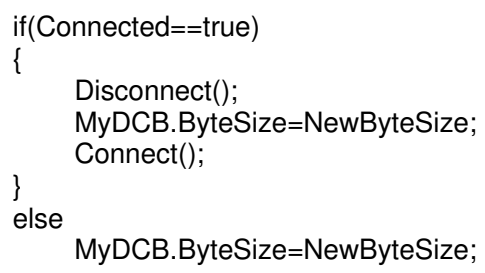


if (Connected $==$ true $)$

\{

Disconnect();

MyTimeouts.ReadTotalTimeoutMultiplier=NewReadTotalTimeoutMultiplier;

\}

Connect();

else

MyTimeouts.ReadTotalTimeoutMultiplier=NewReadTotalTimeoutMultiplier;

int TCommThread::GetReadTotalTimeoutConstant(void)

\{ \}

return(MyTimeouts.ReadTotalTimeoutConstant);

void TCommThread::SetReadTotalTimeoutConstant(int NewReadTotalTimeoutConstant)

\{

if(Connected==true)

\{

Disconnect();

MyTimeouts.ReadTotalTimeoutConstant=NewReadTotalTimeoutConstant;

\}

Connect();

\}

MyTimeouts.ReadTotalTimeoutConstant=NewReadTotalTimeoutConstant;

int TCommThread::GetWriteTotalTimeoutMultiplier(void)

\{

return(MyTimeouts.WriteTotalTimeoutMultiplier);

void TCommThread::SetWriteTotalTimeoutMultiplier(int NewWriteTotalTimeoutMultiplier) \{

if(Connected==true)

\{

Disconnect();

MyTimeouts.WriteTotalTimeoutMultiplier=NewWriteTotalTimeoutMultiplier;

Connect(); \}

else

\}

MyTimeouts.WriteTotalTimeoutMultiplier=NewWriteTotalTimeoutMultiplier;

int TCommThread::GetWriteTotalTimeoutConstant(void)

\}

return(MyTimeouts.WriteTotalTimeoutConstant);

void TCommThread::SetWriteTotalTimeoutConstant(int NewWriteTotalTimeoutConstant)

\{

if (Connected $==$ true $)$

\{

Disconnect();

MyTimeouts.WriteTotalTimeoutConstant=NewWriteTotalTimeoutConstant;

\}

Connect();

\}

MyTimeouts.WriteTotalTimeoutConstant=NewWriteTotalTimeoutConstant;

AnsiString TCommThread::GetAvailableData(void)

\{

unsigned long AvailableBytes;

unsigned long ReadBytes;

ReceivedData="'",

AvailableBytes=BytesAvailable();

if(AvailableBytes $>0)$ 


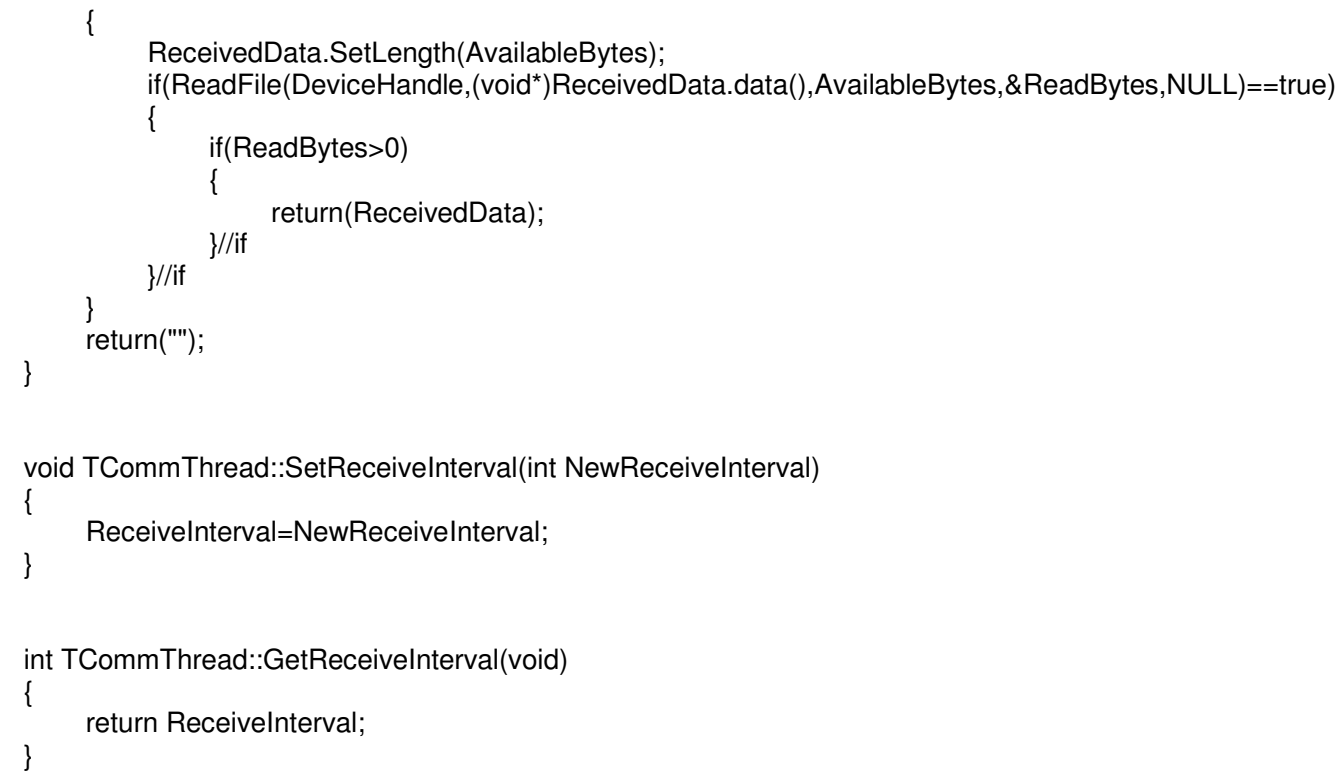

TStringList* TCommThread::GetAvailableDevicesNames(bool IncludeSerial, bool IncludeParallel, TStringList * AvaiableDevicesNames)

\{

TRegistry $\quad{ }^{*}$ Registro = new TRegistry ()$;$

TStringList $\quad$ *StringsTemp $=$ new TStringList () ;

int Indice;

if (AvaiableDevicesNames!=NULL) else 


\title{
APÊNDICE B - RF-24G.C
}

\author{
Código da biblioteca de funções em C para o microcontrolador PIC $\circledast$ para o \\ transceptor de radiofreqüência TRF-2.4G. Compilador utilizado: CCS
}

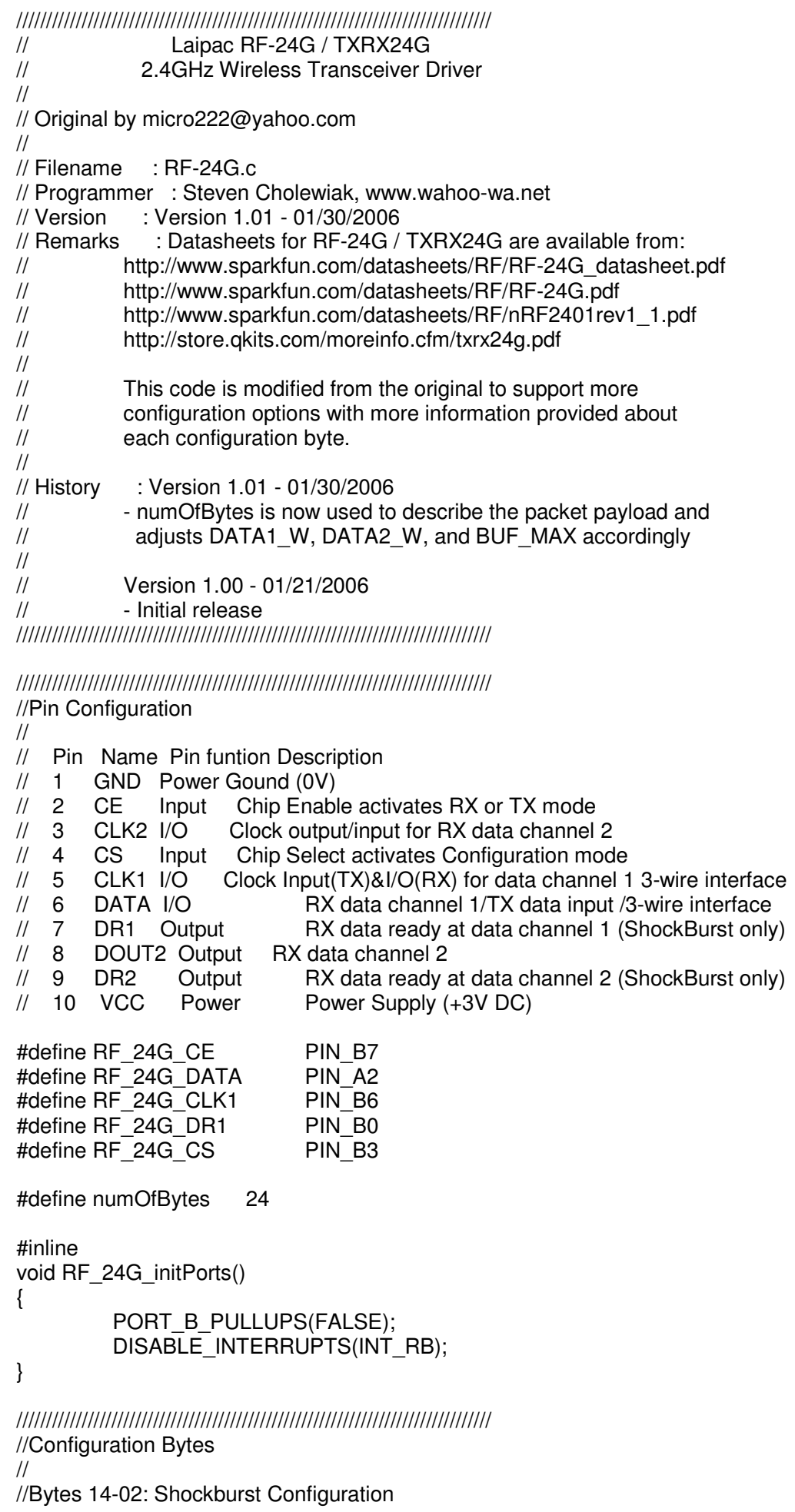




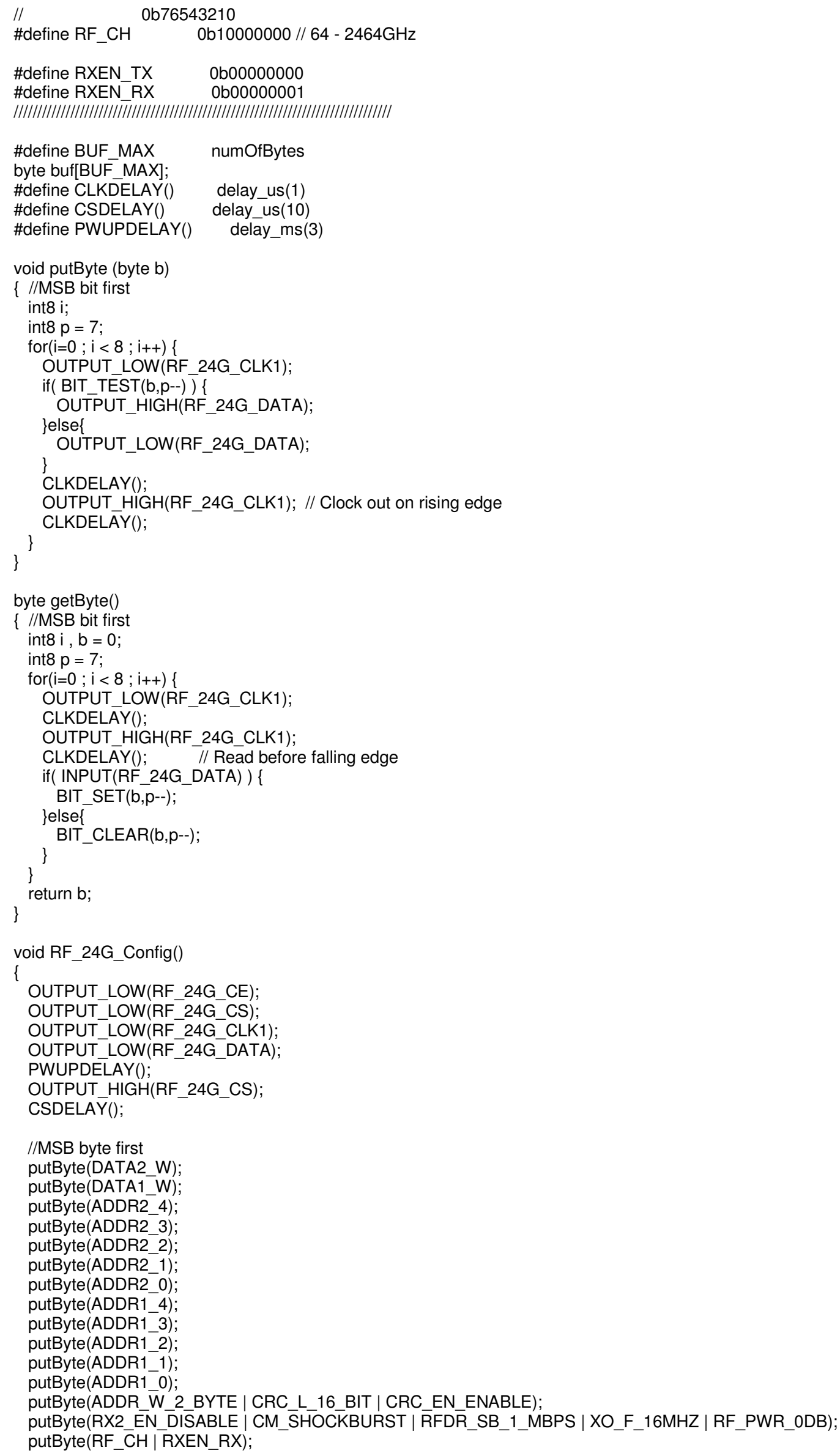

OUTPUT_FLOAT(RF_24G_DATA); 


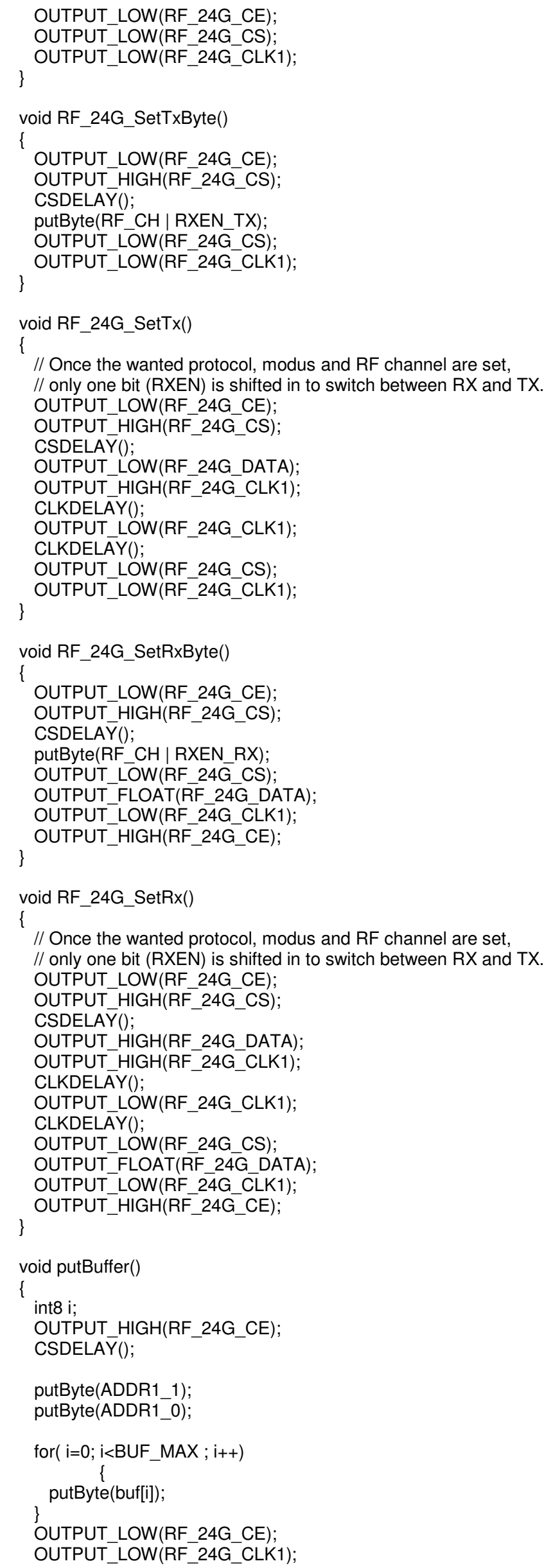


\}

void getBuffer()

\{

int8 $\mathrm{i}$;

for $(\mathrm{i}=0 ; \mathrm{i}<$ BUF_MAX; $\mathrm{i}++)$

buf[i] = getByte();

OUTPUT_LOW(RF_24G_CLK1)

OUTPUT_HIGH(RF_24G_CE); 



\section{APÊNDICE C - Serial.h}

Biblioteca de funções para comunicação serial assíncrona (RS232) utilizando microcontroladores PIC® (família 16F). Compilador utilizado: CCS

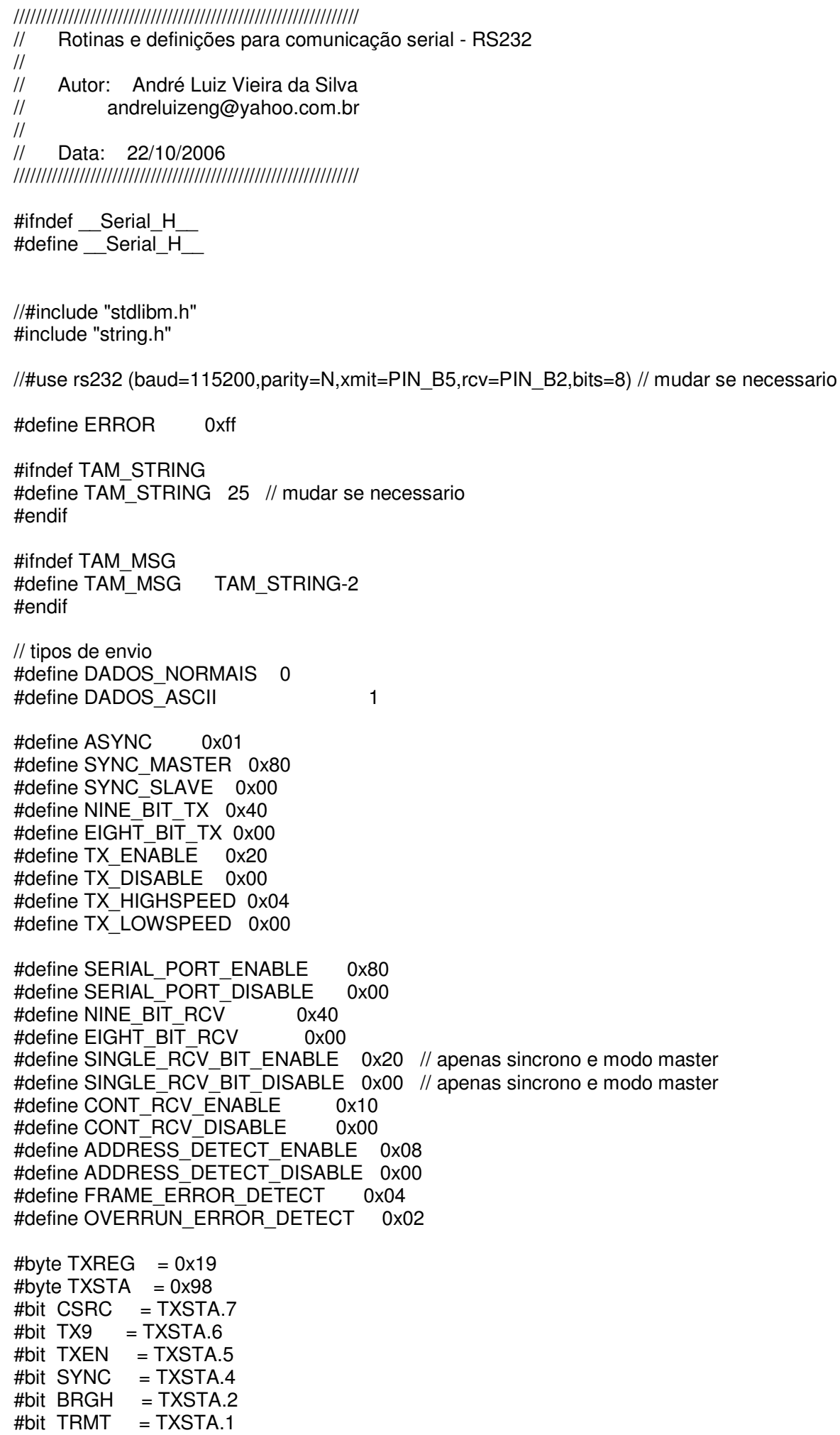




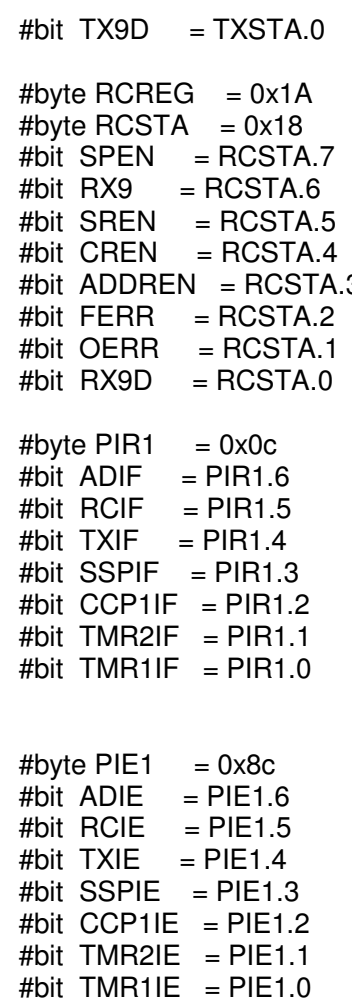

char PegaString (char * String);

char PegaDado (char *Dado);

boolean TratarString (char *StringEntrada, char *StringSaida, char Startchar, char Stopchar); void AjustaRecCont (void);

void EnviaDado (char Dado, boolean Tipo);

void EnviaString (char *Dado, boolean Tipo);

void IniciaString (char *String, char Tamanho, char Valor);

void CriaPacoteSlave (char *Msg, char *Pacote, char StartByte, char StopByte, int Tamanho);

\#endif 


\section{APÊNDICE D - Serial.c}

Biblioteca de funções para comunicação serial assíncrona (RS232) utilizando microcontroladores PIC® (família 16F). Compilador utilizado: CCS

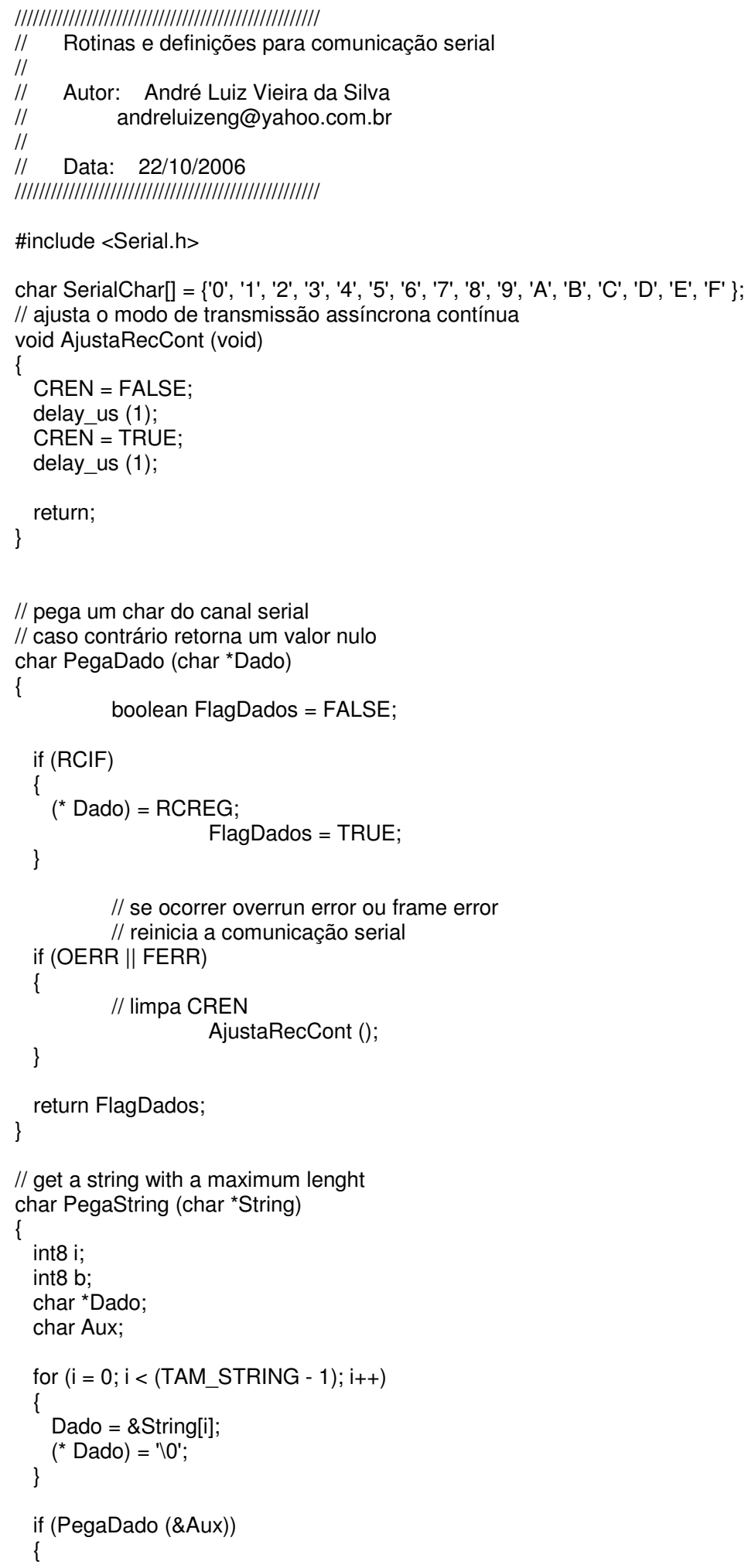




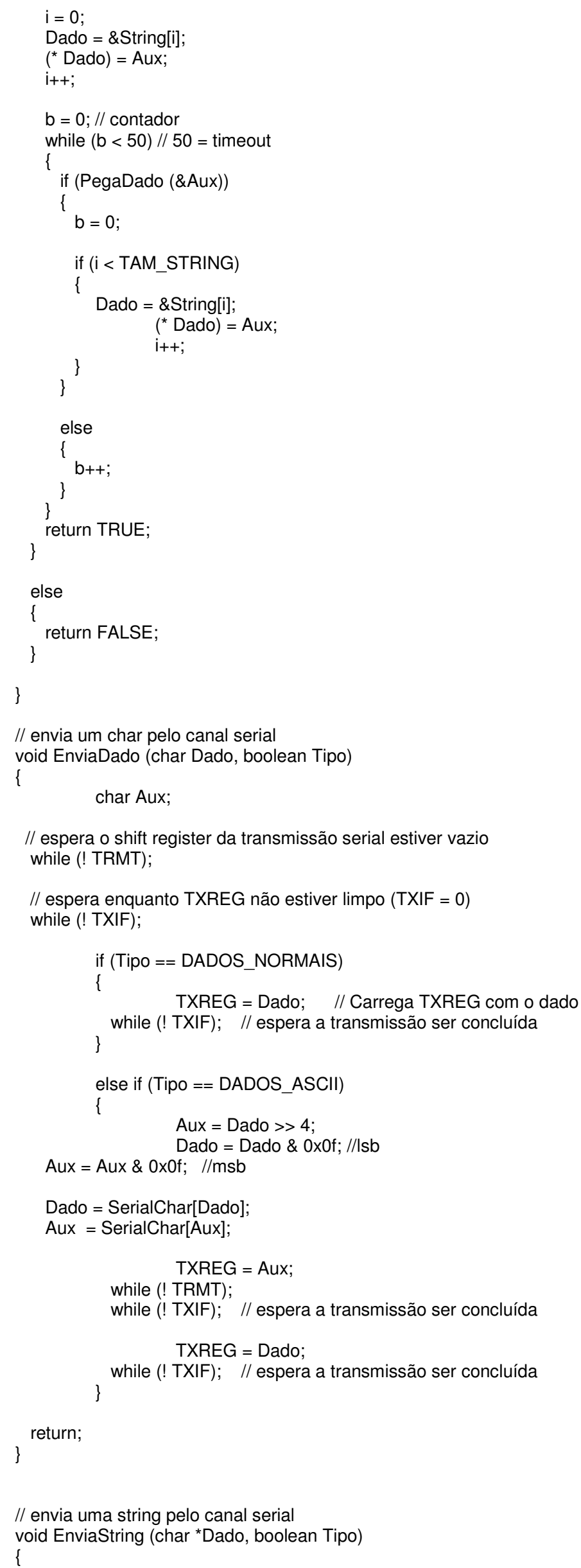




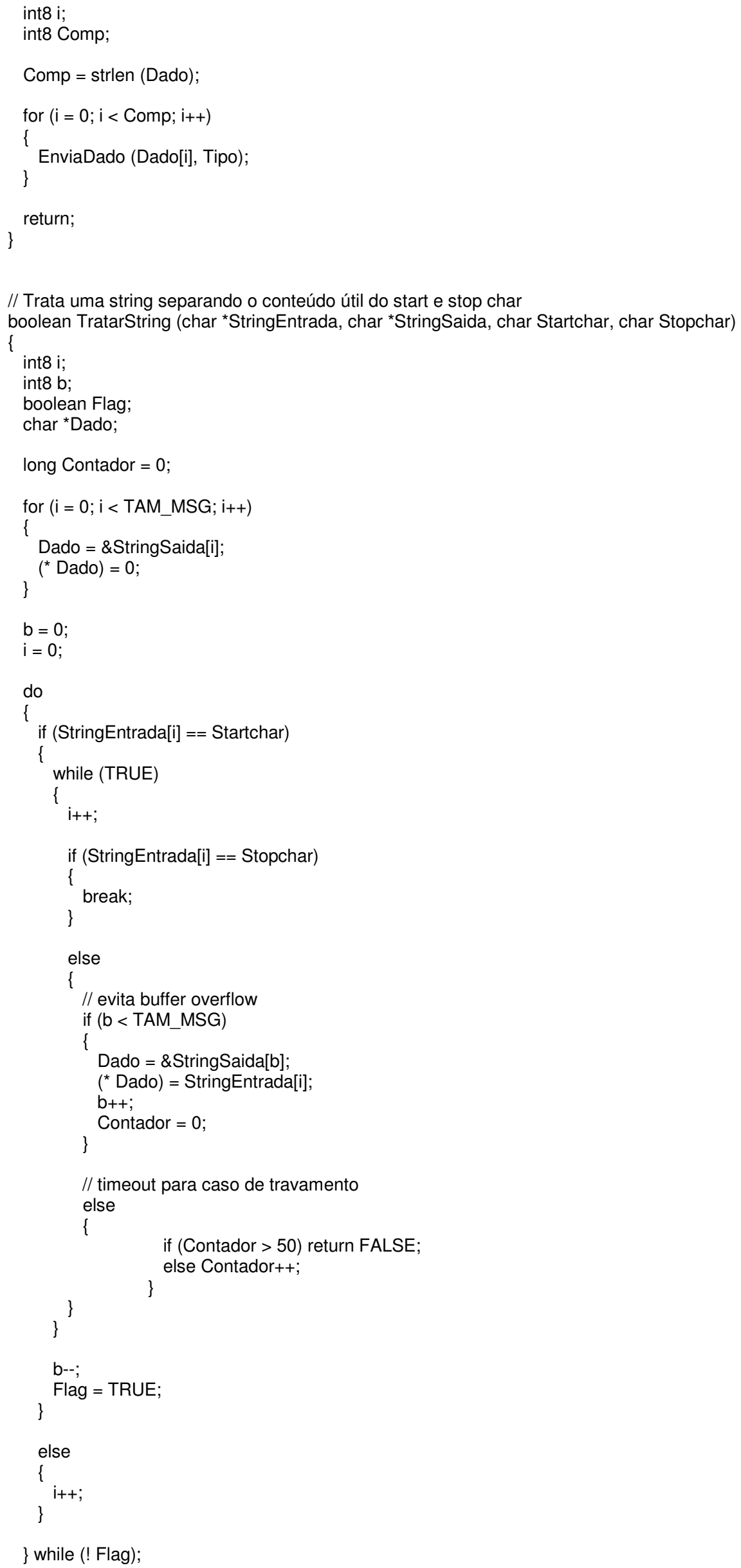


return TRUE;

void IniciaString (char *String, char Tamanho, char Valor)

\{

int8 i;

char *Aux;

for $(\mathrm{i}=0 ; \mathrm{i}<$ Tamanho; $\mathrm{i}++)$

\{

Aux = \&String[i];

$\left({ }^{*}\right.$ Aux $)=$ Valor;

return;

void CriaPacoteSlave (char * Msg, char *Pacote, char StartByte, char StopByte, int Tamanho)

\{

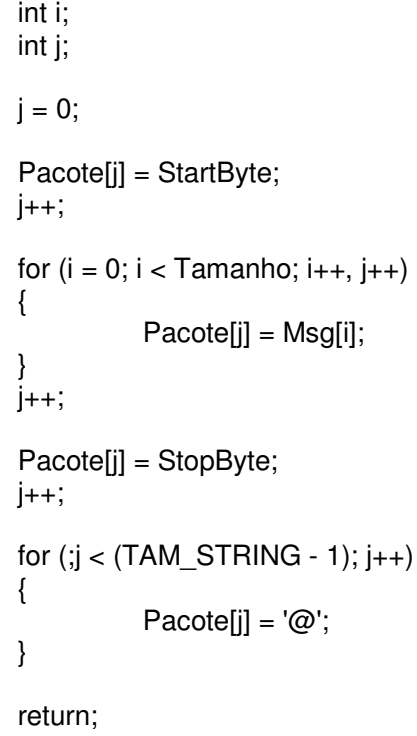




\title{
APENDICE E - SPI.h
}

\author{
Biblioteca de funções para comunicação serial síncrona (SPI) utilizando \\ microcontroladores PIC® (família 16F). Compilador utilizado: CCS
}

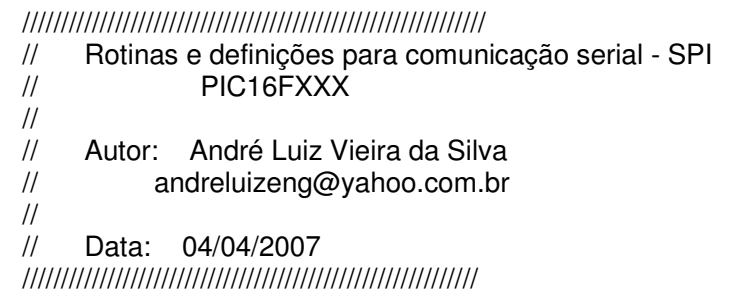

void TransmitirSPI (char *MsgSaida, char *MsgEntrada, char StopByte);

\#endif 



\title{
APÊNDICE F - SPI.C
}

\author{
Biblioteca de funções para comunicação serial síncrona (SPI) utilizando \\ microcontroladores PIC® (família 16F).
}

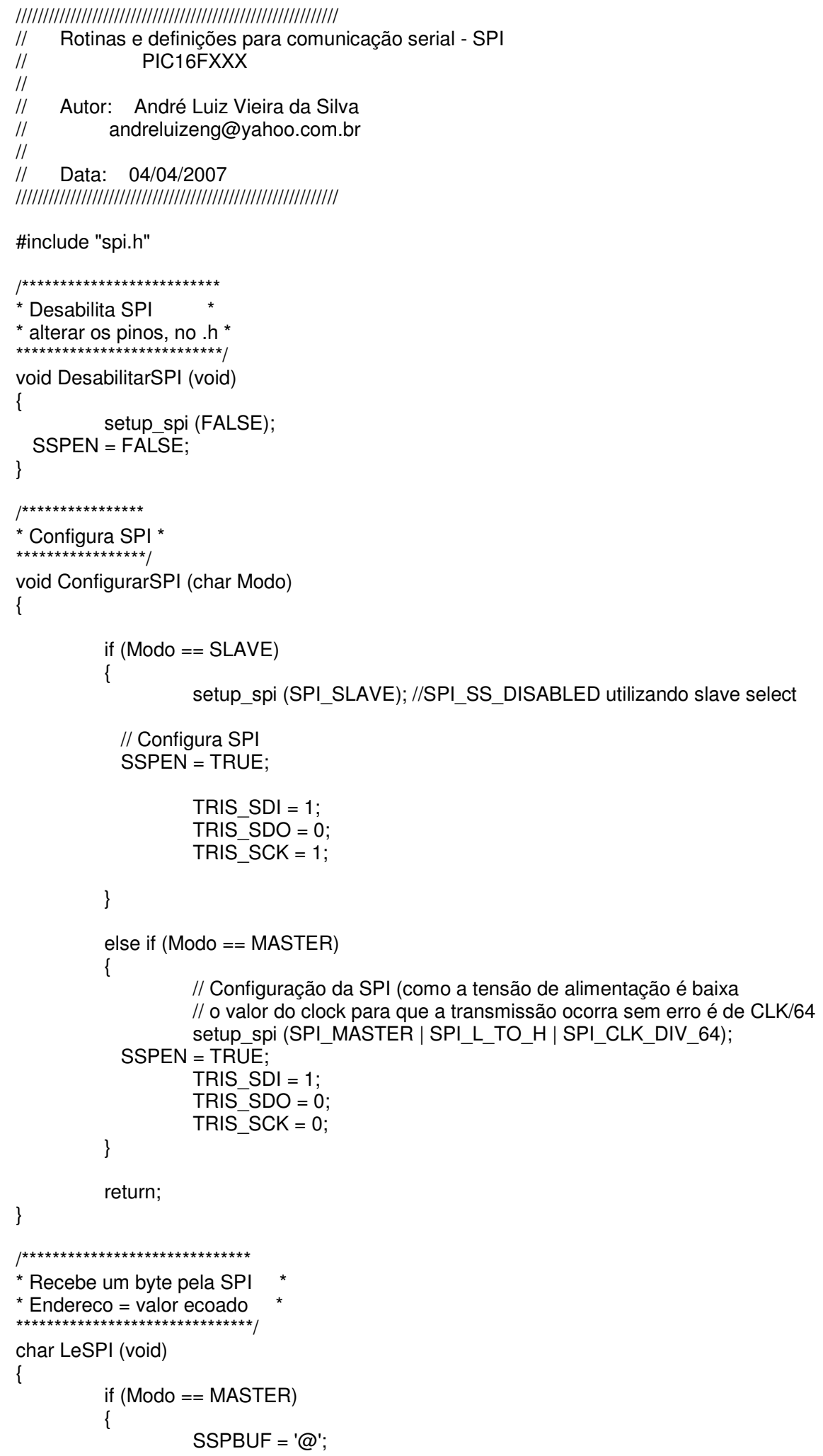




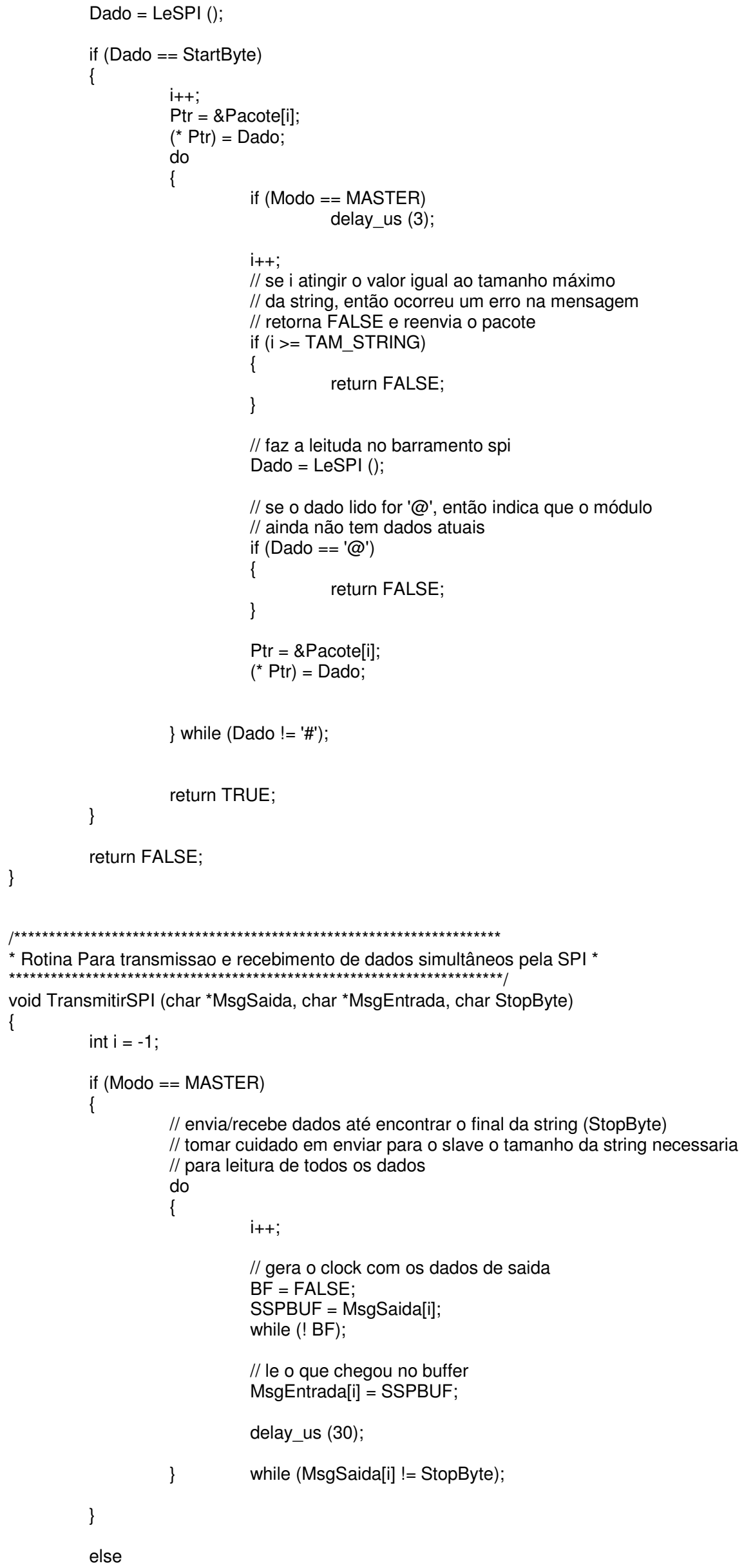


\{

// envia/recebe dados até encontrar o final da string enviada pelo master do

\{

$\mathrm{i}++$;

$\mathrm{BF}=\mathrm{FALSE}$

SSPBUF = MsgSaida[i]; while (! BF);

//le o que chegou no buffer MsgEntrada[i] = SSPBUF;

\} while (MsgEntrada[i] != StopByte);

// se ocorreu algum overflow (limpa o buffer) if (SSPOV) $\mathrm{i}=$ SSPBUF;

\}

return; 